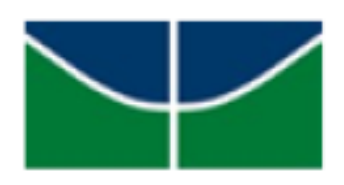

UNIVERSIDADE DE BRASÍLIA

FACULDADE DE ECONOMIA, ADMINISTRAÇÃO E CONTABILIDADE - FACE PROGRAMA DE PÓS-GRADUAÇÃO EM ADMINISTRAÇÃO - PPGA

\title{
TECNOLOGIAS MÓVEIS EM CONTEXTO DE E-LEARNING EM UMA EMPRESA DO MERCADO FINANCEIRO
}

GEORGE LEAL SCHAFFLOR MELLO

Orientadora: Prof. Dra. Gardênia da Silva Abbad

Dissertação de Mestrado em Administração

\section{BRASÍLIA/DF}


UNIVERSIDADE DE BRASÍLIA

FACULDADE DE ECONOMIA, ADMINISTRAÇÃO E CONTABILIDADE - FACE PROGRAMA DE PÓS-GRADUAÇÃO EM ADMINISTRAÇÃO - PPGA ÁREA DE CONCENTRAÇÃO - ESTUDOS ORGANIZACIONAIS E GESTÃO DE PESSOAS

\section{TECNOLOGIAS MÓVEIS EM CONTEXTO DE E-LEARNING EM UMA EMPRESA DO MERCADO FINANCEIRO}

GEORGE LEAL SCHAFFLOR MELLO

Dissertação de Mestrado submetida ao Programa de PósGraduação em Administração da Universidade de Brasília como requisito para a obtenção do grau de Mestre em Administração.

Orientadora: Prof ${ }^{\mathrm{a}}$. Dr ${ }^{\mathrm{a}}$ Gardênia da Silva Abbad

BRASÍLIA/DF 
Ficha catalográfica elaborada automaticamente, com os dados fornecidos pelo(a) autor(a)

MG349t MELLO, GEORGE

Tecnologias móveis em contexto de e-learning?em uma empresa do mercado financeiro / GEORGE MELLO;

orientador GARDÊNIA DA SILVA ABBAD. -- Brasília, 2016. 200 p.

Tese (Doutorado - Mestrado em Administração) -Universidade de Brasília, 2016.

1. Treinamento, Desenvolvimento e Educação. 2 . Transferência de Treinamento. 3. Avaliação de Treinamento. 4. Mobile Learning. 5. Tecnologia. I. DA SILVA ABBAD, GARDÊNIA, orient. II. Título. 


\section{TECNOLOGIAS MÓVEIS EM CONTEXTO DE TREINAMENTO MEDIADO POR TECNOLOGIA EM UMA EMPRESA DO MERCADO FINANCEIRO}

Dissertação submetida ao Programa de Pós-Graduação em Administração como requisito para obtenção do grau de mestre em Administração pela Universidade de Brasília.

Aprovada em pela seguinte Comissão Examinadora:

Prof ${ }^{\mathrm{a}}$. Dr ${ }^{\mathrm{a}}$. Gardênia da Silva Abbad

Orientadora (Universidade de Brasília - PPGA/UnB)

Prof $^{\mathrm{a}}$. Dra ${ }^{\mathrm{a}}$. Thaís Zerbini

Examinador Externo (Universidade de São Paulo)

Prof $^{\mathrm{a}}$. Dr Francisco Antonio Coelho Júnior

Examinador Interno (Universidade de Brasília - PPGA/UnB)

Prof. Dr. Pedro Paulo Murce Meneses

Examinador Interno (Universidade de Brasília - PPGA/UnB) - Suplente 
Dedico esta dissertação aos meus semelhantes, com suas maravilhas, suas dores, seus desafios, seus projetos de vida e sua trajetória. São as muitas histórias, suas cores, suas letras que permitem que haja um corpo em comum, composto de gente, em cuja esfera crescemos e reconhecemos nossa própria existência. Aquilo que é de todos é o conhecimento: atmosfera e oxigênio de tudo o que podemos. 


\section{AGRADECIMENTOS}

"Vai dar tudo certo, estou do seu lado." Assim disse a professora Gardênia, minha orientadora em momento de grande angústia. Para quem vai enfrentar uma batalha que é um trabalho como este, não há nada melhor para se escutar. Muitos são os desafios e os perigos, somente compensáveis pela imensa satisfação e pelas muitas alegrias. Agradeço a todos os que fizeram da minha trajetória, um fardo, de algum modo, seu. Há caminhos que se percorre só, mas há aqueles que são de todos, que pedem as mãos da família, dos amigos, dos companheiros, dos colegas e até de estranhos. Esses levam às minas, aos tesouros. As mãos que me ajudaram são muitas, a primeira já é minha há muitos anos e agradeço a você, Ana Carla Rodrigues Pereira do Valle Schaffor Mello, por ter aquecido as minhas palmas com amor, quando frias e úmidas, substituindo a angústia pelo conforto. As de minha mãe, Grace Leal Schafflor Mello, que me carregaram até que tivessse forças para caminhar, as de meu pai, em memória, que me faziam cócegas e que desenharam magistralmnte as capas dos meus trabalhos de escola. As do meu irmão, Gualter Leal Schafflor Mello pelo abraço da segurança e do afeto. Exponho, com orgulho, a alegria da minha experiência e a gratidão pela dedicação dos professores do Programa de PósGraduação em Admnistração da UnB, que me dispensaram tolerância e esperaça, conhecimento e visão de mundo. À equipe da secretaria do PPGA pelas ajudas inestimáveis com os assuntos acadêmicos de ordem prática. Aos colegas e amigos que fiz nas salas de aulas, nos trabalhos de grupo, nas mensagens trocadas, nas risadas nervosas antes das aulas. Aos colegas e amigos do grupo Impacto pela ajuda na construção e montagem de aulas, apresentações, qualificação etc.: Andreia, Elziane, Nazareth, Rodrigo, Walner, João, da velha guarda. Juce, Maria Cecília, Raphaela, meus contemporâneos. Os novatos Luciana, Fernanda, Júnio, Marcelo, Thaís. Não dá para descrever ou enumerar que aprendi com vocês. Retribuirei sempre, naquilo que me for transformado em dádiva. Agradeço muito especialmente aos parceiros inseparáveis do "Trio Calafrio": Lana Montezano e Rodrigo "Terremoto" Richter, que me deram tanta ajuda, que não é possível retribuir. Nossa amizade irá perdurar até as palavras se apagarem. Obrigado, de coração, pelo apoio, amizade, contriuições ao trabalho, que foram inestimáveis e jamais serão esquecidas. Agradeço aos colegas de trabalho pela ajuda nos levantamentos de dados, pela compreensão e apoio nas horas difíceis e ausências emergenciais. À você, professora Gardênia, que talvez seja a única pessoa a entender a profundidade do que essa labuta representou para mim, os meus agradecimentos sinceros e o meu carinho, pela insistência e aposta em mim. Espero de todo o coração que aquilo que aqui se faz objeto seja júbilo para você também. É a única forma que posso encontrar de agradecer em medida apropriada. Muito obrigado a todos. Isso tudo é para sempre. 


\section{RESUMO}

Esta dissertação estudou o fenômeno da aprendizagem por meio de dispositivos móveis em contexto organizacional, buscando relacionar os saberes sobre aprendizagem, treinamento, desenho instrucional, transferência de treinamento, avaliação e sua aplicação para o uso desses dispositivos em situação real de treinamento. $\mathrm{O}$ estudo tem feição descritiva e exploratória com alguns traços de estudo de caso, dado que o objeto móvel estudado no campo foi aplicado a uma situação real específica de trabalho. O objetivo geral de pesquisa é: analisar a influência do uso de dispositivo móvel, inserido em uma estratégia de mobile learning, em contexto corporativo de trabalho no processo de transferência de treinamento. Trata-se de um estudo predominantemente qualitativo, cujo método foi executado em 6 estudos, que responderam a 4 objetivos específicos da pesquisa, compondo as técnicas de grupo focal, entrevistas e survey. Foram levantadas relações entre variáveis relativas à transferência de treinamento, identificadas na parte teórica, e os atributos percebidos pelos planejadores instrucionais e aprendizes, identificados no campo, apresentados na parte empírica. Os resultados apontam também dificuldades e limitações no uso dos modelos móveis, nas dimensões técnica (tecnológica e no método pedagógico) e comportamental (utilização e aproveitamento da experiência por parte do aprendiz), apontando prioritariamente para a falta de um domínio mais completo e profundo do recurso móvel sob a perspectiva de capacitação. $\mathrm{O}$ encontro entre os conhecimentos resultou objetivamente em dois conjuntos associativos de variáveis e atributos que permitem estabelecer uma relação entre os conceitos/parâmetros e os comportamentos e percepções a respeito de uma experiência de aprendizagem em modelo móvel, fundamentada em uma base técnica e historicamente estruturada sobre a transferência de treinamento, contudo proporcionando espaço para uma discussão retroativa sobre esses últimos. O estudo também como mostra a resistência e a validade atual do modelo Technology Acceptance Model - TAM, quando estendido para a análise de comportamento na utilização de modelos móveis. O estudo propõe um conjunto de construtos, que deverá ser fatorado e testado para possibilitar uma avaliação do uso efetivo e consequente transferência de treinamento na organização. Os resultados indicam também um campo aberto, no qual os modelos de desenho instrucional, com respectiva utilização de aparatos móveis, ainda estão por ser definidos. Os achados sugerem adicionalmente que há implicações adicionais sob a perspectiva da organização, que, embora não façam parte do corpo de estudos em questão, estão postas para reflexão e desenvolvimento nas partes finais da pesquisa.

PALAVRAS-CHAVE: treinamento e desenvolvimento, TDD\&E, e-learning, mobile learning, m-learning, aprendizagem ubíqua, ubiquotous learning. 


\begin{abstract}
This dissertation studied the phenomenon of learning through mobile devices in organizational context, aiming at relating the knowledge about learning, training, instructional design, training transfer, assessment and its application in real training situation. The study is descriptive and exploratory with some case study traits, since the mobile-based object studied in the field was applied to a real working situation. The overall research goal is to analyze the influence of mobile device usage embedded in strategies of mobile learning in training transfer processes within corporate work environment. It is predominantly a qualitative study; the method was performed in 6 studies which responded to four specific objectives of the research, constituting the focus group techniques, interviews and survey. It raised relationships between variables regarding transfer of training, as identified in its theoretical section, and attributes perceived by instructional planners identified in the field, presented in its empirical portion. Results also point out the difficulties and limitations in using mobile models in technical (technological and pedagogical method) and behavioral (use and benefit from experience by the learner) aspects, mainly pointing to the lack of complete and deep mastery regarding mobile resource under a training perspective. The intersection of these knowledges resulted objectively in two associative sets of variables and attributes which establish a relationship between the concepts / parameters and behaviors - and perceptions of a learning experience in mobile model, based on a technical basis and historically structured on the transfer of training, however providing room for a retroactive discussion of the latter. The study also shows the time resistance and the current validity of the model Technology Acceptance Model - TAM when extended to behavior analysis in the use of mobile models. The study proposes a set of constructs that should be factored and tested to enable an assessment of the effective use and consequential transfer of training in the organization. These findings suggest additionally that there are further implications from the organization's perspective, which, although not part of the body of this study, are put to reflection and development in the final section of the research.
\end{abstract}

KEYWORDS: training and develpment, TD\&E, e-learning, mobile learning and ubiquotous learning. 


\section{SUMÁRIO}

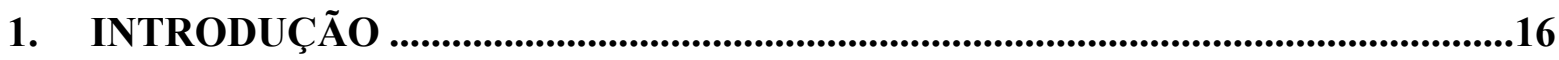

1.1. Educação corporativa, e-learning e m-learning ...........................................22

2. REVISÕES DE LITERATURA EM TRANSFERÊNCIA DE TREINAMENTO E

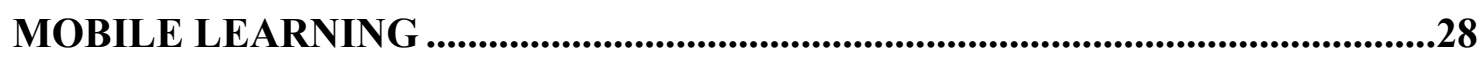

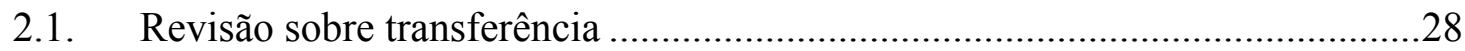

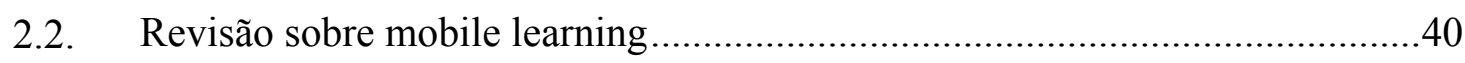

2.3. Considerações sobre as literaturas em transferência e mobile learning.............73

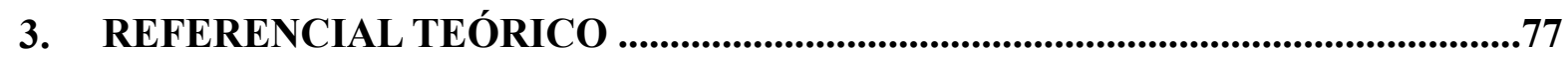

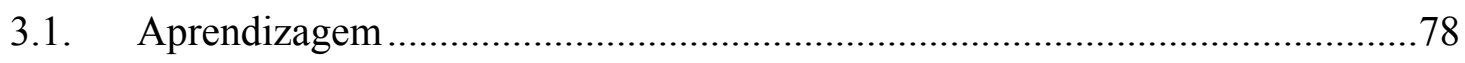

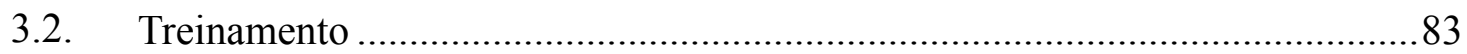

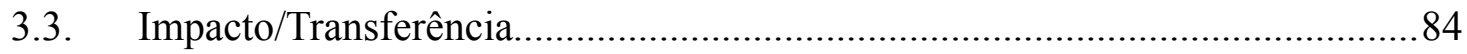

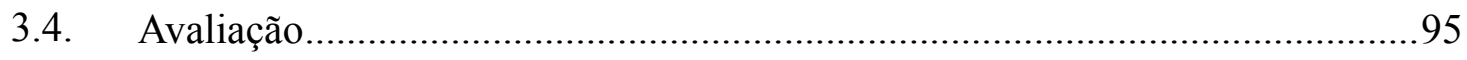

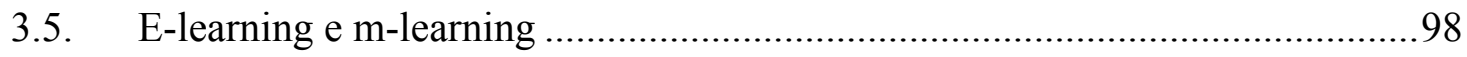

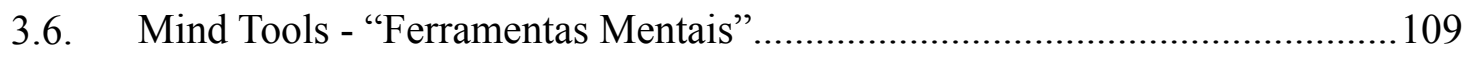

3.7. Mobilidade e Aprendizagem Situada ...................................................... 110

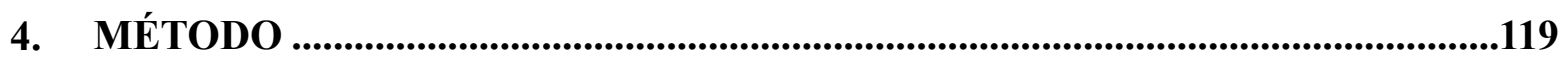

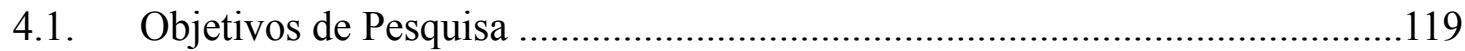

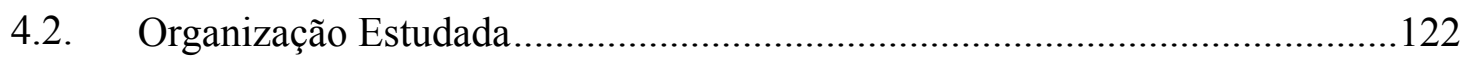

4.3. Características gerais do treinamento estudado ...........................................124

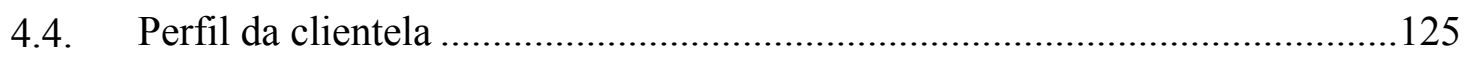

4.5. Estudo 1 - Motivos para o desenvolvimento do modelo móvel face às demandas da organização....................................................................................... 126

4.6. Estudo 2 - Avaliação do planejamento instrucional da oficina ........................127

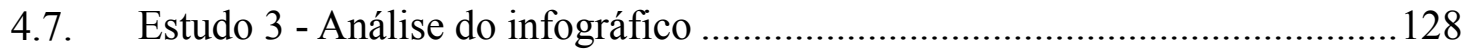

4.8. Estudo 4 - Atributos e motivos para a adoção do modelo móvel..................... 129

4.9. Estudo 5 - Motivos dos usuários para utilização do recurso móvel e os principais atributos percebidos do recurso.................................................................. 134

4.10. Estudo 6 - Motivos dos usuários para a utilização do recurso móvel e os principais atributos percebidos do recurso. 


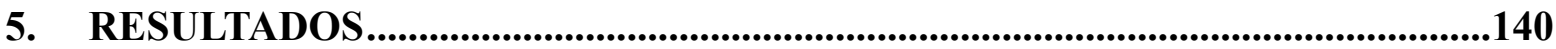

5.1. Resultados do Estudo 1: Necessidades de treinamento ................................... 140

5.2. Resultados do Estudo 2: Desenho instrucional ........................................... 141

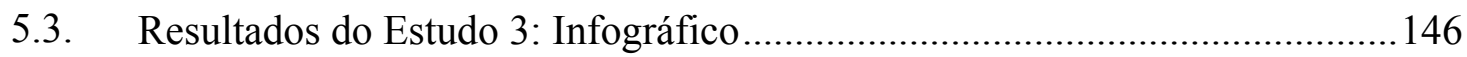

5.4. Resultados do Estudo 4: Atributos e motivos para a adoção do modelo móvel como estratégia de ensino-aprendizagem......................................................149

5.5. Resultados do Estudo 5: Atributos e motivos para a adesão ao modelo móvel pelos usuários

5.6. Resultados do Estudo 6: Atributos e motivos para a adesão ao modelo móvel pelos usuários

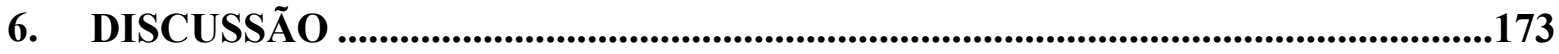

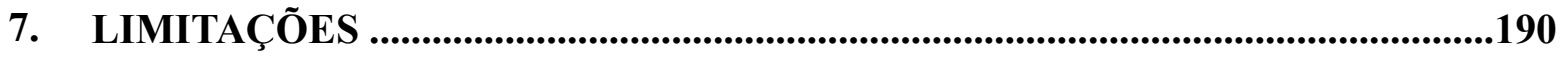

8. CONSIDERAÇÕES FINAIS E AGENDA DE PESQUISA...................................193

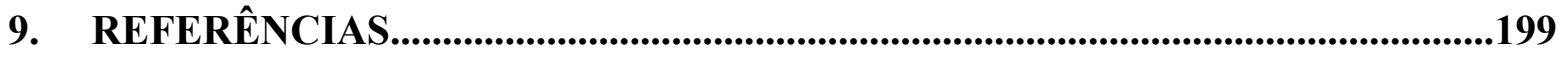




\section{LISTA DE FIGURAS}

Figura 1. Esquema de variáveis contempladas no modelo TAM. ........................................48

Figura 2. Esquema sintético do sistema de TD\&E. .............................................................. 78

Figura 3. Representação esquemática das relações entre treinamento e resultados. ..............85

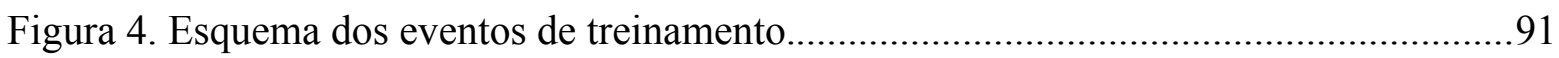

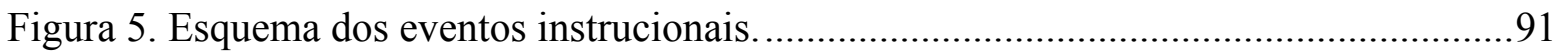

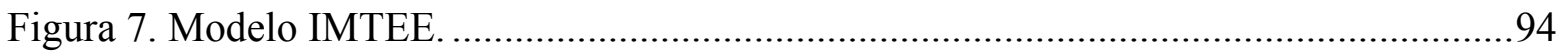

Figura 8. Representação do modelo Impact, conforme Abbad (1999) ..................................97

Figura 9 - Telas do Infográfico Visita ao Cliente MPE ...................................................... 146

Figura 10. Representação esquemática das relações entre treinamento e resultados, mostrando fatores intervenientes no processo de treinamento. 


\section{LISTA DE TABELAS}

Tabela 1. Composição de conceitos de e-learning segundo Romiszowski (2003) 19

Tabela 2. Categorização de variáveis relativas à transferência.

Tabela 3. Mapa analítico de pesquisas sobre avaliação de treinamento mediado por tecnologia no período 1999-2014.

Tablea 4. Distribuição dos artigos por ano de publicação

Tabela 5. Distribuição dos artigos por categoria proposta. 46

Tabela 6. Variáveis testadas e confirmadas em relação às variáveis do modelo TAM e similares

Tabela 7. Síntese dos resultados da categoria Modelos de Aplicação de Eventos. .60

Tabela 8. Organização dos achados da busca .... .65

Tabela 9. Associação das variáveis de transferência de treinamento e mobile learning identificadas neste estudo 72

Tabela 10. Add Ons - Benefícios de funcionalidades adicionados aos dispositivos móveis.100

Tabela 11. Associação entre as características das mediações em treinamento. 104

Tabela 12. Mind tools 107

Tabela 13. Tipificação de mobilidade 110

Tabela 14. Aspectos paralelos entre a nova aprendizagem e nova tecnologia 115

Tabela 15. Descrição dos objetivos específicos deste estudo

Tabela 16. Caraterísticas da Oficina Negocial MPE 123

Tabela 17. Roteiro das questões da análise avaliativa do Infográfico 146

Tabela 18. Descrição das categorias, subcategorias, definições constitutivas e volumetria da incidência das expressões dos participantes. 148

Tabela 19. Consolidação das unidades de registro do grupo focal. 149 
Tabela 20. Descrição das categorias, subcategorias, definições constitutivas e volumetria da

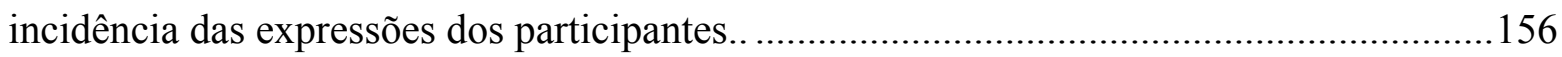

Tabela 21. Consolidação das unidades de registro dos questionários ................................157

Tabela 22. Descrição das categorias, subcategorias, definições constitutivas e volumetria da

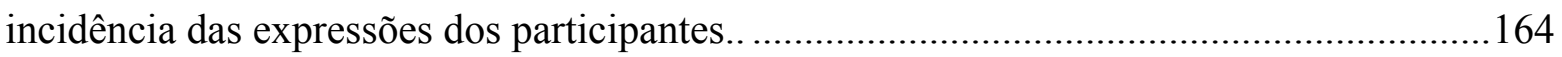

Tabela 23. Consolidação das unidades de registro das duas entrevistas..............................166

Tabela 24. Associação entre as variáveis e atributos identificados nos levantamentos........169

Tabela 25. Aspectos da mobilidade identificados no modelo estudado..............................177

Tabela 26. Elementos comparativos entre os modelos ........................................................ 181 


\section{LISTA DE ANEXOS}

ANEXO 1 - Análise de materiais e recursos didático.

ANEXO 2 - Folhas de perguntas do grupo focal.

ANEXO 3 - Perguntas do questionário registradas no sistema.

ANEXO 4 - Slides contextualização do grupo focal.

ANEXO 5 - Convite para participação no questionário.

ANEXO 6 - Perguntas feitas nas entrevistas.

ANEXO 7 - Relatório crítico-analítico curso estudado.

ANEXO 8 - Telas do infográfico estudado. 


\section{INTRODUÇÃO}

Em evento no Silicon Valley, em outubro de 2015, Tim Cook, CEO da Apple, foi entrevistado por Aaron Levie, CEO da Box, empresa de tecnologia. O tema da conferência era tecnologia móvel e Cook afirmou que o mundo dos negócios apenas conseguiu se apropriar, e de modo bastante frágil, de um pequeníssimo pedaço do potencial da tecnologia móvel. Segundo Cook, a maior parte dos negócios ainda pensa que a tecnologia móvel é um pouco mais do que uma maneira portátil de se checar correio eletrônico. "Para se tirar vantagem disso [tecnologia móvel] em uma grande dimensão, você tem que repensar tudo o que você está pensando", disse. E complementou: "não há dúvida em minha cabeça que as melhores companhias serão as mais móveis"1. O texto mostra bem o quanto temos a caminhar em termos organizacionais a respeito de tecnologias móveis e sugere o quanto há de potencial nisso. Por extensão, treinamento, desenvolvimento e educação seguem a mesma tendência, dado que esse sistema é parte integrante, indissociável e vital das organizações. O pequeno trecho busca duas coisas: dar a dimensão do que está por vir e estimular a pesquisa científica a ingressar profundamente nesse movimento. É uma apropriação do tema por meio da perspectiva do negócio, visto que tratamos do mundo das organizações e, em nosso caso específico, organizações comerciais. Não se trata apenas de mais um recurso à disposição das organizações, mas de uma nova cultura que se instala e está presente em todas as dimensões de nossa vida hoje. Essa perspectiva é importante para a esta pesquisa, dado a amplitude do campo de pesquisa que se desenha.

Este estudo propõe uma investigação de fatores que atuam sobre uma intervenção social planejada e intencional em evento de educação corporativa, constituída pela inserção de dispositivo móvel no planejamento instrucional de um treinamento de uma grande empresa do ramo financeiro, enfatizando a capacitação como diferencial competitivo (Éboli, Fischer, Moraes, \& Amorim, 2010). Aborda o desenvolvimento do recurso pela perspectiva de necessidade de desenvolvimento profissional para a alavancagem de negócios em contextos que apresentam novos desafios e demandas corporativas cada vez mais imperativas no sentido de eficácia do trabalho e resultados organizacionais.

\footnotetext{
${ }^{1}$ Acessado em http://searchmobilecomputing.techtarget.com/news/4500254516/Tim-Cook-Box-share-big-plans-for-MobileEnterprise-adoption, em 30/01/2016.
} 
O trabalho leva em consideração os propósitos educacionais, seus princípios, seus processos e a experiência dos usuários de um programa de capacitação para o negócio, como ponto de partida para o desenvolvimento de saberes e a proposição de fundamentos que possam servir de sustentação para o estudo da avaliação de transferência de treinamento no trabalho, como efeito direto da intervenção proposta. Põe em foco o fenômeno da aprendizagem humana, em nível micro, em direção à resposta do desafio da construção de novas e mais eficazes soluções de aprendizagem nas organizações e tem como ponto de partida modelos já consagrados neste tipo de estudo descritos por Borges-Andrade, Abbad e Mourão (2006) e Abbad, Mourão, Meneses, Zerbini, Borges-Andrade e Vilas-Boas (2012). É um estudo de natureza descritiva e exploratória, na medida em que o fenômeno estudado é bastante recente sob a perspectiva acadêmica e ainda não possui ainda um corpo teórico estruturado que permita sua aplicação consistente e bases sólidas para estudos mais profundos e detalhados sobre os processos e elementos integrantes dos modelos de aprendizagem em modelos móveis, bem como variáveis aplicáveis à aprendizagem nessas circunstâncias, bem como o desenvolvimento de modelos aplicáveis à realidade das organizações.

Em primeiro lugar, são colocados em perspectiva alguns conceitos elementares a fim de se produzir uma linha inaugural de pensamento, com um alinhamento teórico coerente, que possa permitir a construção das bases do estudo. Essas escolhas fazem sentido por harmonizar as visões dos fenômenos estudados e fundamentam-se mutuamente com o objetivo de subsidiar as análises posteriores. Algumas já estão bem consolidadas e consensuadas, outras encontram-se em fase de discussão e outras, ainda, já mostram desgaste perante novas realidades e serão, oportunamente, objeto de discussão.

O sistema de TD\&E da organização estudada está fundamentada em um modelo de gestão por desempenho de competências, desenvolvido internamente. Le Boterf (2003) esclarece que o entendimento do conceito de competências não resume-se ao composto de saber, saber-fazer e saber-ser, mas contempla também sua mobilização em busca de resultados. Ressalta adicionalmente o caráter contextual relacionado ao profissional, como o social, por exemplo. Segundo esse autor, outros fatores são também consituintes da competência, como sua formação e sua experiência profissional e o comprometimento do profissional. Esse autor integra o conceito de competência com o de profissionalismo, ampliando sua dimensão e ressalta o caráter combinatório dos recursos disponíveis ao profissional para a ação. Posiciona 
saberes, saber-fazer e saber-ser (conhecimentos, habilidades e atitudes - CHA) em seus contextos de existência e como resultado combinado de fatores e recursos. O presente estudo incorpora também a perspectiva de uma definição mais próxima do comportamento no cargo, como descrito por Carbone, Brandão e Leite (2005), que afirmam que competências humanas ou profissionais são combinações sinérgicas de conhecimentos, habilidades e atitudes, expressas pelo desempenho profissional dentro de determinado contexto organizacional, que agregam valor a pessoas e organizações. Manifestam-se em contextos determinados, inscritos na estratégia organizacional.

Comprometimento e valor são conceitos-chave nessa abordagem. Ambos implicam necessariamente em "aplicação" do aprendido. O primeiro na dimensão do aprendiz e o segundo na da organização. Dessa combinação surge a ideia de transferência. A definição de Baldwin e Ford (1998) para transferência de treinamento é "aplicação eficaz, no contexto do trabalho, dos CHAs adquiridos durante ações instrucionais, que deve se manter por um período de tempo". O conceito incorpora a ideia de transferência positiva, que significa que algo foi acrescentado no processo de aplicação do aprendido na situação de trabalho, bem como a noção de retenção, ou memorização, que preconiza que aquela nova situação deve perdurar por algum tempo para que seja caracterizada a transferência. Borges-Andrade et al. (2006) distingue duas formas de manifestação da transferência: em sentido (lateral ou vertical) e em direção, (positiva ou negativa). A transferência lateral trata de aplicação do aprendido em situações análogas na situação de trabalho, a vertical trata de composição de processos para a manifestação de competências mais complexas. A transferência positiva trata igualmente de aplicação de conceitos análogos, mas sob o foco do incremento, decremento ou neutralização do efeito da aprendizagem sobre o desempenho. É positiva quando facilita o desempenho, negativa, quando o dificulta (ou o inviabiliza), ou ainda neutra, caso não interfira no desempenho do aprendiz.

A produção científica relativa à mediação digital é bastante robusta sobre e-learning. Conforme Romiszowski (2003), a variedade e multiplicidade de definições dessa modalidade, constantes na literatura sobre o tema tornam uma proposição abrangente e consensual algo difícil de se conseguir. Dada essa dificuldade, o autor apresenta, antes de uma definição sintética, um quadro que pretende mostrar uma compreensão dessa modalidade por suas 
características e potencialidades. A Tabela 1 mostra a proposta do autor, que dá uma noção consistente da modalidade.

\section{Tabela 1}

Composição de conceitos de e-learning, segundo Romiszowski (2003).

\begin{tabular}{lll}
\hline & $\begin{array}{l}\text { Auto-estudo individual - } \\
\text { treinamento baseado em } \\
\text { computador (TBC) }\end{array}$ & $\begin{array}{l}\text { Grupos colaborativos - comunicação } \\
\text { mediada por computador (CMC) }\end{array}$ \\
$\begin{array}{l}\text { Estudo online - comunicação } \\
\text { síncrona em tempo real (real } \\
\text { time) }\end{array}$ & $\begin{array}{l}\text { Surfando na internet, acessando } \\
\text { websites para obter informações } \\
\text { ou aprender novos conhecimentos } \\
\text { e habilidades (ex. WebQuest*). }\end{array}$ & $\begin{array}{l}\text { Comunicação e interação grupal por } \\
\text { chat, quadros interativos eletrônicos, } \\
\text { IRC, áudio/videoconferências, etc. } \\
\text { (ex.: CUSeeme; NetMeeting*). }\end{array}$ \\
$\begin{array}{ll}\text { Estudo offline - comunicação } \\
\text { assíncrona (flextime) }\end{array}$ & $\begin{array}{l}\text { Ulone" (ex.: CD-Rom), ou fazendo } \\
\text { download de materiais da internet } \\
\text { para estudo posterior (ex.: LOD - }\end{array}$ & $\begin{array}{l}\text { listserv, BBS, listas de discussão ou } \\
\text { Learning Management Systems - } \\
\text { learning object download). }\end{array}$ \\
& $\begin{array}{l}\text { Aprendizagem - AVA. Ex.: WebCT; } \\
\text { Blackboard etc. }\end{array}$ \\
\hline
\end{tabular}

*Ferramentas de interação. WebQuest: modelo de pesquisa via Internet, provido por uma organização. (webquest.org). CUseeme: ferramenta de compartilhamento de vídeo via Internet. NetMeeting: ferramenta de videocoferência via Internet já descontinuado. As outras siglas são autoexplicativas ou já de conhecimento público.

O interessante na proposta á a proposição de uma definição fundamentada em vários componentes para melhor se delimitar o conceito pretendido. Curiosamente, o autor, que pesquisou uma definição em mais de 100 artigos, não se refere a e-learning como treinamento baseado em Internet, visto que cita o modelo TBC, que pode ser autônomo e já existia antes de a Internet tornar-se viável para os fins de treinamento.

Driscoll e Carliner (2005) afirmam que mobile learning está associado à mobilidade. Refere-se à utilização de dispositivos que não necessitam de cabos para se conectar, tanto para operar eletricamente (deve ter um sistema de fornecimento de força, como baterias), quanto para acessar dados. Afirma que há muita variedade nas terminologias utilizadas e cita três: wireless learning, mobile learning e m-learning. Essa é uma definição por demais fundada em aspectos físicos de funcionamento, restringindo uma percepção de maior alcance, em contraste com outras neste trabalho. A menção está relacionada ao caráter histórico e, de alguma forma, preciso na limitação do conceito. A definição de O’Malley (2003) para mlearning se apresenta como a mais completa por acomodar dois atributos importantes e 
complementares na utilização dos aparelhos móveis: mobilidade e características do aparelho. Diz o autor que aprendizagem móvel é aquela que se dá quando o aprendiz não está em lugar fixo, pré-determinado ou quando o aprendiz utiliza as oportunidades oferecidas pelas tecnologias móveis. A perspectiva de Driscoll e Carliner (2005) é complementar, mostrando características de ordem objetiva e concreta, o que nos ajuda a interpretar o conceito.

O conceito de aplicativo "app" não encontrou qualquer definição no material levantado por este estudo. Da mesma forma que ubiquidade, os textos apoiam-se no conceito de "aplicação", de caráter descritivo, sem que haja uma apropriação para o universo mobile. No entanto, há nítida distinção da mera abreviação do termo original da realidade incorporada na utilização de dispositivos móveis. Tomaremos por base, definição proposta por este estudo: termo derivado do inglês application e que substitui, em essência e formato, o conceito de software, ou programa, por sua adaptação ao contexto de dispositivos móveis. É composto de funcionalidades especializadas isoladas, ou em conjunto. Pode, também, conter uma funcionalidade web embutida, ou configurar-se como um repositório de conteúdo.

Em contraste com o conceito de software, há diferenças importantes: o modo de oferta, a interação com o usuário, a interface e outras. Algumas poderão ser percebidas no desenvolvimento deste trabalho. Pela reflexão: por que não se usa o termo "software", ou "soft", como são chamados corriqueiramente os programas para computação? É certo que isso é devido a peculiaridades importantes no caso dos dispositivos móveis, mas um detalhamento mais profundo foge aos objetivos deste estudo, estando relacionado à área de tecnologia informática. Optou-se, então, por propor uma definição constitutiva para o termo: "app", termo derivado do inglês application, que substitui, em essência e formato, o conceito de software. É composto de funcionalidades atomizadas especializadas, tais como calcular, editar textos, localizar um endereço, armazenar contatos pessoais, trocar mensagens, tirar fotografias, consultar um dicionário, visualizar vídeos etc. Impõe-se como uma forma de acesso e utilização que terá impacto direto na forma de aprender, permitindo ao usuário/ aprendiz a combinação de funções e conteúdos de acordo com a sua necessidade ou estratégia de aprendizagem.

Embora pareça redundante, uma das características mais importantes da tecnologia móvel é a mobilidade, que implica na percepção de ubiquidade. Quanto à definição desse termo, o que se encontrou não parece contemplar com exatidão uma das características mais 
marcantes dos modelos móveis. O termo tem origem em conceitos religiosos, que referem-se à presença divina, que segundo algumas correntes quer dizer a capacidade de se estar em qualquer lugar a qualquer tempo. Não deve-se confundir esse termo com onipresença, que significa estar em todos os lugares ao mesmo tempo. No entanto, na definição do dicionário Michaelis, o termo apresenta-se dessa forma. As definições encontradas na literatura estudada e outras fontes não científicas de informação não se preocupam em criar uma definição específica para o termo nas considerações a respeito de dispositivos móveis, usando o termo com sua definição de dicionário. Pode-se discutir mais o entendimento de um dispositivo móvel como passível de uma potencial utilização ubíqua, do que a própria definição, em seu sentido mais literal, que parece consensuada.

No contexto, parece mais próprio considerar a potencialidade de acesso em qualquer lugar a qualquer tempo, buscando-se a perspectiva do usuário. No caso dos dispositivos móveis, é natural a presença da percepção da capacidade de se estar em qualquer lugar e acessar a conteúdos. No entanto, temos duas situações típicas de restrição de acesso: a) você não tem acesso a qualquer fonte de conteúdos, ou seja, não há rede wi-fi, ou banda telefônica $(2 \mathrm{G}, 3 \mathrm{G}, 4 \mathrm{G})$ ou outro sistema de acesso sem fio à sua disposição e, dessa forma, o usuário não está conectado e, consequentemente, não está realizando estudo, mesmo que o dispositivo possua todos os recursos necessários; b) o usuário fez uma descarga (download) do material previamente no dispositivo e pode consultá-lo, mesmo sem acesso remoto a qualquer rede. $\mathrm{Na}$ segunda situação, o que difere um dispositivo móvel de um livro de bolso, por exemplo, são as capacidades intrínsecas do aparelho: grande volume de conteúdo (mesmo as versões mais discretas, possuem capacidade de carga muito maior do que um livro de bolso), recursos de interação (manipulação da navegação e acesso, touch screen) e diversidade de conteúdos. Nessa hipótese, ainda há obstáculo de outras naturezas, como a necessidade de baterias de longa duração, visto que são consumidas na proporção da complexidade dos objetos acessados/manipulados. Arquivos de áudio são significativamente menores do que aqueles de vídeo. Ambas as considerações referem-se a atributos físicos. Ainda serão discutidos aqueles de natureza comportamental com maior profundidade no decorrer do trabalho.

Outra discussão relevante refere-se aos conceitos de mediação e interação. Enquanto em alguns estudos o dispositivo é visto como apenas um meio (mídia), em outros, o conceito de interação se faz mais presente, indicando também construção de significados na dinâmica 
de acesso, que pode ser bem compreendido por uma abordagem baseada no interacionismo simbólico. Vale dizer que a relação dos usuários com os aparelhos pode resultar em comportamentos e formas de consumo que dependam, ou sejam moldados, pela própria utilização daqueles aparelhos. As novas formas de se escrever, abreviando-se a maior parte das palavras, por exemplo, pode ser um indicador de como se deve abordar os textos para uma comunicação mais eficaz com o usuário. Rolagem de telas e comunicação táctil também demandam considerações e observação específicas, que não cabem neste estudo, mas devem ser vistas com interesse.

\subsection{Educação corporativa, e-learning e m-learning}

Éboli, Fischer, Moraes e Amorim (2010) posicionam a Educação Corporativa em nível estratégico, desenvolvendo competências e aumentando a competitividade da organização e coloca a qualificação como elemento-chave na criação de diferencial competitivo. Segundo Green e McGill (2011, citado por Mourão, Abbad \& Zerbini, 2014), os esforços financeiros aplicados em treinamento nos EEUU ultrapassaram os US\$ 170 bilhões em 2010. Adicionalmente, de acordo com a American Society for Training \& Development, dos gastos com treinamento naquele país, em 2011, 56\% foram gastos internamente ${ }^{2}$. Os números expressam a importância do treinamento, tanto quanto revelam as expectativas organizacionais a respeito do desenvolvimento do corpo funcional e os resultados organizacionais consequentes. Essas expectativas só poderão ser correspondidas na medida em que se tenham instrumentos de planejamento, desenvolvimento e avaliação precisos e especializados dos resultados do treinamento.

Cabe ressaltar, no entanto, que é necessária a garantia desses resultados, desde que promovidos em suas condições responsáveis, presentes na cadeia de eventos respectivos, que surgem na avaliação de necessidades, passam pelo desenho instrucional e chegam às técnicas e modelos de avaliação, conforme salientam Aguinis e Kraiger (2009). Esses autores confirmam também os benefícios do treinamento em três níveis de análise, quais sejam: indivíduo-equipe, organização e sociedade. Contemplam ganhos paralelos, como o

\footnotetext{
2 Consultado em https://www.td.org/Publications/Magazines/TD/TD-Archive/2012/11/ASTD-2012-State-of-the-IndustryReport em 20/10/2015. Association for Talent Development - ATD (ex-ASTD).
} 
desenvolvimento de habilidades como comunicação e adaptação a contextos culturais diferentes do indivíduo e ainda alguns não relacionados à perfomance, como empoderamento, ou a capacidade de motivar, quando se trata de treinamento em liderança.

Verespej (2001, citado por Borges-Andrade et al. 2006), afirma que uma economia dirigida pela informação está produzindo uma procura do modelo de e-learning pelas organizações. Os motivos são: treinamentos de novos empregados, introdução de novos produtos e situações nas quais um grande número de indivíduos necessita ser treinado. Hyochang Lee e Kichan (2007) complementam afirmando que um ambiente mutável de negócios tem levado as organizações a grandes esforços na direção do e-learning a fim de aumentar sua competitividade, porém questionam se o comportamento dos funcionários está mudando com a aplicação desta prática.

Ainda, segundo aqueles autores, nas companhias norte-americanas, apenas entre $10 \%$ e $15 \%$ do que é aprendido no treinamento é aplicado ao trabalho, o que exige rigor na avaliação dos resultados desse modelo. Segundo Abbad, Pilati, Borges-Andrade e Sallorenzo (2012), de modo geral, a taxa de transferência observada nas organizações está na base de $33 \%$ do que foi aprendido em programas de TD\&E. A comparação mostra que o modelo $e$ learning e similares necessitam de aprimoramento, que, por sua vez, dependem de um método de avaliação consistente para que haja retroalimentação de dados e informações que possam ser aplicados no aperfeiçoamento dos programas baseados em e-learning, como, por analogia, o m-learning.

As ações educacionais corporativas têm feito uso das novas tecnologias, em particular, a Internet. A educação a distância mediada por dispositivos digitais, ou pela Internet (e-learning), permite que se distribua conteúdos praticamente sem limites geográficos ou de volume, além de incorporar diversos recursos característicos dos formatos digitais, que produzem interatividade e ampliam as possibilidades de modelagem dos conteúdos. No entanto, ainda há incertezas quanto à eficácia do modelo e se ele responde às expectativas dos planejadores e profissionais da área de capacitação, conforme Mourão et al. (2014).

De fato, Educação a Distância, onde se inscreve o e-learning, não é, como aparenta, um conceito consensuado, embora largamente usado e compreendido. O que nos primórdios era visto como distância geográfica (século XIX), tem se reconfigurado como um modelo que não se enquadra nos moldes do ensino presencial e, por isso, em algumas referências, como 
em Pretti, Alonso, Foerste, Toschi, Neder, e Bédard (2005), onde é usada a terminologia “não presencial". Hoje, com o avanço tecnológico, a definição se fragiliza mais ainda, quando se imagina que as ações de capacitação (cursos, conteúdos etc.) poderão estar, teoricamente, em todos os lugares, inclusive de modo paralelo, na sala de aula, ou em situação de trabalho. Há hoje modelos de ensino chamados "blended", que combinam ações presenciais e nãopresenciais, coexistindo com modelos puramente presencias ou não presenciais, virtuais, ou tradicionais. Conforme Graham e Dziuban (2003), blended learning refere-se a ambientes que combinam instruções face-a-face com instrução mediada por tecnologia.

Tanto o e-learning, quanto o m-learning, estão fundamentados no uso das Novas Tecnologias de Informação e Comunicação - NTICs pois são essas tecnologias que permitem a distribuição e acesso remoto maciços a conteúdos, trocas de arquivos, atividades síncronas, assíncronas e utilização de uma série de recursos que possibilitam e enriquecem a comunicação. O mobile learning está associado ao conceito de e-learning. $\mathrm{O}$ avanço do elearning está atrelado à crescente oferta de novos aparatos tecnológicos pelo mercado e, com isso, novos modelos de distribuição de conteúdos têm se tornado possível. O fato tem proporcionado desafios e oportunidades inéditas. $\mathrm{Na}$ indústria financeira, por exemplo, o negócio exige mudanças rápidas, tais como a absorção de novos perfis de consumidores e novos hábitos de vida e consumo. Com isso, as novas tecnologias têm ocupado espaço de destaque, visto que oferecem formatos de programas e conteúdos e serviços (funções) que podem ser rapidamente atualizados e acessados.

Sobre o conceito de NTICs, Saccol, Reinhard, Schlemmer e Barbosa (2010) propõem o termo Mobile and Wireless Information Technologies - MWIT (tecnologias de informação móveis e sem fio), avançando na conceituação das tecnologias em estudo. Com isso, criam uma definição a partir do conceito de informação. MWIT inclui ferramentas que permitem acesso a dados por meio de redes sem fio, como aqueles realizados por telefones celulares, palmtops, smartphones, personal digital assistants - PDA ou laptops com capacidade de acesso como os aqueles dispositivos. Esses acessos podem ser, segundo os autores, por RFID ${ }^{3}$ (radio frequency identification), por exemplo, e outros recursos específicos dos próprios dispositivos.

\footnotetext{
${ }^{3}$ Radio Frequency Identification - RFID é uma tecnologia sem fio, desenvolvida para substituir o código de barras. A tencologia é composta de duas partes distintas: uma etiqueta e um leitor RFID ou Interrogador RFID. Consultado em http:// www.ehow.com/about_5061184_rfid-reader.html em 08/10/2015.
} 
Como visto, uma das principais características do mobile learning é a ubiquidade. Cabe notar aqui que essa característica coloca o modelo em situação em que o usuário está exposto à diversas variáveis de contexto e de suporte significativamente diferentes do modelo de e-learning. Essas variáveis são muitas, diversas e decisivas na construção de um desenho instrucional e uma experiência de capacitação eficazes. O e-learning (baseado em Internet) assemelha-se ao mobile learning na questão de haver multiplicado os canais e pontos de acesso à rede. Essa capacidade é multiplicada exponencialmente com os dispositivos móveis e as redes local e global. O grande avanço do mobile learning é realmente trazer o aprendizado à situação-problema ou ao micro ambiente de treinamento, que pode ser construído com centro no dispositivo móvel. Parise (2014) trata de u-learning (ubiquotous learning) e mobile learning como termos distintos. Aparentemente, mobile learning tem fundamento no meio, enquanto $u$-learning assemelha-se mais a um conceito de estratégia. Parece cedo para se ter um consenso a respeito da terminologia.

\section{A realidade móvel}

A digitalização de conteúdos é um marco histórico no mundo em praticamente todas as esferas da vida e do conhecimento humano e o avanço dos dispositivos com capacidade de processar, armazenar e trocar dados e informações produziram uma nova realidade. As máquinas computadoras tiveram progressos notáveis nas últimas décadas em relação a esses processos, desde a qualidade das interfaces até a miniaturização de componentes, permitindo que processos de alta complexidade e conteúdos de grande volume digital (dimensão em bits) coubessem em um dispositivo de uso manual cujas dimensões se aproximam de um pequeno livro de bolso, ou uma carteira de cigarros e de peso igualmente similar.

Outro fator de destaque, referente a esses equipamentos, é a integração de funcionalidades antes completamente díspares entre si, como um telefone e uma máquina de fotografia. Houve um processo de integração (incorporação) por parte dos telefones celulares de outras funções, inicialmente restritas a outros dispositivos, como calculadoras, agendas eletrônicas e até mesmo os computadores tradicionais. Os dispositivos chamados de smartphones (telefones inteligentes, em tradução livre) são computadores de bolso que incorporam centenas de funções, como planilhas de cálculo, processadores de textos, ou ainda 
outras mais complexas, como a edição e publicação de conteúdos (textos, vídeos, sons, imagens). Uma infinidade de outras funções puderam, também, ser incorporadas aos aparelhos por meio de uma unidade de tratamento chamada de "aplicativo", ou "app".

As empresas Apple e Google já registravam no ano de 2014 em suas respectivas lojas virtuais mais de 1 milhão ${ }^{4}$ de aplicativos disponíveis para download cada uma (há outras lojas com a mesma finalidade). Esse volume implica bilhões de downloads em todo o mundo o que indica adicionalmente um fato cultural de larga escala. Em sua maioria são gratuitos, ou de custo muito baixo, o que proporcionou um mercado gigantesco de oferta. A mecânica de oferta de um aplicativo nasce dos chamados desenvolvedores, que produzem os aplicativos, que podem ser disponibilizados nas lojas virtuais especializadas, com relativa facilidade. É importante para ilustrar este estudo, visto que há uma enorme oferta de funções que podem apoiar a aprendizagem e são, primordialmente, de escolha dos usuários, incrementando o fator autonomia e ajuste às estratégias de estudo definidas pelo aprendiz, perspectiva aderente ao estudo.

Essa nova realidade impõe um desafio ao design instrucional sob a ótica da mídia e da comunicação, visto que o fenômeno da comunicação é intermediário no processo de aprendizagem e exercendo sobre esse grande influência. Os programas de treinamento podem, assim, explorar as novas mídias e comportamentos para produzir capacitação por meio de novos modelos, que expandem as possibilidades de aprendizagem centradas no indivíduo. Quais serão as formas e modelos mais adequados à utilização desses dispositivos para produzir aprendizagem? A pesquisa busca, então, divisar aspectos e atributos que permitam, em alguma medida, produzir desenho instrucional, com base em m-learning, que produza resultados positivos de desempenho no trabalho. Ou seja, proporcione transferência de treinamento.

As vantagens percebidas na aplicação de modelos de e-learning (que podem ser extendidas ao m-learning) podem ser enumeradas como: benefícios econômicos (deslocamentos e materiais impressos, entre outros), parcerias internacionais (acesso a conteúdos de outras escolas ou organizações), tempo curto para atingir mercados e reformular conteúdos, satisfação do estudante, feedback, avaliações ricas, flexibilidade da aprendizagem,

\footnotetext{
4 Acessado em http://techcrunch.com/2014/06/02/itunes-app-store-now-has-1-2-million-apps-has-seen-75-billiondownloads-to-date/, em 26/03/2015, às $11 \mathrm{~h} 46$.
} 
construção de comunidades virtuais, colaboração com colegas em todo o mundo e acesso a bibliotecas virtuais, segundo Subhashni (2008). Pela perspectiva da corporação, para ter competitividade em um mundo de negócios que funciona à grande velocidade, os empregados devem estar sempre atualizados em conhecimentos e técnicas, conforme Wang, Wand, e Shee (2007).

O estudo jusfica-se pela premência de saber em relação às vantagens, aplicações e parâmetros para a construção de treinamentos baseados em dispositivos móveis, como resposta a uma nova cultura instalada na sociedade e a novos modelos de capacitação, que produzam, em cenários mais dinâmicos e desafiadores, resultados cada vez mais eficazes e sustentáveis para as organizações. Como, estando situado no campo da administração, trata-se de um estudo em contexto corporativo, no qual as perspectivas de custo-benefício e eficiência operacional se fazem deteminantes para a geração de bons bons resultados.

A construção de desenhos instrucionais compatíveis com a nova realidade, a interpretação, ou reinterpretação, dos elementos que implicam a transferência da aprendizagem e um sistema de avaliação preciso serão necessários para o enfrentamento da competição e para o atingimento dos objetivos corporativos em tempos bem próximos. Esse movimento deve passar pela compreensão dos novos cenários, contextos e comportamentos, que já se mostraram mais complexos e sujeitos a uma mudança bem mais profunda do que se poderia imaginar quando surgiram os primeiros telefones móveis.

O roteiro de estudos passa pelas definições clássicas de aprendizagem, treinamento e avaliação, desenhos de pesquisa, técnicas de coleta, técnicas de análises etc., buscando fundamentação para compreender o que se mantém e o que tende a se transformar com a nova realidade móvel. Quatro estudos de delineamente qualitativo compõem a pesquisa e levantaram dados documentais e testemunhais da situação estudada. Ao mesmo tempo, o trabalho lança propostas de aspectos a serem observados e sugere comparações entre os sistemas móveis e os tradicionais a fim de jogar luz sobre o tema, com suporte científico. Esta pesquisa poderá, neste contexto, contribuir com resultados que venham ao encontro de uma formulação mais consistente sobre a tecnologia (NTICs) aplicada à capacitação, além de tangenciar questões sociais mais abrangentes, como inclusão social e maiores índices de satisfação do mercado consumidor em termos de eficiência na entrega de produtos e serviços. 


\section{REVISÕES DE LITERATURA EM TRANSFERÊNCIA DE TREINAMENTO E MOBILE LEARNING}

\subsection{Revisão sobre transferência}

O presente estudo teve a intenção de fazer um levantamento da produção científica sobre transferência de treinamento, considerando revisões já realizadas sobre o tema, tanto de forma abrangente, em TD\&E, como específica, em transferência de treinamento. O estudo traz à luz pontos-chave que propiciam a compreensão de uma possível avaliação de transferência de treinamento em eventos mediados por tecnologia. Está composto por duas partes: análise da produção científica em transferência de treinamento e revisão de literatura em mobile learning. $\mathrm{O}$ foco do estudo recai sobre a busca da relação entre fatores e variáveis envolvidos na mediação de treinamento baseada em tecnologia e seus reflexos na transferência de treinamento.

O primeiro estudo, sobre transferência, adquiriu a feição de meta meta-análise por concentrar-se nos achados de revisões de literatura anteriores, que abrangem o período de 1992 a 2014. As buscas de novos trabalhos foram realizadas considerando-se como ponto partida a revisão realizada por Santos Junior (2012), visto que essa traz consolidação dos trabalhos anteriores na mesma direção deste estudo. A referência histórica é importante, entretanto, a fim de se tecer um lógica de evolução da pesquisa no campo de TD\&E e construção de modelos e interpretações dos fenômenos em foco, bem como compor um coleção de achados que oriente um conjunto de conhecimentos consistente para o estudo da intervenção aqui proposta, avaliando a aplicabilidade desses achados no novo contexto de educação corporativa. As revisões tratam de TD\&E, avaliação e transferência. O segundo estudo terá o mobile learning como tema e será exposto em sequência.

Foram utilizadas, como roteiro para o estudo das revisões, as perguntas elaboradas por Burke e Hutchins (2007) em sua revisão: 1) quais variáveis na literatura sobre transferência exibiram forte suporte empírico para a explicação da transferência? 2) Onde estão as maiores lacunas dos fatores que afetam transferência? 3) Quais os progressos metodológicos têm sido feitos e quais variáveis permanecem sem estudo? 4) Qual será o futuro da pesquisa sobre transferência de acordo com os achados de pesquisa? 
As revisões em TD\&E mostram o crescimento do entendimento sobre o tema de modo geral e também de vários desdobramentos em asssuntos mais específicos, como transferência de treinamento e treinamento mediado por tecnologia, que estão inscritos nesse contexto. Vale o destaque para as publicações da revista Annual Review of Psycology, que faz revisões regulares de literatura sobre o tema treinamento e desenvolvimento. As duas últimas são a de Cannon-Bowers ( $\left.5^{\mathrm{a}}\right)$ e a de Tannenbaum e Yukl (4a). Antes dessas, Campbell, em 1971, Goldstein, em 1980, Wexley, em 1984 e Latham, em 1988 completam o histórico de revisões do periódico. Como as revisões, em regra, contemplam os resultados das anteriores, é possível obter-se um panorama bastante completo a partir das últimas localizadas na literatura nacional, como em Zerbini e Abbad (2010) e Santos Junior (2012), que também fez levantamento dos trabalhos internacionais. As referências a outras revisões tiveram o caráter histórico (precedentes) e complementares (posteriores).

Outras revisões consideradas relevantes são de Borges-Andrade e Abbad (1996), Abbad, Pilati e Pantoja (2003), Burke e Hutchins (2007), Cheng e Hampson (2008) - essa revisão confirma a validade científica do tema de transferência -, Aguinis e Kraiger (2009), Pereira (2009), Blume, Ford, Baldwin e Huang (2009), Salas (2011). Ainda outras revisões podem ser localizadas nos próprios textos dessas revisões. Essa oferta significativa de trabalhos é um indício do vasto campo de estudos em TD\&E e representa um conjunto de saber consistente.

A revisão de Borges-Andrade e Abbad (1996) tem importância histórica na realidade de treinamento brasileiro por fazer um retrato pioneiro da produção acadêmica sobre treinamento e desenvolvimento e por apontar uma série de caminhos para a pesquisa e, consequentemente, para o ambiente organizacional de modo geral. O estudo, com grande rigor metodológico, mostra uma área de treinamento ainda em estado embrionário, mas com sementes importantes de ação em relação a métodos. O trabalho destaca iniciativas bem estruturadas de avaliação do treinamento. A revisão propõe uma agenda extensa para a pesquisa nacional de TD\&E em 5 frentes: avaliação de necessidades, projeto, contexto, avaliação de treinamento e delineamento de pesquisa. Adicionalmente, mostra, em âmbito nacional, o mesmo que posteriormente Salas e Cannon-Bowers (2001) também registrariam: uma distância significativa entre a pesquisa e a realidade organizacional. Esses autores são uma referência importante ao dar status de ciência ao treinamento. $\mathrm{O}$ estudo analisa e avalia 
30 anos de produção em TD\&E e relata um crescimento extraordinário no campo de pesquisa. No entanto, a aplicação dos achados nas organizações é questionada. Apontam o crescimento de estudos empíricos e maior preocupação com o contexto organizacional, sendo este validado pelo conjunto dos trabalhos analisados. $\mathrm{O}$ treinamento é uma atividade integrada no contexto organizacional. O trabalho cita avanços teóricos significativos dos trabalhos desenvolvidos previamente nas definições de variáveis anteriores ao treinamento, ao estudo de transferência em nível vertical (indivíduo-equipe-organização), o avanço de modelos de avaliação e influência da tecnologia nos processos de aprendizagem, que proporciona novos meios de educar e oferece uma nova vasta gama de recursos.

A tecnologia, segundo os autores, pode tornar ir ao treinamento uma tarefa obsoleta e registram a importância das variáveis pré-treinamento, classificando-as em três grupos: (a) o quê os treinandos trazem para o contexto do treinamento (nesse conjunto, está a variável habilidades cognitivas, que tem impacto sobre o treinamento), (b) variáveis que engajam o treinando ao aprendizado e à participação nas atividades de desenvolvimento e (c) como o desenho do treinamento pode ser feito para maximizar a experiência da aprendizagem. $\mathrm{O}$ trabalho chama também a atenção para as condições pós-treinamento, como avaliação e transferência de treinamento. Relaciona diversas variáveis relativas a esse construto que foram verificadas nos trabalhos estudados: clima para transferência, oportunidade para atuar, suporte da equipe, reforço dos líderes e outras. Afirma que, apesar das descobertas, os problemas de medidas ainda são fonte de preocupação.

A revisão realizada por Burke e Hutchins (2007) aponta as seguintes variáveis com influência forte ou moderada na transferência em três grandes grupos: 1) características da clientela: habilidade cognitiva, autoeficácia, motivação pré-treinamento, afetividade negativa, abertura para novas experiências, utilidade percebida, planejamento da carreira, comprometimento organizacional; 2) desenho/entrega da instrução: objetivos de aprendizagem, relevância do conteúdo, feedback e prática, modelagem comportamental, exemplos baseados em erros (mostrar o que não deve ser feito) e 3) características do ambiente de trabalho: clima para transferência, suporte do supervisor, suporte dos pares.

Cheng e Hampson (2008) dividem os estudos de transferência em três grandes blocos históricos: de 1960 a 1980, a década de 1990 e a partir de 2000. A grande contribuição do primeiro período foi a taxonomia de efetividade do treinamento, definindo a influência do 
treinamento em níveis de avaliação proposto por Kirkpatrick (reação, aprendizagem, comportamento/aplicação e resultados na organização). As relações de causalidade e consequência e relação positiva entre esses níveis não ficou comprovada, demandando estudos mais detalhados. Nesse modelo, Olsen associou a transferência ao nível comportamento. No período, Baldwin e Ford (1988) categorizaram três grandes grupos de fatores que implicam nos resultados do treinamento: características do treinando, desenho do treinamento e ambiente de trabalho, bem como caracterizaram os resultados da transferência como generalização e manutenção do aprendido.

O segundo período, a década de 1990, consolidou como principais variáveis da transferência motivação para transferir e comportamento de transferência, identificadas como dependentes de outras 10 variáveis relacionadas aos quatro níveis de Kirkpatrick. Ressalta também a importância das variáveis de contexto pré-treinamento e associa comportamentos e resultados pós-treinamento como moderadores daquelas duas variáveis principais, ainda outras variáveis são citadas, como apoio de pares, por exemplo e desenho do treinamento. Surge também a identificação da transferência como um construto multidimensional, estrapolando o nível micro de análise. Os estudos do período confirmam a importância das variáveis relativas ao ambiente de trabalho. Um problema metodológico é identificado no estudo desse período, que é a confirmação (identificação, descrição e medida) das variáveis sem o entendimento de como esses fatores podem ser gerenciados. A revisão aponta um crescimento da técnica de meta-análises no campo.

O último período, do ano 2000 para a frente, é aquele no qual se intensificam os estudos de variáveis, como a influência do reforço informal por parte de líderes. Nesse período, Cheng e Ho (2001) realizaram um grande e importante consolidado sobre transferência e motivação, no formato de meta-análise. Em relação à motivação para $a$ transferência, os estudos do período mostraram que há a necessidade de revisão das variáveis preditoras, pois um grande número das correlações verificadas não têm suporte empírico sólido. O período mostra poucas novas variáveis descobertas, como, por exemplo, reforço informal de líderes. Uma nova variável, chamada motivação para melhoria do trabalho por meio do treinamento, que é uma variável multidimensional composta por outras quatro variáveis (motivação para treinar, resultados/desempenho, atitudes de treinamento e motivação para tranferir), mostra forte relacionamento entre traços positivos de afetividade e 
transferência, como comprometimento, por exemplo. A variável prevenção de decadência (relapse prevention) e incremento de treinamento foram testadas para autoeficácia, comportamento de transferência e performance, resultando em frustração na correlação com intervenção pós-treinamento. A causa apontada foi o uso de métodos inconsistentes de investigação. Outro achado importante é que fatores pré e pós-treinamento estão mais fortemente relacionados à transferência do que aqueles que atuam durante o treinamento.

Nesse período, um grupo de pesquisadores também propôs um modelo de instrumento para medir a transferência, o learning transfer system inventory - LTSI, que foi validado empiricamente, mas mostrou precisar de um modelo mais complexo. O modelo, composto por 16 construtos, dividos em quatro categorias (características do treinando, motivação, ambiente de trabalho e habilidade), pôde confirmar correlação entre tipos de organização e tipos de treinamento. Difere do modelo de Baldwin \& Ford (1988) ao excluir a categoria desenho do treinamento e incluir habilidade e motivação. Estudos posteriores com o modelo puderam mostrar que transferência está correlacionada também com tipos de organização, organizações e tipos de treinamento. Por exemplo, os treinandos em empresas privadas percebem que têm mais oportunidades de aplicar os treinamento do que aqueles em entidades públicas. A revisão aponta também muitos resultados inconsistentes e contraditórios na análise das variáveis preditoras de transferência, como, por exemplo, comprometimento organizacional.

O trabalho mostra que, apesar de um grande volume de achados e pesquisas, os resultados têm sido desafiados com frequência, demandando revisões e novas averiguações, como é o caso da correlação entre as variáveis comprometimento organizazional e motivação pré-treinamento (motivação para aprender), testada em 1995 positivamente e em 2000 negativamente. O fato é apontado como uma possível má conceituação das variáveis e estende-se a outras variáveis, como clima para transferência, suporte social e oportunidade para transferência, por exemplo. Os autores também creditam algumas dificuldades relativas ao entendimento do treinamento, ou aprendizagem no contexto do trabalho, e a novas concepções sobre o tema, com ênfase em contexto e o conceito de aprendizagem situada que vem substituindo as abordagens tradicionais.

A Tabela 2 mostra, como ilustração, os agrupamentos de variáveis relativas à transferência propostos por Burke e Hutchins (2007), Cheng e Hampson (2008) e o modelo 
LTSI de Holton (2000, as cited in Cheng e Hampson, 2008). O fato é interessante por mostrar uma convergência na categorização do fenômeno de tranferência.

\section{Tabela 2}

Categorização de variáveis relativas à tranferência.

\begin{tabular}{lllll}
\hline \multicolumn{1}{c}{ Autores } & \multicolumn{2}{c}{ Tipos de variáveis } \\
$\begin{array}{l}\text { Modelo LTSI } \\
(2000)\end{array}$ & $\begin{array}{l}\text { Características do } \\
\text { treinando }\end{array}$ & Motivação & $\begin{array}{l}\text { Ambiente de } \\
\text { Trabalho }\end{array}$ & Habilidade \\
$\begin{array}{l}\text { Burke e Hutchins } \\
(2007)\end{array}$ & $\begin{array}{l}\text { Características da } \\
\text { clientela }\end{array}$ & $\begin{array}{l}\text { Desenho/entrega da } \\
\text { instrução }\end{array}$ & $\begin{array}{l}\text { Características do } \\
\text { ambiente de } \\
\text { trabalho }\end{array}$ & - \\
$\begin{array}{l}\text { Cheng e Hampson } \\
(2008)\end{array}$ & $\begin{array}{l}\text { Características } \\
\text { individuais }\end{array}$ & Variáveis do cargo & $\begin{array}{l}\text { Variáveis } \\
\text { situacionais }\end{array}$ & - \\
\hline
\end{tabular}

Fonte: pesquisa.

Vale destacar o trabalho de Aguinis e Kraiger (2009), visto que o estudo, de abrangência internacional, analisou mais de 600 trabalhos, entre 2000 e 2009, que comprovaram diversos benefícios de ações instrucionais em equipes de trabalho, em resultados organizacionais e na sociedade. O estudo confirma os benefícios do treinamento em nível de indivíduos e equipes, indo além da melhoria do desempenho, afetando positivamente outras variáveis, como ajustamento intercultural, comunicação e ainda outras variáveis indiretamente.

Blume, Ford, Baldwin e Huang (2009) realizaram meta-análise sobre o tema e criticam muitos trabalhos em relação ao método. Nesses trabalhos, alguns resultados de transferência foram medidos por autorrelato e na mesma ocasião em que as variáveis eram testadas, como suporte e transferência, por exemplo. Os autores mostram que estudos realizados com métodos similares para medir a transferência tendem a produzir resultados similares, enviesando resultados. Ou seja, diferentes métodos de avaliação mostram graus de correlação diferentes entre as variáveis. O efeito é chamado same-source/samemeasurements-context - SS/SMC (uso de mesma fonte e mesmas medidas em um mesmo contexto). Reforça a necessidade da variação de métodos de medida de transferência. $\mathrm{O}$ estudo confirma as variáveis do treinando habilidade cognitiva, consciência ${ }^{5}$ e participação

${ }^{5}$ Não há, no trabalho, definição constitutiva da variável. Tomou-se base pela definição vulgar, como entendimento da situação de trabalho, levando-se em conta o contexto descrito no original. 
voluntária como tendo influência moderada na transferência. Outras variáveis observadas tiveram baixa relação com transferência. O estudo mostra que a variável autoeficácia apresenta resultados mais significativos quando mensurada imediatamente após o treinamento. Mostra, também, que a fonte de medida da transferência (o próprio treinando ou pares) resulta em dados muito similares. Reforça a falta de coerência e os resultados desencontrados dos estudos sobre transferência, como em Cheng e Hampson (2008).

Outras duas revisões, realizadas em dissertações, que utilizaram busca pela variável critério transferência de treinamento em pesquisas empíricas, foram examinadas neste estudo: Pereira (2009), e Santos Junior (2012). Essas revisões reafirmam a escassez de estudos empíricos sobre avaliação em TD\&E e confirmam a grande predominância de estudos correlacionais e forte participação de autoavaliação. É importante notar a pouca quantidade de estudos relacionados à própria ação de treinamento. Também foi percebido que os estudos têm pouca permeabilidade de outras ciências, carência já apontada por Tannenbaum e Yukl (1992). Pereira (2009) utilizou os termos avaliação, transferência, impacto e efetividade do treinamento. A revisão mostra crescimento da produção científica, apontando evolução na construção de medidas de avaliação e detecção e identificação de variáveis que exercem influência sobre a transferência de treinamento. O estudo confirmou a predição de transferência de treinamento das variáveis motivação para transferir, suporte externo, suporte social e técnico e percepção dos gerentes sobre práticas de gestão. Dessas, as três primeiras são externas ao processo de aprendizagem. A última é bastante específica do modelo estudado naquele trabalho. $\mathrm{O}$ trabalho reafirma a literatura nacional quanto à importância explicativa de variáveis contextuais. Aponta a prevalência de estudos correlacionais, com poucos experimentos e quase-experimentos. A coleta por meio de questionários e testes mostrou-se predominante com preferência pelo método de regressão múltipla para a análise de dados em contraste com a produção internacional, que utiliza equações estruturais, regressões hierárquicas, Ancova, Mancova e Manova. Foi detectada a predominância de autoavaliação em detrimento de heteroavaliações. O estudo confirma que variáveis externas ao treinamento são preditoras de resultados de ações educacionais.

A revisão de Zerbini e Abbad (2010) mostra grande predominância de delineamento correlacional e as análises de dados são feitas em sua maioria por análise de correlação e regressão múltipla e logística. A autora ressalta a necessidade de mais trabalhos com 
delineamento experimental. Os cursos presenciais foram detectados como a maioria dos eventos estudados. O ambiente corporativo é também o campos de estudos mais estudado. Roteiros de observação e questionários são os instrumentos de coleta mais encontrados. As fontes de informação são em sua maioria o próprio aluno. Há grande superioridade nos estudos sobre impacto em amplitude em relação à transferência de trteinamento. $\mathrm{O}$ trabalho aponta que as variáveis de contexto são as que apresentam maior poder de explicação da ocorrência de transferência de treinamento e impacto em amplitude. As variáveis de suporte suporte ambiental são as que apresentam relação mais forte com transferência, corroborando Lima, Borges-Andrade e Vieira (1989). A autora registra a necessidade de se estudarem outras variáveis. Dessa maneira, verifica-se a necessidade do desenvolvimento de mais pesquisas sobre os efeitos de TD\&E, envolvendo variáveis sociodemográficas e cognitivocomportamentais, principalmente nas ações de educação corporativa, formação e qualificação profissional, ofertadas à distância.

Santos Junior (2012), realizou revisão em transferência de treinamento, partindo de Abbad (2010) sobre o tema Avaliação de Treinamento. O trabalho mostra que houve progressos no estudo das variáveis suporte psicossocial (gerencial e social), relacionamentos interpessoais e autoavaliação de aprendizagem (aquisição), que revelaram força preditiva na variável transferência de treinamento. Em relação as achados internacionais, foi detectada grande predominância de pesquisas nos EEUU, com 40\% dos casos localizados. Estudos quantitativos e a preferência pelo método de equações estruturais para as análises estatísticas também foram detectados nessa revisão, corroborando a revisão de Pereira (2009). Essas duas revisões incorporaram os achados das revisões anteriores, expandindo o estudo em direções específicas, como a testagem de novas variáveis.

\section{Variáveis de transferência treinamento mediado por tecnologia}

Na Tabela 3, estão destacados os trabalhos que averiguaram variáveis na relação entre mediação de tecnologia, ou e-learning, e transferência. Entre 2013 e 2014 (a revisão mais recente consultada analisou a produção até o ano de 2012), apenas um trabalho relevante, não contemplado nas revisões anteriores, foi localizado. Nessa busca complementar, foram usados os termos treinamento, impacto de treinamento e transferência 
de treinamento em artigos publicados em revistas e periódicos científicos com classificação Qualis Capes entre A1 e B1, de psicologia e administração de empresas. A busca resultou em dois artigos, com um descarte, devido à baixa identificação com os propósitos deste estudo. Essa etapa buscou resultados mais delimitados e específicos (transferência e tecnologia), visto que a produção já averiguada nas revisões permite uma visão bastante completa da produção científica no campo de transferência e indica caminhos bem definidos para esta pesquisa, bem como suas limitações.

\section{Tabela 3}

Mapa analítico de pesquisas sobre avaliação de treinamento mediado por tecnologia no período 1999-2014.

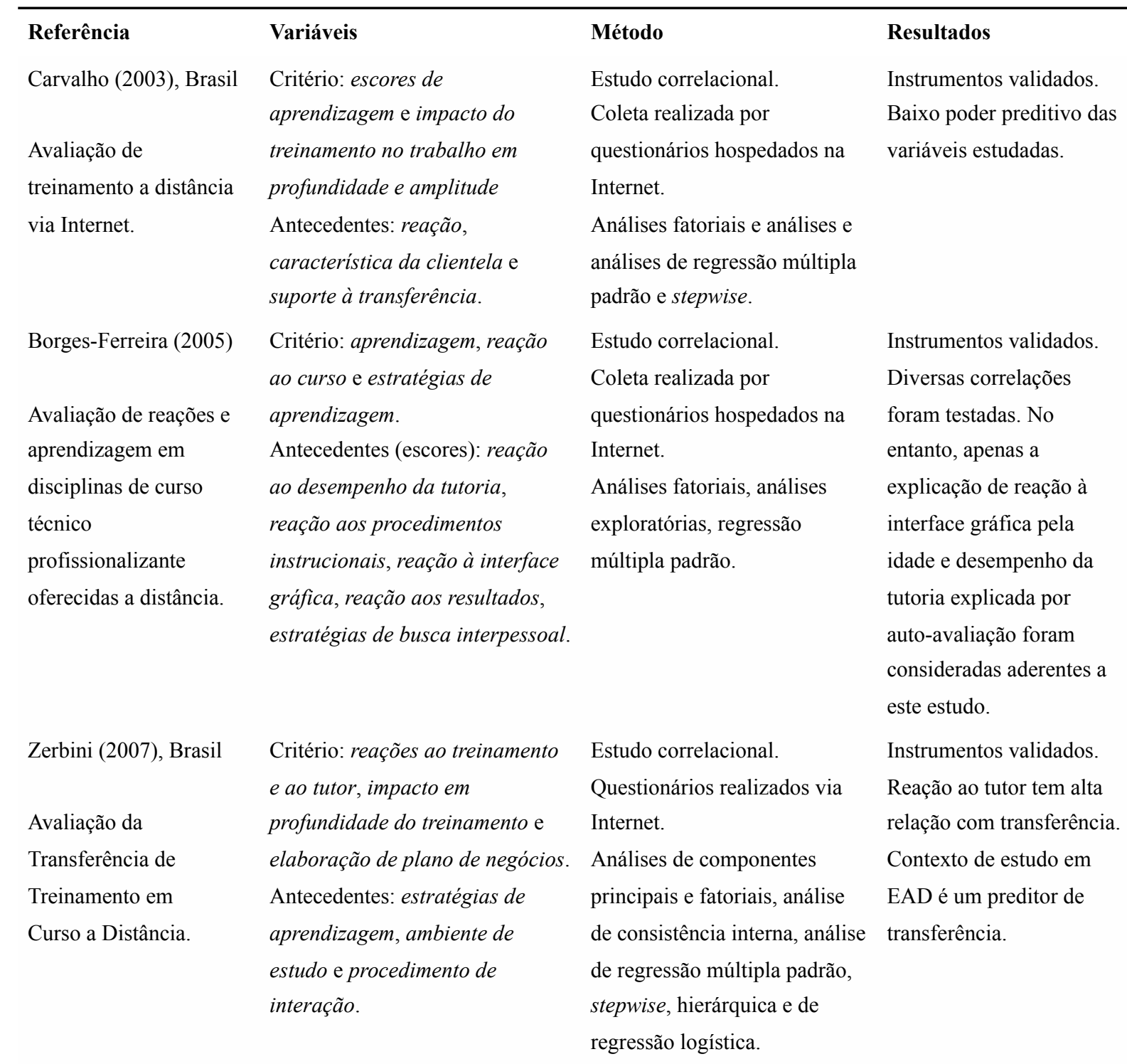




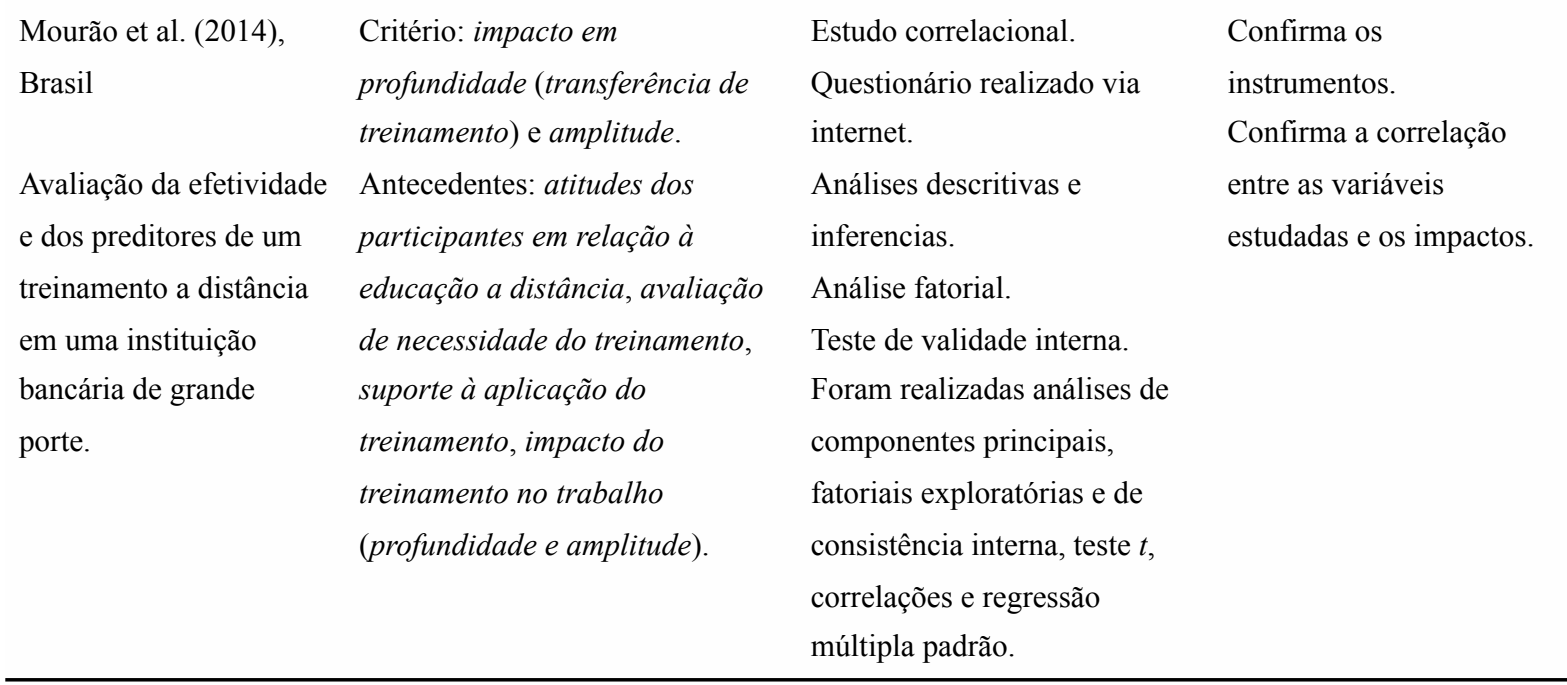

Fonte: Todeschini, Silva, Sales, Coelho, Vieira e Brixi (2006), Pereira (2009), Silva (2011) e Santos Junior (2012).

A primeira observação quanto a esse levantamento específico é a escassez de trabalhos empíricos voltados à transferência de treinamento em modelos mediados por tecnologia. Outro ponto de atenção é que esses estudos foram realizados em modelos tradicionais de treinamento mediado por tecnologia, feitos em computadores do tipo desktop, com apoio de tutoria e baseados em Internet. Zerbini (2007), demonstra que contexto de estudo é uma variável preditora de transferência. A variável indica fatores relacionados à prática de estudo que podem exercer influência nos resultados (regularidade proposta de acesso e de estudo, à disponibilidade do computador, e à conciliação do curso com outras atividades de estudos, profissionais e compromissos familiares). É possível se interpretar que esses fatores tendam a exercer influência nas situações de mobile learning, em função do atributo mobilidade, característico do recurso móvel. A reação ao tutor é um fator importante, mas dependerá fortemente do modelo utilizado. Mourão, Abbad e Zerbini (2014) confirmam a influência das variáveis atitudes em relação à EAD, contribuição do curso para aquisição de competências e suporte à aplicação do treinamento como preditoras do transferência do treinamento em ambientes mediados. Ainda, para os ambientes de e-learning e seus derivados, como no caso deste estudo, são necessários instrumentos específicos para a aferição da transferência nessa modalidade, como relatado por Abbad (2009). Os trabalhos apontam para um composto de atuação do tutor, ambiente (contexto) e material utilizado (qualidade do material), que produzem resultados positivos na transferência. Esses achados 
são um bom ponto de partida para um desenho instrucional eficaz e mostra boas perspectivas para o estudo de mobile learning em contexto organizacional.

Assim, em referência às questões iniciais, podemos responder: 1) quais variáveis na literatura sobre transferência exibiram forte suporte empírico para a explicação da transferência?. Destacamos como fortes preditoras de transferência aquelas com relação mais direta com este trabalho (listadas ao final do trecho sobre transferência). 2) Onde estão as maiores lacunas dos fatores que afetam transferência? As principais lacunas encontram-se na falta de variedade de métodos de levantamento de dados, bem como a utilização de mais de uma fonte, e diversidade nos delineamentos. 3) Quais os progressos metodológicos têm sido feitos e quais variáveis permanecem sem estudo? Com os detalhamentos dos principais construtos, novas variáveis têm sido testadas e com elas novas escalas e instrumentos vem sendo consolidados. 4) Qual será o futuro da pesquisa sobre transferência de acordo com os achados de pesquisa? A resposta a essa pergunta assume um caráter interpretativo, que dá ao pesquisador alguma liberdade no exercício de visualizar os caminhos da pesquisa. No tema específico deste trabalho, diversos processos e modelos terão que ser revistos, dado que o impacto que as tecnologias móveis têm exercido em TD\&E vem se mostrando significativo e profundo. De qualquer modo, a levar-se em conta os achados, pode-se citar a adoção de delineamentos experimentais ou quase-experimentais, variedade de métodos de levantamento de dados (triangulação) e adaptação dos estudos às novas realidades sociais e maior aderência à realidade organizacional.

\section{Síntese}

As revisões apontam aprofundamento e avanço do saber sobre o tema, o desenvolvimento e consolidação de instrumentos de avaliação e a identificação e testagem de variáveis que têm influência sobre a transferência de treinamento, extrapolando o nível micro de análise. No entanto, cabe observar, limitações na pesquisa, como em Cheng e Hampson (2008) que identificam o foco predominante dos estudos em identificação, descrição e medida das variáveis, sem aprofundamento nos fatores que possam atuar sobre elas. Outra limitação apontada em várias revisões é relativa ao método, que privilegia a prática de autoavaliação e/ ou autorrelato, o que restringe os resultados e está sujeita a viéses específicos, que devem ser 
controlados. O mesmo ocorre com o monométodo, restringindo a precisão dos resultados pela falta de corroboração dos achados por técnicas complementares de apoio. Há, também, grande predominância de delineamentos correlacionais. Sob esse aspecto, Zerbini e Abbad (2010) apontam a necessidade de mais desenhos experimentais, a fim de dar maior solidez aos achados de psquisa, além de afirmar que as variáveis de contexto e suporte ambiental têm maior poder de explicação da transferência. As ferramentas e escalas usadas para a avaliação de mais de um construto constitui-se também como fragilidade frequente, dado que instrumentos semelhantes tendem a aproximar resultados, conforme Blume et al. (2009). Pereira (2009) e Santos Junior (2012) registram a falta de permeabilidade de outras áreas do saber, que podem trazer contribuições significativas e ampliar o entendimento dos fenômenos. Essas questões metodológicas têm sido registradas constantemente e corroboradas praticamente em todos os estudos e revisões. No entanto, os achados, mesmo com essas limitações, possuem validade científica e, com isso, não podem ser desprezados como fontes vitais de informação para a construção de teorias e orientação para os trabalhos no campo.

Outra observação pertinente diz respeito à dinâmica do campo TD\&E, visto que o contexto de treinamento (incorpora o contexto de aprendizagem) é mutável e tem se transformado significativamente com o apoio da tecnologia, o que exige regularmente revisão de conceitos e ferramentas de avaliação. Na realidade, a aprendizagem e o contexto organizacional estão sujeitos a questões de natureza cultural, que é matéria dinâmica e em constante mutação, o que gera implicações comportamentais, em nível micro, e contextuais, em níveis meso e macro e, dessa forma, influenciando as variáveis e suas medidas e relações. No contexto deste trabalho esses fatores ganham ainda mais relevância, dadas as características individuais e contextuais que têm se mostrado de grande influência na variável estudada. Posteriormente, no estudo específico sobre variáveis em mobile learning, essas questões mostram-se mais aparentes.

A seguir, uma relação das variáveis preditoras de na tranferência e têm pertinência e relevância com o presente estudo: contexto de estudo e reação ao tutor (Zerbini, 2007), aspectos ambientais (mais influentes do que os individuais) motivação para transferir, suporte técnico (Pereira, 2009), consciência (Blume et. al, 2009) (essa é uma variável de influência moderada, mas pode ter seu valor incrementado em modelos móveis, devido à condição de autonomia), variáveis de suporte ambiental (Abbad, 2010 e Lima, Borges- 
Andrade e Vieira, 1989), autoavaliação de aprendizagem (aquisição) (Santos Junior, 2012), atitudes dos participantes em relação à educação a distância, avaliação da necessidade de treinamento e suporte à aplicação do treinamento (Mourão et al. 2014). Conforme revisão de Burke e Hutchins (2007): autoeficácia, abertura para novas experiências, utilidade percebida, relevância do conteúdo, características do ambiente de trabalho e desenho/ entrega da instrução.

Cabe salientar que muitas dessas variáveis dependerão dos desenhos instrucionais desenvolvidos, dado que ainda não há conhecimento teórico ou empírico que permita desenhos instrucionais adequados à realidade da aprendizagem móvel.

\subsection{Revisão sobre mobile learning}

A revisão de literatura no tema pretendeu reunir, organizar e interpretar a produção científica sobre aprendizagem em dispositivos móveis, mobile learning, com o intuito de nortear a presente pesquisa e contribuir para a construção de um campo ainda embrionário. $\mathrm{O}$ exame do material encontrado buscou localizar variáveis, dados e resultados que identifiquem características e atributos de modelos de aprendizagem com o apoio de dispositivos móveis, com a finalidade de correlacionar esses achados com aqueles referentes à transferência de treinamento.

A primeira etapa da revisão foi a realização de uma busca bibliométrica em mobile learning, cuja função foi mapear o tema na produção científica. O levantamento aponta áreas de concentração, distribuição geográfica, preferência de métodos e outras informações para subsidiar a compreensão do campo de pesquisa. O levantamento foi realizado em outubro de 2015 e localizou trabalhos nacionais e internacionais, nas bases Periódicos Capes, ProQuest e Scielo, além da Biblioteca Digital de Teses e Dissertações do Instituto Brasileiro de Informação em Ciência e Tecnologia - IBICT.

As palavras-chave utilizadas na busca foram: mobile learning, m-learning, aprendizagem móvel, aprendizagem ubíqua, ubiquotous learning e dispositivos móveis. $\mathrm{O}$ volume preponderante de achados encontra-se sobre o termo mobile learning e m-learning. Outros termos similares (ubiquitous learning, ou u-learnming, por exemplo) também são utilizados, no entanto a terminologia mobile learning pode ser considerada hegemônica, 
inclusive na literatura nacional, observando-se que os trabalhos que usaram o termo ubiquotous learning, por exemplo, também estão, em sua grande maioria, indexados por aqueles dois termos.

Foram localizados 95 artigos, dos quais 62 foram considerados pertinentes ao estudo, na análise dos títulos e informações básicas dos trabalhos. Desses, 14 foram descartados por não apresentarem consistência científica (formatos impróprios e falta de definições mínimas de método). 48 artigos foram analisados com maior detalhamento, por meio do exames dos respectivos abstracts, quanto às suas delimitações de tema, método e resultados encontrados. Cinco artigos foram ainda descartados por motivos diversos, como o reduzido número de referências, ou volume de participantes $(\mathrm{N})$ muito baixo, por exemplo, sem que apresentassem uma contrapartida importante. O conjunto ficou, então, reduzido a 42 trabalhos, agrupados em teóricos (23, originalmente, com o acréscimo de 4 trabalhos posteriormente, totalizando 27) e teórico-empíricos (19, originalmente, porém foram feitas duas inclusões posteriores, totalizando-se 21). O conjunto final analisado, ficou composto de 48 artigos estudados.

Os critérios de seleção foram predominantemente de conveniência, a fim de se obter uma visão global e o mais diversificada e abrangente possível, dado o estágio ainda imaturo do campo de estudo. Há baixo índice de publicação em veículos de relevância nos trabalhos encontrados. Levando-se em consideração a referência Qualis Periódicos, da Coordenação de Aperfeiçoamento de Pessoal de Nível Superior - Capes, no conjunto dos trabalhos teóricos, por exemplo, salvo duas revisões internacionais, cujos achados incluem referências que constam no Qualis 2014 (trabalhos elencados nos artigos levantados e não o trabalho em si), há apenas 1 trabalho que atenderia esse critério: Saccol et al. (2010), que publicou no International Journal of Information and Communication Technology Education, com pontuações Qualis B2 em educação e administração e Qualis B4 em ciência da computação. Alguns artigos, pela afinidade com a área de tecnologia, como a revisão de Hung e Zhang (2012), fazem referência ao Social Sciences Citation Index - SSCI, contemplado nas bases da Capes, já examinadas e merece destaque pelo prestígio da publicação.

A orientação principal para a escolha dos trabalhos foi a aproximação com temas que pudessem abrir caminhos para a exploração do tema de pesquisa, referentes à utlização e eficácia da intervenção de dispositivos móveis em eventos de capacitação em contexto organizacional. A busca, no entanto, encontrou um contingente bastante mais significativo de 
estudos em contexto educacional. Os filtros usados para restrição dos resultados foram: revisados por pares e formato artigo. Não houve restrição de data, devido à juventude do tema e a busca do caráter histórico da pesquisa.

Foi realizada, também, busca nos formatos teses e dissertações, na base do IBICT, onde foram localizados 21 trabalhos. Esses trabalhos buscam profundidade e detalhamento, portanto, para efeitos deste estudo, os resultados deveriam apontar para a confirmação de variáveis que tivessem relação específica com transferência de treinamento, ou alguma construção teórica que pudesse fundamentar de modo consistente uma teoria de mobile learning. Os trabalhos analisados não atenderam a esses critérios. Os critérios irão diferir quando aplicado a artigos, que trazem, por sua natureza acadêmica, maior amplitude de temas e resultados mais objetivos. Dessa forma, trazem, em conjunto, contribuições de caráter mais amplo, ilustrando o tema com iniciativas originais em situações bastante diferenciadas. Dos 20 artigos teórico-empíricos selecionados, apenas um se ocupou diretamente do uso desse tipo de tecnologia em organizações para o desenvolvimento de competências profissionais: Saccol et al. (2010), produzido no Brasil.

Destaca-se, nesta mostra, a posição do Brasil, com sete artigos publicados, bastante próximo dos países que apresentam maior volume de publicações sobre mobile learning: Reino Unido e Estados Unidos da América do Norte - EUA. A importância dessa distribuição é a indicação da amplitude da produção científica em vários países. O resultado talvez possa ser interpretado como correspondente à forte penetração da tecnologia móvel em todos os lugares do mundo, ultrapassando barreiras geográficas em termos de uso e, consequentemente, despertando interesse da comunidade científica para o tema. Por esse critério, os EUA vem em primeiro lugar, com 12 ocorrências, em segundo lugar, está o Reino Unido, com oito trabalhos, em sequência vem o Brasil, com sete trabalhos, Formosa com seis, Espanha com quatro, seguidos de Canadá, Malásia, Nigéria, com dois, e África do Sul, Áustria, China, Nova Zelândia, Turquia e Uganda, com um trabalho.

Para efeitos de acentuação das feições metodológicas, os trabalhos foram separados em dois eixos: empíricos e teóricos. A segregação foi usada visando maior foco nos trabalhos empíricos, em função dos objetivos de pesquisa. Dessa forma, os artigos empíricos serão aqui mais detalhados, enquanto os teóricos permearão o trabalho de modo global. Algumas considerações de natureza teórica se mostraram necessárias, mesmo com o foco definido. 
A localização dos períodos de produção é importante por compor uma perspectiva histórica do tema. Para o mobile learning, esse levantamento é particularmente relevante, dado que a produção científica e o desenvolvimento das tecnologias caminham paralelamente, tornando árduo o trabalho de estabelecimento de pontos de referência e suas respectivas análises sob o rigor científico. Como exemplo, os tablets ganham impulso no ano de 2010, com o lançamento do iPad, da empresa de tecnologia Apple. Há poucas menções a esse dispositivo (Bidarra, Rotschild, Squire e Figueiredo, 2013; Kukulska-Hulme, 2011; Saccol et al., 2010 e Huang, Liao, Huang e Chen, 2014), que, em tese, tem bastante potencial para ocupar um lugar de destaque na utilização de dispositivos móveis na educação, levando-se em conta duas grandes limitações apontadas em mobile learning: o tamanho da tela, que dificulta a interação, como apontado por Du, Hao, Kwok e Wagner (2010) e a dificuldade de digitação, conforme mencionado por Siau, Lim e Shen (2001), Gikas e Grant (2013) e Wang, Wu e Wang (2009) (pequenos teclados multifunção), que, em trabalho experimental, identificaram, por meio das manifestações dos usuários, que os pequenos teclados eram um obstáculo a respostas mais elaboradas. A distância entre as datas de produção dos trabalhos, mostra claramente que esse ainda é um desafio aos dispositivos móveis.

Com relação ainda à questão temporal, não é possível considerarmos a mesma experiência de aprendizagem os relatos do início dos anos 2000, daqueles por volta de 2006 e posteriormente, aqueles que ocorreram após 2010 (os marcos são estimados), visto que os aparelhos passaram a ter recursos e configurações que praticamente reinauguram essa forma de mediação em alguns pontos marcantes, com especial destaqu

\begin{tabular}{llll}
\hline Referência & Variáveis & Método & Resultados \\
Carvalho (2003), Brasil & Critério: escores de & Estudo correlacional. & Instrumentos validados. \\
& aprendizagem e impacto do & Coleta realizada por & Baixo poder preditivo das \\
Avaliação de & treinamento no trabalho em & questionários hospedados na & variáveis estudadas. \\
treinamento a distância & profundidade e amplitude & Internet. \\
via Internet. & Antecedentes: reação, & Análises fatoriais e análises e & \\
& característica da clientela e & análises de regressão múltipla & \\
& suporte à transferência. & padrão e stepwise.
\end{tabular}


Borges-Ferreira (2005) Critério: aprendizagem, reação ao curso e estratégias de

Avaliação de reações e aprendizagem em

disciplinas de curso técnico

profissionalizante oferecidas a distância. aprendizagem.

Antecedentes (escores): reação ao desempenho da tutoria, reação aos procedimentos instrucionais, reação à interface gráfica, reação aos resultados,

estratégias de busca interpessoal.
Estudo correlacional.

Coleta realizada por questionários hospedados na Internet.

Análises fatoriais, análises exploratórias, regressão múltipla padrão.
Zerbini (2007), Brasil

Avaliação da

Transferência de

Treinamento em

Curso a Distância.
Critério: reações ao treinamento

e ao tutor, impacto em

profundidade do treinamento e elaboração de plano de negócios. Antecedentes: estratégias de aprendizagem, ambiente de estudo e procedimento de interação.

\section{Critério: impacto em} profundidade (transferência de treinamento) e amplitude.

Avaliação da efetividade e dos preditores de um treinamento a distância em uma instituição bancária de grande porte.
Antecedentes: atitudes dos participantes em relação à educação a distância, avaliação de necessidade do treinamento, suporte à aplicação do treinamento, impacto do treinamento no trabalho (profundidade e amplitude).
Estudo correlacional.

Questionários realizados via Internet.

Análises de componentes principais e fatoriais, análise de consistência interna, análise de regressão múltipla padrão, stepwise, hierárquica e de regressão logística.

Estudo correlacional.

Questionário realizado via internet.

Análises descritivas e inferencias.

Análise fatorial.

Teste de validade interna.

Foram realizadas análises de componentes principais, fatoriais exploratórias e de consistência interna, teste $t$, correlações e regressão múltipla padrão.
Instrumentos validados.

Diversas correlações

foram testadas. No entanto, apenas a explicação de reação à interface gráfica pela idade e desempenho da tutoria explicada por auto-avaliação foram consideradas aderentes a este estudo.

Instrumentos validados. Reação ao tutor tem alta relação com transferência. Contexto de estudo em EAD é um preditor de transferência.

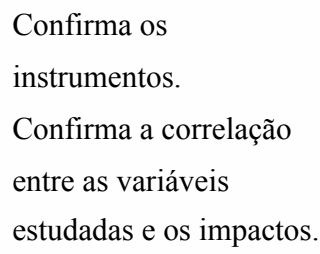

e para o acesso a redes. As ocorrências seguem descritas na Tabela 4. 


\section{Tabela 4}

Distribuição dos artigos por ano de publicação.

\begin{tabular}{|c|c|c|}
\hline \multirow{2}{*}{ Ano de publicação } & \multicolumn{2}{|c|}{ Incidência } \\
\hline & Teóricos & Teórico-Empíricos \\
\hline 1989 & & 1 \\
\hline 1999 & 1 & \\
\hline 2000 & 1 & \\
\hline 2002 & 1 & 1 \\
\hline 2004 & 1 & \\
\hline 2005 & 1 & \\
\hline 2006 & & 1 \\
\hline 2007 & 1 & \\
\hline 2008 & & 1 \\
\hline 2009 & 1 & 2 \\
\hline 2010 & 1 & 4 \\
\hline 2011 & 3 & 1 \\
\hline 2012 & 2 & 1 \\
\hline 2013 & 4 & 2 \\
\hline 2014 & 4 & 5 \\
\hline 2015 & 4 & 2 \\
\hline
\end{tabular}

Fonte: pesquisa.

A referência mais antiga a mobile learning encontrada foi o artigo The design of personal mobile technologies for lifelong de Mike Sharples, datado de 2000. O artigo tem importância fundamental pela originalidade, fundamentação histórica e visão de futuro. É também o mais citado no conjunto levantado, com 10 citações diretas em 43 trabalhos. O artigo refere-se ao conceito lifelong education, que aproxima-se, em português, do termo educação continuada. O texto reflete uma política pública adotada no Reino Unido, consubstanciada no documento oficial (green paper) The Learning Age, que lança uma visão de educação para um mundo em rápido ritmo de mudanças, por meio de mídias de distribuição e acesso on-line. O texto diz que o objetivo de tal política é que se permita que as 
pessoas aprendam onde quiserem, possam avaliar o que fazem e decidam onde querem ir. Fala também da inviabilidade de se instrumentar estudantes nas instituições tradicionais. É bastante visionário no que tange ao conceito de mobilidade, fundamental no estudo de mobile learning. O artigo de Davis (1989) foi incluído devido à sua importância, pois propõe o modelo Technology Acceptance Model, conhecido como TAM, que estabelece importante referencial para as testagens correlatas.

Em relação ao delineamento, foram encontrados nove trabalhos correlacionais, seis experimentais, quatro exploratórios e dois descritivos. Chama a atenção a boa quantidade de estudos de modelagem experimental. Essa modelagem confere maior consistência às relações de causa e efeito do fenômeno estudado. A quantidade de estudos exploratórios pode indicar a imaturidade do campo de pesquisa, que ainda busca objetos mais claros e específicos a serem examinados. É perceptível, também, uma parcela exploratória nos trabalhos de todas as modelagens, mostrando um terreno ainda inexplorado e com poucas referências substanciais.

Em termos de coleta de dados, dez estudos usaram survey/questionário, três aplicaram a técnica de grupo focal, dois se valeram de entrevistas, dois coletaram por meio de estudo de caso e três fizeram levantamentos em dados duros de sistema. Com relação à análise dos dados, sete estudos usaram equações estruturais, seis aplicaram análise fatorial, três fizeram regressão, dois fizeram as análises por meio de análise de conteúdo e três usaram o teste $\boldsymbol{t}$.

A área educacional foi a mais contemplada com a produção sobre o tema. É natural, visto tratar-se do fenômeno de aprendizagem. Alguns aspectos paralelos surgiram no levantamento, como avaliação e modelos tecnológicos, que são igualmente aderentes ao estudo.

\section{Categorização dos achados}

Para efeitos deste estudo, os trabalhos foram classificados em 4 categorias: modelos de criação de ferramenta, modelos de aplicação de eventos (DI), modelos de identificação de variáveis (inclui aceitação de tecnologia) e estratégia de ensino baseada em mobile. Outra classificação, em 4 categorias, de Hung e Zhang (2012), foi localizada na pesquisa: estratégias e referenciais teóricos, aceitação de mobile learning, avaliação e eficácia e estudos de caso. Essas categorias incluíram 12 variáveis de análise. Ainda em $\mathrm{Wu}, \mathrm{Wu}, \mathrm{Chen}$, 
Kao, Lin e Huang (2012) foram utilizadas 4 categorias: avaliação dos efeitos de m-learning, desenho de sistema para m-learning, investigação sobre o domínio afetivo em m-learning, avaliação da influência das características do aprendiz no processe de m-learning. As diferenças mostram as diferenças de propósito dos estudos em questão.

Neste estudo, busca-se o foco em direção à discussão dos aspectos que influenciam o uso dos dispositivos móveis. A testagem de variáveis, as iniciativas de modelagem (pelo aspecto de aplicação deste estudo). Essas foram contempladas na categoria referente à criação de modelos e os estudos que tratam de desenho e estratégias instrucionais. Essas direções poderão trazer clareza ao questionamento de desenhos instrucionais específicos para o mlearning, suas bases tecnológicas de apoio e quais as variáveis deverão ser levadas em consideração em um planejamento instrucional em contexto organizacional. Todas essas informações deverão implicar em um sistema de avaliação específico e preciso. Essas são as bases propostas para o estudo da transferência de treinamento, diretamente relacionada à forma e eficácia da instrução. A Tabela 5 mostra a distribuição dos artigos pelas categorias propostas.

\section{Tabela 5}

Distribuição dos artigos por categoria proposta.

\section{Categoria}

Incidência

1) Modelos de Identificação de Variáveis (inclui aceitação de tecnologia) 8

2) Modelos de Aplicação de Eventos (DI) $\quad 8$

3) Modelos de Criação de Ferramenta 4

4) Estratégias de ensino baseadas em mobile 1

Fonte: pesquisa.

\section{Análise dos trabalhos pela categoria}

A análise individual dos trabalhos por categoria é proposta como forma de mostrar a amplitude do tema e as possibilidades surgidas nas proposições de medidas e modelos didáticos. Os sistemas móveis têm grande versatilidade de aplicação, como será visto no detalhamento das categorias. 
A categoria Identificação de Variáveis contempla os achados que se ocuparam em relacionar variáveis preditivas e, em alguns casos, moderadoras dos comportamentos relacionados ao uso de mobile learning, ou de dispositivos móveis em contexto de aprendizagem. A maior incidência de trabalhos testou variáveis do Technology Acceptance Model - TAM, desenvolvido por Fred Davis, em 1989, ou usou modelos derivados deste, com inclusão de variáveis adicionais. As variáveis originais do modelo são perceived of use (PU) e perceived ease of use (PEOU), testadas empiricamente pelo autor e confirmadas como preditoras do uso tecnologia, com a variável PU tendo mais força de explicação do que PEOU em três dimensões de comportamento: atitude (ATT), intenção comportamental (BI) e uso efetivo da tecnologia (AU), conforme modelo da Figura 1. Alguns estudos propuseram uma ampliação do modelo, como Kurtz, Macedo-Soares, Ferreira, Freitas e Silva (2015), que adicionaram ao modelo TAM variáveis originárias da Teoria do Fluxo e da da Teoria do Comportamento Planejado - TPB. Note-se que o modelo original (a própria data é forte indicador) foi desenvolido para o uso de computadores. No entanto, as ferramentas móveis diferem, em muito, daqueles utilizados à época da formulação do modelo. De qualquer forma, o modelo está presente em todos os trabalhos dessa categoria, o que mostra que essas variáveis são também aplicáveis ao mobile learning. A figura 1 mostra o esquema proposto por Davis (1989).

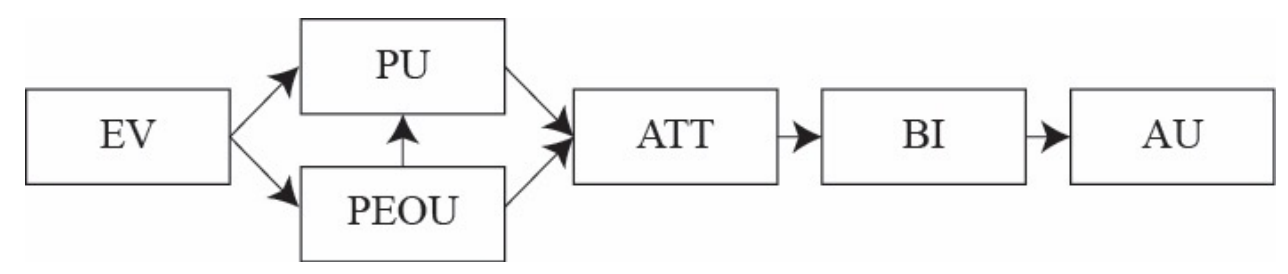

Figura 1. Esquema de variáveis contempladas no modelo TAM.

Fonte: Huang, Lin e Chuang (2006).

Legenda: EV: external variables (variáveis externas); PU: perceived usefulness (utilidade percebida); PEOU: perceived easy of use (facilidade de uso percebida), ATT: attitude (atitude); BI: behavioral intention (intenção comportamental) e AU: actual usage (uso efetivo).

A aceitação da tecnologia pode ser definida como a intenção voluntária do uso efetivo de tecnologia, apoiada em processos cognitivos e pode ser compreendida pela cadeia de construtos definida no modelo, composta de elos consequentes de construtos: atitude, intenção comportamental e uso efetivo, que são resultados parciais e complementares entre si 
da aceitação da tecnologia. Outros autores propuseram e testaram a inclusão de outras variáveis ao modelo, conforme descrito a seguir.

Huang, Lin e Chuang (2006) testaram duas varíaveis adicionais ao modelo TAM: perceived enjoyment (PE), ou diversão percebida, e perceived mobility value (PMV) ou valor de mobilidade percebido. $\mathrm{O}$ trabalho mostra que as duas variáveis são preditoras da intenção de usar m-learning (BI). Paralelamente, afirmam que os participantes percebem o $m$-learning como uma ferramenta eficiente de aprendizagem. Segundo os autores, o m-learning é um modelo complementar ao e-learning, o que não é consesnsual em relação a outros estudos. PMV significa a consciência do valor da mobilidade do m-learning, enquanto PE indica a percepção do quanto a atividade trará de diversão. PMV é a percepção de valor da mobilidade, que é composta por dois elementos: conveniência (no sentido de praticidade, e de adequação) e instantaneidade. Perceived mobility value tem efeito positivo sobre PU. Diversão percebida tem efeito positivos sobre PEOU. Diversão percebida, PEOU e PU tem efeitos positivos sobre ATT. Afirma que o efeito de PU é maior do que PEOU em ATT, confirmando o modelo.

O trabalho de Wang et al. (2009) propõe um modelo de aceitação de tecnologia também específico para m-learning com base em uma teoria unificada, chamada theory of acceptance and use of technology - UTAUT. Foram testadas as seguintes variáveis como preditoras da variável intenção comportamental de uso de m-learning (BI - adaptado para mlearning): 1) expectativa de performance, 2) expectativa de esforço, 3) influência social, 4) diversão percebida e 5) auto-gestão da aprendizagem. Todas com influência positiva na variável critério. Sendo 1, 2 e 3 com influência significativa e 4 e 5 com forte influência em BI.

$\mathrm{O}$ trabalho confirma que idade modera os efeitos em expectativa de esforço e influência social e o gênero modera os efeitos de influência social e auto-gestão da aprendizagem, porém sem efeitos relevantes. Influência social é definida como a pressão do grupo social em direção à adoção de um determinado sistema de informações. Pode ser equiparado como normas subjetivas, estudado por Kurtz et al. (2015). Pode se afirmar, então, que com relação a essa variável, Wang et al. (2009) confirmam os resultados daqueles autores, com a diferença que estes apontam a variável como moderadora e aqueles como preditora de BI em mobile learning. 
As teorias elencadas pelo modelo UTAUT são: 1) Theory of Reasoned Action - TRA (Fishbein \& Ajzen, 1975), 2) o Technology Acceptance Model - TAM (Davis, 1989), 3) o Motivational Model - MM) (Davis, Bagozzi \& Warshaw, 1992), 4) a Theory of Planned Behaviour - TPB (Ajzen, 1991), 5) a combinação de TAM e TPB - C-TAM-TPB (Taylor \& Todd, 1995a), 6) o Model of PC Utilisation - MPCU (Triandis, 1977; Thompson, Higgins \& Howell, 1991), 7) a Innovation Diffusion Theory - IDT (Rogers, 2003; Moore \& Benbasat, 1991) e 8) a Social Cognitive Theory - SCT (Bandura, 1986; Compeau \& Higgins, 1995). Essas teorias permeiam muitos dos trabalhos levantados, mostrando influências importantes e definindo variáveis de relevo, que ajudam a compreender o fenômeno estudado.

Fadare, Babatunde, Akomoafe e Lawal (2011) exploram BI em relação a autoeficácia e m-learning attitude, além de PU, PEOU. Afirmam que autoeficácia é o construto mais influente sobre BI, seguido de PU, PEOU e, ao final, m-learning attitude. Os autorem propõem um modelo expandido do TAM, o TAMM, específico para o mobile learning, que inclui autoeficácia e substitui a variável atitude por atitude para utilizar mlearning (m-learning attitude). Inclui também normas subjetivas e acessibilidade do sistema, embora essas não hajam sido confirmadas, em contraste com Kurtz et al. (2015) quanto a normas subjetivas.

Observemos, no entanto, que, para Davis (1989), PEOU é similar a autoeficácia pois é um conceito derivado deste, baseado em Bandura (1982) e não tem relação com resultados, mas com o comportamento em si. O achado constrasta com todos os outros que mediram PU e PEOU, indicando sempre que PU exercia maior influência do que PEOU. M-learning attitude foi identificada como a variável de menor poder preditivo, que confirma o modelo original quanto à variável AT. Não há maiores indícios para a separação entre PEOU e autoeficácia. Tan, Ooi, Sim e Pushavat (2012) testam também a aceitação com base no modelo TAM. Confirmam PU e PEOU como preditoras da intenção de uso e incluem normas sociais para completar o grupo de variáveis mais influentes sobre a intenção de uso. Relatam testagem com as variáveis moderadoras idade, mostrando que gênero não possui influência sobre as variáveis estudadas, no entanto, idade interfere em normas sociais e PEOU.

Tan, Ooi, Leong, Lin (2014) fizeram testagens correlacionais entre duas variáveis originais do modelo TAM (PU e PEOU). Testaram social influence (SI), já testada por Wang et al. (2009) para exame de variável critério similar à desse trabalho, porém com resultados 
adversos àqueles. Acrescentaram ao modelo mais uma: personal innovativeness information technology (PIIT) que é uma variável associada à característica individual de ser inovador e, com isso, ter maior aceitação à tecnologia. A variável critério adotada foi intenção de adotar m-learning, adaptada do modelo TAM (genérico em relação à tecnologia). Confirma, como outros trabalhos, PU como a variável mais influente do modelo. PITT tem forte influência em predizer PEOU. Nesse estudo, os autores não acharam relação entre influência social (SI) e intenção de usar m-learning, contrariando os achados de Wang et al. (2009) e Kurtz et al. (2015). PITT tem influência positiva sobre PEOU enquanto SI mostrou forte influência em PU. Afirmam que indivíduos com maiores índices de PITT têm mais coragem e maiores valores de personalidade e status sócio-econômico mais elevado. Essa é também uma variável sujeita ao contexto social. As variáveis controle idade, gênero e qualificações acadêmicas não mostraram resultados consistentes.

Ferreira et al. (2014) estudaram as variáveis compatibilidade, PEOU, PU (longo e curto prazo), autoeficácia, atitude (AT) (no estudo, é considerada como atitude para uso de $m$ learning) e intenção comportamental (BI). Os resultados mais relevantes do estudo indicam que PU em curto prazo foi a variável mais influente na (BI) e compatibilidade mostrou influência em PEOU, mas com carga aquém de PU. Os autores fizeram um desdobramento da variável PU, confirmada em vários estudos como a mais forte na intenção de uso de tecnologia em duas: em longo e curto prazo. Essa divisão não trouxe grande contribuição para o estudo, exceto a influência de uma sobre a outra, com short term usefulness influenciando long term usefulness. Compatibilidade foi definida como o grau em que uma inovação é percebida como consistente com valores, necessidades e experiências prévias do usuário.

O estudo das variáveis originárias e derivadas do modelo TAM têm relevância em direção a fundamentos para o desenvolvimento de modelos instrucionais e de avaliação, visto que apontam parâmetros objetivos nos quais podem ser apoiadas estratégias de ensino/ aprendizagem. Do conjunto examinado, destaca-se que as variáveis PU e PEOU são as mais relevantes para a aprendizagem. Dessa forma, se temos um desenho instrucional que percebe e assimila essas condições, teremos resultados objetivos de treinamento com maior consistência e, com isso, apresentando melhores condições de avaliação.

Kurtz et al. (2015) testaram variáveis com base no modelo TAM: facilidade de uso percebida (PEOU) e utilidade percebida (PU). Diversão percebida, concentração, normas 
subjetivas e controle do comportamento percebido são antecedentes importantes para a intenção de uso (BI) do m-learning. Chama a atenção em particular a força do efeito da diversão percebida no m-learning sobre a intenção de uso, sugerindo que o prazer e a sensação de felicidade desempenham um papel fundamental na intenção de uso dos dispositivos móveis em atividades e contextos acadêmicos. $\mathrm{O}$ fato sugere um relacionamento positivo à Teoria do Fluxo (Flow) por meio de suas variáveis ao uso de dispositivos móveis. Sugere, também, que as estratégias baseadas em games seriam adequadas a esses aparelhos, visto que o engajamento em jogos está naturalmente relacionado com diversão e prazer.

As variáveis utilizadas pelos autores foram extraídas das teorias, como segue: TAM: PU e PEOU, FLOW: diversão percebida e concentração e TPB: normas subjetivas e controle do comportamento percebido. O construto normas subjetivas se refere à pressão do grupo social de referência (amigos, por exemplo), percebida pelo indivíduo ao apresentar ou não determinado comportamento. Controle do comportamento percebido, significa percepção de controle do sistema pelo usuário. Fluxo (Flow) é um estado de prazer, de harmonia, da consciência que proporciona ao indivíduo a capacidade de fazer melhores escolhas para a sua preservação. Tem como reflexo, também, a percepção diferenciada do tempo. Permite introspecção e concentração com profundidade e prazer.

Com relação às variáveis originais, o estudo confirma as relações apontadas no trabalho original de Davis (1989). Diversão percebida e concentração atuam positivamente sobre ATT e BI. A primeira fortemente e a segunda com fraca relação. Normas subjetivas e controle do comportamento percebido atuam de forma moderada em BI. Ou seja, as variáveis atuam mais fortemente sobre ATT do que sobre BI em relação ao m-learning.

A Tabela 6 mosta uma síntese da testagem das variáveis relacionadas ao uso de mobile learning, a partir do modelo TAM. Em alguns casos, foram feitos testagens em cadeia, nas quais há correlações múltiplas entre as variáveis. Note-se que no modelo original, todos os construtos implicam em intenção de adoção de m-learning, exceto o modelo original, listado para efeitos comparativos. Dessa forma, os resultados foram sintetizados com o objetivo de se construir um conjunto sólido de varíaveis testadas positivamente para a adoção de modelos de m-learning. As variáveis ATT, BI e AU, constituem para efeitos desta síntese, um conjunto integral que confirma a predisposição para adoção de m-learning. 


\section{Tabela 6}

Variáveis testadas e confirmadas em relação às variáveis do modelo TAM e similares.

\begin{tabular}{|c|c|c|c|c|}
\hline Autores & Ano & Variáveis preditoras & Variáveis critério & Modelo adotado \\
\hline Davis & 1989 & PU e PEOU & & TAM \\
\hline $\begin{array}{l}\text { Huang, Lin e } \\
\text { Chuang }\end{array}$ & 2006 & $\begin{array}{l}\text { Diversão percebida, percepção do valor de } \\
\text { mobilidade e diferenças individuais. }\end{array}$ & & TAM \\
\hline $\begin{array}{l}\text { Wang, Wu e } \\
\text { Wang }\end{array}$ & 2009 & $\begin{array}{l}\text { Expectativa de performance, expectativa de esforço, } \\
\text { influência social, diversão percebida e autogestão } \\
\text { da aprendizagem. }\end{array}$ & & UTAUT \\
\hline Fadare et al. & 2011 & Autoeficácia em m-learning & ATT, BI e AU* & TAMM \\
\hline Tan, et al. & 2014 & Influfência social & & TAM \\
\hline Ferreira et al. & 2014 & Autoeficácia & & TAM \\
\hline Kurtz et al. & 2015 & $\begin{array}{l}\text { Diversão percebida, concentração, normas } \\
\text { subjetivas, controle do comportamento percebido }\end{array}$ & & TAM \\
\hline
\end{tabular}

Fonte: pesquisa.

*As variáveis foram relacionadas em conjunto, visto que são influenciadas pelas antecedentes en cadeia. Vale dizer que atuar sobre ATT, implicará resultados em BI e AU, por exemplo.

De modo descritivo temos 10 variáveis descritas: diversão percebida, percepção do valor de mobilidade, diferenças individuais, expectativas de performance, expectativa de esforço, autogestão da aprendizagem, autoeficácia em m-learning, influência social (ou normas subjetivas) e concentração, controle do comportamento percebido.

As variáveis moderadoras (idade, gênero e experiência prévia) testadas em alguns estudos também não apresentaram resultados relevantes, mostrando pouca ou nenhuma influência sobre a intenção de uso de m-learning. Outro fato interessante é a comparação histórica do momento em que foi definido o modelo TAM e aqueles em que suas variáveis foram testadas. São artefatos e contextos de utilização de tecnologia muito diferentes, mas a confirmação de suas variáveis mostra que o modelo resiste e pode ser aplicado com segurança no momento histórico atual como referência.

A categoria Modelos de Aplicação de Eventos refere-se ao desenvolvimento de desenhos instrucionais dedicados à aplicação mobile. Nessa categoria, buscou-se identificar os resultados de testagens de adequação de recursos mobile a determinados objetos ou ações de aprendizagem. Alguns trabalhos contemplados nessa categoria também fizeram testagem de variáveis, mas com construtos sem relevância direta com este trabalho, como, por exemplo, 
satisfação com as atividades em sala de aula, em Wang, Shen, Novak, Pan (2009), ou prática individual, em Kwok et al. (2010). Esses exemplos são de difícil generalização ou analogia.

O estudo experimental de Wang, Shen et al. (2009) propôs um modelo de oferta de conteúdo, baseado em plataforma avançada, consistindo em palestras ao vivo com possibilidades de interação instantânea com os instrutores, via mensagens e votações. Os autores referem-se a dois modelos de entrega que podem ser desenvolvidos em m-learning: desenvolvimento individual e modelo extendido de sala de aula, com este sendo aplicado como suporte a atividades em sala, demandando atuação em conjunto, como em salas de aula, por exemplo. O modelo examinado pelo estudo provê atividades síncronas e assíncronas à escolha do aprendiz. Há vários materiais gravados para o acesso dos estudantes em vários locais de estudo na China. A instituição possui 17 mil alunos. Afirmam os autores que educação a distância sem interatividade reforça os efeitos negativos de aprendizagem passiva. Essa é uma afirmação controversa, visto que a distribuição maciça, por si só, pode ser uma grande vantagem em um cenário como o chinês. O estudo tabula dados duros (dados numéricos retirados do sistema) sobre acessos a conteúdos.

Os alunos podiam interagir por meio de respostas enviadas à plataforma mobile. As respostas eram consolidadas automaticamente e depois discutidas com os alunos em fóruns. A participação (interação) apresentada foi maciça, com a seguinte distribuição pelas atividades: 1. discutir conteúdos com os pares de classe (85\%); 2. fazer perguntas aos pares $(54 \%) ; 3$. fazer perguntas aos instrutores ou assistentes (90\%); 4. responder perguntas dos instrutores ou assistentes (82\%); 5. responder perguntas de pares de classse (52\%) e 6. trocar ideias com os pares de classe sobre o material (38\%). Esses são dados levantados em sistema.

Experiências na China lidam com grandes números de alunos, porém em contextos de sala de aula, com pequenos grupos. Os modelos de conteúdo preferido por $85 \%$ dos participantes foi o objeto composto por texto, áudio e um pequeno vídeo rodado ao vivo. Outros formatos eram um vídeo somente do instrutor, apresentação do material que estava sendo usado e um vídeo em close-up mostrando expressões faciais e corporais do instrutor. A abordagem pedagógica baseada em interatividade incrementou significativamente a participação dos alunos, denotando engajamento. O estudo produziu resultados alinhados com um modelo de aprendizagem engajada que envolve três dimensões de engajamento: cognitiva, 
social e emotiva. O estudo mostrou bons resultados em três dimensões: satisfação com a aula, satisfação com mobile learning e satisfação com as atividades em classe.

Du et al. (2010) realizaram experimento com modelo de aprendizagem aplicada a grandes grupos de alunos (mais de 100), apoiado em troca de mensagens curtas e feedbacks como suporte à atividade de ensino. Esse modelo incrementa a aprendizagem, dando suporte a esse processo com base em um formato de instrução do tipo computer-aided em um modelo de aprendizagem tecnológico-social (interação em contexto de aprendizagem). O trabalho apoia-se em um conjunto de diretrizes que propõe que a aprendizagem efetiva é um processo de construção de conhecimento e mudança de comportamento causado pela prática (abordagem construtivista) e reforçamento (abordagem objetivista). O estudo posiciona a tecnologia como suporte dos processos cognitivos e construção colaborativa de conhecimento, facilitando participação e interação. Ou seja, uma prática construtivista, baseada em aprender fazendo. Ainda, a tecnologia de aprendizagem deve direcionar uma prática autônoma, supervisionada por um instrutor, que interfere dando feedabacks no decorrrer da tarefa (reforçamento explícito). Tem também que dar suporte a atividades de aprendizagem, sinalizando sucesso ou falha aos aprendizes para autoavaliação instantânea (reforçamento implícito).

Os autores apontam três limitações do modelo: ergonômicas (tamanho de tela, produzindo restrições de entrada e saída de dados), emocionais (esgotamento no uso de tecnologias) e estilos de ensino, que podem não estar alinhados aos novos recursos. O modelo de pequenas mensagens induz a síntese e concisão. A tecnologia permite que, em um contexto como esse, diversas partículas de conhecimento possam ser mineradas ou combinadas, como um sistema de construção de conhecimento. Com base nessas premissas, um modelo de desenho instrucional foi aplicado a um conjunto de alunos e testado quanto à melhor compreensão e satisfação dos participantes do evento. $\mathrm{O}$ modelo é baseado em troca de mensagens curtas, feedbacks e avaliações instantâneas - essa característica relativa à comunicação já era proposta por Driscoll e Carliner (2005) como uma das formas de utilização de m-learning. A comunicação foi, nesse estudo, um elemento de reforço entre instrutores e particiapntes, tanto intragrupo, como entre os grupos.

O grupo controle recebeu os mesmos materiais que o experimental, que tinha à sua disposição PDAs. O grupo sem o recurso teve que fazer e responder perguntas de modo oral 
durante o semestre. Esse formato é também explorado no estudo de Wu, Hwang, Tsai, Chen, Huang (2010), explorando o contraste entre as possibilidades que as novas mídias oferecem e os meios tradicionais. Desse modo, o desenho instrucional apoia-se na capacidade de mediar conteúdos. Há a facilitação de acesso e uso de recursos que poupam processos mentais e físicos. Não há ênfase em possibilidades tecnológicas mais complexas nesses dois casos. A avaliação final da experiência foi realizada por meio de grupo focal a fim de se discutir a experiência dos aprendizes nas duas situações. Os resultados mostraram maior satisfação e melhor aprendizagem com o apoio de tecnologia. A abordagem de aprendizagem utilizada pelos autores foi definida como modelo de aprendizagem tecno-social, visto combinar elementos tecnológicos e sociais no contexto de aprendizagem.

O método de avaliação foi composto por três instrumentos: survey, como fonte quantitativa de informações, grupo focal e observação em campo, feita por experts. Os autores confirmam a eficácia e potencialidade dos modelos teórico (tecnológico-social) e instrucional (mensagens curtas socializadas) aplicado. É interessante notar a referência a um modelo de recursos pobres (lean communication - no sentido de simples, pouco sofisticado) em relação ao que a tecnologia oferece, dado o período do experimento. A opção por um modelo enxuto de objeto, amplia as possibilidades tecnológicas do m-learning, sem a obrigação de apoio em vídeos, animações, conteúdos interativos etc.

Wu, Hwang et al. (2010) abordam o m-learning por uma definição de condição, afirmando que o que realmente importa é se o aprendiz pode acessar os recursos necessários no lugar e período determinado. Foi realizado um experimento que forneceu um recurso do tipo job aid a estudantes do curso de enfermagem que auxiliava o participante a reconhecer o estado dos pacientes que chegavam ao hospital por meio da tecnologia RFID. A estratégia explora uma das formas da aprendizagem situada, na qual o contexto real é parte integrante da aprendizagem.

$\mathrm{O}$ artigo informa que a área médica tem se aproveitado muito de simulações webbased, mas que essas carecem de um elemento chave que é o contexto. No modelo apresentado, a prática de diagnose pelo método do grid é parte integrante de um evento maior de capacitação, que envolve treinamento prévio sobre o tipo de doença que será abordado, no caso, problemas no trato respiratório. 
O modelo consiste em recursos classificados como sensing technologies, ou tecnologias sensíveis ao contexto. O local do paciente possui um dispositivo no qual são registradas diversas informações, que são recebidas pelo dispositivo móvel do indivíduo que vai diagnosticar o paciente assim que aquele se aproxima do local onde se encontra o paciente. O local é uma sala simulada, chamada sickroom. O usuário, então, consulta em uma base prévia (grid) as informações a serem cruzadas com aquelas originárias do emissor e identifica as condições do paciente. Outros participantes utilizam as mesmas informações e grid, porém em mídias tradicionais, assim configurando o experimento como um contraste no modo de entrega. Os resultados informam que houve melhorias na identificação dos problemas, mas destacam o reduzido tamanho da mostra, recomendando novos estudos. $\mathrm{O}$ sistema foi testado para PU e PEOU também, com resultados positivos.

Gikas e Grant (2013) fizeram estudo exploratório sobre o uso de mobile learning em ambiente educacional de nível superior, reunindo m-learning e mídias sociais. Embora esse trabalho esteja associado ao desenho instrucional, não aborda um determinado desenho, mas incorpora diversas iniciativas que utilizaram m-learning. Dessa forma, os resultados colhidos tiveram um caráter de generalização, mas ainda assim reforçam algumas vantagens e desvantagens do uso de mobile. A pergunta de pesquisa já aponta a generalidade da investigação: "quais são as experiências dos estudantes quando são utilizados dispositivos móveis?" Os temas que emergiram foram: vantagens dos dispositivos móveis para a aprendizagem e frustrações na utilização desses dispositivos. Como limitação, o estudo aponta que a mobilidade pode produzir conteúdos fragmentados, conforme apontado também por Driscoll e Carliner (2005). Diversas ferramentas de mídia social foram sugeridas nos programas, conferindo uma característica de construção colaborativa às atividades, visto que o ponto chave do sucesso da experiência foi a interação entre participantes e conteúdos.

As vantagens percebidas pelos estudantes foram: rápido acesso à informação, comunicação e colaboração entre pares e instrutores, variedade de meios de aprendizagem (incluindo gravações em vídeo e voz para carga no ambiente e posterior discussão) e aprendizagem situada. As principais frustrações vieram de aplicativos que não operaram conforme o esperado e os reduzidos teclados, que dificultaram as respostas mais longas. Os autores fazem referência ao termo inteligência coletiva criado por Pierre Levy, que prega que coletivamente os resultados são melhores do que aqueles individuais. O estudo considerou 
dispositivos móveis com as seguintes caraterísticas: acesso constante à Internet, variedade de aplicativos disponíveis, utilitário para comunicação, e pequeno o suficiente para ser carregado em bolso ou bolsa.

O método de coleta primário foi grupo focal via $\mathrm{Skype}^{6}$, que possui ferramenta de gravação dos eventos. Apesar de o vídeo inibir algumas leituras de linguagem corporal, melhor percebidas em contato face-a-face, os pesquisadores puderam distinguir alguns comportamentos dos participantes, que funcionaram como fonte de informação paralela, como o meneamento de cabeça e outros movimentos indicadores de interação não-verbal. Em se tratando de estudo exploratório, faz sentido o uso da técnica, visto abrir oportunidades para o surgimento de perspectivas, informações ou resultados não contempladas no planejamento da atividade. Foi usada a técnica de análise indutiva para o tratamento dos dados obtidos.

Confirma alguns atributos do mobile learning: engajamento pela conectividade constante, construção de significados por meio de colaboração e aprendizagem móvel, pela possibilidade de aprender relacionada a contextos e ambientes.

Huang et al. (2014) fizeram um experimento misto, que envolveu a testagem de modelo aplicado de aprendizagem colaborativa. Foi utilizada uma ferramenta denominada Google + para se criar um ambiente colaborativo. As atividades foram realizadas no mesmo ambiente pelo grupo controle e pelo grupo experimental, com a diferença de que o segundo atuou de forma colaborativa e o primeiro, individual. Os estudantes do grupo experimental se mostraram mias satisfeitos do que os do grupo de controle. Foi observado que os estudantes com maior nível de conhecimento preferem atividades individuais, quando se refere a situações reais. Os estudantes tanto os que realizaram atividades individuais, como os que realizaram as de grupo, informaram que o tipo de atividade (plataforma) aumentou o interesse e a intenção de aprender. Os alunos com níveis médios e baixos de conhecimento preferem as atividades de grupo.

O estudo afirma que as atividades colaborativas exercem uma pressão positiva sobre os indivíduos, que desejam entregar o que podem fazer de melhor. O estudo mostrou que uma estratégia de aprendizagem coletiva tem melhores resultados do que uma individualizada, quando as atividades são realizadas em dispositivos móveis. Foi utilizada aprendizagem situada (aquário). Os visitantes (aprendizes) podem acessar uma rede própria que

\footnotetext{
6 Programa de informática que permite comunicação síncrona com o uso de sistema de vídeo e voz.
} 
disponibiliza o ambiente interativo nos dispositivos móveis. O objeto de aprendizagem era dedicado à tarefa de aprendizagem, sem complementos e suplementos a outros conteúdos ou sistemas. Os estudantes manifestaram a importância de uma experiência associada a situações reais.

O trabalho realizado por Hernando, Arévalo, Catasús e Mon (2014) foi incluído devido ao aproveitamento de QR Codes e por ter abordado os três domínios da aprendizagem: psicomotor, afetivo e cognitivo. O uso de QR Codes é um modelo de informação interativa que depende das informações vindas da etiqueta que contém o código. Dessa forma, é também uma aplicação situada de características próprias. $\mathrm{O} Q \mathrm{QR}$ pode produzir vários tipos de resposta, como abrir um endereço de Internet no dispositivo do usuário, apresentar algo que já esteja no dispositivo, ou ainda outros, dependendo da forma como foi projetado. Ressalte-se que o código pode estar em qualquer lugar. Não está necessariamente fixado no local da situação e pode configurar-se em uma espécie de situação móvel, por exemplo. O contexto de escola de segundo grau (ou paralelo), apesar de diferir da maioria dos trabalhos examinados (contexto de ensino superior, ou organizacões), mereceu atenção pela exploração do sistema.

$\mathrm{O}$ uso do QR code por parte dos alunos aborda uma questão levantada com frequência nos estudos sobre tecnologia, de modo geral, mas acentuadamente, no uso de dispositivos móveis, que é o desenvolvimento de metacompetências. Por exemplo, $87 \%$ dos aprendizes informaram não haverem realizado previamente nenhuma operação com os códigos. Pode-se especular que as novas gerações já dominam a linguagem das funcionalidades em dispositivos móveis, podendo fazer analogias e descobrir funções, sem necessariamente treinamento específico. $81 \%$ dos participantes avaliaram positivamente (escores entre 7 e 10 em uma escala de 1 a 10) a transferência do aprendido para a vida real. $66 \%$ dos estudantes avaliaram a utilidade dos dispositivos móveis e o formato do conteúdo. Note-se que, embora não haja sido testada a variável PU de forma estruturada, a questão da utilidade surge reforçada.

O método de investigação foi o estudo de caso com apoio de estatística descritiva e mostrou que a experiência foi bastante proveitosa, com avaliações positivas. Os QR Codes dispararam conteúdos em formato de voz, vídeo e texto. Outros recursos e formatos foram também explorados, como o Google Forms. Os códigos recebidos também puderam ser 
trocados com colegas de outras instituições, visto que a unidade didática respectiva foi disponibilizada em um ambiente aberto colaborativo.

O estudo de Glackin, Rodenhiser, Herzog (2014) buscou entnder como o uso de dispositivos móveis afeta o acesso dos estudantes a recursos da biblioteca. Desse modo, podemos perceber a intenção de verificar o uso de tecnologia móvel mais como mídia do que como um recurso efetivo de aprendizagem. O estudo teve um caráter longitudinal, ao investigar grupos em 4 semestres consecutivos. O trabalho mostrou que ao se utilizar dois ou mais dispositivos para acesso aos conteúdos aumentou em $14 \%$ as consultas aos e-books disponíveis e o uso do dispositivo móvel, em si, incrementou os acessos a esse conteúdos em $51 \%$. O montante de $81 \%$ dos participantes informaram que a combinação dos aparelhos móveis e o formato $e$-book afetaram positivamente a experiência de aprendizagem.

Os três maiores benefícios apontados pelos usuários foram a acessibilidade, a usabilidade e a economia (o custo dos dispositivos não é uma questão relevante no uso para aprendizagem $^{7}$ ). Os principais problemas relatados por $25 \%$ da amostra, foram o cansaço nos olhos, a dificuldade de leitura e a funcionalidade. As características físicas são objeto de atenção como, por exemplo, a falta de um leitor de e-books que possibilitassem o acesso aos recursos desse formato, como formatos sofisticados de destaques do texto ou ainda a falta de uma funcionalidade que possibilitasse a tomada de notas. $\mathrm{O}$ estudo demonstra o potencial dos dispositivos móveis em termos de acesso e funcionalidade (rapidez, economia de tempo, facilidade de uso e conectividade). Dois aspectos ficaram bem explorados: o formato de ebooks e as características de mobilidade e acessibilidade. Ainda, 56 dos 57 participantes do grupo focal, realizado ao final dos semestres, expressaram boa habilidade de acessar os conteúdos via aparelhos móveis. Ou seja, percebe-se o desenvolvimento de metacompetências para a utilização e um nível bom de autoeficácia na testagem da estratégia.

Em Meer, Berg, Smith, Gunn e Anakin (2015), 437 participantes do estudo testaram a substituição de palestras tradicionais por videoclips, com bons resultados. Desses, o mais relevante mostra a flexibilidade do formato como o aspecto mais positivo do uso do modelo de conteúdo. O formato, além de permitir que o contúdo fosse visto a qualquer hora, em qualquer lugar, tinha flexibilidade para ser visto, revisto, parado em qualquer ponto para a

\footnotetext{
${ }^{7}$ Essa é uma questão essencialmente de cunho local, visto que em alguns lugares, como no Brasil, o custo desses aparelhos é significativo.
} 
tomada de notas no ritmo próprio do usuário. Da amostra, $83 \%$ afirmaram que os vídeos não deveriam ter mais do 15 minutos. Perto de 50\% dos participantes entenderam o vídeo como um objeto de aprendizagem. As respostas abertas indicaram que os estudantes teriam preferências em relação ao conteúdo, informando que esses deveriam ter uma parte introdutória reduzida que informasse do que se trataria o conteúdo.

A Tabela 7 mostra a organização e síntese dos resultados da categoria Modelos de Aplicação de Eventos.

\section{Tabela 7}

Síntese dos resultados da categoria Modelos de Aplicação de Eventos.

\begin{tabular}{|c|c|c|c|}
\hline Autor & Ano & Resultado e modelo & Função do mobile \\
\hline Wang et al. & 2009 & $\begin{array}{l}\text { O modelo produziu } \\
\text { aprendizagem engajada: } \\
\text { cognitiva, social e emotiva. }\end{array}$ & $\begin{array}{l}\text { Apoio ao conteúdo em sala de } \\
\text { aula e repositório de conteúdos } \\
\text { para consulta. }\end{array}$ \\
\hline Du et al. & 2010 & $\begin{array}{l}\text { Troca de mensagens curtas e } \\
\text { feedbacks. Maior satisfação e } \\
\text { melhor aprendizagem }\end{array}$ & Suporte à atividade de ensino \\
\hline $\begin{array}{l}\text { Wu, Hwang, Tsai, Chen, } \\
\text { Huang }\end{array}$ & 2010 & $\begin{array}{l}\text { Melhoria na identificação de } \\
\text { problemas (resultado da } \\
\text { aprendizagem) pelo uso de RFID. }\end{array}$ & $\begin{array}{l}\text { Suporte à aprendizagem com } \\
\text { sistema interativo (usuário/ } \\
\text { sistema/dados) }\end{array}$ \\
\hline Gikas e Grant & 2013 & $\begin{array}{l}\text { Confirma possibilidades gerais } \\
\text { do modelo. }\end{array}$ & Diversas \\
\hline Huang et al. & 2014 & $\begin{array}{l}\text { Sucesso na aplicação de atividade } \\
\text { colaborativa em dispositivo } \\
\text { móvel. }\end{array}$ & $\begin{array}{l}\text { Recurso de apoio à instrução em } \\
\text { atividade de campo }\end{array}$ \\
\hline Hernando et al. & 2014 & $\begin{array}{l}\text { Uso proveitoso de } \mathrm{QR} \text { codes e } \\
\text { atividades colaborativas. }\end{array}$ & $\begin{array}{l}\text { Recurso de apoio à instrução } \\
\text { principal }\end{array}$ \\
\hline $\begin{array}{l}\text { Glackin, Rodenhiser, } \\
\text { Herzog }\end{array}$ & 2014 & $\begin{array}{l}\text { Conjugou com sucesso acesso a } \\
\text { bilbiotecas e formato de } e \text {-book. }\end{array}$ & $\begin{array}{l}\text { Canal de acesso a conteúdos de } \\
\text { biblioteca }\end{array}$ \\
\hline $\begin{array}{l}\text { Meer, Berg, Smith, Gunn } \\
\text { e Anakin }\end{array}$ & 2015 & $\begin{array}{l}\text { Bons resultados em satisfação no } \\
\text { uso do modelo de video }\end{array}$ & Apoio à prendizagem \\
\hline
\end{tabular}

Fonte: pesquisa.

Os casos abordados nessa categoria mostram uma multiplicidade das possibilidades em m-learning, dadas as diferenças e os bons resultados apurados. Embora haja limitações e ressalvas quanto aos métodos de avaliação e restrições dos dispositivos, as abordagens pedagógicas mostram coerência com os modelos e apontam caminhos para boas práticas baseadas em dispositivos móveis. Os trabalhos selecionados mostram iniciativas de apoio à aprendizagem, modelos de aprendizagem situada, aproveitamento de recursos tecnológicos 
promissores e o crescimento do aproveitamento pedagógico e da satisfação dos usuários. Há muito ainda o que se experimentar e testar, quando pensamos em combinar os recursos experimentados e os desenhos aplicados.

A categoria Modelos de Criação de Ferramentas inclui propostas de formatação de ambientes dedicados à aprendizagem, com centralidade das operações no próprio dispositivo. Aqui não há o caráter de suporte, complementaridade ou suplementaridade.

Saccol et al. (2010) propuseram um estudo exploratório para a testagem do desenvolvimento de competências em contexto organizacional, um modelo chamado COMTEXT, que foi proposto para o treinamento de profissionais da área de tecnologia informática. A busca era para se saber quais as reais possibilidades do m-learning no desenvolvimento de competências e também de colaboração. Os resultados mostram resistência a metodologias que demandam autonomia, especialmente no contexto organizacional. O estudo sugere metodologias que estimulem ação-reflexão nos treinandos, como jogos, por exemplo. Tarefas muito complexas são desfavoráveis à aprendizagem, bem como tarefas síncronas são limitadas em ambientes de mobile learning, mais adequado para rápidas e curtas intervenções. O desenvolvimento de competências prevê tarefas de reflexão, que pedem mais profundidade e tempo, que podem ser supridas por funcionalidades específicas. Não houve mensuração objetiva quanto à aquisição de competências. Os usuários não puderam levar consigo o aparelho, que teve que ser utilizado no contexto específico por segurança dos equipamentos. O fato causou frustração nos usuários. O estudo chama a atenção para a sobrecarga de estímulos e múltiplas tarefas associadas ao uso de dispositivos móveis, que podem afetar negativamente a aprendizagem, sob as perspectivas temporal e conceitual.

O trabalho afirma que os respondentes consideraram que a experiência contribuiu para o desenvolvimento das competências-alvo, apesar de não ter havido uma aferição objetiva disso. As vantagens do sistema foram em parte compensadas por problemas ligados à ergonomia e às dificuldades de acesso às redes, além de questões com as cargas de bateria ${ }^{8}$. Os respondentes manifestaram bastante interesse e empolgação pela característica inovadora do m-learning. Esse resultado sugere forte viés, dado o contexto de informática dos

\footnotetext{
${ }^{8}$ Apesar de o estudo ser recente (2005), as baterias ganharam significativamente maior capacidade de carga, durando até 10 horas de atividades em 2015.
} 
profissionais. Informaram também que o modelo não é preferível às ações face-a-face. No entanto, concordam que o modelo adotado é adequando para treinamento corporativo.

$\mathrm{O}$ uso dos chats mostrou que não é adequado para o desenvolvimento de conversas extensas sobre assuntos com maior profundidade. As atividades de colaboração enfrentaram dificuldades na organização dos grupos e entrega dos trabalhos. Os respondentes do questionário afirmaram que o ambiente criado contribui para a aprendizagem. No entanto, afirmam que o modelo não é mais eficiente do que o tradicional (presencial).

A avaliação foi feita por meio de análise de conteúdo, a partir de um workshop realizado com participantes e facilitadores e buscou avaliar percepções. O evento durou duas semanas. Adicionalmente, foi aplicado um questionário estuturado, que avaliou a experiências dos usuários no uso do sistema. O estudo testou também algumas variáveis: PU, PEOU, suporte ao usuário e ansiedade diante de nova tecnologia. O número de apenas 13 participantes parece um elemento bastante limitador para levantamentos mais robustos, ou mesmo para a aferição das variáveis definidas.

Ortigosa, Bravo, Carro, Carlos e Martín (2010) realizaram testagem e avaliação de um modelo adaptável de ambiente. O ambiente pode ser customizado pelo aluno. O sistema aplicado usa mineração de dados para extrair informações sobre problemas potenciais no uso do recurso mobile. É um caso raro de modelo que se vale das possibilidades de geração de dados a partir da plataforma. A plataforma permite que o usuário escolha as melhores formas de usá-la, aproveitando as ferramentas às quais se adapta melhor. Os aparelhos móveis são usados em tempo livre, como complementação do uso do computador. O estudo afirma que combinar as necessidades do usuário às possibilidades dos dispositivos móveis e ao contexto é tarefa árdua de construção do desenho instrucional.

O sistema utilizado chama-se CoMoLE. (Context-based adaptive mobile learning Environments) é uma plataforma adaptável às necessidades do usuário, baseada em web. Refere-se diretamente à atuação dos tutores/instrutores na criação, acompanhamento e avaliação das atividades pelos aprendizes. Particularmente, argumentam que, diferentemente da situação presencial, o instrutor não tem informações imediatas, não recebe feecbacks (voluntários ou não) dos alunos. Dessa forma, é necessária a inclusão de um sistema de feedback nos entornos mediados por tecnologia sem contato face-a-face, porém essa também não é uma tarefa fácil, visto que os estudantes podem ter vários bloqueios ou limitações para 
registrar feedbacks. No entanto, existe a possibilidade de análise dos $\operatorname{logs}^{9}$ dos usuários. A recuperação desses dados é chamada mineração de dados. O termo refere-se à busca de dados dentro de sistemas digitais. A plataforma contém orientações e regras próprias de operação, podendo restringir ou liberar conteúdos em função do perfil de usuário que o acessa. O que chama a atenção no modelo instrucional é a mobilidade entre diferentes dispositivos, incluindo os móveis. O sistema detecta e organiza os conteúdos de atividades conforme o perfil do usuário, gravando suas interações com a plataforma.

Os resultados indicaram que os participantes consideraram o sistema muito útil para desenvolver novas maneiras de estudar um assunto. A mobilidade foi um elemento atrativo. $\mathrm{O}$ modelo também incrementou a motivação na interação com o ambiente e com os colegas. $\mathrm{O}$ ambiente teve grande aceitação dos participantes.

A avaliação por $\operatorname{logs}$ objetiva localizar fontes de problemas experimentados pelos usuários a partir de seu comportamento na plataforma. Para tal, são necessárias técnicas de levantamento (busca, mineração), bem como o tratamento dessas informações. São desenvolvidos algoritmos específicos para as análises de dados. Pode se imaginar que, ao gravar todos os passos dos usuários, o sistema gravará uma quantidade significativamente grande de dados inúteis, cabendo ao sistema de tratamento filtrar e organizar os dados em função de objetivos específicos. O modelo classificado como "ambiente adaptativo" reage de modo diferente aos dispositivos usados e ao perfil do usuário. Prevê uma combinação dos sistemas digitais com a aprendizagem tradicional, o que promove maior motivação e interação com os pares dos estudantes, com base em uma abordagem construtivista.

O estudo cita diversas outras plataformas que possuem esses recursos e se utiliza de técnicas sofisticadas para a classificação e ordenação dos resultados. Essas informações fogem ao propósito da presente pesquisa, mas assinalam a possibilidade de avaliações paralelas do comportamento dos usuários e consequentemente do sucesso na aplicação de métodos e modelos. São informações de caráter objetivo e quantitativo, que ajudam a complementar as informações geradas a partir de outras fontes, em geral, de caráter autorrelatadas.

\footnotetext{
${ }^{9}$ Logs são registros de atividades gerados por programas de computador. No caso de logs relativos a incidentes de segurana, eles normalmente so gerados por firewalls ou por sistemas de detecção de intrusos.

Acessado em http://www.terra.com.br/informatica/especial/cartilha/incidentes_2_1.htm, em 27/12/2015 às 16h04. Vale dizer que quando se acessa uma plataforma de modo registrado ("logado") tudo o que é realizado é gravado em um arquivo chamado de "log".
} 
Ojokoh, Doyeni, Adewale, Isinkaye (2013) apresentaram e testaram um sistema similar ao visto em Ortigosa et al. (2010), no sentido de reconhecimento do usuário, que terá à sua disposição conteúdos referentes ao seu perfil. A plataforma desenvolvida oferece diversas ferramentas ao usuário, construindo um portal de e-learning. $\mathrm{O}$ estudo afirma que m-learning é uma extensão do e-learning, porém isso não é consensual. Em Hummel, Hlavacs e Weissenböck (2002), por exemplo, os autores marcam a mobilidade como principal diferença entre os dois conceitos, em consonância com outros estudos, que também marcam a importância do aspecto situacional, que seguramente cria uma diferença signficativa entre os dois sistemas. A plataforma desenvolvida tem o objetivo de melhorar o estudo em outras modalidades, configurando um caráter complementar da estratégia móvel.

O sistema oferece palestras digitalizadas, recursos de avaliação e feedback aos participantes. O sistema pretende incrementar "imensamente" (immensely) o desempenho e a aprendizagem. O destaque é feito, dado a afirmação ser autoreferente e dar uma dimensão pretensiosa ao recurso. Os resultados são bons, mas não respondem a essa expectativa. $\mathrm{O}$ texto apoia-se na definição que a aprendizagem pode ocorrer no campo, em qualquer lugar onde o dispositivo esteja inteiramente funcional. Essa definição traz o conceito de ubiquidade para um patamar realista. O sistema apresentado está apoiado em duas categorias de interfaces: móvel e Internet. Todos os atores têm acesso a suas áreas para gerenciamento e entrega de conteúdos. Os sistemas digitais estavam, também, integrados a ações de educação formal. O modelo defende que cada peça explore as fraquezas da outra.

Um survey realizado com 20 alunos que tiveram acesso ao sistema. A avaliação abrangeu tanto o sistema móvel quanto o sistema baseado em e-learning, visto estarem integrados. Os resultados apresentaram um bom desempenho, com resultados maciçamente classificados entre os maiores escores da escala adotada. A leitura indica uma construção de plataforma bastante cuidadosa, com ênfase no design das interfaces, ressaltando que uma interface amigável aumenta a aceitabilidade do sistema. Relata brevemente a questão da utilidade e facilidade de uso. Não houve, porém, avaliação dessas variáveis.

Saccol et al. (2010) apresentam um resultado bastante importante para o estudo do mobile. Apresenta, no entanto, resultados que aparentam contradições e alguns viéses. Afirma o estudo que há resistências quanto à autonomia, fazendo uma generalização a partir do modelo que não parece justificável, visto estar associado estritamente ao modelo adotado. 
Não abordou um modelo que previsse atuação em contexto, ou com colaboração. No modelo analisado por este estudo, a tendência tem direção oposta. Aparentemente, o modelo reproduz um ambiente tradicional de e-elearning no dispositivo móvel, com resultados limitados por não haver sofrido uma adaptação mais ampla, levando em consideração outros aspectos da mobilidade e da interface. O estudo de Ortigosa et al. (2010) parece também sofrer desses dois problemas, acrescida a função de tutoria, que apresentou problemas específicos.

O primeiro estudo sugere que o m-learning não é adequado ao desenvolvimento de competência, por exigir tarefas de reflexão e profundidade. Talvez a inadequação não esteja no dispositivo móvel, mas no modelo adotado. No entanto, o trabalho é rico em mostrar as limitações e expectativas da aplicação prática de um modelo móvel em contexto organizacional. O estudo de Ortigosa et al. (2010) chama a atenção é a possibilidade de câmbio entre diferentes dispositivos, com previsão de adaptação às tarefas.

O sistema detecta e organiza os conteúdos de atividades conforme o perfil do usuário, gravando suas interações com a plataforma. Essa é uma grande possibilidade dos sistemas digitais de modo geral, que pedem desenvolvimento. Nos dois estudos, os participantes entendem que os sitemas móveis são úteis para aprendizagem. O último estudo aproxima-se ao de Ortigosa et al. pela integração de mais de uma plataforma de oferta, que convergem diversos recursos de apoio à aprendizagem. Os dois últimos modelos desta categoria destacam-se pelo aproveitamento de informações registradas em sistema, que foram organizadas e analisadas. Todos os modelos propostos estão muito contaminados pelos modelos de e-learning tradicionais.

A última categoria, Estratégia de Ensino Baseada em Mobile, contempla apenas um dos estudos e foi proposta para abrigar iniciativa que ocupa um lugar definido no roteiro instrucional. Dessa forma, o propósito de utilização de uma estratégia mobile está ligada a uma etapa melhor definida no desenho instrucional. No trabalho analisado, de autoria de McConatha, Praul e Lynch (2008), a peça visa preparar os estudantes para exames, disponibilizando conteúdos e questões de revisão. O critério de comparação foram as notas dos dois testes para os quais os alunos tiveram o apoio do mobile. A plataforma utilizada foi web based, ou seja, similar a uma página web adaptada ao formato mobile. Fica configurado, assim, um caráter complementar ao uso do mobile. 
O modelo de pesquisa foi experimental e comprovou que os alunos que acessaram o recurso (42\% de um total de 112) tiveram resultados melhores do que aqueles que optaram por não utilizá-los. O dados foram avaliados por meio de teste $\boldsymbol{t}$. O modelo não tira proveito de aprendizagem situada, mas da mobilidade geográfica. O estudo foi baseado em uma ferramenta disponível no mercado, em contraste com os sistemas customizados. No caso, o que foi customizado foi a função instrucional. Como principal limitação, os autores citam que os mesmos alunos que fizeram uso do material em mobile poderiam ter desempenhos superiores aos outros pela sua própria natureza.

Sobre esta categoria, há pouco a acresentar daquilo efetivamente visto como resultados do estudo de modo geral. Cabe ressaltar que os modelos observados não estão presos às categorias propostas, mas foram assim classificados com o intuito de destacar e marcar uma característica a ser explorada em conjunto com outros benefícios apontados.

\section{Organização dos Trabalhos Selecionados}

O modelo/quadro usado para a organização dos achados é baseado naquele descrito em Todeschini (2006), utilizado para organizar o conjunto de trabalhos teórico-empíricos relacionados à TD\&E, conforme Tabela 8 . Ao se reinterpretar a forma de aprender, como tem sido fortemente sugerido no estudo do campo, todos os outros elos da cadeia deverão ser revistos, em especial as teorias de desenho instrucional e as técnicas de avaliação, passando por novos modelos de coleta e interpretação de dados. Dessa forma, há a possibilidade de adequação futura do quadro-síntese em função dos achados no tema presente.

\section{Tabela 8}

Organização dos achados da busca.

\begin{tabular}{|c|c|c|c|c|c|c|}
\hline \multicolumn{7}{|c|}{ Tabela de Artigos Empíricos em Mobile Learning } \\
\hline Autor & Ano & País & $\begin{array}{l}\text { Delinea- } \\
\text { mento }\end{array}$ & $\begin{array}{l}\text { Quali/ } \\
\text { Quanti }\end{array}$ & Intrumento de coleta & $\begin{array}{c}\text { Método de Análise } \\
\text { de Dados }\end{array}$ \\
\hline Davis, F. & 1989 & USA & Correlacional & Quanti & $\begin{array}{l}\text { Questionário presencial, } \\
\text { respondido por } 152 \text { indivíduos. } \\
\text { Escalas tipo Likert de seis pontos. }\end{array}$ & Regressão. \\
\hline $\begin{array}{l}\text { Hummel, K., } \\
\text { Hlavacs, H., } \\
\text { Weissenböck, H. }\end{array}$ & 2002 & Áustria & $\begin{array}{l}\text { Estudo de } \\
\text { caso }\end{array}$ & Quanti & Survey respondido por 54 alunos. & Estatística descritiva. \\
\hline
\end{tabular}




\begin{tabular}{|c|c|c|c|c|c|c|}
\hline \multicolumn{7}{|c|}{ Tabela de Artigos Empíricos em Mobile Learning } \\
\hline Autor & Ano & País & $\begin{array}{l}\text { Delinea- } \\
\text { mento }\end{array}$ & $\begin{array}{l}\text { Quali/ } \\
\text { Quanti }\end{array}$ & Intrumento de coleta & $\begin{array}{l}\text { Método de Análise } \\
\text { de Dados }\end{array}$ \\
\hline $\begin{array}{l}\text { Huang, J-H, Lin, } \\
\text { YR, Chuang, S-T } \\
\text { Taiwan/2006 }\end{array}$ & 2006 & Taiwan & Correlacional & Quanti & $\begin{array}{l}\text { Survey online com } 19 \text { itens } \\
\text { respondido por } 313 \text { indivíduos. } \\
\text { Escala tipo Likert de } 5 \text { pontos. }\end{array}$ & Equações estruturais \\
\hline $\begin{array}{l}\text { McConatha, D., } \\
\text { Praul, M e Lynch, } \\
\text { M. }\end{array}$ & 2008 & USA & Experimental & Quanti & $\begin{array}{l}\text { Relatórios do sistema para } \\
\text { verificação dos acessos e registros } \\
\text { da notas dos } 112 \text { indivíduos: } \\
\text { grupo experimental com } 42 \text { e } \\
\text { grupo controle com } 70 .\end{array}$ & Teste $t$ \\
\hline $\begin{array}{l}\text { Wang, M, Shen, } \\
\text { R., Novak, D., } \\
\text { Pan, X. }\end{array}$ & 2009 & $\begin{array}{l}\text { Reino } \\
\text { Unido }\end{array}$ & Correlacional & $\begin{array}{l}\text { Quali } \\
\text { Quanti }\end{array}$ & $\begin{array}{l}\text { Pré e pós surveys respondidos } \\
\text { online por } 585 \text { e } 178 \text { participantes } \\
\text { respectivamente. } \\
\text { Análise dos posts no fórum da } \\
\text { disciplina. }\end{array}$ & $\begin{array}{l}\text { Estatística descritiva. } \\
\text { Análise de conteúdo. }\end{array}$ \\
\hline $\begin{array}{l}\text { Wang, Y-S, Wu, } \\
\text { M-C e Wang, H-Y. }\end{array}$ & 2009 & Taiwan & Correlacional & Quanti & $\begin{array}{l}\text { Survey com } 17 \text { itens respondido } \\
\text { por } 330 \text { indivíduos. } \\
\text { Escalas tipo Likert com } 7 \text { pontos. }\end{array}$ & $\begin{array}{l}\text { Equações estruturais. } \\
\text { Análise fatorial. }\end{array}$ \\
\hline $\begin{array}{l}\text { Saccol, A., } \\
\text { Reinhard, N., } \\
\text { Schlemmer, E., } \\
\text { Barbosa, J. }\end{array}$ & 2010 & Brasil & $\begin{array}{l}\text { Exploratório / } \\
\text { correlacional }\end{array}$ & $\begin{array}{l}\text { Quali } \\
\text { Quanti }\end{array}$ & $\begin{array}{l}\text { Questionário estruturado com } 25 \\
\text { questões, respondido por } 10 \\
\text { indivíduos. } \\
\text { Relatórios de encontros } \\
\text { presenciais. }\end{array}$ & Análise de conteúdo. \\
\hline $\begin{array}{l}\text { Du, H., Hao, J-X., } \\
\text { Wagner, C, Kwok, } \\
\text { R. }\end{array}$ & 2010 & China & Experimental & $\begin{array}{l}\text { Quali } \\
\text { Quanti }\end{array}$ & $\begin{array}{l}\text { Survey para avaliação do } \\
\text { professor. } \\
118 \text { participantes no grupo de } \\
\text { tratamento e } 114 \text { no grupo } \\
\text { controle } \\
\text { Complementarmente, análise de } \\
\text { observação e um grupo focal. }\end{array}$ & $\begin{array}{l}\text { Equações estruturais, } \\
\text { regressão e análise de } \\
\text { variância. }\end{array}$ \\
\hline $\begin{array}{l}\text { Ortigosa, A., } \\
\text { Bravo, J., Carro, } \\
\text { R. }\end{array}$ & 2010 & Espanha & Experimental & Qunati & $\begin{array}{l}\text { Sistema de captura e análise dos } \\
\text { logs dos usuários pelas técnicas de } \\
\text { algoritmos de clasificação e regras } \\
\text { de associação. }\end{array}$ & $\begin{array}{l}\text { Análises de relatórios } \\
\text { de sistema. }\end{array}$ \\
\hline $\begin{array}{l}\text { Wu, P-H, Hwang, } \\
\text { G-J, Tsai, C-C, } \\
\text { Chen, Y-C, Huang, } \\
\text { Y-M. }\end{array}$ & 2010 & Taiwan & Experimento & Quanti & $\begin{array}{l}\text { Survey com pré e pós-teste com } \\
48 \text { participantes: } 25 \text { no grupo } \\
\text { experimental } 23 \text { no grupo } \\
\text { controle. } \\
\text { Escala Likert de } 6 \text { pontos. }\end{array}$ & $\begin{array}{l}\text { Testes } \boldsymbol{t} \text {. } \\
\text { Estatística descritiva. }\end{array}$ \\
\hline $\begin{array}{l}\text { Fadare, O.G., } \\
\text { Babatunde, O.H., } \\
\text { Akomolafe, D.T., } \\
\text { Lawal, O.O. }\end{array}$ & 2011 & Nigeria & Correlacional & Quanti & $\begin{array}{l}\text { Questionário com } 31 \text { questões } \\
\text { respondido por } 458 \text { estudantes. }\end{array}$ & $\begin{array}{l}\text { Equações estruturais e } \\
\text { análise descritiva. } \\
\text { Análise fatorial } \\
\text { exploratória. }\end{array}$ \\
\hline $\begin{array}{l}\text { Tan, G., Ooi, K-B., } \\
\text { Sim, J-J., } \\
\text { Phusavat, K. }\end{array}$ & 2012 & Malasia & Correlacional & Quanti & $\begin{array}{l}\text { Questionários com } 11 \text { itens } \\
\text { respondidos por } 401 \text { indivíduos. }\end{array}$ & $\begin{array}{l}\text { Regressão múltipla. } \\
\text { Análise fatorial } \\
\text { exploratória. }\end{array}$ \\
\hline Gikas, J. Grant, M. & 2013 & USA & Exploratório & Quali & $\begin{array}{l}\text { Entrevistas em grupos focais } \\
\text { feitas e gravadas via Skype. } \\
\text { Roteiro semi-estruturado com } 15 \\
\text { questões. } \\
\text { Observação de comportamento } \\
\text { (gestual). }\end{array}$ & Análise indutiva. \\
\hline
\end{tabular}




\begin{tabular}{|c|c|c|c|c|c|c|}
\hline & & Tabela & le Artigos & ipírico & em Mobile Learning & \\
\hline Autor & Ano & País & $\begin{array}{l}\text { Delinea- } \\
\text { mento }\end{array}$ & $\begin{array}{l}\text { Quali/ } \\
\text { Quanti }\end{array}$ & Intrumento de coleta & $\begin{array}{l}\text { Método de Análise } \\
\text { de Dados }\end{array}$ \\
\hline $\begin{array}{l}\text { Ojokoh, B., } \\
\text { Doyeni, O., } \\
\text { Adewale, O., } \\
\text { Isinkaye, F. }\end{array}$ & 2013 & Nigeria & Correlacional & Quanti & $\begin{array}{l}\text { Survey respondido por } 20 \\
\text { indivíduos, composto por } 12 \\
\text { questões. } \\
\text { Escala likert de } 5 \text { pontos. }\end{array}$ & Estatística descritiva. \\
\hline $\begin{array}{l}\text { Ferreira, J.B., } \\
\text { Freitas, A.S., } \\
\text { Carvalho, M.L.A., } \\
\text { Azevedo, H.C., } \\
\text { Gobbo, A.M.C., } \\
\text { Giovannini, C.J. }\end{array}$ & 2014 & Brasil & Correlacional & Quanti & $\begin{array}{l}\text { Survey composto por } 402 \\
\text { questões. }\end{array}$ & $\begin{array}{l}\text { Equações estuturais. } \\
\text { Análise fatorial } \\
\text { confirmatória. }\end{array}$ \\
\hline $\begin{array}{l}\text { Glackin, B., } \\
\text { Rodenhiser, R., } \\
\text { Herzog, B. }\end{array}$ & 2014 & USA & Experimento & $\begin{array}{l}\text { Quali } \\
\text { Quanti }\end{array}$ & $\begin{array}{l}2 \text { surveys online, compostos por } \\
36 \text { questões. } \\
\text { Esccala Likert de } 10 \text { pontos. } \\
\text { Grupo focal, adaptado da técnica } \\
\text { Delphi. }\end{array}$ & $\begin{array}{l}\text { Teste t, Chi quadrado. } \\
\text { Análises estatísticas e } \\
\text { descritivas. } \\
\text { Análise estatística } \\
\text { bivariada. }\end{array}$ \\
\hline $\begin{array}{l}\text { Meritxell, H., } \\
\text { Arévalo, C., } \\
\text { Catasús, M., Mon, } \\
\text { C. }\end{array}$ & 2014 & Espanha & Experimento & $\begin{array}{l}\text { Quali } \\
\text { Quanti }\end{array}$ & $\begin{array}{l}\text { Questionário respondido por } 128 \\
\text { participantes. }\end{array}$ & Estatística descritiva. \\
\hline $\begin{array}{l}\text { Tan, G. W-H., Ooi, } \\
\text { K-B., Leong, L-Y., } \\
\text { Lin, B. }\end{array}$ & 2014 & Malasia & Correlacional & Quanti & $\begin{array}{l}\text { Survey com } 20 \text { itens respondido } \\
\text { por } 216 \text { indivíduos. } \\
\text { Escala Likert de } 5 \text { pontos. }\end{array}$ & $\begin{array}{l}\text { Modelo híbrido de } \\
\text { Equações Estruturais } \\
\text { com abordagem de } \\
\text { redes neurais } \\
\text { artificiais. } \\
\text { Análise exploratória } \\
\text { de fatores e rotação } \\
\text { varimax. }\end{array}$ \\
\hline $\begin{array}{l}\text { Huang, Y-M, Liao, } \\
\text { Y-W, Huang, S-H } \\
\text { and Hsin-Chin } \\
\text { Chen, H-C }\end{array}$ & 2014 & Taiwan & Experimento & $\begin{array}{l}\text { Quali } \\
\text { Quanti }\end{array}$ & $\begin{array}{l}\text { Questionários de pré e pós testes } \\
\text { com } 15 \text { itens, respondidos por } 63 \\
\text { indivíduos, } 30 \text { do grupo } \\
\text { experimental e } 33 \text { do controle. }\end{array}$ & $\begin{array}{l}\text { Estatística descritiva. } \\
\text { Ancova. } \\
\text { One-way Anova. }\end{array}$ \\
\hline $\begin{array}{l}\text { Kurtz, R., } \\
\text { Macedo-Soares, } \\
\text { T., Ferreira, J., } \\
\text { Freitas, A., Silva, } \\
\text { J. }\end{array}$ & 2015 & Brasil & Correlacional & Quanti & $\begin{array}{l}\text { Survey composto por } 25 \text { itens, } \\
\text { respondido por } 212 \text { indivíduos. } \\
\text { Escalas likert de } 5 \text { pontos. }\end{array}$ & $\begin{array}{l}\text { Dados tratados por } \\
\text { equações estruturais. } \\
\text { Análise fatorial } \\
\text { confirmatória (CFA). }\end{array}$ \\
\hline $\begin{array}{l}\text { Meer, J., Berg, D., } \\
\text { Jeffrey, S., Gunn, } \\
\text { A., Anakin. M. }\end{array}$ & 2015 & $\begin{array}{l}\text { Nova } \\
\text { Zelândia }\end{array}$ & Exploratório & Quanti & $\begin{array}{l}\text { Survey composto por } 26 \\
\text { questões, respondido por } 437 \\
\text { indivíduos. } \\
\text { Escala Likert de } 5 \text { pontos. }\end{array}$ & Aanálise fatorial. \\
\hline
\end{tabular}

Fonte: pesquisa.

\section{Síntese}

Reflexões sobre a revisão de literatura em mobile learning indicam duas grandes linhas de pesquisa teórico-empíricas: 1) a testagem da predisposição para o uso de aparatos tecnológicos (10 em 20 estudos usam variáveis dessa natureza) e 2) a testagem de modelos 
aplicáveis à aprendizagem. Todos os resultados apresentaram, de modo geral, dados positivos sobre o uso de mobile learning, mas há pouca consistência em termos de resultados dos últimos.

As testagens a respeito da aceitação de tecnologia baseiam-se no modelo TAM, com alguns casos adaptados para o estudo de m-learning, com instrumentos e escala validados para o estudo das variáveis com impacto na aprendizagem em dispositivos móveis, com bons resultados em termos de suporte ao desenho instrucional. No entanto, pode ser que não haja tanta resistência ao mobile quanto havia em relação aos computadores, o que é sugerido pelo modelo original. A inferência surge do termo "acceptance", aceitação, que está diretamente ligado à rejeição ou resistência ao uso de tecnologia. $\mathrm{O}$ modelo, entretanto, resiste ao tempo e às mudanças culturais com adaptações produtivas, produzindo um conjunto confiável de variáveis a serem consideradas no desenvolvimento de soluções instrucionais. Conforme Huang, Lin e Chuang (2006), o modelo é considerado uma ferramenta robusta para mensurar a adoção de novas tecnologias pelos usuários. Tem sido utilizado com sucesso e validado para muitas aplicações, incluindo sistemas baseados em web. Os sistemas baseados em tecnologia dependem significativamente da predisposição do usuário à sua utilização.

Os estudos empíricos testaram de forma sistemática a aceitação da tecnologia, porém acabaram por extrapolar a essa função. Com a percepção de que o contexto é um fator vital para o sucesso das ações em mobile learning e que produz alterações de comportamento (ver definições de mobilidade), outras teorias foram agregadas à análise das variáveis, como a Teoria do Comportamento Planejado - (Planned Behavior Theory - PBT), a Teoria do Fluxo (Flow), abordada por Kurtz et al. (2015) e a Teoria da Atividade (Activity Theory), por exemplo, abordada por Sharples, Taylor, Vavoula (2005). Essas teorias têm forte concentração no aspecto comportamental e na experiência do sujeito, predispondo-o em maior ou menor escala ao engajamento aos conteúdos dispostos em artefatos móveis.

Os estudos sobre modelos e estratégias não apresentam resultados tão consistentes, possivelmente pelo fato de que o campo ainda é bastante incipiente, o que confere um traço exploratório aos estudos, pela falta de identificação de variáveis que suportem os achados Discussão e compreensão de modelos aplicados e testados também são muito úteis na definição da relação direta entre as etapas do desenho instrucional: objetivo, desenho instrucional, resultados e avaliação, tanto pelos acertos, quanto pelos erros. A variedade dos 
modelos aponta um terreno fértil para a elaboração de desenhos versáteis e interessantes para o desenvolvimento de atividades de aprendizagem.

Os usuários mostram entusiasmo com os modelos e apontam atributos considerados vantajosos, como acesso rápido às informações, ubiquidade, diversão, colaboração, diversidade de recursos disponíveis e outros. Mostram também algumas frustrações, como performance de rede e de aplicativos não correspondentes às expectativas, além de limitações a interações mais extensas e dificuldades de entrada de dados (teclados reduzidos). Esse entusiasmo se reflete em engajamento e resultados melhores do que em sistemas tradicionais para determinados tipos de tarefas. A mobilidade traz também a possibilidade de aprendizagem situada, que aproxima o aprendiz da situação real, como não é possível em outros sistemas de ensino.

Há uma boa quantidade de estudos experimentais (6 em 20), mas percebe-se falta de precisão das variáveis envolvidas nos estudos, como em Huang et al. (2014), cuja variável critério é o método instrucional ${ }^{10}$, ou Hernando et al. (2014), que estuda aprendizagem da unidade estudada. Ambos são construtos amplos, que demandam fatoramento. No entanto, garante a relação entre a intervenção e os resultados. Há sete estudos mistos (quantitativos e qualitativos), sendo 2 exclusivamente qualitativos, o que mostra interesse em informações de caráter opinativo. Foi identificada boa diversidade de instrumentos de coleta, com predominância de surveys e variedade de instrumentos de coleta. Quanto à análise de dados, foram identificados também pertinência e variedade nos métodos.

Uma questão importante que surge no estudo da literatura é a diferença entre os modelos de e-learning e de m-learning. Aparentemente, um é derivado do outro, mas os resultados e propostas de definição abrem espaço significativo entre os dois modelos. O ponto mais marcante dessa diferença é o contexto, visto que o acesso a dispositivos móveis é predominantemente realizado em contextos não educacionais e também não controlados. Salvo alguns estudos que mostram intencionalidade na definição do local do estudo (como aqueles de aprendizagem situada, ou context aware), a maior parte dos acessos se dará em local não determinado e com interferências imprevisíveis. É importante perceber também que o contexto não se limita às circunstâncias ambientais, mas de outras naturezas, como

\footnotetext{
10 Algumas variáveis critério não estão declaradas e foi buscada uma definição com a finalidade de se compreender a cadeia de consequência dos fatores.
} 
menciona Zerbini (2007) e está relacionado às várias dimensões da mobilidade. É notável, e representa importnte lacuna de conhecimento, a falta da exploração de variáveis de contexto nos estudos de mobile learning estudados, dado que é esse o fator mais relevante na aplicação de modelos móveis, bem como no modelo de avaliação de aprendizagem/transferência adotado, que reflete as descobertas no campo das variáveis de treinamento e especificamente de transferência de treinamento.

Casos de utilização de mobile learning para apoiar ações de EAD, como ações completas ou ainda como ações independentes é uma outra discussão em andamento. Naturalmente, como ainda não há muitas certezas científicas na aplicação de modelos, as intervenções estão ainda sendo testadas para um desenho instrucional mais adequado.

Com relação ao contexto organizacional, Saccol et al. (2010) realizaram estudo em instituição de ensino superior e com profissionais que tinham, em sua maioria ( 7 em 10), formação em TI. Essas duas características devem ser levadas em consideração, visto que possivelmente cria dois viéses: o perfil do público de uma instituição de ensino superior pressupõe o contato intenso com ferramentas de ensino/aprendizagem, reduzindo, assim, a resistência a novas ideias e modelos. O segundo viés é bastante flagrante, visto que praticamente elimina qualquer dificuldade com a operação de sistemas e dispositivos de computação, comprometendo um dos achados do trabalho, onde se afirma que, segundo os usuários, o modelo apresentado é aplicável ao treinamento corporativo e fácil de usar. Dessa forma, apesar de ser o único artigo realmente dedicado ao contexto organizacional, há contribuição limitada para o estudo presente como definição de diretrizes na pesquisa.

Do conjunto de variáveis relatadas, três merecem atenção: 1) diversão percebida, 2) autogestão da aprendizagem e 3) valor percebido de mobilidade, estudadas por Wang, Wu e Wang (2009) (1 e 2), Huang, Lin e Chuang (2006) (1 e 3) e Kurtz et al. (2015) (1). Esses componentes trarão contribuição para o desenho instrucional no que diz respeito à autonomia, engajamento (aqui, com referência à concentração e elementos do estado de fluxo) e ao uso dos dispositivos móveis pela consciência da mobilidade (não apenas a locomoção). Uma das limitações percebidas foi que a maior parte das escalas foram adaptadas de modelos de $e$ learning. 


\subsection{Considerações sobre as literaturas em transferência e mobile learning}

Este trecho tem a função de alinhar os achado das duas revisões de literatura e buscar traços comuns, ou complementares, que possam organizar os conhecimentos das duas áreas e convergir orientações para o entendimento conjunto dos dois fenômenos.

Ambos os campos se utilizam de técnicas baseadas em autorrelato e monométodo (traço oposto à triangulação, que visa dar mais consistência aos dados). Com isso, a área de mobile learning repete tendências apontadas na área de tranferência. Há algumas iniciativas na área de m-learning que fazem levantamentos de informações de sistema, que podem dar um caráter mais seguro aos achados, visto que os sistemas informáticos são capazes de registrar e recuperar todo o comportamento dos usuários. Esse campo também tem se valido de modelos experimentais com maior frequência, o que produz maior consistência nos achados. É outra vantagem dos sistemas digitais, que pode segregar quaisquer tipo de usuários por pefis pré-determinados. Não foi localizada, nos estudos de m-learning, técnicas de triangulação de dados. Dessa forma, em termos de metodologia, não há muita novidade no campo de m-learning, exceto iniciativas tímidas de avaliação por dados duros de sistema. A Tabela 9 relaciona as variáveis relativas à transferência e aos dispositivos móveis, buscando maior clareza sobre os aspectos comuns ou similares. Para efeitos práticos de representação, os dados foram divididos em duas colunas, respectivamente associadas aos dois campos. As variáveis que se aproximam em conceito estão destacadas em negrito.

\section{Tabela 9}

Associação das variáveis de transferência de treinamento e mobile learning identificadas neste estudo.

\begin{tabular}{|c|c|c|}
\hline \multicolumn{3}{|c|}{ Variáveis Identificadas } \\
\hline & $\begin{array}{l}\text { Variáveis Relacionadas à } \\
\text { Transferência de Treinamento }\end{array}$ & $\begin{array}{l}\text { Variávveis relacionadas à adoção } \\
\text { de Mobile Learning }\end{array}$ \\
\hline & Contexto de estudo & \\
\hline & Aspectos ambientais & \\
\hline \multirow{3}{*}{$\begin{array}{l}\text { Características do } \\
\text { ambiente de } \\
\text { trabalho (ou } \\
\text { aplicação) }\end{array}$} & Características do ambiente de trabalho & \\
\hline & Variáveis de suporte ambiental & \\
\hline & Avaliação da necessidade de treinamento & \\
\hline
\end{tabular}




\section{Variáveis Identificadas}

Suporte à aplicação do treinamento

Suporte técnico

Desenho/entrega da instrução

Características da clientela

Relevância do conteúdo

Desenho/entrega da instrução

Reação à interface gráfica

Autoeficácia

Utilidade percebida

Autoavaliação de aprendizagem

Abertura para novas experiências

Atitudes dos participantes em relação à educação a distância

Consciência

Motivação para transferir

Reação ao tutor
Autoeficácia em m-learning

Percepção de utilidade

Autogestão da aprendizagem
Percepção do valor de mobilidade

Percepção de facilidade de uso / Expectativa de esforço

Controle do comportamento percebido

Concentração

Influfência social/Normas subjetivas

Expectativa de performance

Diferenças individuais

Diversão percebida

Burke e Hutchins (2007) confirmam autoeficácia como preditora de transferência. O fato converge com achados para mobile learning, conforme Fadare et al. (2011). Esta no entanto, refere-se à predisposição para o uso. O paralelismo corrobora a importância desse item no planejamento de treinamento. O mesmo vale para percepção de utilidade e autogestão, que, embora não tenham precisamente a mesma definição constitutiva, indicam 
nítido alinhamento de fatores relevantes para uma combinação de saberes. A carência de variáveis relativas ao desenho da instrução em mobile learning é explicável pelo caráter essencialmente experimental dos modelos, como visto na revisão específica, também em contraste com os estudos de transferência.

Os achados em relação às pesquisas sobre treinamento mostram uma prática corrente predominante de mensuração de variáveis que têm impacto sobre a variável transferência de treinamento, que se ocupam de propor e testar variáveis, por inclusão de novas, ou desdobramento das já testadas. Em termos metodológicos, as sugestões sobre a inclusão de novas ferramentas e métodos complementares são frequentes, com a finalidade de trazer maior compreensão dos fenômenos por outras fontes. Os trabalhos sobre transferência parecem, assim, sedimentar práticas já consagradas da produção científica, garantindo, com isso, rigor e confiabilidade nos resultados obtidos.

A frequência de estudos e revisões que apontam, como problema, dados provenientes de autorrelato e monométodo, é alta, como em Pereira (2009), Santos Junior (2012) e outros autores anteriores. Adicionamente, Zerbini e Abbad (2010) destacam a falta de trabalhos no modelo experimental, embora sejam de difícil aplicação em ambientes naturais, particularmente em contexto organizacional. Em contrapartida, nos trabalhos sobre mobile learning os modelos experimentais e buscas de fontes complementares surgem com maior frequência. Outras variações estão igualmente presentes, como a testagem de modelos, visto que os recursos disponíveis nos aparelhos móveis proporciona bastante variedade de utilização e aplicação, permitindo grande versatilidade na modelagem de aprendizagem. Esses resultados ainda carecem, dada a imaturidade do campo, de confirmações mais sólidas e confiáveis.

As revisões mostram a grande importância do contexto, como elemento influente e informativo nos efeitos da intervenção de dispositivos móveis do fenômeno de tranferência. Nota-se, na Tabela 9, pela disposição dos itens, a carência de testagem de variáveis de contexto/ambiente. Considerando-se que as variáveis de contexto/ambiente são as mais influentes, conforme Abbad (2010) e Perreira (2009), que afirma que aspectos ambientais são mais influentes do que os individuais, deixa a clara a lacuna de pesquisa já apontada.

O contexto tem relação direta com a aprendizagem situada, que, por sua vez, trata a situação problema onde esta se apresenta. Está associada ao conceito de cognição situada, ou 
seja, todo o pensamento tem que ser visto como situado em um contexto no qual existe a situação problema, conforme Young (1993). Extrapolando-se o conceito para o treinamento, podemos ter a ação de transferência ocorrendo simultaneamente à ação de aprendizagem. $\mathrm{O}$ estudo mostrou que o elemento contextual em mobile learning pode ser explorado de várias formas, fornecendo informações e contextualização. Tendo como base que o contexto em aprendizagem móvel é bastante mutável (mesmo quando controlado por modelo e regras de uso) pode-se supor que as variáveis atuantes sobre os modelos de treinamento baseados em dispositivos móveis serão ainda mais complexas do que os modelos tradicionais de aprendizagem e EAD.

É possível também se imaginar que as novas formas do trabalho, associadas às novas formas de aprendizagem produzirão novas relações de predição, novos desenhos instrucionais, novas formas de transferência e de avaliação. Em consideração à tendência, observada no campo da trasferência de treinamento, de pulverização dos elementos relativos composição das variáveis, cabe colocar, conforme preocupação de Salas e Cannon-Bowers (2001) (distanciamento entre pesquisa e organização), a respeito da perspectiva de ciência aplicada ao campo da administração, que em si prevê conceitualmente que os achados dos estudos tenham pertinência à vida da organização.

Parece que o tratamento de uma situação relativa à vida organizacional, que tenha que levar em conta, dezenas de variáveis para a construção de modelos instrucionais, pode tornar impraticável o apoio direto e a interpretação dos fatores determinantes dos fenômenos de aprendizagem e transferência (aplicação). Paralelamente, a questão de conceituação é também problemática, dado que para serem confirmadas precisam ser compreendidas do modo mais objetivo e mais claro possível. Quando se desdobra uma variável como percepção de utilidade (PU) em percepção de utilidade em longo prazo e curto prazo, é possível que se esteja produzindo variáveis, em lugar de isolarmos um conceito preciso e melhorarmos a compreensão do fenômeno. 


\section{REFERENCIAL TEÓRICO}

As organizações, impulsionadas pelo surgimento de novas tecnologias, concorrência de empresas estrangeiras e uma nova organização do trabalho, iniciaram um período de transição na área de Gestão de Pessoas. Da antiga atuação operacional e burocrática (modelo instrumental) a área de $\mathrm{RH}$ passou a atuar de forma estratégica capaz de impulsionar resultados positivos (modelo desenvolvimentista) e propiciar a base, necessária mas não isoladamente determinante, para o atingimento dos resultados esperados.

A partir desse novo posicionamento, diversos estudiosos passam a reconhecer o fator de diferenciação e adaptação das empresas bem sucedidas nesse processo: o conhecimento. Drucker (1993, citado por Nonaka e Takeuchi, 1997) afirmou que o conhecimento deixou de ser um recurso de produção e passou a ser "o recurso". Logo, processos que envolvam criação, produção e distribuição de produtos e serviços, são executados por meio do conhecimento e do capital intelectual como principais recursos produtivos, e cabe ao Sistemas de TD\&E prover as organizações com esses recursos.

A formação do capital intelectual pode se dar de várias formas, estruturadas ou não. Dentre as ações estruturadas (aprendizagem intencional), está o treinamento. Salas e CannonBowers (2001), afirmaram que os eventos de treinamento deixaram de ser tratados como um conjunto de ações isoladas, tornando-se integradas e vinculadas à estratégia corporativa. Baseados nesse quadro e com a expectativa de que um grande número de profissionais transfira os conhecimentos aprendidos para o ambiente de trabalho, as organizações passam a investir grandes quantias em ações formais de Treinamento, Desenvolvimento e Educação TD\&E (Zerbini \& Abbad, 2010).

Desses investimentos em capacitação e desenvolvimento e da necessidade de justificálos decorre a constituição do sistema de TD\&E, composto pelos subsistemas : a) avaliação de necessidade, b) planejamento e execução e c) avaliação, sendo este último, o responsável pelo provimento de informações, retroalimentação e aperfeiçoamento do sistema, no que diz respeito a efetividade dos treinamentos e a variáveis preditoras de resultados de TD\&E (BorgesAndrade, Abbad, e Mourão (2012), como representado na Figura 2. 


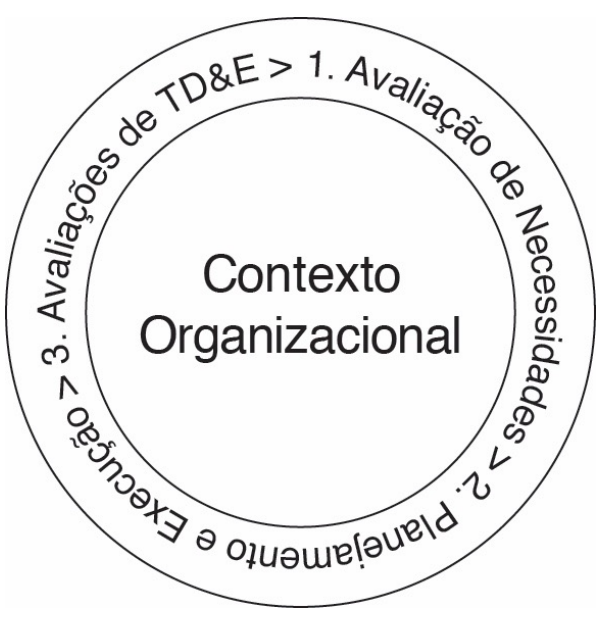

Figura 2. Esquema sintético do sistema de TD\&E.

Fonte: adaptado de Borges-Andrade, Abbad, e Mourão (2012).

O universo empresarial busca qualificação de seu corpo funcional a fim de ganhar competitividade e atingir objetivos voltados primordialmente aos resultados provenientes de ações nos mercados nos quais se inserem. Neste contexto, agilidade e eficácia são atributos imprescindíveis ao desempenho. Custos, autonomia e facilidade de acesso levaram as empresas a buscar modelos de educação a distância, especialmente os mediados por tecnologia e, mais especificamente, por redes, com destaque para a Internet.

\subsection{Aprendizagem}

Conforme Abbad e Borges-Andrade (2004), por se tratar de contexto organizacional, a objetividade é imperativa para que se possa produzir uma ação instrucional em resultados mensuráveis. A forma de pensar a aprendizagem é que determinará o modelo e diretrizes para o desenvolvimento de uma ação instrucional que acomode, ao mesmo tempo, adequação às demandas organizacionais e as potencialidades de aprendizes e recursos. As teorias de aprendizagem estão organizadas em três paradigmas principais: behaviorista (comportamentalista), cognitivista e construtivista.

A abordagem do presente trabalho afiniza-se, primeiramente, com a interpretação cognitivista-objetivista da aprendizagem, dado que, no contexto do trabalho, para o desenvolvimento dos CHA, é necessária uma objetivização do conteúdo a ser aprendido, pois 
esse deverá ser mensurado em termos concretos, mensuráveis, a fim de justificar uma ação corporativa, conforme Borges-Andrade et al. (2006). A abordagem behaviorista está centrada em um processo de estímulo-resposta, que estará sempre presente de algum modo no processo de aprendizagem. Resultados emanados da própria experiência do aprendiz estão na dimensão de sua liberdade na problematização das situações às quais está exposto e sua reação perante as possibilidades de ação e solução e, por isso, expõem uma prática mais alinhada a uma ideia construtivista.

Ainda segundo Abbad e Borges-Andrade (2004), aprendizagem está fundamentada em dois processos distintos: aprendizagem natural e aprendizagem induzida. A aprendizagem induzida, que é o tipo de processo do qual tratam os temas neste estudo, prevê intencionalidade e, por isso, deve estar baseada em processos bem estruturados e planejados para que facilitem a aquisição, manutenção e generalização, ou em caráter mais amplo, aprendizagem, a retenção e a transferência. Esses conceitos estão inseridos no conceito de transferência baseado no desenvolvimento dos CHA (conhecimento, habilidades e atitudes), conforme Le Boterf (2003). Para esse autor a competência nunca é uma competência pura, mas uma competência para e que deve estar a serviço da ação. A competência não está relacionada somente à sua essência, mas está inserida no contexto social e é por ele influenciada. Dessa forma, políticas organizacionais e movimentos sociais também entram na composição da ação da competência, que deve ser observada em um contexto de desempenho.

As teorias instrucionais têm caráter prescritivo e visam garantir o atingimento de objetivos instrucionais, descritos em termos de comportamentos observáveis, enquanto as teorias de aprendizagem têm caráter descritivo, conforme Borges-Andrade et al. (2006). Esses autores afirmam que as teorias de aprendizagem eram insuficientes para explicar a complexidade desse processo nas organizações, em referência ao sistema de competências, fazendo surgir as teorias do desenho instrucional. A teoria instrucional de Gagné aborda a aprendizagem em duas perspectivas: condições internas e externas. As primeiras elaboram o comportamento do aprendiz, enquanto as segundas visam os objetivos e técnicas aplicadas à ação de aprendizagem. Reconhecendo as diferenças entre indivíduos, o ideal seria que se desenvolvesse uma ação personalizada para os aprendizes. As teorias instrucionais, ao classificarem resultados, constroem as bases para a definição do desenho instrucional, visto 
que a classificação é que antecipa as fases do planejamento instrucional. Fatores exógenos incluem suporte, recursos, ambiente e outros.

Abordagem instrucional: combinação de ferramentas, métodos e conteúdos (CannonBowers, 2001). A teoria de aprendizagem define transferência como a reaplicação análoga do que foi aprendido, conforme Gagné (1988), no que diz respeito à aprendizagem. Segundo Abbad (1999), identificar a retenção e generalização (treinando reconhece situações no trabalho que podem ser aplicados os conhecimentos - esse reconhecimento não implica a transferência) é condição necessária, mas não suficiente, para que os comportamentos aprendidos ocorram no trabalho. Nesse ponto, surge alguma imprescisão do que seria realmente a transferência, na convergência entre a teoria da aprendizagem e a do desenho instrucional.

Reigeluth (1999) define a teoria de desenho instrucional como a teoria que oferece diretrizes explícitas sobre como ajudar as pessoas a aprenderem. As formulações necessárias ao trabalho de desenho instrucional demandam que os limites e elementos constituintes (objetos e processos) estejam bem definidos por imposição do contexto organizacional. O desenho instrucional deve estar preparado para lidar com as novas características do profissional e do mercado, como o desenvolvimento constante e aquisição de CHA mais complexos. As teorias de desenho instrucional possuem dois componentes: métodos para o desenvolvimento humano e onde e quando usar os métodos. Métodos devem considerar as condições na qual a aprendizagem ocorrerá. O planejamento instrucional é o produto de três tipos de teoria: aprendizagem, instrucional e desenho instrucional.

Campos e colaboradores (conforme citado em Broges-Andrade et al., 2007, p.268) definem desenho instrucional como um ciclo de atividades baseado em uma teoria de aprendizagem, na qual são definidos os objetivos educacionais, as informações necessárias e o modelo de avaliação. Johnson e Aragon (idem, p.270) enfatizam a importância do planejamento instrucional para que os aprendizes alcancem os objetivos educacionais desejados e desenvolver competências para o trabalho. Esses autores apresentam a noção de ambientes de aprendizagem online e sugerem que fatores pedagógicos e de desenho do curso são tão ou mais importantes do que a tecnologia que será utilizada. No que se refere às teorias de aprendizagem, os autores defendem que a aprendizagem é um processo psicológico complexo e, assim, não pode ser explicada apenas por uma teoria de aprendizagem. Portanto, 
os autores sugerem a junção de princípios derivados das teorias behavioristas, cognitivistas e sociais.

Segundo Borges-Andrade et al. (2006), o processo de construção de um evento instrucional passa por seis etapas: redação de objetivos, escolha de modalidade, estabelecimento da sequência das ações, definição de procedimentos, definição de critérios para avaliação e testagem. Todas as etapas devem ser detalhadamente e cuidadosamente preparadas, com base nas teorias que fundamentam cada uma, buscando a adequada correlação dos objetivos com os CHAs esperados, itens próprios de avaliação que possam ser objetivamente aferidos, escolha de modelos viáveis e compatíveis com a clientela etc.

É importante observar, entretanto, conforme Sharples, Taylor e Vavoula (2005), que é necessária a reconceitualização da aprendizagem na era da mobilidade, dadas as características de comunicação e mobilidade dessa modalidade de aprendizagem, principalmente no que diz respeito ao contexto. Segundo Fantin (2015), a introdução, por si só, de elementos tecnológicos não é suficiente para desencadear processos transformadores nas práticas pedagógicas. É necessário o rompimento com paradigmas da educação. O autor propõe uma metodologia chamada Episódios de Aprendizagem Situada - EAS. Meer et al. (2015) vão ainda mais longe, propondo nova reconceituação da pedagogia.

A aprendizagem situada, conforme Young (1993), está associada ao conceito de cognição situada, ou seja, todo o pensamento tem que ser visto como situado em um contexto no qual existe a situação problema. Essa abordagem está baseada em uma compreensão do pensamento como percepção-ação, em lugar daquela baseada em conceitos do processamento da informação. O conceito adotado, enquanto área de saber, é o de psicologia ecológica. No modelo tratado no trabalho, são propostas quatro etapas para a definição de um desenho de aprendizagem situada: seleção das situações, provimento de uma plataforma, determinação do papel do professor e avaliação. A ideia geral é de que esse tipo de aprendizagem se realiza nos contextos realistas das situações que exigem aprendizado, com fundamento no conceito de aprendizagem experimental de Dewey (1938, as cited in Young, 1993).

Nessa abordagem, a memória cede lugar à percepção como meio de aprendizagem, em contraste com a abordagem de teorias esquemáticas, nas quais o significado está registrado e deve ser recuperado. Esse significado, em aprendizagem situada, é produzido no momento do encontro com a situação, por meio de percepção e ação. O conceito de memória, 
então, é reduzido, no entendimento de conhecimento e aprendizagem, sendo substituído por sintonia, atenção e percepção. Ou, ainda, configurando-se como uma aprendizagem perceptual. Há dois componentes envolvidos nessa situação/processo: o agente e o contexto.

A inteligência e o conhecimento devem ser vistos como a relação entre o agente e o ambiente. O processo envolve habilidades do agente/ator e atributos relevantes do ambiente, sob a ótica dessa interação. Considera que os indivíduos possuem diferentes formações e personalidades, influenciando a percepção do ambiente. Certamente, dados os fatores culturais e de comportamento, os agentes poderão chegar a respostas diferentes às situaçõesproblema. O conhecimento, nessas situações, não reside mais nos agentes, mas no próprio contexto, registrada em livros, mecanismos de monitoramento de pacientes, intrumentos etc.

Essa abordagem parece adequada para a aplicação e modelos do tipo job aid (consequentemente, mobile learning), no qual o trabalhador lança mão de um conteúdo, como instrução, orientação, procedimento, por exemplo, que será aplicado em contexto, na situação da tarefa. Na ocasião, o aprendiz estará frente a frente com a situação-problema, exigindo, muitas vezes, a interpretação do contexto para a ação e tomada de decisão.

Saccol et al. (2010) buscam na visão construtivista de Piaget (1995) a relação de protagonismo do sujeito em relação à aprendizagem, que fundamenta a adoção de uma referência interacionista/construtivista/sistêmica para melhor entender o fenômeno da aprendizagem móvel. Sob esse ponto de vista, o aprendiz é agente, que possui conhecimentos prévios e interage com a realidade, estabelecendo relações e expressando aprendizagem (Schlemer, 2002, como citado em Saccol).

$\mathrm{Na}$ realidade, as diferentes características estão sempre presentes na aprendizagem, com maior ou menor intensidade, associando-se o paradigma a uma feição dominante. Conforme Naismith, Lonsdale, Vavoula e Sharples (2006), a teoria comportamentalista tem foco nas mudanças observáveis nas ações dos aprendizes. Isso está presente nas atividades móveis, como por exemplo o recebimento de alguma instrução por meio de mensagens, que provocarão alguma resposta do aprendiz. Em contrapartida, atividades compartilhadas, o conhecimento pode estar sendo construído simultaneamente à realização de tarefas, assemelhando-se, assim, a uma proposta construtivista. 


\subsection{Treinamento}

Há convergência da ideia de treinamento na literatura de modo geral, indicando uma ação organizacional sistemática, planejada com o objetivo de se desenvolver conhecimentos, habilidades e atitudes a fim de se proporcionar aumento do desempenho do indivíduo no trabalho, conforme Pilati e Abbad (2005). Algumas definições são mais detalhadas e abordam ainda outros processos, mas a ideia geral é bastante similar e consistente. O treinamento está, dessa forma, associado à produção, ou seja, ao reflexo de algo abstrato, como um conhecimento, em algo concreto, mensurável, como um objeto produzido, ou o alcance de uma meta, e em consonância com objetivos externos ao indivíduo, aqueles de caráter corporativo. Esse fenômeno é denominado em Psicologia Organizacional de transferência de treinamento, que será tratado mais detalhadamente, adiante, neste estudo.

Abbad, Carvalho e Zerbini (2007) alertam para a importância de avaliar ações educacionais ofertadas a distância, principalmente as mediadas por NTICs, visando evitar ineficácia das mesmas e consequente descrédito. O primeiro desafio é a localização dos fenômenos 1) avaliação, 2) aprendizagem e 3) impacto/transferência, havendo uma tendência a que se distribuam entre os campos da psicologia e da administração. No âmbito deste estudo, o foco recairá sobre o campo da administração, visto que a relação direta buscada reside, em última análise, nas justificativas para os investimentos em capacitação. As revisões de literatura, como será visto em capítulo específico, apontam aprofundamento do saber sobre o tema TD\&E, mostrando o desenvolvimento e consolidação de medidas, instrumentos de avaliação e, ainda, a verificação do fatoramento construto transferência de treinamento em variáveis diversas, extrapolando o nível micro de análise. No entanto, o contexto de treinamento é mutável e tem se transformado significativamente pela influência da tecnologia, o que exige regularmente revisão de conceitos e ferramentas de avaliação. Uma limitação apontada em várias revisões é a prática de autoavaliação, o que restringe os resultados e está sujeita a viéses específicos, que devem ser controlados. 


\subsection{Impacto/Transferência}

Transferência de treinamento é um conceito que vem sendo bastante estudado e explorado, devido a ser o processo que transforma o resultado da aprendizagem em resultado no trabalho, também definido como impacto em profundidade. O conceito não pode ser estudado em separado do conceito de avaliação, visto que a avaliação é a ação sobre o fenômeno, de modo que existem de modo recíproco e interdependente.

As revisões de literatura, dessa forma, trazem resultados e reflexões para os dois parâmetros. Baldwin e Ford (1988) afirmam que "transferência de treinamento" pode ser definido como aplicação eficaz, no contexto de trabalho, de conhecimentos, habilidades e atitudes adquiridos durante ações instrucionais, ou seja, mudanças na forma de desempenhar atividades de trabalho e que perduram por algum tempo. Já Impacto é conceituado como efeitos específicos ou amplos, diretos ou indiretos das ações de TD\&E. Por outro lado, Abbad, Mourão et al. (2012) afirmam que Impacto é o efeito da transferência de treinamento, enquanto a transferência é decorrência direta do treinamento. Desse modo, há alguma imprecisão sobre a delimitação do fenômeno. Pilati e Abbad (2005) afirmam que a delimitação de conceitos e o teste dos construtos respectivos tornam-se relevantes para a pesquisa na área.

A transferência poderá ocorrer de diversas formas e com resultados diferentes, pois está relacionada a grande número de variáveis. $\mathrm{O}$ fato de se estabelecer um novo parâmetro no treinamento, como no caso deste estudo (inserção do recurso móvel), poderá trazer resultados não esperados, visto que a interferência desse se dará em treinamento com relativo grau de complexidade e em condições ainda não totalmente mapeadas. A transferência, como expressão dos CHAs, deverá ser positiva e implicar em produtividade, ou melhoria na qualidade do trabalho, em função da definição precisa dos objetivos instrucionais, que, por sua vez, fundamentam os instrumentos e medidas a serem utilizados. A transferência, aqui, deverá se dar, em relação ao que se espera do aprendiz, de modo lateral, ou seja, a aplicação análoga dos conceitos aprendidos, visto que o processo de trabalho, refletido no "desempenho esperado no trabalho", envolve análise e aplicação de conceitos. Dessa forma, o treinando deverá se apropriar de alguns saberes e utilizá-los em situações diversas. 
Conforme Zerbini (2007), as organizações e as Universidades Corporativas investem alto em ações formais de TD\&E com a intenção de que um grande número de funcionários e profissionais transfira positivamente os conhecimentos, habilidades e atitudes para o ambiente de trabalho. Entende-se, por extensão, que os funcionários devem produzir melhores resultados na situação de trabalho e, por consequência, deve haver incremento nos resultados organizacionais (em nível do profissional, da equipe ou da organização). Por isso, as empresas e as Universidades Corporativas se interessam em identificar aspectos que expliquem a maior ocorrência desta transferência de aprendizagem.

Abbad, Pilati e Pantoja (2003) situam transferência sob a ótica da organização, indicando escopo bem definido de todas as implicações dos investimentos em treinamento e recuperação de capital em resultados. Esses podem ser refletidos em produtividade, lucro, eficácia operacional, imagem, clima e outros. No entanto, todo o processo de TD\&E, desde a identificação das lacunas de competências até a avaliação dos resultados, é complexo e composto por uma vasta série de variáveis e fatores que influenciam essa cadeia de eventos. $\mathrm{O}$ estudo de transferência está inserido, especificamente, na sequência de eventos de treinamento, como na Figura 3.

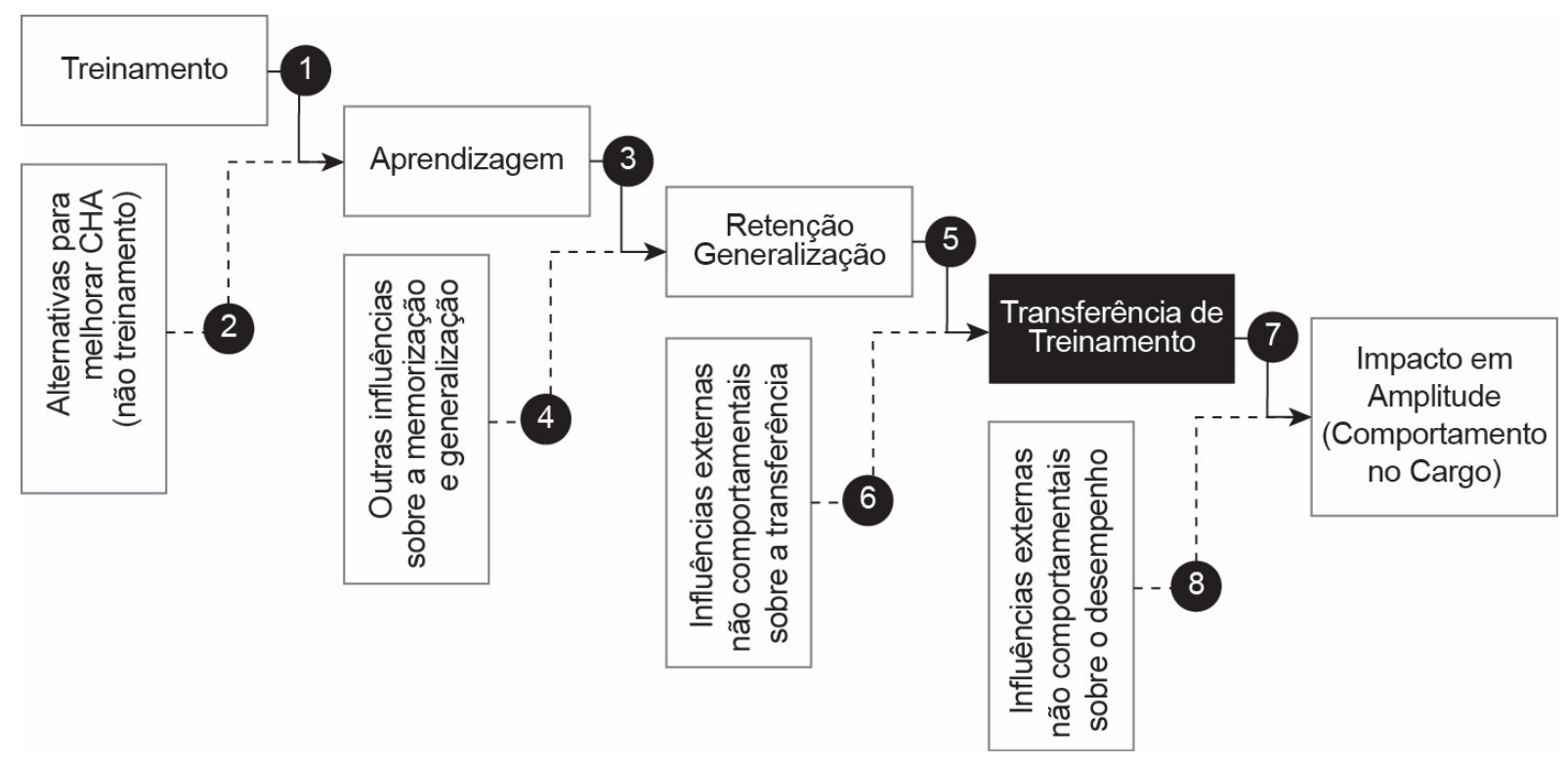

Figura 3. Representação esquemática das relações entre treinamento e resultados.

Fonte: Taylor e O'driscoll (1998), conforme citado em Abbad, Mourão et al. (2012). 
Para seu estudo devem ser observadas as implicações de seus eventos precedentes e causadores, bem como aqueles subsequentes e resultantes que darão impulso aos outros elos da cadeia.

Eduardo Salas afirma no prefácio do trabalho Treinamento, Desenvolvimento e Educação em Organizações do Trabalho (Borges-Andrade et al., 2006), diz:

A ciência do treinamento, representada em parte neste volume, procura compreender as condições que facilitam a aquisição de habilidades e a transferência do treinamento ... criar ambientes de aprendizagem que promovam a aquisição de habilidades e o desenvolvimento de conhecimento, assim como facilitem a transferência de habilidades para o trabalho.

O trecho ilustra bem a importância do fenômeno estudado, situando-o em local central no estudo de TD\&E.

Conforme Cheng e Hampson (2008), não importando a maneira pela qual o conhecimento (ou resultados de aprendizagem) é adquirido, ele tem que ser transferido para o trabalho, ou de um trabalho para o outro, e essa decisão está a cargo do aprendiz. Esse fato valida o o estudo da transferência de treinamento. Tendo em vista que este estudo tem como uma de suas preocupações, a variável transferência de treinamento, é necessária uma busca pela precisão no entendimento deste fenômeno, que tem início na compreensão do termo. Para isso, será feita uma discussão a fim de delimitar do que se trata em um dos temas essenciais deste estudo. A importância do debate é expor a existência de alguma sobreposição, ou confusão entre os termos utilizados para a descrição do mesmo fenômeno. Por fim, o debate é encerrado com a adoção de uma definição já bastante utilizada nos trabalhos acadêmicos e pretende dar respaldo a essa decisão.

Abbad (1999) discute o uso do termo transferência com o objetivo de se delimitar melhor o conceito, visto que várias definições vem sendo utilizadas para descrever o mesmo fenômeno. As terminologias utilizadas para essas definições são: transferência de aprendizagem, transferência de treinamento e impacto do treinamento em profundidade - em algumas leituras, o uso do termo transferência, usado isoladamente parece ser suficiente. Uma das razões possíveis para os diferentes conceitos é o campo de conhecimento no qual se desenvolveu o conceito (psicologia experimental e psicologia organizacional, por exemplo). 
Para efeitos de avaliação, que é o foco da autora, a imprecisão do conceito pode induzir a interpretações diferentes e produzir distorções nas medidas de avaliação.

É um conceito dual, que envolve as noções de desempenho e motivação. A literatura mostra que as diferenças não se extinguiram, permitindo o convívio dos conceitos. No entanto, a realidade, com novas formas de capacitação, desafia e pressiona os estudiosos por definições mais claras e precisas. No caso de e-learning e do m-learning, mais especificamente, a transferência poderá ocorrer simultaneamente à aquisição, ou recuperação, de um conhecimento, o que ameaça as definições em uso, em sua construção logicamente e cronologicamente encadeada. Neste caso, a aprendizagem, o impacto e a transferência poderão se dar na mesma ocasião, na mesma ação.

A primeira limitação a ser destacada é o campo onde o termo se define, que neste caso é a psicologia. Dadas as frequentes e consistentes discussões sobre definições em qualquer área e praticamente sobre quase todos os termos, vale mais ter-se uma ideia clara do que aquele termo distingue, delimita, ou classifica, conforme destacado em Abbad (1999), do que pode representar a ideia e isso depende do contexto aplicado. No entanto, como já abordado, quando se fala em avaliação, medidas e dados objetivos, a precisão se faz necessária.

A autora afirma que, na expressão transferência de aprendizagem, o termo transferência vem sendo usado no sentido metafórico de transporte, movimentação, deslocamento de habilidades, capacidades e atitudes da situação de treinamento para a situação de trabalho. Falar de transferência de aprendizagem, nesse contexto é dizer algo semelhante a: "é como se habilidades, capacidades, atitudes elou conhecimentos fossem transportados ou carregados do treinamento para o ambiente de trabalho". O texto denota que a definiç̧ão de transferência, puramente, não satisfaz plenamernte o entendimento da ideia, caso contrário, não caberia especulação acerca da denominação. O termo tranferência, neste contexto, assemelha-se ao seu uso, por exemplo, em tranferência de tecnologia (como aqueles que são previstos em alguns acordos internacionais), cujo uso também é metafórico, visto que transferência, em seu sentido mais direto, significa retirar algo de algum lugar e colocar em outro. 
Segundo o dicionário Michaelis, ${ }^{11}$ transferência significa ação ou efeito de transferir ou de ser transferido, ato pelo qual se declara ceder a outrem a propriedade de uma renda, título etc., deslocamento de funcionário, ou empregado, para outro quadro, cargo ou carreira, troca, permuta. No entanto, nas duas acepções (aprendizagem e tecnologia), o termo representa multiplicação, replicação, espelhamento. O termo aplicação, utilizado nos conceitos constitutivos dos três termos postos em debate, é mais esclarecedor pois significa emprego, uso, que claramente expõe uma utilidade para aquele conhecimento ou competência. Com relação ao termo impacto, o mesmo dicionário apresenta dois conceitos concomitantes para o termo: o primeiro como empurrado, impelido contra, metido à força. Nessa acepção, pode haver alguma confusão com a definição de transferência.

No entanto, o significado mais comum em língua portuguesa é o conceito de choque, embate, encontrão, choque de um corpo em movimento com outro em repouso, choque emocional; expectativa..." O termo choque significa nitidamente efeito, em contraposição a processo, ação. Em resumo, boa parte da imprecisão pode ter origem na ambiguidade do termo em português. No dicionário Merriam-Webster, ${ }^{12}$ o significado da palavra impact é to have a strong and often bad effect on, to hit with great force (ter um forte e ocasionalmente ruim efeito sobre, bater com grande força). Nessas definições, como outras em inglês, não surge a ideia de movimento em direção de algo. A referência é sempre de efeito.

Nas pesquisas estrangeiras, os termos mais utilizados são transferência de aprendizagem ou transferência de treinamento, que se assemelha ao conceito de impacto em profundidade, no Brasil, embora nas revisões o termo mais encontrado seja transferência de treinamento (transfer of training). Este refere-se especificamente às tarefas executadas com relação aos conteúdos ensinados no programa de treinamento. Dessa forma, o conceito de transferência está descrito como aferição do que foi aprendido no curso e aplicado de forma eficaz no trabalho. A literatura mostra que as diferenças ainda não se extinguiram, permitindo o convívio dos termos, embora perceba-se uma tendência à utilização de transferência de treinamento, como em Pereira (2009) e Santos Junior (2012).

\footnotetext{
${ }^{11}$ Consultado em http://michaelis.uol.com.br/moderno/portugues/index.php?lingua=portuguesportugues\&palavra=transfer\%EAncia, em 01/10/2015.

12 Consultado em http://www.merriam-webster.com/dictionary/impact em 20/10/2015.
} 
As palavras-chave relacionadas ao tema utilizadas na busca de Abbad, Pilati e Pantoja (2003) foram: training impact at work, transfer of training, outcomes of training, results of training, training and development, support (climate) to transfer. Não há menção de tranfer of learning tanto na busca quanto nos resultados. Aguinis e Kraiger (2009) utilizaram os termos training benefits, training design, training delivery e training evaluation em sua revisão de literatura em Treinamento e Desenvolvimento. Novamente, o termo transfer of learning não surge. Os autores definem transferência de treinamento como "a extensão na qual novos conhecimentos e novas habilidades aprendidas durante o treinamento são aplicadas ao trabalho".

Santos Junior (2012) utiliza, em sua revisão sobre avaliação, os termos avaliação de treinamento (training evalutation), impacto de treinamento (training impact) e transferência de treinamento (transfer of training) e ainda training outcomes. Nos 23 trabalhos em âmbito nacional elencados pelo autor, 8 apresentam como variável critério impacto do treinamento no trabalho (medido em profundidade), 3 apresentam impacto do treinamento no trabalho (sem especificação), 1 apresenta transferência de aprendizagem, 1 transferência do aprendido, 1 transferência de conhecimentos e 1 transferência de treinamento.

No levantamento da literatura estrangeira, o autor selecionou 12 trabalhos que usaram a variável transferência de treinamento. Desses, 9 utilizam esse termo ipsis litteris. Os outros usam terminologia similar, como efetividade do desenvolvimento gerencial e outros. Abbad et al. (2012) afirmam que o conceito transferência de treinamento pode ser definido como: aplicação eficaz, no contexto de trabalho, de conhecimentos, habilidades e atitudes adquiridos durante ações instrucionais. Ou seja, mudanças na forma de desempenhar atividades de trabalho. Essa definição está baseada nos trabalhos de Ford e Kraiger (1995) e Baldwin e Ford (1988) e já foi exposta na introdução deste estudo.

Este último condiciona a transferência de treinamento a dois fatores: a) generalização do que foi aprendido na situação de treinamento ao trabalho e b) retenção - preservação das habilidades adquiridas por um período de tempo. Em Pilati e Abbad (2005) p. 44, o termo transferência de aprendizagem está definido como: "transferência de aprendizagem pode ser definida como a aplicação eficaz no trabalho dos conhecimentos, habilidades e atitudes adquiridos em treinamento". 
Generalização é o primeiro processo decorrente do treinamento já no ambiente de trabalho. Nele, o treinando deverá reconhecer situações análogas àquelas vivenciadas no treinamento e nas quais poderá, por fim, aplicar os conhecimentos, habilidades e atitudes adequadas. É considerada por Baldwin e Ford (1988) como condição para que a transferência ocorra. Borges-Andrade et al. (2006) afirmam que, em psicologia experimental, os conceitos de generalização e transferência de aprendizagem são correlatos.

Abbad, Mourão et al. (2012) afirmam que a transferência é medida pelo grau do impacto do treinamento sobre o comportamento no cargo do egresso, determinado como impacto em profundidade. Afirmam que impacto é o efeito direto da transferência de treinamento, enquanto a transferência é decorrência direta do treinamento. Os autores afirmam que as competências, se aplicadas eficazmente, podem produzir impactos no trabalho e nos resultados da organização. A importância dessa colocação é o estabelecimento claro da cadeia de eventos (aquisição dos CHA, aplicação desses CHA, impacto nos processos e impacto nos resultados), bem como alerta para as condicionantes do processo. Vale dizer que a transferência (ação) é um fenômeno imanifesto (processo psicológico), enquanto o impacto (resultado, efeito) é a realização e, portanto, manifesto, objetivamente presente e observável. A transferência é portanto observada pelo impacto no trabalho, promovido pela alteração do comportamento no cargo do treinando.

Nas pesquisas brasileiras, ainda segundo aqueles autores, o termo mais frequentemente usado para a definição de transferência de treinamento é impacto do treinamento no trabalho, visto estar apoiado no modelo de Hamblin (1978) no nível do comportamento do cargo. Esse conceito não pode ser aplicado a treinamentos abertos, nos quais não é possível se verificar o comportamento no cargo, porém aplica-se a qualquer modalidade de treinamento: presencial, a distância ou híbrida (blended).

Em Borges-Andrade et al. (2006) e Zerbini e Abbad (2010), está proposta uma distinção entre eventos dentro e fora de um ambiente corporativo dado (ou o que o valha), quando se fala em instrumentos de medida: impacto em profundidade e transferência de treinamento, respectivamente. No entanto, Santos Junior (2012), em sua revisão, localizou um trabalho nos EEUU e Portugal (Velada, Caetano, Michel, Lyons e Kavanagh, 2007) que realizou mensuração de transferência de treinamento em contexto corporativo, ou Pereira (2009), que utiliza a mesma variável critério em contexto similar. Desse modo, fica reforçado 
o uso não consensuado da terminologia. A diferença reside na decisão dos instrumentos e medidas, visto que os resultados, embora da mesma natureza, sejam medidos de modos específicos.

A Figura 4 situa a transferência na cadeia de eventos de um treinamento. Todas as etapas estão sujeitas a variáveis externas ao treinamento que têm influência sobre os resultados de cada etapa. Nesse caso, transferência de treinamento confunde-se com impacto em profundidade, ou impacto do treinamento no trabalho.

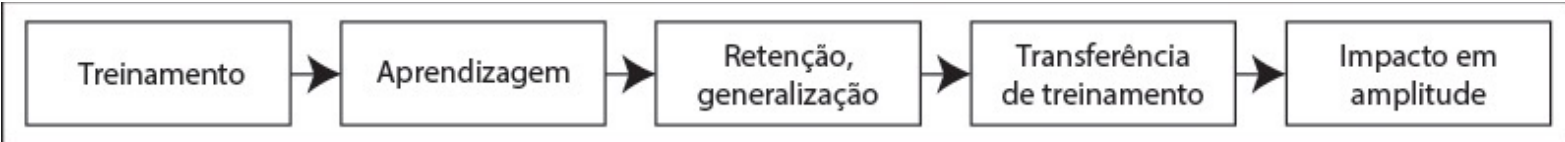

Figura 4. Esquema dos eventos de treinamento.

Fonte: adaptado de Abbad, Mourão et al. (2012).

A Figura 5 apresenta a cadeia de eventos do processo de aprendizagem modelado por Pilati e Abbad (2005).

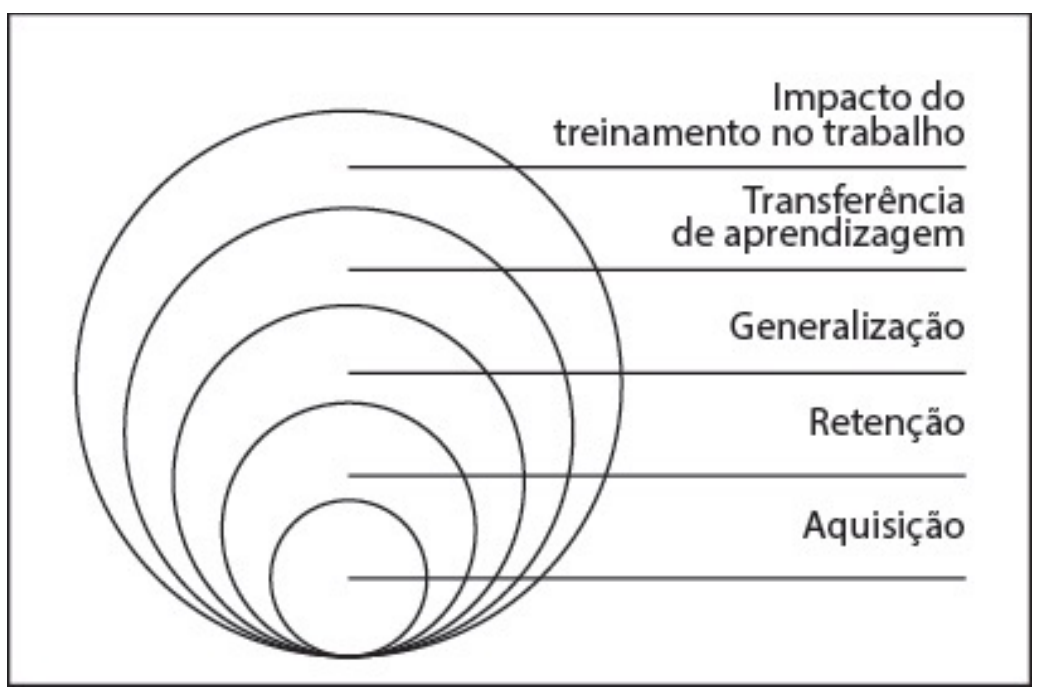

Figura 5. Esquema dos eventos instrucionais.

Fonte: adaptado de Pilati e Abbad (2005).

O modelo é definido pelos autores, no trabalho citado retro, como modelo conceitual de impacto do treinamento no trabalho e construtos correlatos. Em Abbad, Mourão et al. 
(2012), o mesmo modelo é descrito como características do sistema psicológico aprendizagem considerando os eventos instrucionais em Psicologia Organizacional do Trabalho. Dessa forma, o mesmo modelo aplica-se a duas abordagens similares, que diferem entre si em nuances.

O termo impacto do treinamento no trabalho refere-se ao impacto em amplitude, ou seja, não referente especificamente aos objetivos instrucionais e é definido por Abbad (1999) como a mudança duradoura no desempenho do treinado, proporcionada pelo treinamento e corresponde ao impacto em amplitude de Hamblin.

As definições de transferência de aprendizagem e transferência de treinamento são correlatas, conforme relatado, e ambos apropriados de Baldwin e Ford (1998). Desse modo, pode-se entender que há uma questão meramente arbitrária na construção dos diagramas, que levam em consideração a intenção dos autores e os contextos de análise (psicologia experimental e psicologia organizacional). Para efeitos deste estudo, como já mencionado, o termo adotado será transferência de treinamento.

Posto e arbitrado, portanto, o conceito de transferência, a discussão abre novos horizontes quanto ao processo de treinamento, quando uma nova realidade se apresenta, com o surgimento de novas formas de acesso e novos recursos de treinamento baseados em tecnologia, produzindo novas variáveis e interferindo no processo de aprendizagem e possibilitando novos desenhos instrucionais. Esses desenhos já levarão em conta novas formas de interação com conteúdos e flexibilização/reinterpretação dos processos aquisição, retenção e transferência, conforme modelo de Pilati e Abbad (2005) e, portanto, interferir no processo de transferência de treinamento.

No caso das modalidades de e-learning e m-learning a transferência poderá ocorrer simultaneamente à aquisição, ou recuperação, de um conhecimento, o que flexibiliza os modelos em uso em sua construção lógica e cronologicamente encadeada. Neste caso, a aprendizagem, e a transferência poderão se dar na mesma ocasião, na mesma ação.

Nos casos de manuais técnicos, por exemplo, um profissional pode ter acesso a um tutorial de substituição de uma peça de máquina. Certamente terá que possuir algumas competências fundamentais ou básicas, tais como a operação de ferramentas, mas no que se refere ao reparo, é possível que a tarefa seja executada sem aprendizagem específica prévia. 
O indivíduo poderá passar pela etapa de aquisição, por meio do conhecimento da operação, com o apoio de imagens e animação e/ou mensagens sonoras, e da compreensão (as duas na esfera de aquisição), podendo também lançar mão de mecanismos de ajuda ou buscar em redes outros conhecimentos, ou experiências, que o ajudarão a ter uma ideia consistente da operação (na esfera da generalização).

A etapa de retenção poderá, dependendo do processo, ser reduzida significativamente, dado o farto acesso a dados e informações, que podem ser recuperadas instantaneamente. Poderá, ainda, ocorrer naturalmente pela repetição do processo. A transferência de treinamento poderá, a juizo do operador, ser realizada in loco, ou em momento posterior, como tradicionalmente.

O fato de se estabelecer um novo parâmetro no treinamento, como no caso deste estudo, poderá trazer resultados não esperados, visto que a interferência desse se dará em treinamento com relativo grau de complexidade (o método detalhará esse item).

A transferência, aqui, deverá se dar de modo lateral, em relação ao que se espera do aprendiz, ou seja, a aplicação análoga dos conceitos aprendidos, visto que o processo de trabalho (refletido no "desempenho esperado no trabalho"), envolve geralmente análise e aplicação de conceitos e regras para solucionar problemas. Segundo Gagné (1977) e Royer (1979), é positiva quando facilita o desempenho, negativa, quando o dificulta, ou ainda neutra, caso não interfira no desempenho do aprendiz no cargo. Gagné (1965) também classifica a transferência como lateral ou vertical, sendo a primeira referente à aplicação do aprendido em situações similares àquelas do evento de aprendizagem e a segunda, quando o aprendido é utilizado para a realização de tarefas mais complexas do que aquelas aprendidas.

A Figura 6 mostra a relação de variáveis testadas em relação à transferência de treinamento. $\mathrm{O}$ fracionamento da etapa de transferência visa separar o que é um processo interno, psicológico, de outro externalizado, manifestado e observável. Justifica a escolha de novo modelo de avaliação baseado em testes situacionais, por meio do qual, o primeiro processo detectável de aplicação do aprendido pode ser observado. A opção tem fundamento nos significados claramente distintos entre transferência e impacto. 


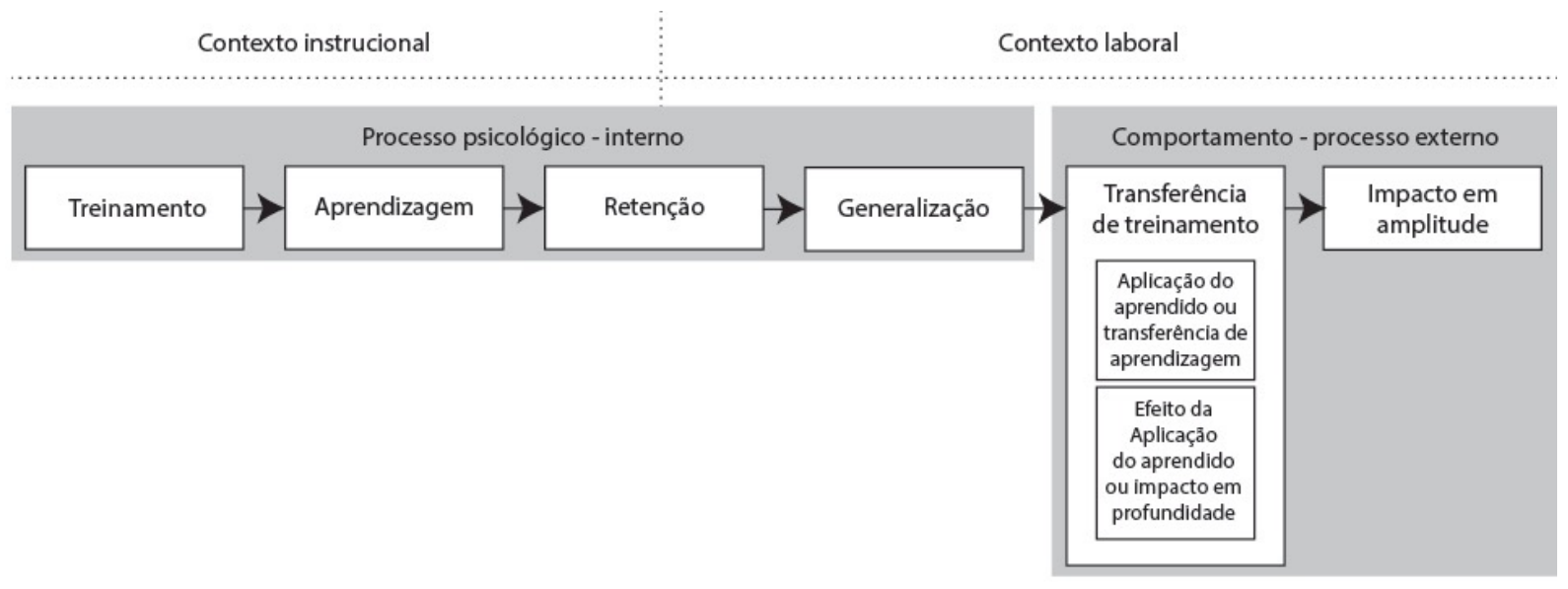

Figura 6. Modelo sugerido para acomodação dos dois fenômenos presentes na transferência do treinamento.

Fonte: pesquisa.

O modelo proposto, representado na Figura 6 aproxima-se daquele representado no Modelo Integrado de Avaliação e Efetividade de Treinamento (Integrated Model of Training Evaluation and Effectiveness - IMTEE), representado na figura 7, sendo que, nesse modelo, à etapa de transferência de treinamento, segue-se a de impacto em amplitude.

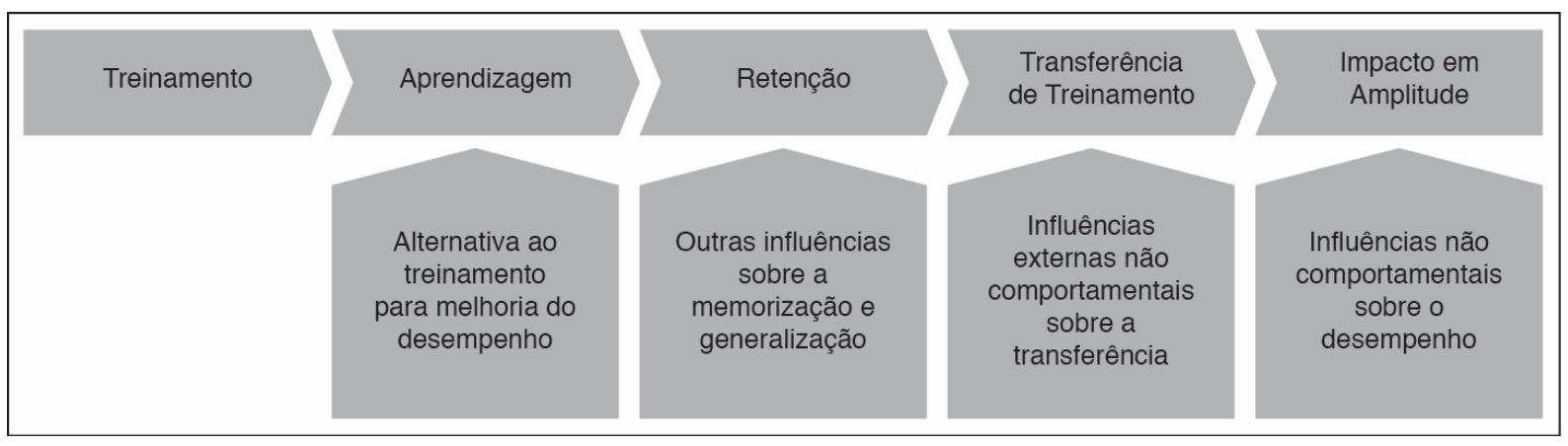

Figura 7. Modelo IMTEE.

Fonte: adaptado de Zerbini, Coelho Jr., Abbad, Mourão, Alvim, Silvana e Loiola, E. (2012).

$\mathrm{Na}$ revisão de literatura realizada por Blume et al. (2009), os autores evidenciam o caráter dual do fenômento estudado, quando dizem que a transferência de treinamento tem sido medida como o uso de um conhecimento ou habilidade e a efetividade na aplicação do aprendido (habilidade ou conhecimento) pelo egresso. Para efeitos deste estudo, a importância dessa distinção reside no isolamento de um conjunto de variáveis que têm influência sobre a efetividade, ou resultados objetivos no trabalho. Essas variáveis escapam dos interesses deste 
estudo. Dessa forma, se o aprendizado trouxe bons resultados, deverá trazer reflexos no trabalho de duas naturezas: capacidade de reconhecer onde e como aplicar o aprendido e a produção de resultados mensuráveis de desempenho, como metas e outros.

Algumas dicas nos mostram também que o caráter avaliatório está presente em algumas das definições de transferência de treinamento, com em Abbad (2006) "o quanto novas aprendizagens...”. Na definição de Baldwin e Ford (1978), consta “...the degree to which trainess apply..." Ou seja, o grau em que os treinandos aplicam, os CHA. Em Aguinis e Kraiger (2009), a terminologia é “...the extent to which new knolwledge... are apllied to the job”. As três definições denotam que a manifestação do aprendido está expressa por uma medida. Dessa forma, o conceito de transferência está atrelado, em essência, ao conceito de avaliação, visto que a avaliação é ação sobre o resultado do fenômeno, de modo que existem de modo recíproco e interdependente. Ainda no trabalho de Borges-Andrade et al. (2006), em quadro de definições, os autores ressaltam na definição de transferência de treinamento a sentença: “... e é definida, para fins de mensuração, como aplicação eficaz...” Essa observação cabe como ressalva, dado que o conceito para este trabalho já está definido.

Dessa forma, são estabelecidos os parâmetros para o tratamento da transferência de treinamento no âmbito deste trabalho. Claramente, a etapa sofre influência de diversos outros fatores e variáveis relacionadas ao indivíduo, ao contexto e às características do treinamento. No entanto, o intuito desta abordagem é aparar arestas com a finalidade de buscar a melhor forma de compreender o processo de transferência de treinamento.

\subsection{Avaliação}

A partir da década de 1960, McGehee e Thayer, Scriven, Kirkpatrick e Hamblin (1978), iniciam estudos que deram origem à modelos de Avaliação de Necessidades de Treinamento e Avaliação de Resultados de Treinamentos. No Brasil, Borges-Andrade (1982) propôs o Modelo de Avaliação Integrada e Somativa (MAIS). O Modelo CIPP, de Stufflebeam, de 1978, assim como o MAIS, inclui na avaliação , além dos resultados ou produtos do treinamento, variáveis de contexto, exógenas ao treinamento, e os processos de ensino-aprendizagem. Esses modelos de avaliação de treinamento propõem avaliação 
somativa, que integra análise de relações entre variáveis antecedentes e consequentes ao treinamentos.

Nos modelos clássicos de Kirkpatrick, de 1976, e Hamblim de 1978, são enfatizadas as relações entre os resultados de treinamento (4 níveis: reações, aprendizagem, transferência ou comportamento no cargo, resultados - mudança organizacional e valor final) e pouco exploradas as relações entre esses efeitos do treinamento com os processos de ensinoaprendizagem e o contexto do treinamento. Entretanto, outras pesquisas, incluindo Abbad, Gama e Borges-Andrade (2000), não confirmaram relações positivas entre os resultados de treinamentos, apontando, por exemplo, que a aprendizagem é condição necessária, mas insuficiente para a transferência positiva de treinamento para o trabalho, um dos principais resultados esperados pela organizações que investem em capacitação de pessoal (Tamayo e Abbad, 2006; Carvalho e Abbad, 2006 e Gonçalves e Mourão, 2011).

Segundo Hamblin (1978), muitas vezes não podemos avaliar o treinamento porque não é uma atividade isolada. Associa diretamente treinamento a desempenho e cria a ideia de desempenho global, baseada em sua integração com outras atividades. O autor define avaliação de treinamento como "qualquer tentativa no sentido de obter informações sobre os efeitos de um programa de treinamento e para determinar o valor do treinamento à luz dessas informações (Hamblin, 1970, página 21, conforme citado em Hamblin, 1978)”. Ressalta a importância da precisão e capacidade de mensuração dos objetivos do treinamento. No modelo de Hamblin, esse efeito do treinamento se manifesta no nível comportamento no cargo, encadeado a partir do nível aprendizado. Em termos de avaliação, a transferência de treinamento para o trabalho encontra-se nesse nível.

O modelo avança em relação aos modelos de Kirkpatrick, de 1967, e Warr, Bird e Rackham, de 1970, embora seja muito similar ao de Kirkpatrick, do qual difere, entre outros aspectos, na divisão do nível resultado em dois outros: organização e valor final. Desse modo, os autores posteriores usarão um modelo comumente conhecido como de Hamblin e Kirkpatrick. Hamblin (1978) autor ressalta, entretanto, que há que se estabelecer também com precisão o que é esperado em termos desse comportamento no cargo e seus efeitos. Dessa forma, o treinamento produzirá mudança no comportamento, que terá efeitos sobre o que é produzido. Pode-se estabelecer dois conceitos distintos: mudança de comportamento do 
egresso no cargo e seu efeito, que deverá implicar melhoria de resultado de alguma natureza. Fala o autor da dificuldade em se medir esses efeitos.

Devido à falta de sustentação empírica dos modelos clássicos de avaliação de treinamentos e com base no Modelo MAIS, Abbad (1999) propôs o Modelo Integrado de Avaliação do Impacto do Treinamento no Trabalho - IMPACT, descrito na Figura 8, que integra os níveis de avaliação de reação, aprendizagem e impacto dos modelos clássicos a variáveis externas aos procedimentos instrucionais, como percepção de suporte organizacional e outras. Esse modelo associa variáveis preditoras às variáveis critério, está fundamentado em uma análise teórica multinível, e avalia as variáveis no nível dos indivíduos, incluindo transferência de treinamento para o trabalho. O modelo tem grande pertinência ao estudo de mobile learning, visto estudar correlacionadamente e integrar um amplo espectro de variáveis relativas ao processo de transferência. Alguma adaptação será necessária para que contemple os modelos móveis, como, por exemplo, a inclusão de uma perspectiva dedicada a variáveis ambientais de modo mais amplo.

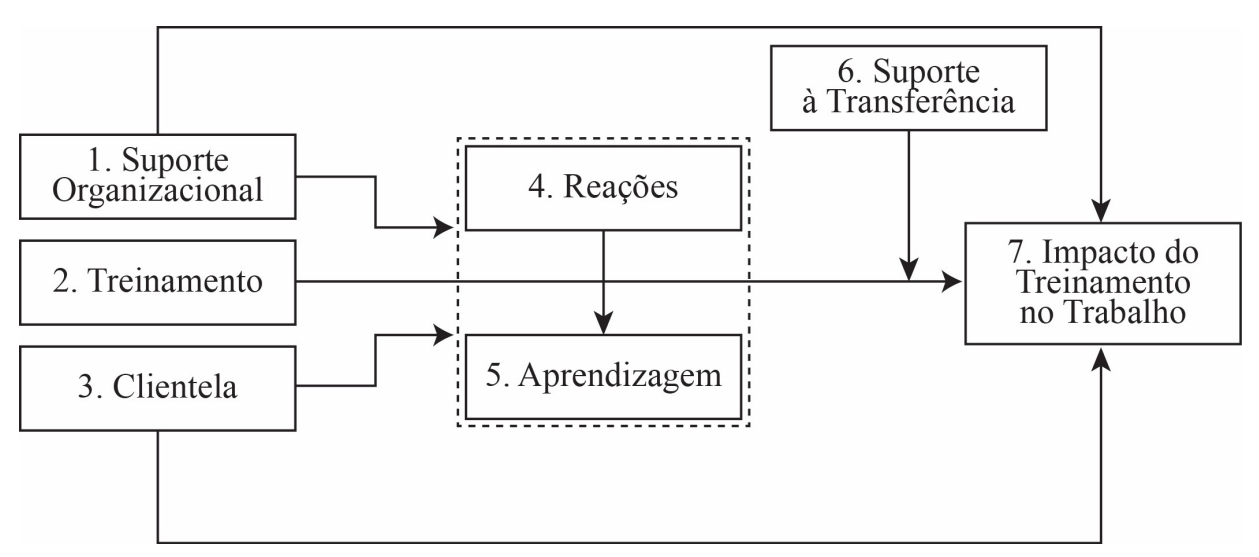

Figura 8. Representação do modelo Impact, conforme Abbad (1999)

A mensuração de aprendizagem em organizações e trabalho envolve (ou deveria envolver) avaliação da generalização dos CHAs aprendidos no treinamento, mas, em grande parte das vezes, mede apenas aquisição e retenção de CHAs intermediários e/ou incompatíveis com a natureza ou grau de complexidade dos objetivos de ensino (Borges-Andrade et al., 2006, p. 471). 


\subsection{E-learning e m-learning}

A distribuição e acesso maciços a conteúdos mudou a configuração dos programas de capacitação das organizações, que passaram a investir largas quantias de recursos financeiros para desenvolvimento de programas dessa natureza. O rápido avanço dos computadores (desempenho, armazenamento e acesso), associado a grandes ofertas de banda de tráfego de dados por meio de linhas telefefônicas fixas, ou móveis, ou ainda sistemas de rede, como wifi e bluetooth, permitiu um grande avanço nos modelos com ações mediadas por tecnologia, especialmente em ambiente web.

Até o momento, não há uma definição mais precisa do que se classifica como $e$ learning, como já visto. Alguns trabalhos, como Zerbini (2007) e Mourão et al. (2014), colocam o treinamento avaliado como "mediado pela Internet" ou "realizado pela Internet", evitando, assim, alguma possível imprecisão semântica. A Internet aqui refere-se à estrutura física e seus protocolos respectivos (formatos específicos de dados usados para tipos específicos de arquivos). O termo "e" é vulgarmente atribuído ao contexto web, mas originalmente, provém do termo "eletronic learning", indicando o uso de computadores para o ensino/aprendizagem e associado à Internet. A observação deve-se ao fato de que aparelhos móveis guardam algumas diferenças para os computares tradicionais (desktop e laptop) e operam com formatos próprios de informação e conteúdo. Dessa forma, a adoção da perspectiva de m-learning como um espaço dentro do e-learning é de efeito prático e refere-se mais ao modo de utilização e operação, aproximando-se do que seria a opção pela noção de eletronic learning, do que uma definição precisa. O assunto ainda será discutido no decorrer deste trabalho.

A criação de um corpo teórico para o e-learning é necessária para a compreensão e avanço desse campo de estudo. A opção por esse modelo e o crescimento da oferta de formatos (Ambientes Virtuais de Aprendizagem - AVA, livrarias, blended, mobile e suas combinações) demanda um conjunto de saberes que estão em tempos de construção. $\mathrm{O}$ mesmo vale para o mobile learning, ainda mais incipiente. Driscoll (2002) afirmou que a educação online (web-based training) é uma poderosa ferramenta, embora superestimada pelas organizações. Apesar da distância no tempo haver produzido diferenças significativas no meio de prover esse tipo de educação, os conceitos-chave de distribuição e mediação por 
dispositivos informáticos, com base em conteúdos digitais, continuam válidos. Ainda, segundo os autores, o modelo tem como vantagem a entrega, em âmbito mundial, conteúdos de forma consistente, tempestiva e de qualidade. Outra vantagem apontada é a resposta a ciclos de produtos mais curtos, visto que é uma forma mais ágil de ofertar treinamento.

A diferença fundamental entre os sistemas presencial e a distância é a forma de interação, que no caso presencial requer instrutor/educador e aprendiz interagindo presencialmente face-a-face. O modelo blended (muitas das referências estudadas aqui mostram utilização combinada de m-learning com outros tipos de ações, aproximando os conceitos), que propõe contemplar as duas formas (presencial e a distância), conforme Graham e Dziuban (2003), possui três vantagens: melhorar a eficácia da aprendizagem, aumentar a capacidade de acesso e melhorar a relação custo-beneficio e reportam que evidências seguras das vantagens apresentadas, dependendo, obviamente, do contexto e das variáveis envolvidas em cada caso. Pode-se entender que, afora a primeira, que refere-se diretamente à posição de apoio, as outras duas aplicam-se aos outros sistemas não presenciais, particularmente os apoiados em tecnologia informática, dadas suas capacidades de distribuição e acesso. Também, os autores, em 2008, afirmaram que em termos de satisfação dos estudantes, os fatores mais importantes são: conveniência, flexibilidade e redução de custos. No entanto, é possível que esses fatores possam ser extrapolados para os modelos a distância, sem composição com atividades presenciais. Os impactos no corpo docente são igualmente favoráveis ao modelo. É necessário também, de acordo com o estudo, que a relação entre instrutor/educador seja repensada a fim de transformar essa combinação em uma estratégia (ou ambiente) de aprendizagem mais ativa. Os autores afirmam que há um número grande de possibilidades nessa modalidade.

O m-learning, assemelha-se a uma evolução do e-learning. Talvez porque ambos estejam baseados em recursos mediados por tecnologia e possuam algumas similaridades, principalmente na linguagem das interfaces digitais. No entanto, pode-se perceber, pelos estudos localizados, que m-learning tem natureza muito particular e distinta do e-learning. Segundo Tan, Ooi, Leong, L-Y e Lin, B. (2014), m-learning é diferente de e-learning, visto que a diferença entre usar um dispositivo em um ambiente de acesso que necessita conexão física com a Internet (com fios) e outro cuja conexão se dá sem fio (wireless) é significativa. $\mathrm{O}$ estudo aponta três grandes vantagens do m-learning em contraposição ao e-learning: 
conveniência, colaboração e diversão (destaque para esse último, que será discutido posteriormente), além do tamanho e portabilidade, podendo ser carregado conforme a conveniência do usuário. Essas diferenças são importantes em termos de modelos de capacitação, visto abrirem um vasto leque de possibilidades de combinações e modelagens.

Os dispositivos móveis são o "hardware" da tecnologia móvel, se buscarmos uma comparação com os computadores tradicionais. São eles basicamente o telefone celular, do tipo smartphone, e os tablets. Apesar de outros aparelhos estarem inscritos na mesma categoria (lap tops, personal digital assistants - PDA, aparelhos de jogos e outros), para efeitos deste estudo, as análises serão predominantemente referentes aos modelos indicados com o objetivo de se ganhar em foco e evitar digressões sobre a classificação dos aparelhos, tarefa bastante complexa e que não implicará ganhos reais no estudo. Há uma tendência de convergência para os smartphones. Para um estudo que preveja ações em mobile, é importante também a observação das variáveis de contexto, levando-se em conta que ao permitir que o usuário acesse os conteúdos teoricamente em qualquer circunstância, ele estará sujeito a fatores diversos no momento do consumo dos objetos pretendidos.

A posse do aparelho é um fator a ser considerado, visto que há uma tendência a esse respeito chamada bring your own device, ou BYOD (trazer seu próprio dispositivo, em tradução livre do autor), que exprime que esse tipo de aparelho é usualmente adquirido pelo próprio usuário, que o acompanha usualmente por boa parte de suas atividades. No cenário corporativo, é prática a cessão de aparelhos móveis (smartphone, tablet) para alguns cargos. Essa condição está presente na organização estudada, que disponibiliza esses dispositivos aos funcionários para uso em serviço. A cessão do aparelho é feita pelo critério de cargo. Dessa forma, se a ação educacional estiver voltada aos públicos contemplados, temos um cenário adequado, caso contrário, é possível que sejam geradas situações de exclusão, ou ainda alguma outra distorção, visto que os que estão em cargos de menor representatividade administrativa terão que usar seus próprios aparelhos, o que pode apresentar riscos de segregação.

A evolução dessa categoria de equipamentos é marcada por alguns atributos/funções importantes: tecnologia touch screen (tela sensível ao toque), comunicação gestual multifunção (clicar, arrastar, pinçar e outros), dimensão das telas - que já estão em patamares mais aceitáveis, mas ainda se aproximam de 1/4 de uma página A-4, no caso dos smartphones 
-, qualidade das telas, inclusão de câmeras nos aparelhos, acesso sem fio (wi-fi, bluetooth), acesso via rede telefônica $(2 \mathrm{G}, 3 \mathrm{G}, 4 \mathrm{G})$, capacidade de processamento e armazenamento, desenvolvimento da filosofia de aplicativos (app) e ainda outras que surgem com variedade e velocidade incríveis. A identificação biométrica por reconhecimento da impressão digital é um exemplo bastante recente.

Recursos oferecidos pelos dispositivos móveis - imagens, textos, som, animação, interatividade, integração de aplicativos e conteúdos, avisos do tipo push (mensagens curtas enviadas ao usuário do telefone), mecanismos de bate-papo e correio eletrônico são os exemplos mais comuns. Desse modo, não é possível comparar as possibilidades de um aparelho de telefone celular fabricado em 2005 com outro produzido em 2010, devido, tanto à inclusão de recursos, quanto à melhoria no desempenho das tarefas demandadas, inclusive em relação a fatores externos ao dispositivo, como as bandas de acesso.

Jeng, Wu, Huang, Tan e Yang (2010) propuseram uma consolidação dos recursos adicionados aos dispositivos móveis (add ons), conforme a Tabela 10. A listagem, embora não contemple todos os recursos adicionados, pois concentrou-se em aspectos físicos, dá uma excelente ideia do conjunto de possibilidades a serem utilizadas para fins de capacitação. Os recursos apontados estão presentes nos modelos estudados na revisão da literatura respectiva.

\section{Tabela 10}

Add Ons - Benefícios de funcionalidades adicionados aos dispositivos móveis.

\begin{tabular}{lll}
\hline \multicolumn{1}{c}{$\begin{array}{c}\text { Equipamento } \\
\text { adicionado }\end{array}$} & \multicolumn{1}{c}{ Descrição } & \multicolumn{1}{c}{ Objetivo } \\
Conexão à rede sem fio & $\begin{array}{l}\text { Fornece conexão entre os } \\
\text { dispositivos móveis e a Internet }\end{array}$ & $\begin{array}{l}\text { Comunicar-se com servidores de aplicações } \\
\text { remotos que podem trazer informações sobre o } \\
\text { contexto para uso em ambiente de aprendizagem } \\
\text { situada. }\end{array}$ \\
Câmera integrada & $\begin{array}{l}\text { Permite a captura do ambiente } \\
\text { em situação de aprendizagem } \\
\text { móvel }\end{array}$ & $\begin{array}{l}\text { Carga de arquivos de imagem do ambiente } \\
\text { situado para servidor de aplicação. Com esforço } \\
\text { colaborativo, as imagens podem suscitar } \\
\text { discussões e comentários que promovem } \\
\text { conhecimento situado. }\end{array}$ \\
GPS integrado & $\begin{array}{l}\text { Fornece a localização do } \\
\text { dispositivo }\end{array}$ & $\begin{array}{l}\text { Monitorar a posição do dispositivo móvel do } \\
\text { aprendiz e fornecer materiais de aprendizagem } \\
\text { autênticos do local. }\end{array}$ \\
Leitor RFID & Conecta e troca informações com \\
as etiquetas próprias do RFID & $\begin{array}{l}\text { Capturar informações que correspondem à } \\
\text { atividade de aprendizagem e trazer benefícios } \\
\text { em ambientes de aprendizagem situada. }\end{array}$ \\
\hline
\end{tabular}

Fonte: Jeng et al. (2010). 
Há diferenças significativas nas regiões a serem contempladas pelo programa de $m$ learning, indicando diferentes condições de acesso. Diferenças e similaridades nos aparelhos móveis em termos de acesso e navegação também podem interferir no acesso. Todas essas características surgiram em anos recentes, tendo evolução contínua. Hoje, há, também, à disposição dos usuários, o sistema chamado geolocalização (que usa como recurso base o Global Positioning System - GPS), que permite ao usuário se localizar, bem como de alguns sistemas o localizarem, o que gera um diferencial significativo em termos de possibilidades, visto que o deslocamento do usuário é um fator importante para a capacitação ubíqua.

O ambiente, no qual o usuário se encontra, em geral, apresenta grande competição com sons, imagens e outros estímulos e irá variar em termos de nível de controle, visto que podemos ter programas com ações de uso completamente autônomo (fichas de consulta, memoriais, glossários, por exemplo), ou estudos de campo, em fábricas, ou ainda em situações com maior nível de controle, como a utilização de aparelhos móveis em salas de aula ou ambientes educativos como apoio à capacitação, que oferecem maior controle da situação de ensino-aprendizagem.

Levando-se em consideração contexto e recursos, a aprendizagem situada parece um modelo adequado, visto que o aprendiz poderá experimentar objetos de capacitação na própria situação de trabalho. $\mathrm{Na}$ adoção de um novo modelo de oferta em aparelhos móveis, o aplicativo ( $a p p$ ) é fator relevante a ser considerado, visto que difere de formas de acesso tradicionais, mesmo em aparelhos móveis. O disparo de uma funcionalidade é realizado instantaneamente em resposta ao toque no ícone respectivo na tela do aparelho. Um risco à navegação em ambiente mobile é a competição por conteúdos. Nessas circunstâncias, o usuário tem muitos escapes por meio de outros aplicativos vizinhos e com um nível de atratividade muito alto, como os bate-papos virtuais, como o Messenger e o WhatsApp. Os apps aparentemente se estabelecem pelo uso estimulado pela atratividade e utilidade. Um indício desse fato são as múltiplas ofertas de apps que realizam a mesma função, decorrente também do alto grau de autonomia na operação das funções no smartphone. Outro ponto que pode levar à desistência, são aplicativos que não respondem conforme o esperado, conforme o estudo de Gikas e Grant (2013), que mostrarm isso como fator de frustração. 
Muyinda (2007) defende a definição de que m-learning é uma forma de aprendizagem que emprega comunicação sem fio para a distribuição de conteúdos e suporte ao treinamento. Afirma que a maioria dos conteúdos é ainda baseada em formatos para computadores tradicionais. Em 2004, segundo o trabalho, havia 1,5 bilhões de aparelhos no mundo. Em 2013, previa-se que até o final do ano, haveria 2,7 bilhões de usuários ${ }^{13}$.

Driscoll e Carliner (2005) afirmam que m-learning é uma estratégia de entrega, não uma estratégia de aprendizagem. A autora adota essa perspectiva, levando em conta que as potencialidades para aprendizagem por meio dessa mídia ainda não haverem sido descritas. Dessa forma, os conteúdos utilizados forma são referências de outros modelos, em alinhamento com Muyinda (2007). Destaca ainda a importância da definição precisa de termos, que começam por definir o que é "wireless" (sem cabo para transmissão de dados), um dos princípios da mobilidade. Mais precisamente, ainda segundo a autora, mobile learning é aquela aprendizagem que ocorre com dispositivos portáteis que não necessitam de linhas fixas para operar. Podem, no entanto, também operar em modo conectado a uma linha fixa, ou ainda de modo desconectado, com dados previamente gravados.

autores descrevem quatro dimensões de exame do mobile learning: conteúdo, dispositivo, conectividade e colaboração. Os conteúdos devem levar em consideração a forma de uso, predominantemente no trabalho, o que implica um tempo menor de acesso e, por isso, deve ser mais objetivo. Afirma, à época do trabalho, que se e-learning ainda está nos primeiros estágios de desenvolvimento, o m-learning é embrionário. Deve-se levar em consideração o grande avanço da tecnologia desde então, mas não necessariamente o avanço do desenho instrucional. Essa é uma questão para reflexão. O trabalho aponta que nos EEUU mais de 50\% dos empregos eram móveis, sem que o trabalhador estivesse em local fixo, o que aponta, naquela realidade, um bom fator de decisão pela adoção do modelo. Outro fator importante é a massificação de aparelhos móveis.

As estratégias de mobile podem basicamente ser de duas formas: acesso a conteúdos ou comunicação, conforme os autores. Na primeira, o usuário privilegia o acesso a diversas informações, na segunda, o usuário utiliza o aparelho para se conectar com alguém ao vivo ou

\footnotetext{
${ }^{13}$ Acessado em http://g1.globo.com/tecnologia/noticia/2013/02/mundo-tera-mesmo-numero-de-celularesquanto-pessoas-em-2013.html, em 27/03/2015, às 10h32.
} 
via correio, ou similar, como consulta a especialistas, ou tutores, por exemplo. Neste caso, é um suporte ao desempenho. Hoje, há muitas funcionalidades de conversa disponíveis, que já fazem essa utilização, porém, em sua maioria, de modo desestruturado. Os aparelhos móveis podem ainda ser utilizados como e-learning e possibilitarem acesso a conteúdos via web, como os computadores tradicionais.

Essa abordagem aponta diretamente para a utilização de dispositivos móveis em situações de trabalho. A maioria dos exemplos apresentados referem-se a vendas e ao segmento de varejo, no qual muitos produtos são lançados em um curto espaço de tempo e informações sobre eles devem estar disponíveis todo o tempo. Em um cenário de instituições de ensino (podem ser universidades corporativas), os dispositivos podem ainda ser utilizados na própria sala de aula, em eventos presenciais, como suporte ou recurso didático.

Kinshuk, Sutinen e Goh (2003) afirmam que, apesar das vantagens do mobile, essa estratégia ainda não é bastante explorada (há que se levar em conta o ano do texto). Mas é possível se imaginar que face ao volume de aparelhos e suas capacidades, ainda há muito a se percorrer em direção a uma compreensão e disseminação da capacitação móvel. Os autores usam as expressões "stand alone (off line - sem conexão)" e "online (conectado)" para distinguir os tipos de interação mediada. Como fatores positivos, podem ser listados a pequena dimensão e o peso, acesso instantâneo, multiplicidade de conteúdos e preço acessível. Esse último item depende da realidade local, contudo a grande quantidade de aparelhos comercializados leva a supor que há condições para a aquisição em massa desse tipo de aparelho. Como limitações, pequenas telas (smartphones ampliaram recentemente os padrões) e dificuldades de input (digitação e operação da inserção de dados ainda são problemas). No entanto, algumas tecnologias, como os códigos do tipo quick response, ou $Q R^{14}$ codes, teclados virtuais, comunicação gestual, comandos de voz e outros, que independem de digitação, estão mudando essa realidade. À época ainda não havia uma cultura de utilização de apps que se popularizaram posteriormente.

Como limitações, o ritual de estudo é fragmentado (os usuários não se dedicam em períodos de tempo muito longos ao conteúdo em dispositivos móveis) e é necessário o desenvolvimento de metacompetências na utilização dos equipamentos. Essas limitações

\footnotetext{
${ }^{14}$ Quick Response: Imagens, que se assemelham a códigos de barras em duas dimensões, que produzem ações nos aplicativos específicos para essa leitura como abrir um endereço na web, por exemplo, ou acionar uma outra função disponível no dispositivo.
} 
também estão expressas em Driscoll e Carliner (2005). Sob o ponto de vista da organização, as plataformas mobile são de alto custo e a segurança é um item de preocupação, visto que comunicações trocadas por meio sem fio são mais vulneráveis à interceptação. O consumo de banda de dados (capacidade de troca de arquivos, medida por volume) também deverá ser computado para que não haja restrições de acesso não programadas, comprometendo o estudo. Os dispositivos móveis evoluem na medida do mercado de consumo e não pelas demandas educacionais. Desse modo, as tendências que modelam os equipamentos estão baseadas no uso de tais dispositivos para algumas finalidades detectadas pelos fornecedores e fabricantes como necessidades dos usuários, tais como acesso à Internet, acesso a chats, jogos e ainda outros.

Em outras ações de treinamento a distância (EAD), há maior variedade de dispositivos e situações de aprendizagem menos dependentes de qual tipo de recurso estiver sendo utilizado, proporcionando ao método menor centralidade na ocorrência fenômeno. Portanto, o estudo e a compreensão das características técnicas (interface e navegabilidade) e físicas do dispositivo (tamanho, peso e desempenho) são de grande importância, pois suas características é que irão interferir no escopo da ação de aprendizagem em maior ou menor participação dos recursos móveis. Por exemplo, o tamanho e qualidade das telas, bem como o desempenho de acesso (neste caso, mais importante do que a performance de processamento), são decisivas para o desenvolvimento do design instrucional e consequente alcance de objetivos instrucionais e organizacionais.

A Tabela 11 agrupa as características das modelagens de eventos de capacitação em função de potencialidades e vantagens na adoção dos modelos. A organização tem a função de comparação e auxílio nas decisões a serem tomadas pelos profissionais de treinamento ao desenhar a instrução.

\section{Tabela 11}

Associação entre as características das mediações em treinamento.

\begin{tabular}{llll}
\hline & EAD & E-Learning & M-learning \\
Tipos de mídias & $\begin{array}{l}\text { Modelos tradicionais: } \\
\text { impressos, vídeos TV }\end{array}$ & $\begin{array}{l}\text { Computadores do tipo desktop } \\
\text { ou lap top. }\end{array}$ & $\begin{array}{l}\text { Dispositivos móveis: } \\
\text { smartphones ou tablets. }\end{array}$
\end{tabular}




\section{EAD}

Autonomia do aprendiz

Redução de custos com referência à educação ou organizações
Alta, como determinação do ritmo de aprendizagem pelo aprendiz. No entanto, o contato com a tutoria pode não ser tão dinâmico, dependendo do modelo adotado, ou pode ainda não existir, deixando sob a responsabilidade do aprendiz o desenvolvimento do programa.

Otimização baseada em escala de produção e distribuição.

\section{E-Learning}

Alta, como determinação do ritmo de aprendizagem pelo aprendiz. No entanto, o contato com a tutoria pode não ser tão dinâmico, dependendo do modelo adotado. Os sistemas de ajuda e helpdesk potencializam a autonomia do aprendiz. Acesso às redes pode potencializar a consulta em várias bases de conhecimentos.

Conteúdos centralizados em plataforma remota. Relação de distribuição potencializada. Ajustes feitos em matrizes de conteúdo, sem necessidade de alteração nos suportes/mídias.

\section{Recursos pedagógicos \\ Portabilidade/ ubiquidade}

Locus do conteúdo

Monitoramento

Modelos de Avaliação
Realizado em modos tradicionais, quando possível.

Modelos e instrumentos consagrados e testados em prática.
Computadores e redes.

Permitem a utilização de diversos recursos providos pela tecnologia como hiperlinks, imagens, animações.

Pode ser utilizado em equipamentos do tipo lap top.

Pode ser utilizado em

Conteúdos dispostos nas próprias mídias ou em repositórios digitais e bibliotecas digitais em servidores distribuídos por todo o mundo.

Sistemas permitem acompanhamento com altos níveis de detalhamento e sofisticação.

Modelos e instrumentos consagrados e testados em prática. próprias mídias ou em repositórios digitais e bibliotecas digitais em o mundo.

Sistemas permitem sofisticação. específicos para essa smartphones e tablets.

\section{M-learning}

Alta, como determinação do ritmo de aprendizagem pelo aprendiz. No entanto, o contato com a tutoria pode não ser tão dinâmico, dependendo do modelo adotado. Os sistemas de ajuda e helpdesk potencializam a autonomia do aprendiz. Acesso às redes pode potencializar a consulta em várias bases de conhecimentos. Apoio de aplicativos de suporte.

Conteúdos centralizados em plataforma remota (repositórios digitais, bibliotecas em servidores distribuídos por todo o mundo). Relação de distribuição potencializada. Ajustes feitos em matrizes de conteúdo, sem necessidade de alteração nos suportes/mídias. A maioria dos usuários já possui seu próprio equipamento (BYOD).

Engloba as vantagens do elearning e possui outros recursos como a portabilidade.

Conteúdos dispostos nas servidores distribuídos por todo acompanhamento com altos níveis de detalhamento $\mathrm{e}$

Não foram localizados, nas buscas, modelos disponíveis modalidade.

Fonte: pesquisa.

A questão dos resultados e sua aferição está baseada no cômputo de todas essas características, em parte, ou conjuntamente. Desse modo, as decisões a respeito da adoção de 
modelos que envolvam o mobile learning devem levar em consideração diversos aspectos para que se concretizem os objetivos instrucionais e organizacionais.

O estudo deslocou para essa posição um resultado originalmente registrado na revisão de literatura, mas que mostrou pertinência ao referencial teórico pelo aspecto histórico. Martin, Diaz, Sancristobal, Gil, Castro, e Peire (2011) realizaram uma meta-análise sobre os estudos do projeto Horizon Reports, que avalia anualmente tendências da tecnologia no campo da educação a com projeções para os 2 e 4 anos seguintes à publicação. $O$ trabalho enfoca o período entre 2004 e 2014, apresentando projeções e verificações desses impactos. O interesse deste estudo nos relatórios baseia-se na localização temporal das previsões e a coleção de conceitos emersos das pesquisas dessas tecnologias. Esses conceitos são fundamento, ou consequência, do impacto das tecnologias em termos de comportamento e práticas na educação. $\mathrm{O}$ relatório é bastante abrangente e não contempla no conjunto de palavras-chave "training" ou "organization", o que resultou em volumes de respostas maiores do que aquelas realizadas por este estudo. Não se restringiu, também, a periódicos específicos, realizando buscas por meio do Google Scholar (Google Acadêmico). Apesar disso, o estudo apresenta resultados que trazem contribuições para este trabalho. Destaca os conceitos de "digital learning object" e "semantic aplications". O primeiro define o que são objetos de aprendizagem digitais, que são, segundo os autores, conteúdos reutilizáveis, manipuláveis e possíveis de serem descobertos (“discoverable”). O segundo indica aplicações que são capazes de extrair significado de informações e fornecer informações de acordo com as necessidades dos usuários.

Os relatórios apresentam a tecnologia mobile pela primeira vez em 2007, como previsão para serem influentes em 2010. Também estão apresentadas as tecnologias relacionadas ao mobile learning, que são, segundo aqueles relatórios, educative gaming, virtual worlds e massive gaming (jogos educativos, mundos virtuais e jogos massivos). $\mathrm{O}$ conceito de computação ubíqua, definida aqui como o processamento que faz tarefas invisíveis ao usuário e que reage conforme o comportamento do usuário, também foi classificada como relevante, mas foi incorporada ao contexto do mobile learning. O estudo conclui que as tendências de computação ubíqua e de aplicações que reagem ao contexto (respondem ao perfil do usuário e estão sujeitas às condições de uso), que devem ser absorvidas pela tecnologia mobile, são tendências promissoras e já classificadas como bem- 
sucedidas, devido ao grande número de trabalhos a elas dedicados. A realidade aumentada, que também está em processo de integração à tecnologia mobile, ainda não mostrou relevância, levando-se em consideração os critérios dos relatórios.

Cabe notar, em contraste com o entusiasmo natural característico das novidades, especialmente em tecnologia, os riscos que também fazem parte da utilização de tecnologias para qualquer atividade, em particular da aprendizagem. Conforme relata Romiszowski (2003), todas as grandes novidades em termos de mediação, sofreram o que o autor batizou de "Efeito Fênix". Ou seja, tiveram grande impulso na ocasião de seu lançamento, perdendo força significativamente em período posterior. Os gráficos apresentados no estudo configuram-se como um perfil de sino, parabólicos, mostrando um pico relevante e um retorno a níveis similares aqueles anteriores ao evento e estão associados à inovação. $\mathrm{O}$ autor ressalta o grande volume de fracassos em programas de e-learning. Aponta que a grande variedade de possibilidades pode ser, paradoxalmente, uma fonte maior de problemas do que de soluções. Relaciona o ciclo de "Fênix" a um fator de financiamento. Ou seja, no surgimento de alguma novidade promissora de tecnologia, investe-se significativamente, com bons resultados, mas os resultados tendem a perder força com a mesma rapidez com que atingiu importantes índices de sucesso. Isso reverte-se em redução de investimentos, incrementando a curva descendente.

$\mathrm{O}$ autor relata um estudo sobre TV educativa que mostra uma ascensão vertiginosa entre 1967 e 1973, apresentando após esse ano um ritmo de queda acentuado. Ou seja, um período de tempo bastante curto para a ascensão e queda de um sistema tão promissor. É possível que tenhamos variáveis na dimensão ideológica (controle do conhecimento) e comerciais (aumento do valor de tempo na TV). No entanto, esses fatores são especulativos e constam para trazer novas ideias e dimensões de análise para outros trabalhos. Em suas discussões com outros autores, aponta que muito da terminologia e das técnicas aplicadas são meras adaptações dos sistemas tradicionais de treinamento e educação, indicando que pode aí residir uma armadilha que poderá levar ao insucesso das ações dessa modalidade. Nos mais de cem trabalhos examinados, pouco mais de 10 ocuparam-se com profundidade do processo de aprendizagem ("l”, de learning). Ressalta a necessidade do bom planejamento e, neste caso, com mais cuidados, devido ao contexto de aprendizagem submeter o aprendiz a um conjunto de variáveis mais complexo daquele tradicionalmente experimentado. aponta um 
dado intrigante, indicando que autossuficiência do aprendiz não é uma variável preditora de aprendizagem nessa modalidade.

\subsection{Mind Tools - "Ferramentas Mentais"}

A tecnologia, como recurso instrucional, evoluiu bastante, extrapolando um papel de mero suporte, ou mídia. Os recursos hoje disponíveis vão bastante além disso, configurandose como reais assistentes da forma de agir e de resolver tarefas, contudo o estudo de Jonassen (1999) já havia classificado recursos de apoio à aprendizagem por tecnologia, que definiu como mind tools, que represenetam funções que funcionam como extensão da mente. $\mathrm{O}$ autor definiu mind tools como um recurso para se usar o computador no engajamento em atividades de pensamento de ordens superiores (críticos) conforme descritos na Tabela 12. Ou seja, o computador será um apoio para atividades cognitivas mais básicas para que o estudante se concentre em atividades mais complexas, privilegiando habilidades de pensamento em análise, síntese e avaliação. Essa visão mostra alinhamento com a taxonomia de Benjamin Bloom em termos de processos mentais utilizados em aprendizagem. Poder-se-ia inferir que as atividades que seriam contempladas pelas mind tools seriam: conhecimento, compreensão e aplicação. Esse autor afirma que tecnologias não deveriam somente instruir os aprendizes, mas servir de base para a construção de conhecimento. Assim, os aprendizes teriam um papel de desenhista instrucional, ou seja, ao mesmo tempo em que aprendem, organizam sua aprendizagem.

\section{Tabela 12}

Mind tools*.

\section{Classe}

Semantic Organization Tools Ferramentas de organização semântica

\section{Semantic Networking} Rede de significado

Dynamic Modeling Tools Ferramentas de modelagem dinâmica

\section{Definição}

Mapas conceituais e bases de dados.

Mapas conceituais compartilhados que representam ideias estruturadas.

Modelos que descrevem relacionamentos entre as ideias. 


\section{Classe}

Spreadsheets

Planilhas

Expert Systems

Sistemas especialistas

Systems Modeling Tools

Ferramentas de modelagem de sistemas

Microworlds

Micromundos

Information Interpretation

Tools

Ferramentas de interpretação

da informação

Visualization Tools

Ferramentas de visualização

Knowledge Construction Tools Ferramentas de construção de conhecimento

\section{Hypermedia}

Hipermídia

Conversation Tools

Ferramentas de inteiração por meio de conversa

\section{Definição}

Organizadores de dados.

Sistemas especializados que realizam operações.

Sistemas complexos interativos, como simuladores de operações, fluxos.

Sistemas que fornecem cenários nos quais os usuários podem explorar, interagindo com a interface.

Sistemas que interpretam grandes volumes de informação. Mecanismos de busca estão incluídos nesta categoria.

Ferramentas que realizam visualizações, como modelos químicos tridimensionais, por exemplo. Auxiliam na interpretação de conceitos complexos ou abstratos.

Ferramentas usadas como se o usuário fosse o desenhista instrucional. Poderiam ser classificadas como ferramentas de autoria. Provavelmente à época o termo ainda não havia adquirido notoriedade e consenso.

"Nós" de conhecimento. Recurso pelo qual podem ser recuperados conteúdos. Configuram-se em conjuntos e podem ser editados, com acréscimo ou modificação do nó.

Ferramenta de processos sociais de comunicação e interação (síncronas ou assíncronas).

Fonte: Jonassen (1999)

*Tradução livre do autor.

Apesar de o estudo referir-se a tecnologias anteriores ao surgimento dos dispositivos móveis, a abordagem de relacionamento entre a funcionalidade e os processos de aprendizagem parece aplicar-se bem às práticas pedagógicas mediadas, como roteiro de classificação taxonômica de atividades.

\subsection{Mobilidade e Aprendizagem Situada}

Mobilidade é um conceito chave para o entendimento do uso de dispositivos móveis para a educação. Confunde-se, em alguma medida, com o conceito de portabilidade, sendo que esse é redutor, resume-se à capacidade de ser transportado, está centrado no dispositivo 
puramente. Pressupõe as considerações físicas de peso, tamanho e outros. Em contraste, mobilidade carrega um significado mais amplo, particularmente com referência ao contexto de tecnologia e aprendizagem e está centrado no usuário. O termo portátil foi de grande apelo na comercialização de aparelhos mecânicos e eletrônicos, como máquinas de escrever ou televisões e similares em décadas passadas. Esse conceito não explora as diferenças de contexto no qual a tarefa será executada. A literatura sobre mobile learning tem colocado a mobilidade, descrita em uma dimensão mais complexa, como o grande diferencial dos dispositivos móveis. A portabilidade está inscrita no conceito de mobilidade, ou seja, a portabilidade permite a mobilidade.

Os estudos sugerem que o aspecto mais importante da portabilidade seja a operação de tarefas em contextos diferentes, o que transcende o conceito original de transporte apenas. Mobilidade ganhou, sob a perspectiva da realidade móvel, significado mais complexo e amplo, como, por exemplo, o desenvolvimento de mecanismos de inclusão social de pessoas com limitações de locomoção (deficientes físicos, idosos, obesos etc.), ou ainda da inclusão de comunidades isoladas geograficamente, mas com capacidade para a instalação de sistemas de telefonia celular. Ganha, nesse caso, uma perspectiva mais de cunho social. Em uma visão mais atual, mobilidade deve ser interpretada não mais como um conceito fechado, mas como um conjunto de fatores que compõem um determinado entendimento, mais complexo sobre o comportamento do indivíduo em situações e contextos diversos.

Kukulska-Hulme, Sharples, Milrad, Arnedillo-Sánchez e Vavoula, (2009) decompuseram o construto mobilidade em 5 fatores, com base nos trabalhos de Kakihara e Sørensen (2002), da seguinte forma: a) mobilidade fisica (geográfica), b) mobilidade tecnológica (conteúdos acessados em diferentes plataformas, devido às diferentes condições de uso), c) mobilidade conceitual, d) mobilidade social - os contextos de acesso são diferentes e e) mobilidade temporal. O fator social é interpretado por Saccol et al. (2010) como interacional, afirmando que pessoas aprendem de modo diferente em contextos sociais diferentes, como trabalho e casa, por exemplo. Esses autores, em trabalho de 2011, ainda incorporam o conceito de mobilidade emocional, proposto por Lasen (2004), que afirma que tecnologia móvel é uma tecnologia emocional, dada a sua relação de proximidade com a comunicação humana e pelo fato de estarem fisicamente junto ao corpo. Esse elemento emocional é capaz de mobilizar o usuário, ou produzir rejeição a determinadas formas de 
interação, conforme Ciborra (2002). Esse construto está relacionado a um campo denominado Affective Tecnologies, que trata da dimensão emocional da tecnologia. As variáveis apresentadas nos estudos utilizados neste trabalho não apontam para essa dimensão, apesar de abordarem questões de motivação para o uso de tecnologia.

A mobilidade implica em novas interações entre as pessoas e entre pessoas e conteúdos e práticas. Kukulska-Hulme et al. (2009) situam a mobilidade como um fenômeno de largo alcance, de caráter cultural, afetando o comportamento, a cultura, a comunicação. Dessa forma, implicam modificações nas esferas do trabalho e da vida pessoal. Afirmam que o mobile learning é parte de uma nova sociedade móvel. A tabela 13 consolida os tipos de mobilidade localizados no estudo.

\section{Tabela 13}

Tipificação de mobilidade.

\begin{tabular}{ll}
\hline Tipo de Mobilidade & \multicolumn{1}{c}{ Definição } \\
Física & $\begin{array}{l}\text { Capacidade de deslocamento geográfico. Possibilidade de acesso em lugares } \\
\text { diversos. }\end{array}$ \\
Tecnológica & $\begin{array}{l}\text { Diversidade de aparatos tecnológicos para consulta. O usuário poderá aprender o } \\
\text { mesmo conteúdo em dispositivos diversos, o que implica em modelagens } \\
\text { específicas. }\end{array}$ \\
Ronceitual & $\begin{array}{l}\text { Refere-se às interações da situação de aprendizagem e à disputa de nosso interesse, } \\
\text { criando condições diferentes de percepção. } \\
\text { Refere-se ao contexto de aprendizagem. Ao se deslocar, o usuário irá se inserir em } \\
\text { um outro contexto social, que determinará um outro tipo de comportamento. } \\
\text { Temporal }\end{array}$ \\
$\begin{array}{l}\text { Notadamente, o aprendiz utilizará o composto tempo/local a seu favor, construindo } \\
\text { um contexto favorável à atividade. Refere-se também às parcelas de tempo } \\
\text { "mortas" (dead times). Ou seja, espaços (fatias) de tempo disponíveis, que poderão } \\
\text { ser utilizadas na aprendizagem. }\end{array}$ \\
\hline
\end{tabular}

Fonte: adaptado de Saccol et al. (2010).

Propomos o conceito de mobilidade pedagógica, visto que o usuário dependendo de sua situação, poderá optar por recursos diversos baseados em plataformas diversas, o que implica necessariamente em desenhos instrucionais específicos. Ou seja, dependendo do tempo que tenha disponível e do local onde se encontre, o aprendiz poderá ouvir uma lição, assistir um vídeo, acessar um conteúdo, realizar um movimento em um jogo etc. Esses conteúdos podem ter a mesma função, dedicada à situação. Com relação à aprendizagem 
situada, esse aspecto fica mais evidente quando desenhamos uma modalidade de conteúdo dependente dos objetivos instrucionais e de condições ambientais.

A adaptação do conteúdo não implica somente em uma reformatação. Vê-se que os períodos mais curtos e tamanhos reduzidos terão reflexos no desenho instrucional. Vale dizer que se o usuário acessa um vídeo de 15 minutos em um computador desktop, ao utilizar um dispositivo móvel, o desenho instrucional deverá prever um novo comportamento de consumo. Como estará em contexto diverso, não apenas o dispositivo será outro, como a oferta deverá prever a relação com o contexto (proposital ou não). Em linguagem mais especializada, os aplicativos que reagem à mídia na qual estão hospedados (mudam de formato ao reconhecer que o acesso está sendo feito por um smartphone ou tablet, por exemplo) são chamados responsivos. Nessa perspectiva, os aplicativos reagiriam não só quanto ao formato, mas quanto à forma de interação.

\section{Aprendizagem situada}

Conforme Sharples, Taylor e Vavoula (2005), é necessário reconhecer o papel essencial da mobilidade no processo de aprendizagem. Isso significa entender o que a mobilidade pode proporcionar, além da possibilidade de deslocamento do usuário. Essa ideia conduz à noção de aprendizagem situada, que tem sido tema relevante e recorrente na pesquisa sobre mobile learning, como em Cheng e Hampson (2008), que realizarsam revisão de literatura sobre transferência, que afirma que sob essa perspectiva, os estudos tradicionais de transferência podem não estar adequados. O termo está relacionado também a context awareness, ou seja, algo similar a atento ao contexto, consciente dele, ou influenciável por ele. Vale dizer que a mobilidade possibilite ao o contato direto e simultâneo com um dado contexto, podendo esse estar presente como um fato situacional, no qual o aprendiz está imerso na realidade local, mas que não necessariamente está apoiado em dados objetivos podemos imaginar que uma aula de botância realizada na natureza possa implicar um nível de engajamento mais intenso e proporcionar mais insights do que essa mesma aula realizada em uma sala de aula - ou pode estar recebendo informações objetivas sobre o que está aprendendo do próprio ambiente, ou alimentadas pelo parâmetro de estar naquele lugar/ situação/ambiente. 
O aprendiz pode acessar um repositório de informações ou instruções que atendem a uma necessidade que se apresenta no transcorrer de uma tarefa designada. Imaginando a aula de biologia, o estudante pode ser desafiado a identificar um tipo de bioma, de criatura etc. Pode ainda, ter como tarefa, fotografar a incidência de algum fenômeno específico da região onde se encontra para posteriormente, ou colaborativamente, discutir, teorizar ou ser avaliado com relação ao que lhe foi designado a fazer. Há uma terceira possibilidade que prevê que o local tenha informações codificadas, ou fonte de informações, que lhe são fornecidas de modo condicional. Ou seja, o aprendiz só terá acesso àquelas informações quando estiver situado no local e hora programados. As tecnologias com leitores de RFID são um bom exemplo. As fontes de informação podem ser percebidas pelo dispositivo do usuário, reconhecê-lo e interagir com o sistema utilizado no dispositivo móvel, fornecendo informações ou até validando o acesso daquele usuário em tempo e local pré-definidos. Esse recurso é também utilizado em controle de estoques, pedágios e outros. $\mathrm{O}$ desenho instrucional pode prever que o usuário acessará um determinado conjunto de informções se estiver em hora marcada e local designado, ou ainda se tiver algum pré-requisito definido, como tarefas prévias. Caso não atenda esses requisitos, não terá acesso aos conteúdos ou instruções.

É possível ainda uma outra forma de interação a partir da realidadade aumentada. Nesse caso, o sistema reconhece o contexto e a situação e complementa os dados da realidade próxima com dados e informações pré-definidas, gerando uma imagem, por exemplo, de algo que não está naquele contexto. Todas essas formas de interação são possíveis com uso de dispositivos móveis e sistemas interrelacionados e apresentam uma verdadeira revolução em termos de possibilidades para as práticas pedagógicas ainda embrionárias.

$\mathrm{O}$ que se aponta como maior vantagem do m-learning não é a mobilidade em si, como surge naturalmente, mas a relação com o contexto (context awarness), que, por sua vez, é proporcionada pela mobilidade. É uma migração de foco. Ninguém aprende em movimento. Isso é uma metáfora, como afirmam Driscoll e Carliner (2005). Recomendam, esses autores, ainda, motivar e preparar os usuários para a experiência móvel, buscando melhorar suas metagcognições. Outro desafio interessante será o desenvolvimento da capacidade de distribuir atenção e utilização de coisas ao mesmo tempo. O óculos da Google, por exemplo, possiblita a visualização de coisas ao mesmo tempo (a tela e o cenário, por exemplo), porém parece ainda tarefa fisiologicamente difícil. 
Nas atividades de aprendizagem e correlatas (o dispositivo móvel permite atividades complementares ao estudo) executadas em contextos distintos do educacional (previsto e controlável) o usuário está sujeito a variáveis e interferências de contexto mais complexas do que aquelas realizadas em situações tradicionais de ensino-aprendizagem. Podem ser específicas co contexto em que se encontra, como ruídos, clima, interferências visuais etc. Como também podem estar relacionadas ao contexto digital, como aplicativos de bate-papo, redes sociais, jogos e outros distratores. Dessa forma, os modelos móveis devem ser sensíveis ao contexto, tanto como fonte de informação, como referência de limitações ao processo de aprendizagem. Não se pode, também, ignorar aqueles fatores históricos ligados à educação a distância, como facilidade para a desistência, maior probabilidade de falta de engajamento e outros já bastante estudados e provavelmente presentes também nos modelos móveis.

No esforço de consolidação, estudiosos e teóricos têm lançado mão de diversas teorias a fim de promover bases para a construção de uma teoria sobre aprendizagem móvel e fundamentar hipóteses e achados, tais como: Tecnology Acceptance Model (Modelo de Aceitação da Tecnologia) - TAM, de Davis (1989), Flow Theory - The Psycology of Optimal Experience (Teoria do Fluxo - A Psicologia da Experiência Ótima), de Csikszentmihalyi (1990), Theory of Planned Behavior (Teoria do Comportamento Planejado) - TPB (Ajzen, 1991), Activity Theory (Leontiev, 1978), Theory of Reasoned Action (Teoria da Ação Razoável) - TRA (Fishbein \& Ajzen, 1975), The Motivational Model (MM) (Davis, Bagozzi \&Warshaw, 1992), The Combined TAM e TPB (C-TAM-TPB) (Taylor \& Todd, 1995a), The Model of PC Utilisation (MPCU) (Triandis, 1977; Thompson, Higgins \& Howell, 1991), The Innovation Diffusion Theory (IDT) (Rogers, 2003; Moore \& Benbasat, 1991), The Social Cognitive Theory (SCT) (Bandura, 1986; Compeau \& Higgins, 1995), a Philosophy of Pragmatic Technology (Dewey, 1990) e Conversation Theory (Pask, 1976). Nesse conjunto, percebe-se a predominância dos estudos comportamentais.

A busca de modelos comportamentais para a formação de uma teoria de mobile learning assemelha-se à uma reconstrução do entendimento da aprendizagem em suas origens. As discussões a respeito dos paradigmas de aprendizagem também surgem com frequência, apontando uma tendência a uma interpretação construtivista da aprendizagem móvel. Outra teorias são também contempladas como a teoria da aprendizagem situada, citada por Muyinda (2007). Esse autor afirma que dispositivos móveis são particularmente 
adequados a essa abordagem. A teoria da aprendizagem colaborativa, citada por Sharples (2000) está também presente pelo caráter colaborativo, apresentado como tendência nos trabalhos estudados. Diaz, Moro e Carrión (2014) dizem que o futuro da aprendizagem gira em torno de quatro eixos: mobilidade, interação, inteligência artificial e recursos baseados em tecnologia. Combinando esses meios aos modelos móveis, com interação e cenários inteligentes, podem ser criadas abordagens que poderão extrair benefícios dos tempos e espaços disponíveis aos aprendizes.

Conforme Börner (2010), ainda não há uma teoria consolidada a respeito do mobile learning, bem como definições consensuais precisas e completas. Segundo esse autor, é mais importante a definição dos aspectos-chave, como desafios de pesquisa, estudos de caso, fatores motivacionais, ou aspectos afetivos, do que a busca de uma definição precisa do termo. Ele propõe substituir a pergunta “o que é mobile learning”, pela pergunta "o que é aprendizagem na era da mobilidade" (aqui referida como as ações sociais que envolvem dispositivos móveis). É uma proposta bastante promissora, visto a dificuldade de visualização do fenômeno de aprendizagem por meio de dispositivos móveis.

Sharples, Taylor e Vavula (2005) propõem em seu trabalho, entitulado Towards a Theory of Mobile Learning (em direção a uma teoria de aprendizagem móvel) algumas diretrizes para o futuro do modelo móvel. Segundo esses autores, essa teoria deverá levar em consideração a transferência de conhecimentos e tarefas permeada pela mudança de contextos. Deve estar alinhada a uma abordagem construtivista. A aprendizagem deve estar centrada no aprendiz, no conhecimento, na avaliação e na comunidade. Por fim, deve estar alinhada ao acesso à tecnologia móvel. Os autores propuseram a seguinte correlação entre aprendizagem e tecnologia, conforme a Tabela 14.

\section{Tabela 14}

Aspectos paralelos entre a nova aprendizagem e nova tecnologia.

\begin{tabular}{ll}
\hline Nova Aprendizagem & Nova Tecnologia \\
Personalizada & Pessoal \\
Centrada no aprendiz & Centrada no usuário \\
Situada & Móvel \\
Colaborativa & Em rede
\end{tabular}




\begin{tabular}{ll}
\hline Nova Aprendizagem & Nova Tecnologia \\
Ubíqua & Ubíqua \\
Continuada & Durável \\
\hline
\end{tabular}

Fonte: Shaples, Taylor e Vavoula (2005).

A tabela mostra uma comparação entre duas perspectivas para o fenômeno da aprendizagem móvel. Tem pertinência ao fazer distinções em um ambiente onde as barreiras conceituais e práticas parecem estar em direção a uma flexibilização e apresentam contornos menos precisos, mais fluidos. A relação entre o conceito de usuário e aprendiz está de tal forma integrada, que permance praticamente no campo teórico, sendo de difícil distinção nesse cenário. A implicação maior disso é a compreensão de um novo sujeito aprendiz, mais autônomo, que traz suas tarefas diárias e boa parte de sua realidade consigo o tempo todo, permeando cenários, ambientes e situações diferentes e sendo por elas influenciado. Outro aspecto importante é a definição das variáveis, a delimitação do entendimento da conceituação. A aprendizagem está inserida nesse contexto e precisará ser desenhada para ganhar uma fatia dessa realidade.

O estudo das revisões nos sugere que há um contraste de paradigmas predominantes nos dois campos (transferênica e mobile learning). Enquanto a área de TD\&E está fundamentada predominantemente em conceitos congnitivistas, dada a busca de precisão no atingimento de objetivos instrucionais bem definidos, os estudos em mobile learning caminham para uma interpretação construtivista, como visto em Peng, Su, Chou e Tsaib (2009), Muyinda (2007), Sharples (2000), Sharples, Taylor e Vavoula (2005) e Meer et al. (2015), por exemplo. O fato demanda uma conciliação entre essas visões, a fim de melhor se compreender os fenômenos estudados.

A falta de dados mais sistemáticos e técnicas consolidadas para a investigação no campo impôs uma pesquisa na direção de compreender comportamentos e perspectivas de resultados, com o intuito final de lançar luz sobre possibilidades de criação de modelos para a avaliação de transferência de treinamento específicos para a aprendizagem via mobile, dado que a aplicação de recurso móvel para esse fim tem mostrado que esse formato guarda muitas particularidades em relação aos modelos de aprendizagem e avaliação tradicionais e mesmo os de e-learning, que é a realidade mais próxima do m-learning. 
A mobilidade poderá ser um fator indutor de transferência? Será possível uma medida nessa direção? Quais são os fatores que teriam influência no desenho de uma instrução voltada para a melhor relação entre as vantagens do mobile learning e as variáveis que atuam sobre a transferência de treinamento? Essas são as perguntas que norteiam a interpretação dos dados neste estudo, extraídos de fontes documentais e da experiência daqueles que participaram do evento em estudo e que estão refletidas nos objetivos específicos, descritos neste capítulo.

Há diversas variáveis externas ao evento de treinamento que atuam sobre a transferência e sobre a utilização do dispositivo móvel. O método buscará, também, identificar os conjuntos de dados que permitem estabelecer uma correpospondência entre os dois eventos. O conjunto de variáveis que atuam sobre a transferência de treinamento e a adoção de modelos móveis convergem na classe de Características da Clientela e referem-se a aspectos cognitivos e comportamentais, que contemplam a prediposição para ambas atitudes: transferência e adoção do modelo. Isso indicou, para esta investigação, o exame da experiência dos sujeitos participantes, o que aponta para técnicas de caráter qualitativo de levantamento de dados, dada a falta de identificação de escalas e desenvolvimento de medidas para variáveis que vão além da predisposição de uso. O conceito de adoção implica a identificação de atributos efetivamente experimentados, extrapolando a expectativa contida nas experiências dos modelos de adoção de tecnologia, cujas variáveis estão contidas nas estapas anteriores à utilização efetiva dos dispositivos.

Uma estratégia de aprendizagem apoiada por um job aid (formato do objeto estudado, que refere-se a artefatos a serem usados em situação de trabalho) pode ter efeito decisivo na utilização eficaz do dispositivo móvel, dado que pode ser consultado e utilizado (generalização e tranferência) no momento da prática, ou no período de necessidade, ou comodidade, do usuário. Levando-se em conta, a falta de recursos formais de avaliação das visitas aos clientes - não há, na organização, um relatório de visitas obrigatório que pudesse registrar os aspectos reforçados no objeto mobile - a referência mais concreta sobre a influência do objeto mobile será, portanto, a experiência vivida pelo usuário. 


\section{MÉTODO}

Esta pesquisa utilizou um delineamento qualitativo, com modelagem descritiva e exploratória, baseada em múltiplas fontes (humanas e documentais), de modo a buscar maior riqueza de dados e resultados mais confiáveis sobre o fenômeno em questão. Para isso, o estudo foi composto de quatro técnicas de coleta de dados: análise documental, grupo focal, entrevistas e questionários. A utilização de técnicas variadas cria uma teia de apoio mútuo conceitual e empírico dos achados e propostas originadas na pesquisa científica.

\subsection{Objetivos de Pesquisa}

Objetivo geral de pesquisa: analisar a influência do uso de dispositivo móvel, inserido em uma estratégia de mobile learning, em contexto corporativo de trabalho no processo de transferência de treinamento. Para esse fim, a principal tarefa a ser cumprida será identificar os principais elementos que atuam positivamente sobre o processo de aprendizagem apoiada por dispositivos móveis.

Objetivos específicos: 1) analisar os principais motivos de construção de um produto educacional para responder às demandas da organização; 2) avaliar as principais características do planejamento instrucional do treinamento analisado: Oficina MPE (onde está integrado o infográfico); 3) identificar os principais motivos e atributos da adoção do modelo móvel para fins de capacitação pela organização e os principais atributos precebidos do recurso e 4) identificar os principais motivos dos usuários para a utilização do recurso móvel e os principais atributos percebidos do recurso. Os componentes e especificações das técnicas e instrumentos aplicados estão descritos na Tabela 15. 
Tabela 15

Descrição dos objetivos específicos deste estudo.

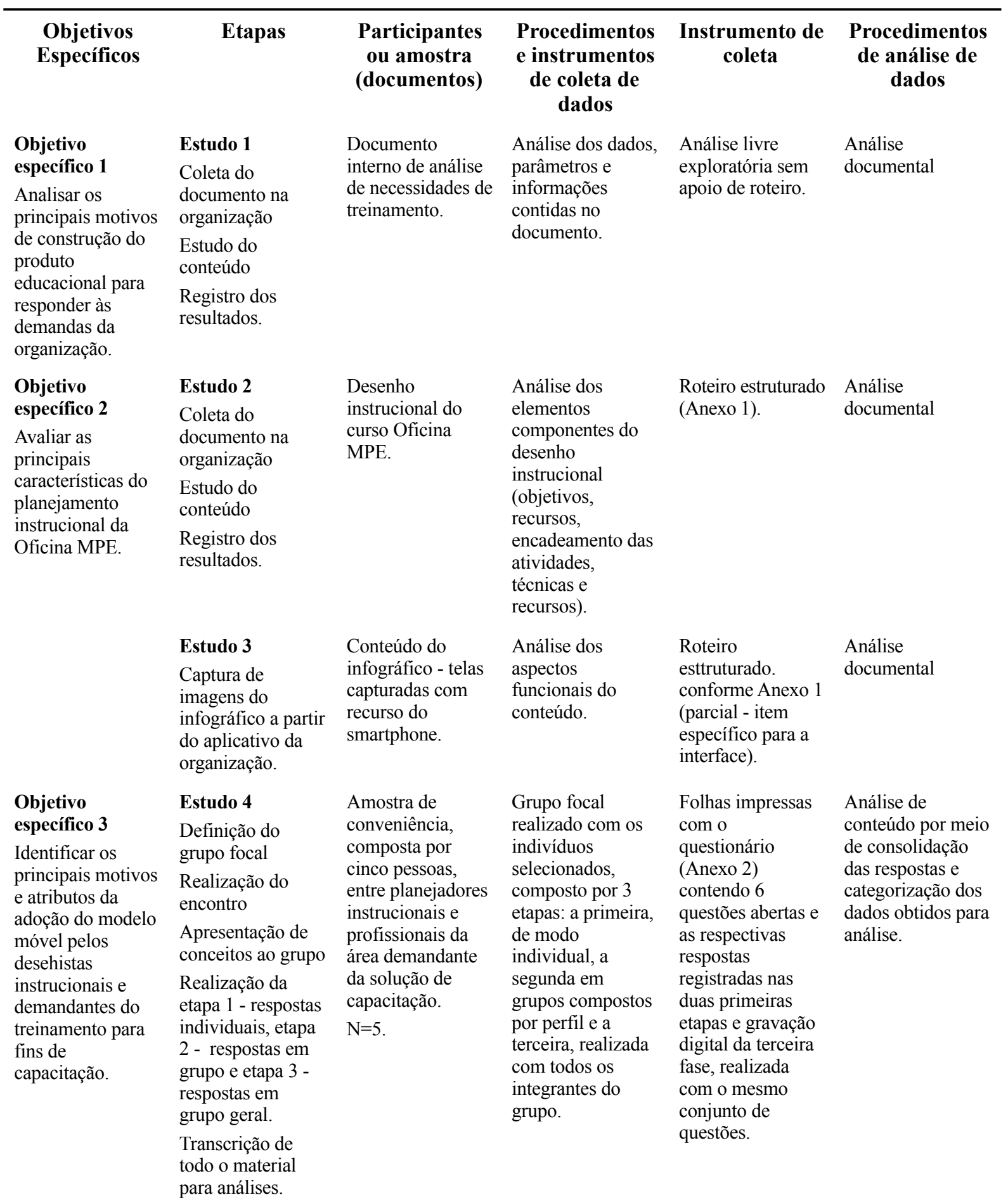




\begin{tabular}{|c|c|c|c|c|c|}
\hline $\begin{array}{l}\text { Objetivos } \\
\text { Específicos }\end{array}$ & Etapas & $\begin{array}{l}\text { Participantes } \\
\text { ou amostra } \\
\text { (documentos) }\end{array}$ & $\begin{array}{l}\text { Procedimentos } \\
\text { e instrumentos } \\
\text { de coleta de } \\
\text { dados }\end{array}$ & $\begin{array}{l}\text { Instrumento de } \\
\text { coleta }\end{array}$ & $\begin{array}{c}\text { Procedimentos } \\
\text { de análise de } \\
\text { dados }\end{array}$ \\
\hline \multirow[t]{2}{*}{$\begin{array}{l}\text { Objetivo } \\
\text { específico } 4 \\
\text { Identificar os } \\
\text { principais motivos } \\
\text { dos usuários para } \\
\text { a utilização do } \\
\text { recurso móvel e os } \\
\text { principais } \\
\text { atributos } \\
\text { percebidos do } \\
\text { recurso. }\end{array}$} & $\begin{array}{l}\text { Estudo } 5 \\
\text { Levantamento da } \\
\text { população que } \\
\text { realizou o curso } \\
\text { no período } \\
\text { estudado. } \\
\text { Extração do grupo } \\
\text { que acessou por } \\
\text { completo o } \\
\text { infográfico. } \\
\text { Construção do } \\
\text { questionário a ser } \\
\text { aplicado } \\
\text { Validação } \\
\text { semântica do } \\
\text { questionário no } \\
\text { grupo de pesquisa. } \\
\text { Envio de convite à } \\
\text { participação. } \\
\text { Consolidação e } \\
\text { organização dos } \\
\text { dados. }\end{array}$ & $\begin{array}{l}\text { Amostra - } \\
\text { população dos } \\
\text { usuários que } \\
\text { atenderam aos } \\
\text { dois critérios } \\
\text { simultaneamente: } \\
\text { a) participação na } \\
\text { oficina e } \\
\text { b) conclusão } \\
\text { integral do } \\
\text { infográfico. } \\
\text { Amostra: } 48 \\
\text { indivíduos, dentre } \\
\text { os } 304 \text { que } \\
\text { realizaram a } \\
\text { Oficina. } \\
\text { 19 questionários } \\
\text { válidos (39,6\%). } \\
\text { N=19. }\end{array}$ & $\begin{array}{l}\text { Questionários com } \\
\text { usuários que } \\
\text { completaram o } \\
\text { treinamento no } \\
\text { dipositivo móvel. }\end{array}$ & $\begin{array}{l}\text { Questionário } \\
\text { estruturado com } 7 \\
\text { perguntas abertas } \\
\text { (Anexo 3), } \\
\text { disponibilizado na } \\
\text { plataforma } \\
\text { LimeSurvey, na } \\
\text { intranet da } \\
\text { organização. } \\
\text { Os dados foram } \\
\text { gravados e } \\
\text { organizados no } \\
\text { próprio programa. }\end{array}$ & $\begin{array}{l}\text { Análise de } \\
\text { conteúdo por meio } \\
\text { de consolidação } \\
\text { das respostas e } \\
\text { categorização dos } \\
\text { dados obtidos para } \\
\text { análise, conforme } \\
\text { técnica descrita } \\
\text { por Bardin (2011). }\end{array}$ \\
\hline & $\begin{array}{l}\text { Estudo } 6 \\
\text { Seleção por } \\
\text { conveniência de } \\
\text { indivíduos } \\
\text { localizados na } \\
\text { mesma cidade de } \\
\text { realização da } \\
\text { pesquisa para } \\
\text { efeitos práticos. }\end{array}$ & $\begin{array}{l}\text { Amostra de } 2 \\
\text { indivíduos por } \\
\text { conveniência } \\
\text { dentro da } \\
\text { população dos } \\
\text { indivíduos do } \\
\text { Estudo } 5 .\end{array}$ & $\begin{array}{l}\text { Entrevistas com } \\
\text { usuário da área } \\
\text { demandante (a) e } \\
\text { usuário final (b). }\end{array}$ & $\begin{array}{l}\text { Roteiro } \\
\text { semiestruturado, } \\
\text { com perguntas } \\
\text { abertas. } \\
\text { Público (a): } 14 \\
\text { perguntas e } \\
\text { desdobramentos } \\
\text { (perguntas } \\
\text { secundárias por } \\
\text { extensão do tema. } \\
\text { Público (b): } 19 \\
\text { perguntas e } \\
\text { desdobramentos. }\end{array}$ & $\begin{array}{l}\text { Análise de } \\
\text { conteúdo por meio } \\
\text { de consolidação } \\
\text { das respostas e } \\
\text { categorização dos } \\
\text { dados obtidos para } \\
\text { análise, conforme } \\
\text { técnica descrita } \\
\text { por Bardin (2011). }\end{array}$ \\
\hline
\end{tabular}

Fonte: pesquisa.

Segundo Barbour (2009), a pesquisa qualitativa busca o entendimento do fenômeno pela experiência humana a ele relacionada. Afirma que os métodos e teorias devem se adequar àquilo que se estuda. Dessa forma, os estudos preliminares do fenômeno no campo observado e as referências da literatura convergiram para uma análise das experiências dos usuários e planejadores, relacionadas à avaliação de transferência com apoio de dispositivo móvel em lugar de uma busca de dados duros pela falta de indicadores confiáveis com relação aos temas tratados neste trabalho, como transferência, por exemplo. Esses, na forma que se espera responder à pergunta de pesquisa, ainda não estão disponíveis, tanto no campo, quanto na literatura. Conforme a autora, essa técnica está presente com bons resultados nas ciências 
sociais e no estudo das organizações. O grupo focal também produz bons resultados sob a forma de insights, que podem surgir das interações entre os participantes, uma vez que o diálogo proporciona reflexão instantânea e cooperativa. Um dos riscos que envolve a aplicação dessa técnica é a perda das participações individuais. Neste estudo, foi realizada uma etapa individual e outras em dois grupos menores e, por fim, uma etapa conjunta, composta por todos os membros, para que esse componente individual, se relevante, se mantivesse nos depoimentos.

A literatura sobre aprendizagem móvel indica que há pouco desenvolvimento de critérios de natureza objetiva e consistentes para fundamentar uma pesquisa quantitativa na direção desejada e, por isso, o trabalho adquiriu, neste ponto, uma tendência exploratória, exigindo, assim, um modelo que pudesse levar à compreensão de vários aspectos do fenômeno. Posteriormente, os resultados poderão indicar caminhos e direções melhor definidas e estratégias mais adequadas para o levantamento de dados quantitativos de qualidade.

O objetivo do grupo focal, neste contexto, foi levantar expectativas, características percebidas (atributos) e motivos para a adoção do modelo. As coletas envolveram dados documentais, dados oriundos de informações prestadas por planejadores instrucionais, demandantes do treinamento e percepções de egressos do treinamento. Dessa forma, buscando obter-se uma compreensão contextual global do uso do m-learning na oficina e possibilitar posteriormente a formulação hipóteses sobre as relações entre as variáveis apontadas neste estudo: uso de um recurso móvel para ensino-aprendizagem e transferência de treinamento.

Foram utilizadas fontes primárias para os levantamentos da percepção dos indivíduos da amostra e também fontes secundárias de informações, como documentos que descrevem a demanda da solução, o planejamento e execução do planejamento instrucional e a representação do próprio objeto em estudo.

\subsection{Organização Estudada}

A organização é uma grande empresa do ramo financeiro no Brasil, com mais de 200 anos de atuação. Está presente em mais de 20 países, possui por volta de 119 mil funcionários 
e é responsável pela gestão de mais de R\$ 1 trilhão em ativos. É uma empresa de economia mista, que atende ao mercado e também está inserida no contexto de políticas públicas governamentais, atuando como um agente de desenvolvimento. A organização tem tradição em educação corporativa e avaliação de desempenho, tendo sua primeira estrutura de capacitação inaugurada em 1965.

A organização utiliza o formato de Universidade Corporativa para o desenvolvimento e oferta de cursos e oportunidades de capacitação e tem por base um modelo de gestão de desempenho por competências como eixo central do desenvolvimento e treinamento do corpo funcional. O planejamento estratégico da organização é feito anualmente com perfil quinquenal, com base nas técnicas do Balance Score Card - BSC, de onde emanam os objetivos e ações estratégicas que norteiam a gestão de pessoas e, por conseguinte, a educação corporativa.

A Universidade Corporativa dispõe de uma rede de dependências, sob a responsabilidade da Direção de Gestão de Pessoas, composta por 30 órgãos regionais, dotados de infraestrutura e recursos para oferecer as ações de capacitação, como sala de aulas para ações presenciais, bibliotecas e outras facilidades de apoio à educação corporativa. A rede permite ações de grande capilaridade nas áreas de atuação da instituição. A organização possui um sistema de capacitação baseado em competências, alinhando capacitação ao desenvolvimento estratégico da organização.

Os cursos na modalidade e-learning do portifólio da empresa em estudo subiram de um número de 16 em 1 de janeiro de 2013 para 138 até outubro de 2013, mostrando o investimento nas modalidades de EAD. Em 2014 o investimento foi da ordem de R\$ 7 milhões para as ações de e-learning, sendo, destes, R\$ 384 mil para o modelo mobile. Possui também um Portal na Internet, que foi transposto da estrutura interna para a externa (Internet) em 2010 e que oferta por volta de 150 treinamentos em diversos formatos, como conteúdos de linha em e-learning, e-books, videoaulas, conteúdos em PDF, games e outros conteúdos correlatos e complementares. Em fevereiro de 2014, a Universidade Corporativa lançou um aplicativo ( $a p p$ ) para dispositivos móveis com a finalidade de estar mais disponível aos treinandos, potencializando a capacitação. 


\subsection{Características gerais do treinamento estudado}

A modalidade do treinamento estudado é presencial, com apoio de meios digitais: o portal de treinamento e o aplicativo da universidade corporativa. O recurso digital é aplicado em caráter suplementar, ao treinamento presencial de aprendizagem, que é o evento principal da capacitação. O treinamento em estudo denomina-se Oficina Negocial Micro e Pequena Empresa, ou Oficina Negocial MPE. Esse evento presencial tem a característica de ser obrigatório, de modo que mesmo os participantes que já dominam essas competências terão que realizá-lo. A Tabela 16 descreve esse programa de treinamento em suas características gerais.

\section{Tabela 16}

Caraterísticas da Oficina Negocial MPE.

\begin{tabular}{ll}
\hline $\begin{array}{l}\text { Objetivo Geral de } \\
\text { Aprendizagem }\end{array}$ & $\begin{array}{l}\text { Ao final do treinamento, espera-se que os participantes apliquem os conceitos de } \\
\text { negociação e gestão de carteiras em situações simuladas e no planejamento da } \\
\text { carteira, visando à efetivação de resultados sustentáveis, com foco na visão } \\
\text { cliente. }\end{array}$ \\
$\begin{array}{l}\text { Área de conhecimento } \\
\text { Atendimento (a classificação de área do conhecimento é genérica e não está } \\
\text { segmentada por perfil de clientela). }\end{array}$ \\
$\begin{array}{l}\text { Resempenhos } \\
\text { esperados no cargo } \\
\text { visam à expansão de negócios sustentáveis, prestando atendimento de } \\
\text { excelência. Atuar com foco no relacionamento duradouro, buscando resultado } \\
\text { nos negócios e satisfação do cliente. }\end{array}$ \\
$\begin{array}{l}\text { 24 horas-aula, distribuídas em três dias consecutivos de oito horas em encontros } \\
\text { presenciais. }\end{array}$ \\
$\begin{array}{l}\text { Requisitos para a } \\
\text { participação no } \\
\text { treinamento }\end{array}$ & \begin{tabular}{l} 
Cliente MPE, código Y e Visitando o Cliente MPE, código Z*. \\
\hline
\end{tabular}
\end{tabular}

Fonte: documentação interna da organização.

*Os códigos “X”, "Y" e “Z” substituem a numeração original, com o objetivo de resguardar dados internos da organização e facilitar a compreensão. Representam a identificação do curso no sistema interno da organização.

Especificamente, este estudo concentrou-se no recurso instrucional Infográfico Visita ao Cliente MPE, de apoio ao treinamento descrito, mas que não possui documentação específica descrevendo seus propósitos, objetivos ou outros dados técnicos. A estratégia do curso e seus materiais foram objeto de análise e avaliação pelo grupo Impacto, sob responsabilidade da professora doutora Gardênia da Silva Abbad, coordenadora do grupo, que 
opera no PSTO, Departamento de Psicologia Organizacional do Trabalho, da Universidade de Brasília. Esses resultados estão expressos no Estudo 3, relativo ao Objetivo Específico 2.

\subsection{Perfil da clientela}

A população do perfil atendido pela Oficina é de 3.805 gerentes de relacionamento ${ }^{15}$. Para efeitos deste trabalho, foram considerados aqueles que se encontram em situação de trabalho efetivo. Todos os indivíduos pertencem à mesma Vice-Presidência, que é responsável pela área de varejo e está subdividida em três diretorias, responsáveis pela rede, que, por sua vez, comporta 25 superintendências, distribuídas uma para cada estado, à exceção de São Paulo, que possui quatro superintendências desse perfil. Do total de indivíduos levantados, foram excluídos 83, em situação de trabalho real apenas a partir de março de 2015. Vale dizer, que esses voltaram à situação de funcionários efetivos nos últimos seis meses do ano de 2015, bem como outros 619 que assumiram a comissão no mesmo período. Todos estão lotados em unidades negociais da organização. Três indivíduos foram excluídos por não estarem associados à nenhuma dessas unidades. O público final totalizou 3.100 indivíduos.

A população foi segregada segundo os seguintes critérios: nível de escolaridade, tempo de atuação na organização, gênero, faixa etária e unidade da federação. A fonte dos dados foi a tabela de recursos humanos, fornecida pela organização, a partir de sistemas intrernos de processamento de dados, cujo endereço não constará no estudo por motivos de confidencialidade.

Em relação à escolaridade, a população está distribuída pelos níveis superior em andamento $(5,26 \%)$, superior $(42,77 \%)$, especialização $(42,32 \%)$, médio $(8,52 \%)$ e outros $(1,13 \%)$, conforme extração de dados na intranet da organização estudada. Quanto ao tempo na organização, os indivíduos se encontram nas faixas de 30 a 40 anos (3,35\%), 20 a 29 anos $(12,74 \%), 10$ a 19 anos $(47,74 \%)$ e de 0 a nove anos (36,16\%). O público é composto por $67,16 \%$ de homens e $32,84 \%$ de mulheres. Com relação à faixa etária, os indivíduos estão distribuídos nas faixas de 75 a 55 anos (3,48\%), 54 a 45 anos (25,29\%), 44 a 35 anos $(42,39 \%)$ e de 34 a 23 anos $(29,00 \%)$. Quanto à região geográfica, 5,10\% estão na região 
norte, $14,48 \%$, na região nordeste, $11,13 \%$, na região centro-oeste, $50,03 \%$, na região sudeste e 19,26, na região sul do País.

Os funcionários da clientela do treinamento estão categorizados em 4 comissões: Carteira Empresa, códigos X e Y e Carteira Pequena Empresa, códigos Z e W, generalizados como Gerentes de Relacionamento. Os códigos "X", "Y", "Z" e "W" substituem a numeração original, com o objetivo de resguardar dados internos da organização e facilitar a compreensão. Representam a identificação do cargo no sistema interno da organização. Levantamento apontou que 842 funcionários participaram da Oficina no período de 25/08/2015 a 16/12/2015. No mesmo período, 3.206 funcionários acessaram a peça mobile, classificada pela organização como infográfico, com 892 conclusões $(27,8 \%)$. O mesmo infográfico foi disponibilizado também no portal de educação corporativa da organização e registrou 9.334 acessos, com 8.396 conclusões (89.9\%).

O fato deve-se a que o acesso ao infográfico em ambas plataformas (mobile e portal/ intranet) é aberto, ou seja, mesmo usuários fora da clientela podem acessar os conteúdos. $\mathrm{Na}$ contagem filtrada pelas comissões referentes à clientela, a relação entre acessos e conclusões foi de 68,2 \%. Levando-se em conta o acesso livre e estimulado via canais de comunicação, o interesse sobre o produto no público de interesse é significativo. O número de participantes da Oficina nas comissões especificadas foi de 683. A descrição tem o intuito de traçar um perfil de todo o público e possibilitar analogias e percepção das informações levantadas pelas amostras específicas de cada estudo.

4.5. Estudo 1 - Motivos para o desenvolvimento do modelo móvel face às demandas da organização

Essa etapa foi realizada a partir de duas versões do documento de levantamento de necessidade de treinamento específico da organização, que descreve a avaliação das necessidades de treinamento e indica as ações correspondentes. Os documentos foram consultados na intranet da organização para a presente análise. A técnica de análise utilizada foi a análise documental, conforme os princípios enunciados por Bardin (2011). O modelo do documento é baseado em desenho de cenário (análise do mercado e posição da organização perante o cenário) que serve de base para uma proposta de estratégia em busca de soluções 
para o problema identificado. Os documentos foram acessados na intranet da organização e exportados em formato de texto para análises por parte do pesquisador. Não constam em anexos devido à confidencialidade dos dados, visto que envolvem informações a respeito da estratégia organizacional. A função da análise foi busccar elementos que mostrem o encadeamento das informações e ações desde o surgimento da demanda em nível de atuação organizacional à efetivação de resultados, passando pelas etapas de desenho instrucional, construção dos eventos e objetos de capacitação e seus resultados (ou perspectivas) no cargo.

A forma de estrtuturação do documento envolve reunião entre as áreas de negócio que detectaram algum tipo de problema de atuação organizacional. $\mathrm{O}(\mathrm{s})$ encontro(s) têm o objetivo de alinhamento entre as áreas e a função de localizar dentre as ações possíveis aquelas que têm relação com cacitação e desenvolvimento de competências. Após essa etapa, são registradas as ações propostas e negociadas entre as áreas envolvidas na plataforma. $\mathrm{O}$ registro discrimina detalhadamente as providências (objetivos, cronogramas, responsabilidades etc.) $\mathrm{O}$ documento é assinado pela gerência executiva (segundo nível hierárquico da organização) de ambas as áreas e, por fim, executado. Em alguns casos, como o estudado aqui, o conteúdo do documento e suas estratégias e ações podem sofrer ajustes de acordo com as circunstâncias. Neste caso, houve uma alteração do cenário negocial, que implicou em documento complementar. O documento é composto de seis páginas e relata a identificação da situação problema detectada, responsáveis, alinhamento estratégico com os documentos oficiais e as propostas de ações de capacitação.

O escopo da ação na qual se insere o treinamento é a adoção de um novo modelo de relacionamento da organização estudada com o segmento de micro e pequenas empresas. A carteira MPE atingiu na organização, no $1^{\circ}$ trimestre de 2014 o valor de R\$ 100 bilhões. As empresas do segmento estudado são aquelas com faturamento entre R\$ 1 milhão e R\$ 25 milhões, conforme dados acessados na intranet da organização. Esses dados são necessários para dar ideia do nível de importância da ação de capacitação estudada.

4.6. Estudo 2 - Avaliação do planejamento instrucional da oficina

O desenho instrucional da Oficina (técnicas e recursos) foi analisado e avaliado pelo pesquisador com o intuito de identificar objetivos instrucionais, estratégias de ensino- 
aprendizagem, planejamento das atividades (duração, tipo) e, com isso, avaliar a pertinência da relação entre objetivos, técnicas aplicadas e resultados esperados, tendo por peça central a relação entre a taxonomia de resultados de aprendizagem utilizada para o desenvolvimento do curso e a natureza das competências a serem desenvolvidas. Essa análise visou, também, a avaliação da inserção do recurso móvel no desenho instrucional. A análise do desenho instrucional da oficina foi realizada por meio de roteiro, desenvolvido pelo grupo Impacto, da UnB (Anexo 1) aplicado também por Santos Junior. (2012).

O roteiro abrangeu questões como: clareza e factibilidade dos objetivos do curso, adequação das estratégias de aprendizagem à clientela e à modalidade de ensino, pertinência dos exercícios, adequação da carga horária e da linguagem dos textos, qualidade da interface do ambiente virtual do treinamento, usabilidade, pertinência na aplicação dos recursos, pertinência do uso do mobile e as tarefas designadas para essa mídia e outros. $\mathrm{O}$ exame foi realizado com base nos seguintes documentos disponibilizados para consulta pela organização: Roteiro do Educador e Caderno de Atividade. Esses documentos contêm todas as orientações, conteúdos e técnicas do curso.

\subsection{Estudo 3 - Análise do infográfico}

O infográfico é descrito pela organização como: "peça que aborda um conteúdo, explicando-o por meio de um desenho esquemático interativo. Ideal para esclarecer procedimentos e processos ou diferenciar conceitos", conforme consta no contrato firmado entre a organização e o fornecedor da solução (portal de desenvolvimento pessoal e profissional). Outro ponto a ser levando em consideração diz respeito às estratégias instrucionais de ensino-aprendizagem. Considerando-se que o conteúdo contemplado pelos dispositivos móveis não podem ser exclusivamente disponibilizados naquele recurso, caberá ao treinando optar por consumir aquele conteúdo ou exercício específico via mobile, em lugar de acessá-lo no portal de treinamento, ou em material instrucional impresso (treinamento EAD ou presencial).

A técnica de coleta foi a captura das telas em navegação por todo o conteúdo do Infográfico. A técnica de análise do material é a análise documental, orientada por roteiro desenvolvido pelo grupo Impacto (Anexo 1). A função da análise é examinar os parâmetros 
aplicados ao objeto e sua correspondência com as propostas descritas no grupo focal e a coerência com os objetivos do planejamento instrucional global. O recurso integra-se como apoio instrucional suplementar. O recurso do infográfico está disponível no aplicativo da universidade corporativa, que pode ser usado em celulares do tipo smartphone e tablets. Os participantes interessados devem ter o aplicativo instalado no dispositivo para acessar o conteúdo específico. A captura das imagens das telas foi realizada a partir do acesso ao Infográfico em estudo, por meio do aplicativo instalado no smartphone do pesquisador.

4.8. Estudo 4 - Atributos e motivos para a adoção do modelo móvel

A decisão feita pelo recurso móvel na ocasião do desenvolvimento do desenho instrucional está relacionada a vários fatores não descritos na documentação técnica, tais como: histórico de tentativas similares, expectativas da reação do público diante de novas estratégias, expectativa do impacto relacionado à técnica inovadora, sensibilidade quanto à natureza do conteúdo a ser explorada e outros fatores decisivos, ou influentes na criação do programa. Dessa forma, o grupo focal teve a função de detectar os elementos que constituiram a decisão e, com isso, contribuir nas análises de resultados, em função das expectativas criadas na construção do programa de capacitação.

A técnica de grupo focal utilizada teve, também, a função de captar a percepção de integrantes de perfis variados (demandantes e desenhistas instrucionais) em uma mesma oportunidade e explorar com maior profundidade o tema, que, dado o seu ineditismo e a falta de referência histórica na organização. Buscam, adicionalmente, uma compreensão mais abrangente da pertinência da aplicação do recurso estudado (dispositivo móvel), examinando o relacionamento entre as necessidades de capacitação, como a promoção de inovação e investimento crescente em tecnologia, por exemplo, sob a ótica da estratégia corporativa.

Gondim (2003) afirma que o grupo focal pode gerar conhecimento para a construção de instrumentos de medida e avaliar impacto de produtos em desenvolvimento. Como em nosso caso, o infográfico possui um caráter experimental, foi aplicado em busca de resultados exploratórios. Por último, Morgan (1997) afirma que os grupos focais podem ser usados em combinação com outras técnicas, como é o caso deste estudo, que adotou três técnicas. 
Os participantes do grupo foram escolhidos por conveniência e por afinidade ao objeto estudado, configurando-se como uma amostra flexível. O grupo foi composto por 4 (quatro) mulheres e 1(um) homem, apresentou uma média de idade de 39,4 anos, 80\% dos participantes têm nível de pós-graduação e 20\%, nível de graduação (4 e 1. respectivamente). O tempo médio de serviço na organização é 12,4 anos. Três são planejadores educacionais da e participaram da construção da solução em dispositivo móvel ora estudada e dois funcionários da área negocial, demandante da solução global (definição do documento de levantamento de necessdades), incluindo o Infográfico.

Os demandantes estão lotados em uma diretoria que atua junto a micro e pequenas empresas. Completam o grupo, uma estudante de mestrado da Universidade de Brasília e componente do grupo de pesquisa Impacto, que foi a responsável pela condução do grupo focal, e o autor deste trabalho, que, em função de trabalhar na mesma organização dos participantes do grupo, participou, como observação, fazendo anotações de ocorrências relevantes nas discussões do grupo e prestando esclarecimentos sobre alguns conceitos e dúvidas eventuais relacionadas à terminologia e à pesquisa.

\section{Procedimentos e instrumento de coleta de dados}

Os participantes do grupo focal foram convidados a participar dessa atividade por meio de correio eletrônico e contato telefônico, nos quais foram informados os objetivos da técnica, a dinâmica a ser realizada e as condições de sigilo. Foram detalhados os critérios de confidencialidade das informações, ressaltando que os dados seriam acessados somente pelos pesquisadores e tratados de modo agrupado.

A construção do grupo buscou um perfil homogêneo em relação à posição hierárquica a fim de proteger as manifestações de influências de uma possível interferência da relação hierárquica funcional. Dessa forma, não havia diferença significativa entre os níveis profissionais e sócio-culturais dos participantes. Foi informado que não havia qualquer tipo de avaliação das respostas, ou do comportamento dos participantes, bem como não havia necessidade de se responder qualquer questão que lhes trouxesse desconforto (essa parte teve caráter preventivo, visto que não havia realmente nenhum tema sensível a ser discutido). Outros cuidados tomados, conforme orientado por Morgan (1997), foram: a) controlar o 
grupo para que uma só pessoa fale por vez, b) evitar que ocorram discussões paralelas, c) inibir o monopólio da palavra por alguma pessoa e d) garantir que todos tenham direito à voz.

O encontro foi realizado em $1 / 12 / 2015$, com duração prevista de 120 minutos. A duração real foi de 130 minutos. O local escolhido foi uma sala de reunião na organização estudada pela facilidade de acesso pelos participantes. O grupo ocorreu de acordo com o seguinte roteiro:

- Recepção dos participantes;

- Explicação da atividade aos participantes;

- Apresentação de slides com explicação e contextualização do trabalho (Anexo 4) e esclarecimento do tema e da terminologia utilizada. Todos os conceitos-chave abordados na dinâmica foram apresentados ao grupo no início do evento com o objetivo de dirimir dúvidas do grupo e alinhar o entendimento do tema.

- Distribuição das folhas de questões para serem respondidas, em primeiro lugar, de modo individual, em uma segunda etapa, em grupos divididos por perfil (planejadores instrucionais e assessores da áera demandante) e uma terceira etapa de consolidação geral, registrada em sua totalidade por meio gravação digital e degravada (transcrita). Os grupos foram distribuídos conforme definições iniciais; e

- Encerramento, com agradecimento aos participantes.

O roteiro das questões utilizado é semiestruturado, composto de cinco perguntas para conduzir os assuntos estudados. Algumas questões complementares surgiram no decorrer do trabalho em função de se abrir perspectiva de uma nova ideia, ou para se detalhar algum item. As perguntas apresentadas foram: 1) quais foram os motivos para a escolha de uma ação em mobile?; 2) vocês acham que outros cursos deveriam ter esse formato também?; 3) como você imagina a possibilidade de se tirar proveito da portabilidade, da mobilidade no uso de dispositivos móveis com a finalidade de incrementar a aprendizagem e transferência?; 4) quais foram as dificuldades que vocês perceberam? e 5) quais são os feedbacks que vocês já tiveram sobre o uso do infográfico? As perguntas buscaram um encadeamento lógico e 
semântico, com uma abordagem de cronologia dos eventos, começando na opção pela solução e finalizando com avaliação.

A variação de grupo focal adotada neste estudo ocorreu de acordo com as seguintes etapas em ordem sequencial: (1) apresentação dos objetivos do grupo focal e método empregado; (2) respostas individuais às perguntas abertas apresentadas em questionário impresso; (2) a formação de dois grupos, divididos por perfil (desenhistas instrucionais e assessores solicitantes da solução) similar à atividade precedente e (3) discussão com a participação de todos. A divisão em três etapas teve a função de detecção de algum tipo de percepção, que estivesse caracterizada por perfil, ou outro traço relevante para o estudo. A discussão aberta com o grupo total visou a busca do levantamento de um conjunto amplo de conceitos provenientes da experência e expectativa do grupo de profissonais envolvido no desenvolvimento da solução educacional. Todas as dinâmicas utilizaram o mesmo conjunto de questões.

\section{Procedimentos da análise de dados}

Consolidação do material obtido: a) organização e conslidação das respostas obtidas nos questionários escritos e b) degravação (transcrição) e tratamento das informações coletadas em áudio digital, produzindo o corpus do resultado.

A categorização dos resultados foi realizada em grupo, por três pesquisadores do grupo Impacto ${ }^{16}$, da UnB, coordenado pela Profa. Dra. Gardênia da Silva Abbad. A consolidação e a análise foram realizadas pelo próprio pesquisador. Após essa etapa, foram tecidas considerações e construída uma síntese da experiência, sob a luz dos objetivos do trabalho, que comparão a seção de resultados.

Os registros dos questionários escritos funcionaram como um consolidador das ideias dos participantes, que, por fim, ficaram expressos no debate final. Todos os elementos e categorias foram registradas na dinâmica final, o que ensejou o descarte para a análise das respostas dadas de modo individual e nos pequenos grupos (dinâmicas 1 e 2). A categorização resultante da etapa 3 (grupo com todos os participantes), comporta todas as manifestações e

\footnotetext{
${ }^{16} \mathrm{O}$ grupo Impacto é composto por alunos graduandos e pós-graduandos, que realizam pesquisas nas áreas de TD\&E desde 1997. O grupo agrupa pesquisadore da àrea de administração, saúde e psicologia.
} 
conjunto de conceitos significativos expressos nas primeiras. Levou-se em consideração os mesmos critérios de exclusão utilizadas na transcrição da etapa 3.

A etapa 3 foi o debate simultâneo com todos os integrantes sobre os temas, estimulado pelas mesmas perguntas escritas, produzindo um corpus original, sem tratamento, composto por 23.326 caracteres, ou 4.915 palavras.

O corpus foi tratado a fim de trazer maior clareza ao tema, resultando em um conjunto de 22.249 caracteres, ou 4.686 palavras. A redução de conteúdo foi de $4,62 \%$. A diferença deve-se à exclusão de algumas manifestações prejudiciais para o entendimento do texto final, como algumas correções de português e ajustes do formato de fala para o escrito para melhor entendimento dos conteúdos abordados, porém com a preocupação de manter o sentido e a narrativa íntegros. Como não há interesse no estudo dos aspectos comportamentais, salvo aqueles não referentes ao tema (riscos de monopólio da fala, recolhimento, intimidação etc.), esses pequenos ajustes não produziram qualquer interferência para os fins deste trabalho. Foi possível a eliminação de formas como "né?", "aham" e algumas outras. Em determinadas situações, foram mantidas algumas formas análogas, quando foi percebida relevância no uso. Como exemplo, a expressão "é, rápida.", que denota concordância, reforço ao conceito apresentado.

A técnica utilizada para a análise do coletado no grupo focal foi uma variação da análise de conteúdo, nos moldes propostos por Bardin (2011) e serviu para que fossem levantadas as ideias preponderantes no tratamento dos temas abordados e lhes conferir relevância por meio da relação de significado e do volume de incidências das ideias. Dessa forma, permitindo se tratar as expectativas da organização e dos planejadores em relação à opção pelo modelo, aplicabilidade da solução, portabilidade e transferência e avaliação, representados nas perguntas. Apesar do caráter indutor das questões, planejadas originalmente para distinguir os temas centrais, as categorias contemplaram manifestações consideradas de modo transversal, ou seja, que ocorreram em todo o corpus do trabalho. Dessa forma, houve uma natural concentração de temas nas falas sobre o tema abordado nas questões, porém os conceitos e ideias permearam todo o trabalho, resultando em uma categorização ampla, que mostram com nitidez as ideias de maior incidência e maior relevância semântica, visto que o foco da análise recaiu sobre as respostas escritas dos participantes às questões do roteiro. 
4.9. Estudo 5 - Motivos dos usuários para utilização do recurso móvel e os principais atributos percebidos do recurso

O questionário deste estudo foi do tipo survey, composto por questões abertas e foi adotado com o intuito de se compreender quais os critérios para a adoção do recurso pelos participantes e os principais atributos reconhecidos. O questionário foi adotado, devido à grande dispersão geográfica da amostra e o volume significativo de usuários. Essa técnica produziu alguma perda na liberdade para manifestação, dadas as características mais diretivas das questões, porém, em contrapartida, ganhou-se em volume de informações e consistência de informações, visto que é uma amostra que garante a representatividade dos conteúdos. Como trata-se de estudo exploratório, as questões foram abertas, de modo a possibilitar manifestações sobre a experiência de uso do dispositivo móvel e infográfico.

\section{Participantes}

O público total de egressos da oficina é composto por 304 indivíduos, divididos em três grupos: aqueles que acessaram o Infográfico de modo completo (48 indivíduos), os que acessaram parcialmente (10 indivíduos) e os que não acessaram (296 indivíduos). O grupo de interesse para este estudo foi o primeiro e, por isso, os outros dois foram descartados e poderão, eventualmente, fazer parte de estudo complementar sobre os motivos da não adoção do recurso.

O grupo estudado foi composto por 49 indivíduos, dos quais, 21 responderam o questionário. Após a exclusão de 2 registros (um só respondeu a uma pergunta e outro informou que desconhecia o recurso), o conjunto final contou com 19 questionários, resultando em uma taxa de $38,8 \%$ de respostas válidas. O grupo completo refere-se aos usuários que acessaram o infográfico entre 25/08/2016 e 08/12/2016 e cursaram a parte presencial da Oficina MPE.

Perfil dos usuários: $31(64,6 \%)$ homens e 17 mulheres (35,4\%). Com relação ao tempo na organização: 4 (8,3\%) entre 0 e 5 anos; 17 (35,4\%) entre 6 e 10 anos; $17(35,4 \%)$ entre 11 e 15 anos; $7(14,6 \%)$ entre 16 e 20 anos e outros três (6,2\%) acima de 20 anos. Em termos de formação, 26 possuem pós-graduação $(54,2 \%), 18$ graduação $(37,5 \%)$ e 4 nível médio $(8,3 \%)$. Em relação ao tempo na função: $37(77,1 \%)$ entre 1 e 3 anos; $8(16,7 \%)$ entre 4 e 6 anos e 3 
$(14,6 \%)$ com 7 anos. O levantamento dos usuários e os dados sociográficos respectivos foi realizado por meio de relatório produzido pelo fornecedor do infográfico (contratado externamente à organização). A partir desse relatório, foram escolhidos os usuários de interesse pelos filtros adequados: realização da oficina e período definido para o estudo.

\section{Procedimentos e instrumento de coleta de dados}

A coleta foi feita por meio do aplicativo LimeSurvey, especializado em surveys, utilizado internamente pela organização estudada. O programa disparou automaticamente os questionários, acompanhados de mensagem de correio eletrônico, convidando e sensibilizando o público a responder o instrumento (Anexo 5). A decisão pelo uso do sistema interno da organização teve a função de incrementar o volume de respostas e facilitar o registro e o tratamento dos dados.

O sistema registrou todas as respostas, que foram posteriormente transpostas para a planilha de dados Numbers (aplicativo de mesma natureza do Excel) e, por fim, tratados, organizados e categorizados em grupo. Nessa última etapa, a consolidação final, a descrição da definições constitutivas e alguns ajustes necessários foram realizados pelo pesquisador e debatidas e validadas no grupo Impacto. As questões foram validadas pelo mesmo grupo de pesquisa e com 2 profissionais da organização, técnicos em avaliação e estatística.

Os questionários foram enviados no dia 26/01/2016, com um prazo de uma semana para respostas. O prazo foi prorrogado por mais uma semana no último dia para a resposta, com envio de novo aviso eletrônico de estímulo. As respostas foram consolidadas no dia $12 / 02 / 2016$.

As perguntas feitas aos usuários foram similares àquelas utilizadas no grupo focal, em forma de questionário semiestruturado com perguntas abertas, como segue: 1) quais foram os motivos para a sua opção por utilizar um conteúdo mobile, o infográfico Visita ao Cliente MPE?; 2) descreva como foi a experiência de utilizar o infográfico, levando em consideração aspectos da facilidade de uso, aplicabilidade do conteúdo do infográfico no trabalho e mobilidade (acesso a conteúdo a qualquer hora e lugar); 3) você considerou o conteúdo útil para a sua aprendizagem? Em caso positivo, o que efetivamente foi utilizado no trabalho e em qual situação? Em caso negativo, explique.; 4) O conteúdo do infográfico incrementou o 
resultado do seu trabalho? De que forma? Você tem alguma ideia de como medir essa melhora?; 5) Quais dificuldades você encontrou nesse acesso? O que você acha que pode melhorar no infográfico para melhorar o treinamento?; 6) Quais benefícios essa estratégia de aprendizagem traz, em sua opinião? Você acha que outros cursos poderiam usar esse modelo (dispositivo e conteúdo)? e 7) O conteúdo da Oficina incrementou o resultado do seu trabalho? De que forma? A similaridade das questões buscou promover um alinhamento entre as ideias dos planejadores e as percepções dos usuários. As questões foram validadas semanticamente no grupo de pesquisa Impacto e por dois profissionais da organização, com afinidade com o assunto. As questões abordaram os temas: motivação para o uso, atributos do recurso, a descrição da experiência e a repercussão no resultado do trabalho.

\section{Procedimentos de análise de dados}

Consolidação do material obtido: recuperação (geração de arquivo e planilha eletrônica a partir dos arquivos nativos do programa, por meio de exportação de dados), organização e conslidação das respostas obtidas, originados no programa utilizado, produzindo o corpus do resultado.

A categorização dos resultados foi realizada em grupo, por três pesquisadores do grupo Impacto ${ }^{17}$, da UnB. A consolidação e a análise foram realizadas pelo próprio pesquisador. Após essa etapa, foi elaborada uma síntese dos resultados sob a luz dos objetivos do trabalho.

A coleta produziu um corpus de 2.082 palavras, ou 11.170 caracteres, bruto. Quando descontados trechos que não interessaram ao estudo, o volume resultante era composto por 2.020 palavras, ou 11.090 caracteres, os quais foram submetidos à análise de conteúdo de acordo com a técnica de Bardin (2011), com adaptações. As análises tiveram como objetivo classificar as manifestações dos participantes e detectar novo significados para a experiência em termos da percepção do uso dos dispositivos nas condições propostas. As classificações permitiram uma percepção da convergência de determinados temas e sua importância, pela força da expressão e pela frequência apresentada. Por fim, os resultados serão comparados

\footnotetext{
17 O grupo Impacto é composto por alunos graduandos e pós-graduandos, que realizam pesquisas nas áreas de TD\&E desde 1997. O grupo é composto por pesquisadores da àrea de administração, saúde e psicologia.
} 
entre as outras técnicas com a finalidade de detecção de linhas mestras e informações relevantes para este estudo.

4.10. Estudo 6 - Motivos dos usuários para a utilização do recurso móvel e os principais atributos percebidos do recurso

A técnica da entrevista individual, adotada neste estudo, visou uma descrição mais detalhada do tema, devido à maior liberdade de expressão do participante, com a possibilidade de surgirem, durante a conversa, informações e perspectivas novas. Foram definidas entrevistas com dois usuários de perfis diferenciados, com a finalidade de aprofundamento na experiência relatada, possibilitando triangulação com as demais técnicas adotadas, como previsto por Flick (2009), conferindo maior confiabilidade e consitência aos achados produzidos por meio de outras técnicas. Neste estudo, o questionário funcionou como técnica principal e entrevista como complemento. A técnica foi realizada conforme princípios e orientações de Bardin (2011) e Flick, produzindo categorias com identificação próprias, sem superposição de conceitos, contendo um volume de dados, ou relevância, que justifique a posterior categorização. As categorias foram também definidas de modo que as unidades de registro não encontrassem abrigo em mais de uma categoria.

\section{Procedimentos e instrumento de coleta de dados das entrevistas}

As entrevistas foram gravadas presencialmente em meio digital, com autorização dos entrevistados, conforme identificação dos encontros, e posteriormente transcritas para formato de texto digital. A seleção dos entrevistados foi feita por conveniência, devido à grande dispersão geográfica do público. Os dois indivíduos selecionados são lotados em Brasília, o que viabilizou o trabalho de coleta. Essa escolha deveu-se ao público da oficina possuir trabalho itinerante e dispender a maior parte de seu tempo em deslocamento, visitando clientes. Dessa forma, o contato por telefone deveria ser feito por meio de telefone celular e com faixas de horário bastante restritas, com o risco de perda de concentração do entrevistado e o risco de interferências no decorrer da entrevista. 
Como o perfil da clientela do curso é bastante homogênea para os fins deste estudo, a definição pela localização geográfica não apresentou riscos. Os encontros foram realizados na casa de um deles (entrevista 1) e no ambiente de trabalho do outro (entrevista 2). Na primeira entrevista, a entrevistadora foi uma pesquisadora da Universidade de Brasília e membro do grupo Impacto. O pesquisador acompanhou o trabalho do entrevistador como apoio, fazendo anotações sobre o evento. Na segunda entrevista, o próprio pesquisador realizou a técnica, por questões práticas, visto que após a identificação do perfil e o respectivo contato telefônico, o entrevistado informou que sairia de férias no dia 19/01/2016. As perguntas seguiram os temas, porém com um caráter mais aberto, visando maior liberdade para entrevistador e entrevistado.

A primeira entrevista foi realizada em 18/01/2016 e durou 12 minutos e 42 segundos com uma funcionária que possui 45 anos, com 12 anos na organização, é pós-graduada, gerente de relacionamento em unidade de Brasília. As pergunta feitas aos entrevistados foram baseadas em temas correlacionados aos do grupo focal, que abordam motivação para o uso, atributos relevantes. Os intrumentos dirigidos aos usuários da solução também contemplaram a experiência no uso do recurso. Esses temas foram também utilizados no questionário de percepção dos usuários. A segunda entrevista foi realizada em 08/02/2016 e durou 14 minutos e 56 segundos. O participante é lotado na diretoria demandante do treinamento, é pósgraduado, está há 14 anos na organização, possui 45 anos e ocupa cargo de assessoria. Foram feitas 23 perguntas na primeira entrevista e 12 na segunda, conforme (Anexo 6).

\section{Procedimentos de análise de dados}

Os conteúdos arquivos eletrônicos das gravações foram transcritos, produzindo um corpus de 2.046 palavras no estado bruto e 1.770 palavras na versão tratada (retirados ruídos e expressões sem significado) na entrevista 1 e 2.248 palavras no estado bruto e 1.897 na versão tratada (idem). Os textos resultantes foram submetidos à análise de conteúdo, conforme a técnica e orientações de Bardin (2011), que permitiu classificar as manifestações dos usuários em blocos de significado próximo, mostrando temas e percepções relevantes para a compreensão dos participantes. O estudo ganha força ao complementar as outras técnicas e traz algumas contribuições decisivas na interpretação do estudado. Cabe ressalvar que as 
entrevistas, dadas as condições de realização, estão sujeitas a viéses significativos, expostos na seção de limitações do estudo. 


\section{RESULTADOS}

\subsection{Resultados do Estudo 1: Necessidades de treinamento}

As ações relacionadas à estratégia para o segmento contemplam identificação de oportunidades e comportamento de consumo, aplicação de modelos de relacionamento, satisfação do cliente e suporte técnico às dependências que operam com esse segmento. $\mathrm{Na}$ justificativa definida no documento original, criado em 13/05/2014, está expressa a conclusão que aponta para carências no atendimento e para a falta de conhecimento das soluções negociais da organização, que, segundo o documento, resultam de lacunas de competências. Essa conclusão mostra que, sob esse aspecto, soluções por meio de ações formais de capacitação são adequadas. A ação indicada para a solução foi o treinamento Oficina Gestão de Carteiras Pessoa Jurídica, com indicação de atualização.

A solução previu o desenvolvimento das competências específicas, como: a) atendimento, identificação e aproveitamento de oportunidades e b) conhecimento de produtos, serviços, processos (TI) e estratégias da área de atuação. Os desempenhos esperados no cargo identificados foram: a) realizar abordagem proativa ao cliente micro $e$ pequena empresa, de acordo com um modelo de relacionamento (definido pela organização); b) realizar consultoria a esse cliente, oferecendo soluções para problemas financeiros do cliente e c) auxiliar o cliente na identificação de oportunidades de negócios financeiros e na resolução de problemas da empresa, inclusive de inovação, visando o crescimento da carteira e a ampliação de negócios. Tanto as competências, quanto os desempenhos esperados estão relacionados diretamente com o conteúdo do tema de visitas.

Devido a novas configurações no cenário do mercado, um novo documento de necessidades de treiamento foi criado em 10/07/2015, trazendo novas diretrizes, acrescentando novos fatos e ações propostas. Na análise que resultou na construção do documento, foi identificado um aumento do nível de exigência do cliente em termos de aumento de qualidade nas soluções negocias oferecidas, que implicaram em ações voltadas ao atendimento personalizado, envolvendo interações e visitas, consultoria especializada aos clientes, proatividade, novos produtos/soluções e agilidade. A nova proposta de valor apontou os seguintes itens: a) atendimento exclusivo e especializado, por gerentes capacitados $e$ 
proativos, b) foco na consultoria especializada e visitas ao cliente e c) agilidade nos processos de atendimento e negociais. Igualmente ao tema das competências, os valores têm relação direta com as ações de visita.

A justificativa apontada nessa nova versão, já indicava soluções baseadas em aprendizagem móvel. Entende o demandante: por tratar-se de processos especificos e já mapeados, sugerimos a criação de vídeos de curta duração (2 a 5 minutos), com abordagem rápida e de forma interativa, apoiados por soluções como infográficos, helpcard e outras de mercado, que possam ser facilmente atualizados e preferencialmente, serem disponibilizadas na solução mobile da universidade corporativa. O documento analisado atrbuir grande importância no contato com o cliente, que deve ser potencializado ao máximo, sob vários aspectos. A visita é, segundo o documento, uma oportunidade para aproximação e estreitamento da relação negocial e, portanto, deverá ser produtiva e eficaz. O recurso móvel poderia, nesse contexto, contribuir para que a visita tivesse essas qualidades.

Considerando-se o fator ubiquidade, as tarefas que mais se aproximam de uma necessidade de acesso móvel são aquelas que estão localizadas fora do ambiente habitual do funcionário, como nas visitas aos clientes, por exemplo. Gerentes que visitam clientes precisam atuar junto aos para produzir situações negociais. Dessa forma, os preceitos e técnicas precisam estar bem internalizadas no agente. O profissional deverá ter ao seu alcance ferramentas que o ajudem a fixar, relembrar, aplicar e refletir sobre os conteúdos aprendidos em programas regulares de capacitação. As ferramentas móveis podem estar ao alcance desse profissional a qualquer tempo e hora (ubiquidade) por meio de dispositivo móveis, combinando, assim, as necessidades contempladas e as potencialidades do m-learning. Parece que a relação de complementação entre teoria e aplicação encontra um bom modelo de convergência. Em última análise, o recurso deveria servir para melhorar a qualidade da visita aos clientes, servindo de apoio ao desempenho do funcionário nessa atividade externa às dependências da organização.

\subsection{Resultados do Estudo 2: Desenho instrucional}

O trecho, a seguir, foi extraído do relatório crítico-analítico, elaborado para dar suporte à análise ora proposta (Anexo 7). O curso é presencial, e prevê a intervenção de um 
dispositivo móvel, embora não haja referências a esse recurso no planejamento instrucional. Não é totalmente desenvolvido em ambiente virtual, por isso, há duas perspectivas na utilização dos recursos: aqueles específicos da modalidade presencial e os que serão incorporados em formato digital, demandando orientações e regras específicas. As instruções específicas sobre a utilização (como fazer a instalação) do dispositivo móvel são informadas pelo educador do curso, sem, no entanto, abranger orientações para o uso.

O conteúdo mobile foi disponibilizado no aplicativo específico da universidade corporativa da organização, já de uso e conhecimento de $25 \%$ dos funcionários da organização, aproximadamente, não indicando necessidade de instruções específicas, embora seja recomendado o reforço para download e acesso.

O curso possui uma estrutura/organização didática padronizada, organizada em dois volumes: o Roteiro do Educador e o Caderno do Participante. O aluno recebe o Caderno do Participante, que traz as informações importantes para o aluno, além do conteúdo a ser estudado. O educador, por sua vez, recebe o Roteiro do Educador, contendo as instruções e os planos de aula (cronogramas, relação de atividades etc.). Além desses materiais, estão previstos slides, textos, cartelas, fichas, esquemas e textos de casos para estudo.

Na primeira página, está expresso o objetivo geral de aprendizagem: "aplicar os conceitos de negociação e gestão de carteiras em situações simuladas e no planejamento de carteira, visando à efetivação de resultados sustentáveis, com foco na visão cliente”. Não há registro de recursos de mídias, nem apresentação de normas, porém, nas atividades previstas, há um acordo de convivência definido no grupo (educador e participantes). Não há um índice dos conteúdos, embora o volume estudado contenha todo o conteúdo. A organização do conteúdo do Caderno já funciona como um roteiro.

Após o objetivo, o documento apresenta uma série de princípios organizacionais, constantes da Proposta Político-Pedagógica, que é um instrumento de definição dos princípios filosóficos da educação empresarial da organização estudada. Após um texto de apresentação, há uma seção dedicada exclusivamente a mostrar a estrutura do curso: denominação, código (importante para a localização nos sistemas e registro no currículo funcional do treinando), área de conhecimento, desempenhos esperados no trabalho, perspectivas da gestão de desempenho por competências (adotado na instituição), objetivo geral de aprendizagem, requisitos, conteúdo programático, carga horária e número de participantes. 
O objetivo geral de aprendizagem é aplicar os conceitos de negociação e gestão de carteiras em situações simuladas e no planejamento da carteira, visando à efetivação de resultados sustentáveis ${ }^{18}$, com foco na visão cliente. Podemos fatorar o objetivo em seus três componentes básicos: a ação: aplicar, condição: em situações simuladas e critério: visando resultados sustentáveis. O verbo aplicar fica bem claro no contexto estudado pelos participantes e é observável, embora de difícil mensuração. No sentido exposto, para mesnuração, seria necessário perguntar ao egresso não somente o quê foi aplicado do aprendido, mas também o quanto foi aplicado. O critério poderia ser melhor definido, como, por exemplo, usando a expressão com resultados sustentáveis. O termo visando gera a percepção de haver um objetivo dentro de outro. O termo sustentável é originário da política de crédito da organização, que preconiza negócios mais duráveis e, com isso, análises de perfil históricos e orientações de modo global, com foco no perfil do cliente e não somente na rentabilidade de um determinado produto.

Quanto à estratégia instrucional, há alguns padrões definidos que são típicos da organização, como carga horária e exercícios simulados. A linguagem é clara a acessível ao perfil da clientela, com conteúdo essencialmente técnico. O perfil de escolaridade varia de ensino médio à pós-graduação. As estratégias e atividades são adequadas à clientela e o domínio predominante é o cognitivo. O conhecimento dos conceitos e técnicas é o conteúdo predominante. Em uma das atividades, há dois objetivos específicos voltados à perspectiva adtitudinal que possuem traços de ação afetiva e psicomotora: demonstrar postura e atuar como consultor, visto que envolvem emoção e controle corporal. Em outra, também há dinâmicas atitudinais, que envolvem relacionamento entre os membros do grupo, que apontam comportamentos de liderança, flexibilidade, negociação etc. Nessas partes, o domínio afetivo também está presente, bem como o psicomotor, dado que há movimentações no ambiente da sala, que demandam posicionamentos e negociação de espaços físicos.

Com relação aos objetivos específicos, construídos com base na taxonomia de Bloom, temos a seguinte distribuição, na qual, a classificação foi feita com base no verbo de ação:

- Conhecimento - 2 conjuntos de objetivos - 2 atividades.

- Compreensão - 5 conjuntos de objetivos - 18 atividades.

\footnotetext{
18 Resultados sustentáveis - Busca de soluções ambientalmente corretas, economicamente viáveis e socialmente justas voltadas para o desenvolvimento de comunidades produtivas, capazes de promover a cadeia de valor, a bancarização responsável das classes em ascensão e a democratização do acesso ao crédito.
} 
- Aplicação - 3 conjuntos de objetivos - 3 atividades.

- Análise - 2 conjuntos de objetivos - 2 atividades.

- Síntese - 2 conjuntos de objetivos - 3 atividades.

- Avaliação - 1 conjunto de objetivos - 1 atividade.

Em alguns casos, percebe-se alguma imprecisão entre o objetivo instrucional de caráter cognitivo com o objeto a ser entregue ou a atividade a ser realizada, como o uso dos verbos refletir, propor e atuar, por exemplo. Os cursos da organização passam por uma etapa de validação em situação de sala de aula, na qual são aferidos os tempos de realização das tarefas em todas as suas características (profundidade, complexidade, compreensão, factibilidade etc.). Todos os textos se referem às situações reais de trabalho. Algumas informações, como nomes, ou dados cadastrais, são fíctícios, devido à proteção dos indivíduos. Os exercícios apresentados têm pertinência com os conteúdos propostos e com os objetivos apresentados.

Outro ponto a ser levando em consideração diz respeito às estratégias de ensinoaprendizagem. Visto que o conteúdo contemplado pelos dispositivos móveis não podem ser exclusivamente disponibilizados naquele recurso (o contexto organizacional não permite), caberá ao treinando optar por consumir aquele conteúdo via mobile, definindo o caráter voluntário do consumo dos conteúdos. O objeto está diretamente associado a uma oficina presencial e tem como função suplementar a aprendizagem e funciona como um manual de procedimentos para uso na prática - modelo job aid, fora do contexto tradicional do treinamento. Nessa oficina, é realizada uma ação de estímulo por parte dos educadores do treinamento a fim de potencializar o recurso. A independência entre o objeto mobile adotado e o desenvolvimento do curso poderá nublar em alguma medida a tentativa de avaliação do resultado da ação, como consequência da utilização do recurso em combinação com o evento presencial. Vê-se nos dados de acesso que o número global de funcionários que acessou o infográfico (2.180) é bastante maior do que aquele dos funcionários que cursaram a oficina (304) no período estudado, mostrando interesse na solução. O infográfico está disponível aos funcionários permanentemente.

O treinamento avaliado neste estudo pretende desenvolver habilidades cognitivas complexas que podem ser classificadas como de análise, avaliação e criação e envolvem fatos, conceitos e procedimentos, pois o treinamento propõe ao participante a realização de 
análises variadas, como do perfil do cliente e do negócio, que serão utilizadas na construção da melhor solução (avaliação) para o cliente (criação). Essa última categoria, refere-se à taxonomia de Anderson, Krarathwohl, Airasian, Mayer, Cruikshank, Pintirch, Raths e Wittrock (2001), que é uma atualização da taxonomia de Bloom.

Essa ação pressupõe entendimento, de modo mais global, das estratégias de negócio e, mais especificamente, das características dos produtos e das ferramentas disponíveis para essas análises e aplicação de parâmetros à solução. Dessa forma, de acordo com a taxonomia adotada, as funções cognitivas de "aplicar", "analisar", "avaliar" e "criar" estarão presentes na aprendizagem e na transferência dessas aprendizagens para o trabalho, expressas nas ações desse profissional com seus clientes.

O tema visita está contemplado na atividade 7 do Caderno de Atividades do material didático e prevê uma série de conhecimentos de atividades que envolvem o cliente de forma mais ampla e profunda, que são discutidas com profundidade na atividade presencial. $\mathrm{O}$ estudo presencial abrange atividades mais complexas e de naturezas diversas. Dessa forma, o Infográfico pode ocupar um lugar de um roteiro, um check list de caráter prático para aplicação na situação de trabalho. O objetivo específico relacionado a essa etapa é "identificar as características das etapas de visita ao cliente MPE”. A análise e avaliação do Infográfico foramm dificultados pela falta de documentação específica sobre os propósitos e objetivos relativos recurso. Foi possível, no entanto, a compreensão de modo global das funções do recurso pelos levantamentos feitos com os usuários. No caso da aplicação no trabalho, o funcionário já deverá haver identificado os principais pontos da atividade da visita. Assim, o objetivo do recurso precisará ser definido oportunamente a fim de que seja avaliado. Uma sugestão seria: aplicar de modo eficaz as verificações da rotina de visita ao cliente.

O aplicativo poderia conter um mecanismo de feedback, que permitisse ao funcionário conferir sua ação no cliente. Poderia incluir também as outras características da visita, que não só o roteiro. De modo geral, o desenho instrucional é consistente e coerente, conforme avaliação feito por meio do roteiro. Peca pela falta da descrição formalizada do recurso em estudo, mas ainda assim fornece subsídios (conhecimentos e técnicas) que permitem o aprendiz a fazer um uso eficaz do Infográfico. 


\subsection{Resultados do Estudo 3: Infográfico}

Ao acessar o aplicativo, o usuário seleciona em um índice o ícone Infográficos e acessa o conteúdo específico. O conteúdo é composto por 28 telas, que simulam um passeio dentro das instalações de um cliente fictício, configurando um formato de roteiro. Oito telas são referentes ao caminho percorrido pelo funcionário dentro ambiente do cliente. As outras são informações escritas e trazem as orientações e dicas de forma literal. A estética usa ilustrações e ícones de apoio com forte alinhamento à identidade visual corporativa. $\mathrm{O}$ usuário pode escolher entre uma personagem feminina ou masculina. As imagens são bastante atrativas e a movimentação assemelha-se a um jogo, conforme exemplos na Figura 9. As imagens completas estão no Anexo 8. A Tabela 17 apresenta os resultados da análise do recurso.
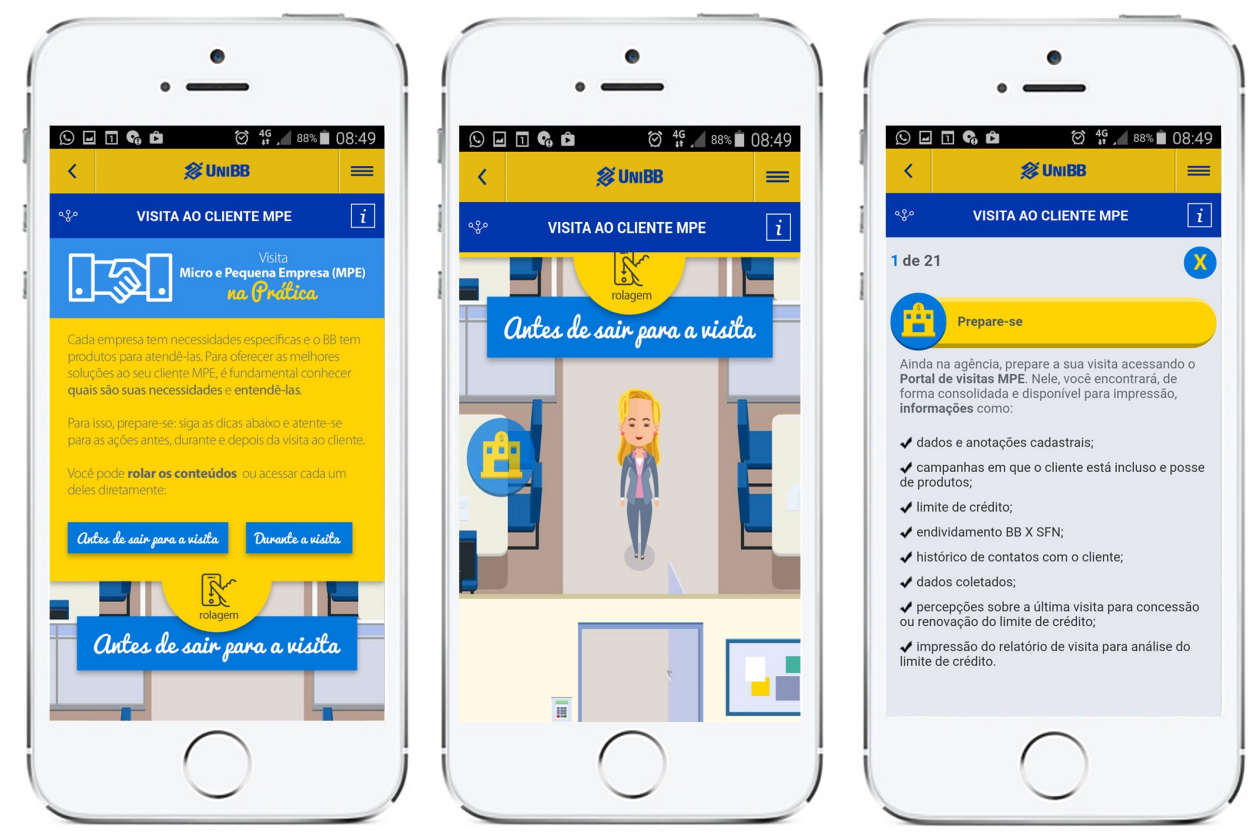

Figura 9 - Telas do Infográfico Visita ao Cliente MPE 


\section{Tabela 17}

Roteiro das questões da análise avaliativa do Infográfico.

\section{INTERFACE GRÁFICA REFERE-SE AO INFOGRÁFICO}

Há relação entre os nomes dos comandos e suas funções?

Há coerência entre o ícone (desenho, seta) e sua função?

A função de um mesmo comando permanece em todas as telas?

As mensagens que o computador dá como resposta às suas ações são claras?

Há indicação sobre o que fazer ao cometer erros de navegação?

A quantidade de passos para se chegar à informação de que preciso é a mínima possível?

A apresentação visual das telas é agradável?

A disposição dos comandos na tela para encontrar as informações desejadas é adequada?

Existem informações que permitem evitar erros de navegação?

A quantidade de conteúdo por tela é adequada (no máximo 20 linhas)?

Há informações sobre sua localização no ambiente eletrônico, em cada momento?

O ambiente eletrônico do curso é coerente à sua experiência com o uso da Internet?

Letras (cor, tipo, tamanho) usadas nos textos são fáceis de ler e coerentes (título maior que subtítulo, subtítulo maior que texto, cor que contraste com o fundo, etc.)?

Qualidade das mensagens que recebo do ambiente eletrônico quando cometo erros de navegação é adequada?

Velocidade das respostas do ambiente eletrônico às minhas ações é a menor possível?

Os recursos de multimídia (animações, sons, vídeos, etc.) funcionam corretamente?

\section{Respostas}

Os comandos são icônicos e intuitivos. Como o espaço é bastante limitado, os poucos comandos possuem um desenho ou letra, que indicam a sua função. $\mathrm{O}$ acesso aos links é totalmente intuitivo.

Sim, conforme item referente à interface gráfica do Roteiro completo no Anexo 1.

Sim. Há funções de navegação dentro do aplicativo (janela com outras opções para conteúdos) e um botão para informações sobre o conteúdo.

Não há respostas do sistema, que apenas responde aos comandos básicos.

Não.

Sim. O acesso, a partir da tela inicial do aplicativo, é feito em três etapas. No conteúdo interno, só há dois níveis de profundidade (passeio e informações a acessadas a partir dos ícones).

Sim. As imagens são bem produzidas e a feição de jogo bem atraente.

Sim. Há poucos comandos na tela.

Não. A navegação é bastante primária e unidirecional.

Sim.

A localização é intuitiva. Só há um cenário que é percorrido pela personagem, que, por sua vez só se desloca em uma direção.

Sim. Apesar das diferenças entre os dois ambientes, a lógica da interface é bastante similar. com a inclusão dos recursos touch screen, raros na experiência com a Internet.

Sim. Os textos são curtos e com apenas dois níveis de leitura (título e conteúdo), alinhados e corridos. Não há conjunto de informações com mais de um título.

Não há interações dessa natureza no Infográfico.

Sim. As respostas são instantâneas. Não há respostas que demandem processamento.

Sim. 


\section{INTERFACE GRÁFICA \\ REFERE-SE AO INFOGRÁFICO}

Há utilização de recursos de multimídia no lugar de texto corrido, quando adequada?

Os recursos de multimídia são utilizados de forma a propiciar o processo de ensinoaprendizagem?

\section{Respostas}

Sim. No conteúdo examinado, as imagens predominam e os textos são informações complementares.

Sim. Atraem a atenção e são objetivos e concisos, facilitando a compreensão e retenção.

Fonte: pesquisa. Roteiro adaptado de instrumento, conforme Abbad (1999)(2010). O roteiro completo econtra-se no Anexo 1.

Apesar de bastante dinâmico, o Infográfico tem baixa interatividade. O usuário percorre um caminho com o avatar e segue os passos da visita, podendo parar em diversos pontos para consultar informações relativas àquele ponto do roteiro da visita. A interatividade é lúdica, traz mais leveza e um pouco de sensação de jogo. Não há inserção de dados ou processamento de informações para tomadas de decisão e, sobretudo, não há troca de informações entre participantes da dinâmica. A baixa interatividade, entretanto, aparenta ser uma estratégia correta, visto que a entrada de dados é um dos maiores desafios dos dispositivos móveis, em especial, os smartphones, evitando-se frustrações e desistências no uso do Infográfico. Em contrapartida, já há outras formas de entrada de dados que podem ser adicionadas, como comandos de voz, fotografias e fontes externas (colaboração), que poderiam ilustrar a visita etc. O volume de texto é adequado (usando-se um critério de objetividade, síntese - 1 página para cada conjunto de informações, evitando-se a rolagem de tela), visto que há grande possibilidade de consulta em lugares com baixa probabilidade de concentração. O apelo estético é muito bom, trazendo atratividade e clarificando as informações repassadas por meio de imagens. O tamanho do conteúdo é adequado e foi verificado nos levantamentos. O acesso ao Infográfico possui alguns dos atributos mais relevantes do modelo identificados neste estudo, como facilidade, acessibilidade $e$ objetividade, por exemplo. O resultado geral é que o objeto possui todas as características necessárias para cumprir com sua função instrucional. 
5.4. Resultados do Estudo 4: Atributos e motivos para a adoção do modelo móvel como estratégia de ensino-aprendizagem

Os resultados do grupo focal puderam ser organizados por meio da categorização das manifestações dos participantes. O produto final é resultante da consolidação de três propostas originadas no grupo Impacto, resultando em um conjunto composto por 5 categorias e 10 subcategorias, como mostra a tabela 18. As quantidades indicadas referem-se à incidência do comentário, indiferentemente de seu tamanho específico. Como a extensão do comentário pode estar relacionado ao modo de manifestação do respondente e não à relevância do conteúdo, julgou-se mais pertinente relacionar-se, na tabela sintética, as quantidades e fazerem-se as considerações respectivas ao conteúdo nas análises. Esse mesmo sistema será utilizado para os Estudos 5 e 6.

\section{Tabela 18}

Descrição das categorias, subcategorias, definições constitutivas e volumetria da incidência das expressões dos participantes.

\begin{tabular}{|c|c|c|c|c|}
\hline Categorias & Definição Constitutiva & Subcategorias & Definição Constitutiva & $\begin{array}{l}\text { Qtd. } \\
\text { ocorrên- } \\
\text { cias }\end{array}$ \\
\hline \multirow{3}{*}{$\begin{array}{l}\text { Características } \\
\text { Desenho } \\
\text { Instrucional }\end{array}$} & \multirow{3}{*}{$\begin{array}{l}\text { Descreve a percepção } \\
\text { dos participantes sobre } \\
\text { os atributos relativos à } \\
\text { modelagem pedagógica } \\
\text { dos conteúdos. }\end{array}$} & $\begin{array}{l}\text { Aplicabilidade no } \\
\text { trabalho / Suporte à } \\
\text { transferência }\end{array}$ & $\begin{array}{l}\text { Descreve a } \\
\text { aplicabilidade do modelo } \\
\text { à situação de trabalho. }\end{array}$ & 3 \\
\hline & & $\begin{array}{l}\text { Domínio dos } \\
\text { planejadores } \\
\text { instrucionais sobre o } \\
\text { recurso/potencialidde }\end{array}$ & $\begin{array}{l}\text { Descreve a falta de } \\
\text { domínio sobre as } \\
\text { possibilidades dos } \\
\text { recursos móveis. }\end{array}$ & 5 \\
\hline & & $\begin{array}{l}\text { Natureza do recurso } \\
\text { instrucional em } \\
\text { dispositivo móvel }\end{array}$ & $\begin{array}{l}\text { descreve o caráter } \\
\text { complementar da } \\
\text { aplicação do recurso no } \\
\text { modelo de ensino- } \\
\text { aprendizagem. }\end{array}$ & 12 \\
\hline \multirow{2}{*}{$\begin{array}{l}\text { Características do } \\
\text { dispositivo móvel }\end{array}$} & \multirow{2}{*}{$\begin{array}{l}\text { Descreve características } \\
\text { do modelo relativas à } \\
\text { condição física e a traços } \\
\text { do conteúdo. }\end{array}$} & $\begin{array}{l}\text { Mobilidade / } \\
\text { Ubiquidade / } \\
\text { Portablidade }\end{array}$ & $\begin{array}{l}\text { Descreve a condição de } \\
\text { acessar o conteúdo em } \\
\text { diversos lugares e em } \\
\text { qualquer tempo. }\end{array}$ & 8 \\
\hline & & $\begin{array}{l}\text { Adequação da } \\
\text { linguagem ao } \\
\text { dispositivo móvel }\end{array}$ & $\begin{array}{l}\text { Descreve conceitos de } \\
\text { linguagem leve, simples, } \\
\text { objetiva e rápida, } \\
\text { facilitando a aplicação } \\
\text { em tarefas. }\end{array}$ & 4 \\
\hline $\begin{array}{l}\text { Cultura de uso e } \\
\text { Contexto }\end{array}$ & $\begin{array}{l}\text { Descreve o } \\
\text { comportamento dos } \\
\text { usuários quanto à adesão } \\
\text { ao modelo mobile } \\
\text { learning. }\end{array}$ & $\begin{array}{l}\text { Adesão a uma cultura } \\
\text { móvel }\end{array}$ & $\begin{array}{l}\text { Descreve aspectos de } \\
\text { adesão dos usuários ao } \\
\text { uso dos dispositivos } \\
\text { móveis. }\end{array}$ & 16 \\
\hline
\end{tabular}




\begin{tabular}{|c|c|c|c|c|}
\hline Categorias & Definição Constitutiva & Subcategorias & Definição Constitutiva & $\begin{array}{l}\text { Qtd. } \\
\text { ocorrên- } \\
\text { cias }\end{array}$ \\
\hline \multirow[b]{2}{*}{$\begin{array}{l}\text { Restrições à solução } \\
\text { móvel como recurso de } \\
\text { aprendizagem }\end{array}$} & \multirow[b]{2}{*}{$\begin{array}{l}\text { Descreve obstáculos à } \\
\text { adesão ao modelo de } \\
\text { aprendizagem móvel. }\end{array}$} & $\begin{array}{l}\text { Dificuldade de acesso } \\
\text { ao conteúdo }\end{array}$ & $\begin{array}{l}\text { Descreve dificuldades } \\
\text { relativas à infraestrutura } \\
\text { tecnológica. }\end{array}$ & 4 \\
\hline & & $\begin{array}{l}\text { Dificuldade de } \\
\text { desenhar instruções em } \\
\text { mobile learning }\end{array}$ & $\begin{array}{l}\text { Descreve dificuldades de } \\
\text { desenvolvimento e gestão } \\
\text { de recursos instrucionais } \\
\text { apoiados em tecnologia } \\
\text { da informação. }\end{array}$ & 7 \\
\hline \multirow{2}{*}{$\begin{array}{l}\text { Avaliação do sistema / } \\
\text { Resultados }\end{array}$} & \multirow{2}{*}{$\begin{array}{l}\text { Descreve aspectos de } \\
\text { avaliação do modelo. }\end{array}$} & $\begin{array}{l}\text { Avaliações formais } \\
\text { (reação/impacto/ } \\
\text { pesquisa) }\end{array}$ & $\begin{array}{l}\text { Descreve métodos } \\
\text { potenciais de avaliação } \\
\text { de desempenho e de } \\
\text { reação. }\end{array}$ & 10 \\
\hline & & Avaliações informais & $\begin{array}{l}\text { Descreve casos de } \\
\text { feedback informais } \\
\text { genéricos sobre o uso do } \\
\text { infográfico. }\end{array}$ & 2 \\
\hline
\end{tabular}

A Tabela 19 registra as subcategorias relacionadas às unidades de registro (UR) e as observações a respeito de cada subcategoria. Os participantes estão indicados da seguinte forma: P1, P2 e P3, para os planejadores instrucionais e D1 e D2 para os participantes da área demandante. O surgimento de concentração de falas em um dos integrantes de cada grupo deu-se pela organização interna dos conjuntos, nos quais, uma das pessoas representou os resultados do grupo, permitindo intervenções dos outros participantes, visto que não era uma orientação, ou norma, da prática. Dessa forma, poderá ser notada, no grupo de planejadores instrucionais, a predominância do participante P2 (3.395 caracteres). É importante notar, pelo mesmo motivo, que a fala tem representatividade do grupo. Vale dizer que, dados os resultados das etapas preliminares, as falas dos dois grupos estão representadas com alguma independência de qual membro do grupo expressou alguma ideia. 


\section{Tabela 19}

Consolidação das unidades de registro do grupo focal.

\section{Características Desenho Instrucional}

\section{Subcategoria Natureza do Recurso Instrucional em Dispositivo Móvel \\ Unidades de Registro}

1. P1 - ... a gente parte da premissa que a gente não põe ações que são obrigatórias em mobile.

2. P1 - A gente ainda estimula a quem usa como complementar.

3. P2 - ... já é uma coisa que a gente pode desenvolver paralelamente. D1 - Ações, soluções complementares. A gente tem o portal UniX que ele é gigante, tem lá um montão de cursos e tem também os cursos que são presenciais e ai nós temos inclusive o curso de visitas que é online, um curso online, tem a duração de uma hora aproximadamente.

4. P1 - Sim. é complementar, exatamente.

5. P1-Essa foi uma das divergências que ele colocou, que teria que ser utilizado também como material de apoio, material complementar...

6. P2 - ... hoje, com as possibilidades que a gente tem, tem usado como material de apoio dentro do contexto que a gente está hoje.

7. P2 - Não, porque essa peça não é obrigatória. É uma coisa disponivel para ajudar, um facilitador, é algo a mais para você consultar se você precisar.
8. P2 - É para ajuda mesmo.

9. D1 - São informações rápidas. ... excesso de informação, assim, a gente é bombardeado por uma série de informações todo dia, a gente não tem falta de treinamento, a gente tem milhões de treinamentos disponiveis. Então realmente falta é se organizar e se estruturar para poder ver o que que realmente vai ser mais útil, mais importante, mais...

10. P1 - De que o caminho tem várias possibilidades. Eu vejo que não é limitador não como material de apoio, ele pode oferecer também como material em si de um curso.

11. P2 - Alguns cursos que tem em mobile têm código, as vídeo-aulas. As videoaulas que tem no Portal [referindo-se ao registro no currículo do funcionário].

12. P2 - Mas nós partimos do pressuposto que isso não é uma peça obrigatória, é complementar, hoje não tem como, e, aí, assim, disponibilizar aquela informação em outros lugares, essa informação desse infográfico já teve em outros cursos, então a pessoa teria acesso aquele conteúdo em outro lugar mas não aquele infográfico talvez, ...

\section{Subcategoria Aplicabilidade no trabalho / Suporte à transferência Unidades de Registro}

1. P2 - ... até de algum conteúdo que seja comum no trabalho dele que é uma forma dele consultar resumidamente.

2. P2 - Então, dentro disso que a gente conversou agora, e no contexto do que a gente vive hoje, a possibilidade que a gente viu aqui é que, por exemplo, como ele vem com um conteúdo objetivo mais resumido da ação ali, que ele foi, no caso desse infografico.
3. P2 - Ele teve o conteúdo de visitas lá no curso e ele tem o infográfico no mobile. Então ele pode pegar aquele conteúdo que está no infográfico e aplicar no trabalho dele. Então seria essa a transferência que ele teria nesse contexto aqui. Nas possibilidades atuais. P1 - Que são soluções que têm aplicação direta no local de trabalho e ...

\section{Subcategoria Domínio sobre o Recurso/Potencialidade Unidades de Registro}

1. P1-A gente colocou assim que essa questão que é pouco conhecida por que está num estágio inicial de implantação do mobile. tem muito pouco tempo ...

2. P1 - Eu acho que é interessante até no sentido do que a gente falou de avançar na construção de novas peças e só vamos conseguir quando identificarmos os problemas que existem...
3. P1 - A gente colocou aqui a necessidade de se estudar um pouco mais as possibilidades ... e que a gente poderia avançar um pouco mais para melhorar a aprendizagem. 
4. P1 - ... que acho que a gente conhece muito pouco ainda, não tenho segurança para dizer isso, né? Acho que a gente teria que estudar mais essa questão da interatividade, ... a gente trazer uma interatividade dentro de um processo de aprendizagem e não só de movimentação de tela, algumas outras possibilidades, você estudar um pouco mais a ferramenta. ...
5. P1-Assim, a gente talvez tenha que avançar. É uma coisa nova. D1 - A gente ainda ouse pouco em relação ao treinamento e pode ser que um dia ainda venha a substituir o portal. P1 - Eu acho que é tudo novo ainda, essa é a grande questão, é que a gente começou a usar agora, ... ai a gente vai desenvolver cada vez mais isso, criando embasamento teórico ...

\section{Subcategoria Mobilidade / Ubiquidade / Portablidade \\ Unidades de Registro}

1. P1 - A gente colocou a mobilidade, né? Que o formato proporciona ... o objetivo ser a visita a clientes que eles poderiam usar esse fator positivo ... no caminho eles poderiam acessar essas informações.

2. P2 - Você assiste em mobile em qualquer hora. Tem futuro. Assiste qualquer hora.

3. P1 - ... que possam ser acessadas não somente no local fisico de trabalho ... qualquer lugar.

4. P2 - ... como o público é gerente, eles também tem smartphone corporativo era uma coisa que também facilitava porque ninguém teria problema de não ter uma peça compativel, assim, recurso compativel pra ver a peça.

5. P2 - Facilidade de acesso mesmo, quando ele tá com o smartphone ele pode olhar a qualquer momento é só colocar o dedo, não precisa ficar ligando o computador...
6. P2 - ... E quando chego em casa faço os downloads no wi-fi e depois assisto quando tô indo pro trabalho. ... Aí, se for uma videoaula por exemplo que é um pouquinho maior, aí consome um tantão. A pessoa baixa, depois vai escutando no caminho para o trabalho. ... "baixe no cellular para poder acessar os conteúdos mobile” [refere-se a uma suposta mensagem de estímulo ao uso] ...

7. D2 - ... você vai acessar na hora que você não estiver fazendo nada e não na hora que você falar com o seu cliente tête-à-tête, e que você precisa resolver alguma coisa que você vai acessar ...

8. P3 - ... então ele poderia fazer, o que já existe hoje, mas tem que aumentar um pouco mais, que é a pessoa ter a essa possibilidade de fazer um download dessas peças, para que ele possa fazer a consulta offline ...

\section{Subcategoria Adequação da Linguagem ao Dispositivo Móvel}

Unidades de Registro

1. P3 - ... também colocamos que a peça permite uma linguagem mais leve, mais simples mais objetiva, formato interativo.

2. P2 - Porque a gente identificou também que os outros cursos também possuem conteúdo que podem ser disponibilizados lá no mobile de forma objetiva para facilitar essa aplicação do que ele aprendeu no treinamento ou ...
3. D2 - Assim. o meu pai, na minha família, ele não gosta muito de smartphone, mas no dia que ele viu código de barras, ele falou: agora eu vou baixar! ...

4. D1 - São informações rápidas.

\section{Subcategoria Adesão a uma Cultura Móvel Unidades de Registro}

1. D1 - No mobile, o X Mobile (nome do aplicativo), embora lá tenha cada dia um número maior de acessos, ...

2. P2 - Então, hoje em dia a maioria das pessoas tem né? (smartphone)

3. D1 - Acho que a gente atrai dessa forma.

4. D1 - É buscar alternativas de divulgação mesmo, de incentivo.

5. P2 - Acho que é mais de estímulo mesmo porque de divulgação já fizemos tudo. A solução é estimular mesmo, descobrir alguma forma de trazer mesmo essa importancia para ele. É criar necessidade para ele poder usar o negócio. É para ajuda mesmo.
6. D1 - ... excesso de informação, assim, ... a gente não tem falta de treinamento, a gente tem milhões de treinamentos disponíveis. Então realmente falta é se organizar e se estruturar para poder ver o que que realmente vai ser mais útil, mais importante, mais...

7. D2 - ... ter condição de acessar de estímulo, incentivar a utilização.

8. D2 - ... então é desenvolver peças que sejam mais atraentes para os funcionários, úteis para o desenvolvimento do trabalho.

9. D2 - Outra dificuldade aí mesmo é de o funcionário saber que existe saber que é útil. 
10. D2 - Nem um quarto do número de funcionários. 25 mil, então a pessoa não sabe que existe, não é que não goste ou não acesse porque ela não goste, mas é porque ela não sabe que tem e colocamos como solução que temos que criar peças mais ligadas diretamente ao trabalho da pessoa, que ela sinta necessidade de acessar na hora que ela está fazendo alguma coisa.

11. D2 - Ah, tenho aqui um guia rápido que pode me ajudar com esse problema que eu estou aqui, que ela vai ter que entrar e eu não preciso ficar divulgando pra ela. Ela sabe que ela pode entrar e ter aquela informação. Acho que as peças que a gente tem até então, até antes desses infográficos eram muito ligados a assuntos que não estavam relacionados diretamente ao trabalho.
12. Pl - ... tem gente que não sabe que tem mobile, que foi uma questão até que foi colocada aqui.

13. D1 - ... ainda tem essas restrições, nem todo mundo tem mobile, nem todo mundo baixou o aplicativo da UniX mobile. G2 - Tem gente que não tem celular compativel. G5 - São dificuldades...

14. P1-É que a gente tem que ultrapassar algumas barreiras, da acessibilidade.

\section{Subcategoria Dificuldade de Acesso ao Conteúdo Unidades de Registro}

1. P2 - Como o banco é muito grande tem lugar que não tem infraestrutura suficiente. Acesso à rede, internet para as pessoas usarem nem a internet no computador, quanto mais uso no celular.

2. D1 - As operadoras hoje não disponibilizam uma rede, pelo Brasil todo, então, por exemplo, uma fronteira lá no norte, talvez não tenha uma antena que suporte um acesso para uma pessoa fazer um download no cellular. Em alguns lugares que a internet $2 G$ é a melhor que tem. Isso dificulta um pouco essa parte de todo mundo poder acessar e assim não tem nada que a gente possa fazer com relação a isso.
1. P2 - ...porque ela tem a dificuldade em acessar o aplicativo. Isso foi uma coisa que a gente listou. [manifestação de caráter genérico. Não especifica que tipo de dificuldade]

3. P3 - E colocamos também o problema de conexão. Imaginamos que a pessoa está lá, trabalhando, tem o ambiente, está numa grande cidade, tem a conexão, de repente vai para o interior, viaja, e nesses locais às vezes não têm acesso. Então como ele fica? Com acesso limitado, ...

\section{Dificuldade de Desenhar Instruções em Mobile Learning Unidades de Registro}

1. P1 - ... Temos a nossa tecnologia [refere-se à área de TI da organização] que trabalha em cima de priorizações. É complicado a gente imaginar uma coisa bem mais complexa, tipo um game.

2. D1 - ... Teve lá um decreto tal que mudou tal coisa e a gente tem que mexer nos nossos produtos para se adequar, então já é uma exigência legal, primeiro lugar. Segundo lugar, aspectos negociais e tudo mais que impacta diretamente o resultado do Banco e ai acaba que essas ações, elas nunca são priorizadas, então.

3. D2 - ... temos uma estrutura que pode desenvolver, que pode fazer, mas acho que esse problema ai está profundo lá dentro dessa estrutura, assim, como ela faz para poder attender todas as áreas.
4. D 2 - ... Meu conceito é assim: tem algum problema para resolver? Tem, mas infelizmente, não é da nossa alçada é la dentro. Não conheço a estrutura, não sei como é mas a gestão tem que ser melhorada.

5. P1 - Quando a gente migrou para o Portal, saímos um pouco desta questão de ficar refém da tecnologia e entrar nessa fila porque com o Portal temos o fornecedor que desenvolve essas ações pra gente.

6. Pl - ... Existe. Então, existem dificuldades, mas tentamos com muita criatividade e habilidade conhecendo o Banco, driblá-las e criando soluções, mas quanto às dificuldades em TI, conseguimos sair um pouco dela quando colocamos no Portal. É, temos hoje mais celeridade para desenvolver as peças.

7. P1-É um fornecedor externo. Ai temos a restrição orçamentária porque tem que pagar o fornecedor. 


\section{Subcategoria Avaliações formais (reação/impacto/pesquisa) Unidades de Registro}

1. P3 - Nós colocamos aqui que a gente consegue medir o indice com uma avaliação de reação, de repente no formato de quiz ao final do aplicativo com perguntas rápidas ou então também com...

2. P1 - Porque a gente não tem avaliação de reação né?

3. P3 - É, então concluiu a peça e tal, o que que ele achou, bem rapidinho, formato de quiz interativo.

4. $\quad$ P2 - ... pensei mais avaliação de impacto no trabalho, ... como a gente tinha uma lacuna de desempenho, de como desenvolver o modelo de treinamento e a gente partiu disso para desenvolver uma ação que se ajustasse àquele problema. Então a gente teria como fazer a avaliação de impacto no trabalho...

5. D1 - Na verdade, a gente tem dentro do banco uma ferramenta de avaliação de desempenho, do gerente da carteira, então a gente pensou, assim, em isolar de alguma forma variar [sic] esse resultado. Se as pessoas que acessaram a solução mobile, se de alguma forma elas melhoraram o resultado de sua carteira, de clientes, nesse sentido.

6. P2-Aí, poderia avaliar o antes e depois, como incremento, talvez nessa parte das visitas. É mas a gente entende também a dificuldade de inferir esse resultado à ferramenta à solução específica. Não tem como você garantir. Ou, isolar é muito dificil. O que dá pra fazer é um link: as pessoas que acessam efetivamente fazem visitas e essas visitas geram negócios. Apesar de a gente ter $n$ estímulos para visitas acontecerem da forma correta. ... Mas a gente pode associar que esse indicador contribui para o sucesso. A gente pode é isolar ele. Não sei se isolar é a palavra, mas a gente pode avaliar quem já acessou essa carteira e quem não acessou.

7. D2 - No momento do registro da visita a gente pode perguntar: foram utilizadas as orientações do infográfico? Sim ou não? Isso daí acho que até estimularia o acesso porque ele pode dizer que da primeira vez não sabia, mas da segunda, tem um negócio lá.

8. [Vários participantes se sobrepondo e concordando com pesquisa] Acho que seria pesquisa. Objetiva, com pergunta objetiva. É, rápida. O importante é a pesquisa não durar mais do que a própria duração da peça.

9. D2 - Aí, eu mencionei a questão de uma pesquisa com o funcionário, uma pesquisa direta, se tem usado no trabalho...

10. P3 - Uma outra possibilidade seria através de pesquisa espontânea respondida pelo participante. A pessoa concluiu, é ticado lá, manda um e-mail, alguma coisa, um convite pra acessar o link e responder. Mais ou menos na linha do que você comentou.

\section{Subcategoria Avaliações informais \\ Unidades de Registro}

1. D1 - ... mas informalmente tem sido muito positivo, as pessoas tem acessado, têm gostado ... um dos educadores da oficina, que diz que sempre que está aplicando a oficina, se ele fala sobre o aplicativo para as pessoas baixarem e fala que as pessoas gostam, mencionam que é legal, alguns dizem que nem sabiam que existia e assim, elogiam, mas só informalmente. Fulano já recebeu uns feedbacks positivos. Todo mundo comenta.
2. D1 - A gente tem milhões de informações, então assim, tem todo tipo de percepção possivel, tem funcionário que ama, que adora e tem aquele que reclama mesmo.

Foi possível compreender que as duas primeiras etapas do grupo focal (questionários escritos) tiveram relevância ao consolidar e harmonizar as percepções dos integrantes. Os conceitos (manifestações/respostas) se consolidaram nas primeiras etapas e surgiram como direcionadores da discussão final, respondendo precisamente à função do grupo focal, conforme a base teórica adotada. Os trabalhos, nas três etapas, mostraram um alto grau de alinhamento e convergência. $\mathrm{O}$ fato deve-se provavelmente a que todos os particpantes trabalharam no projeto, com maior ou menor contribuição. Assim, muitos dos debates relatados podem já haver ocorrido em outros no desenvolvimento do produto. A primeira 
etapa, conforme descrito neste método, consistiu em uma etapa individual, que alinhou-se conceitualmente aos resultados dos grupos por perfil e do grupo geral, permitindo se afirmar que o conjunto final traz consigo as impressões e ideias expressadas pelos participantes, também de modo individual, enriquecendo os resultados e evitando-se esse problema típico dos grupos focais.

Os resultados da análise da incidência numérica dos termos mais relevantes não trouxeram contribuições significativas à análise do resultado, mas confirmam itens naturalmente associados ao contexto estudado, como o termo trabalho, o mais presente no corpus. Por tratar-se de ambiente organizacional, é natural que assim o seja. O papel dos participantes também é outro fator possível para esse resultado, visto que o treinamento deverá ser aplicado em situação de trabalho por função e natureza do treinamento. O termo complementar também mostra alguma relevância e revela um traço forte no entendimento do modelo utilizado. Rápido, objetivo e resumido também têm a mesma característica daquele, porém diz respeito a um conceito mais abrangente, o de eficácia, visto que é, pelo interpretado a partir dos registros, condição importante para sua aplicação à realidade de trabalho. Os outros termos examinados não mostram relevância em relação à quantidade de incidências, mas guardam outros atributos analisados no exame das categorias. Os resultados foram interpretados e agrupados por um caráter transversal, fragmentando os temas genéricos, apresentados nas questões. O exame da coleta do grupo focal permitiu a identificação das ideias e percepções que nortearam a opção pela solução da estratégia móvel pela organização.

As manifestações dos planejadores e demandantes sugerem que a organização não está ainda consciente do potencial dos dispositivos móveis (essa carência é declarada). As análises indicam uma visão prática do tema, mas ainda baseadas principalmente em ideias intuitivas sobre as características e atributos do modelo. Confirma essa ideia, a subcategoria Domínio sobre o recurso/potencialidade, cujas manifestações revelam o pouco conhecimento sobre o recurso e da necessidade de aprofundamento para a construção de novas peças.

No entanto, há percepção de que há melhorias a serem incorporadas, como mais interatividade. Outra noção que surge fortemente é a discussão sobre o caráter complementar da solução, que se justifica por vários motivos, mas também releva dependência do recurso às práticas tradicionais. Não houve unanimidade nesse aspecto, reforçando o caminho ainda a ser percorrido até soluções completas para o treinamento no contexto estudado. Mobilidade é 
um atributo marcante nas manifestações dos participantes, mas também com timidez em relação à exploração das nuances dessa característica.

As categorias localizadas correspondem bem às questões induzidas, mostrando acerto no método, no desenho do grupo e na identificação dos temas mais relevantes. Puderam mostrar bem as expectativas dos intervenientes da solução sobre resultados esperados. A principal é que o modelo seja construído para conteúdos objetivos e aplicáveis à situação de trabalho de modo eficaz (rápido, objetivo etc.). Embora aparentemente essa afirmação esteja associada à prática de visitas, tarefa para a qual foi desenvolvido o infográfico, essa característica pode ser extrapolada, com base no levantado no que refere à prática e o modelo job aid.

Na subcategoria Adequação da Linguagem ao Dispositivo Móvel, na unidade de registro 2, um dos participantes (P2) afirma que já foram identificados outros conteúdos que podem ser modelados para o dispositivo móvel. Essa expectativa alinha-se à variável testada positivamente para dispositivos móveis utilidade percebida (perceived usefulness - PU) do modelo TAM de Davis (1989), quando aplicada ao usuário, mas proposta coerentemente pelos desenhistas instrucionais. Vale dizer que a proximidade do recurso à realidade do usuário predispõe o indivíduo à utilização desse modelo tecnológico. No caso específico do treinamento, poderá ter influência sobre a transferência de treinamento.

Outro fator que surge de modo indireto é a autonomia. O trecho "ele teve o conteúdo de visitas lá no curso e ele tem o infográfico no mobile, então ele pode pegar aquele conteúdo que está no infográfico e aplicar no trabalho dele." O trecho (UR 3), classificado na subcategoria Aplicabilidade no trabalho/Suporte à Transferência, indica que o usuário, por estar fora da situação de aprendizagem formal, poderá lançar mão do conteúdo complementar e isso ocorrerá quando ele detectar a oportunidade ideal e adequada para a consulta. Esse comportamento está associado à variável independente autogestão da aprendizagem, testada por Wang, Wu e Wang (2009) para a variável critério intenção comportamental de uso de mlearning. A testagem se deu por um modelo derivado do TAM, o UTAUT, abordado na revisão de literatura, e que adapta as varíaveis do modelo original ao m-learning. A variável valor percebido de mobilidade (perceived Mobility Value - PMV), integrada ao modelo TAM por Huang, Lin, Chuang (2006), que representa a consciência do valor da mobilidade, foi também testada positivamente para o m-learning e surge como conceito importante nas 
manifestações do grupo, mas como previsão, visto que não houve ainda uma avaliação dos usuários, que será objeto do estudo 3. Autoeficácia, apontada por Fadare et al. (2011) como a variável mais influente no construto behavorial intention (intenção comportamental), parte do modelo TAM, não surgiu no debate como problema, talvez por sua localização no usuário.

As dificuldades para a aplicação do modelo, segundo o grupo, apontam fatores intrínsecos da organização, como produção dos conteúdos e meios de demanda ao fornecedor. E fatores extrínsecos, como a oferta de sinal de telefonia em regiões atendidas pela organização. No que diz respeito à avaliação, o grupo realizou um exercício de imaginar qual seria a melhor solução a avaliação dos conteúdos do modelo. A principal lacuna aparente é, como outras situações de educação mediada, a utilização de instrumentos testados e utilizados para outros modelos de capacitação, o que pode fragilizar a avaliação dos resultados das soluções baseadas nos modelos móveis. Questões de custo, referentes à gestão orçamentária e de custos também foram mencionados bem como alguns problemas de gestão interna da organização, visto que há necessidades de priorização de ações a serem executadas no âmbito de toda a universidade corporativa.

5.5. Resultados do Estudo 5: Atributos e motivos para a adesão ao modelo móvel pelos usuários

A categorização do conteúdo das respostas dos participantes resultou em um conjunto composto por 4 categorias e 8 subcategorias, como mostra a tabela 20 .

\section{Tabela 20}

Descrição das categorias, subcategorias, definições constitutivas e volumetria da incidência das expressões dos participantes.

\begin{tabular}{|ll} 
Categorias $\quad$ Definição Constitutiva & Subcategorias \\
& $\begin{array}{l}\text { Características físicas } \\
\text { do dispositivo } \\
\text { (tamanho, peso, } \\
\text { facilidade de } \\
\text { manuseio) }\end{array}$
\end{tabular}

Definição Constitutiva

Qtd. ocorrên -cias

Descreve os atributos de mobilidade, disponibilidade, agilidade e praticidade. 


\begin{tabular}{|c|c|c|c|c|}
\hline Categorias & Definição Constitutiva & Subcategorias & Definição Constitutiva & $\begin{array}{l}\text { Qtd. } \\
\text { ocorrên } \\
\text {-cias }\end{array}$ \\
\hline \multirow[t]{2}{*}{$\begin{array}{l}\text { Características } \\
\text { do } \\
\text { dispositivo } \\
\text { móvel }\end{array}$} & \multirow[t]{3}{*}{$\begin{array}{l}\text { Descreve características } \\
\text { do modelo móvel em } \\
\text { termos físicos } \\
\text { (aparelho), lógicos } \\
\text { (navegação) e } \\
\text { pedagógicos } \\
\text { (infográfico). }\end{array}$} & $\begin{array}{l}\text { Características da } \\
\text { interface }\end{array}$ & $\begin{array}{l}\text { Descreve os atributos de } \\
\text { interatividade, } \\
\text { navegabilidade, } \\
\text { acessibilidade, facilidade, } \\
\text { simplicidade e praticidade } \\
\text { de navegação. }\end{array}$ & 21 \\
\hline & & $\begin{array}{l}\text { Características do } \\
\text { conteúdo }\end{array}$ & $\begin{array}{l}\text { Descreve os atributos de } \\
\text { aplicabilidade, eficácia, } \\
\text { qualidade, clareza e } \\
\text { objetividade do } \\
\text { infográfico. }\end{array}$ & 13 \\
\hline \multirow{3}{*}{$\begin{array}{l}\text { Aplicabilidade } \\
\text { no trabalho }\end{array}$} & & $\begin{array}{l}\text { Aplicação prática dos } \\
\text { conteúdos }\end{array}$ & $\begin{array}{l}\text { Descreve objetivamente a } \\
\text { aplicação dos conteúdos na } \\
\text { prática do trabalho e } \\
\text { confirma a possibilidade de } \\
\text { incremento no resultado do } \\
\text { trabalho. }\end{array}$ & 23 \\
\hline & \multirow[t]{2}{*}{$\begin{array}{l}\text { Descreve os atributos } \\
\text { relativos à aplicação } \\
\text { prática do aprendido no } \\
\text { trabalho }\end{array}$} & $\begin{array}{l}\text { Aplicação na gestão } \\
\text { da tarefa }\end{array}$ & $\begin{array}{l}\text { Descreve os benefícios } \\
\text { quanto aos modos de } \\
\text { realizar as tarefas } \\
\text { abordadas. }\end{array}$ & 19 \\
\hline & & $\begin{array}{l}\text { Avaliação/Melhora no } \\
\text { processo da tarefa/ } \\
\text { Resultados }\end{array}$ & $\begin{array}{l}\text { Desreve aprimoramentos } \\
\text { na execução das tarefas } \\
\text { abordadas. }\end{array}$ & 7 \\
\hline $\begin{array}{l}\text { Dificuldade de } \\
\text { Acesso }\end{array}$ & $\begin{array}{l}\text { Descreve as } \\
\text { dificuldades gerais de } \\
\text { acesso ao infográfico }\end{array}$ & - & - & 6 \\
\hline $\begin{array}{l}\text { Aplicabilidade } \\
\text { em outros } \\
\text { treinamentos }\end{array}$ & $\begin{array}{l}\text { Descreve a intenção de } \\
\text { consumir conteúdos no } \\
\text { modelo móvel }\end{array}$ & - & - & 13 \\
\hline
\end{tabular}

Fonte: Pesquisa.

A Tabela 21 mostra o detalhamento das categorias e suas respecitvas unidades de registro. 


\section{Tabela 21}

Consolidação das unidades de registro dos questionários.

\section{Categoria Características do Dispositivo Móvel \\ Subcategoria Características Físicas do Dispositivo}

Unidades de Registro

\section{Pergunta 1}

1. R6-Maior acessibilidade ...

2. R6-Agilidade

3. R13 - Disponibilidade da ferramenta, podendo ser acessada a qualquer momento.

4. R19-Maior facilidade em acessar a ferramenta da UniX.

5. R19 - Posso utilizar em vários locais onde eu esteja com acesso à internet.

Pergunta 2

6. $R 1$ - ...mobilidade

7. R6 - Tendo em vista que posso ter acesso a qualquer hora e em qualquer lugar.

8. R15 - Achei importante porque posso relembrar alguns conceitos das visitas mesmo estando fora da agência.

9. R5 - ... Pois, podemos acessar o conteúdo a qualquer hora e lugar, ou seja, as informações, dicas e passo a passo tudo em um lugar só...

Pergunta 6

16. R14 - Ganho de tempo na coleta dados para visitas.

17. R10 - Praticidade ...

18. R3 - Agilidade e facilidade de acesso.

19. R1 - ... facilidade do aceso as informaçoes.

20. R6 - Os benefícios são o acesso fora do horário de trabalho, tendo melhor aprendizagem.

21. R13 - Disponibilidade de horário para realização dos cursos, podemos utilizar tempo ocioso que perdemos no transito dentro de ônibus, Metrô para realização dos mesmo...
10. R18 - Quanto a questão da portabilidade do conteúdo, onde o funci pode acessar a qualquer hora e lugar (desde com conexão à Internet).

11. R11 - ... seja no ambiente de trabalho ou no deslocamento para realização de visita ao nossos clientes.

12. R16 - ... pois mesmo no táxi, a caminho da visita podemos checar se não esquecemos nada.

Pergunta 3

13. R6 - Pois não preciso de hora nem local próprio para uso.

Pergunta 5

14. R2 - ... sempre traz orientações que na correria do dia à dia, deixamos de observar.

15. R12 - O mobile possibilita estudo em várias situações/ambientes/horários.

22. R8 - Acho uma excelente estratégia por se tratar de algo simples...

23. R15 - $O$ acesso fora do local de trabalho.

24. R19 - O beneficio é que o funcionário pode acessar em qualquer lugar onde estiver e possuir acesso a internet.

25. R18-Como principal beneficio, podemos citar a portabilidade da informação, onde o usuário pode acessá-lo a qualquer hora e lugar.

26. R11-Ampliação e facilidade no acesso.

27. R16 - Facilidade de acesso... pois aproveitaríamos melhor o tempo, enquanto estamos, por exemplo no táxi. 


\section{Subcategoria Características da Interface \\ Unidades de Registro}

Pergunta 1

1. R10 - Interatividade e...

2. R10 - ... praticidade.

3. R3 - Facilidade para leitura.

4. R17 - Facilidade no acesso através do aplicativo UniX.

5. R9-Praticidade ...

6. $R 6$ - ... facilidade...

7. R4 - Facilidade de acesso, ...

8. R3 - ... facilidade de acesso.

9. R11 - A utilização dos aplicativos através da plataforma mobile se deve pela facilidade...

10. R16 - ... prático.

11. R11 - ... e simplicidade no acesso, ...
Pergunta 2

12. R10 - Ferramenta de fácil navegação ...

13. R14 - ... com fácil acesso conteudo.

14. R13 - Fácil de utilizar...

15. R9-Achei prático...

16. R13 - ... fácil de utilizar...

17. R19 - ... considerando todos os aspectos que ajudam e facilitam o uso da ferramenta no celular.

18. R12 - ... facil navegação...

19. R18 - Infográfico com layout amigável, facilitando a navegação entre as etapas.

Pergunta 3

20. R5 - ... e facilidade de acesso.

21. R1 - ... devido a facilidade de acesso as informações

\section{Subcategoria Características do Conteúdo}

Unidades de Registro

\section{Pergunta 1}

1. R4 - ... clareza e objetividade.

2. R17 - ... adquirir conhecimento.

3. R5 - Conhecimento, ...

Pergunta 2

4. R1-... e com texto claro.

5. R17 - ... e com boas dicas.

6. R2 - Conteúdo apresentado, serve como orientação para se preparar para uma visita

7. R13 - ... conteúdo muito bom.
Pergunta 3

8. R16 - [Muito útil] ... em especial o "faça perguntas", o "fique atento" ...

9. R10 - Conteúdo bastante produtivo e atualizado.

10. R5 - Resumo do conteúdo.

Pergunta 7

11. R6 - As dicas tanto teóricas quanto práticas foram muito eficazes. Através da revisão de conceitos do nosso cotidiano.

12. R1 - ... durante a oficina debatemos como abordar os clientes durante a visita...

13. R16 - Através da facilidade de acesso e pelo conteúdo. 


\section{Categoria Aplicabilidade no Trabalho \\ Subcategoria Aplicação Prática dos Conteúdos \\ Unidades de Registro}

\section{Pergunta 1}

1. R14 - Auxiliar visita aos clientes com mais informações.

2. R1-Para orientar na forma de preparo e abordagem durante as visitas.

3. R8-Aprimorar a forma de visitar os clientes.

4. R15 - Os motivos foram: - melhora na abordagem para visita; - adotar o padrão da empresa X nas visitas.

5. R11 - ... sendo o conteúdo inserido no tema Visita ao Cliente MPE, de total relevância e aplicabilidade em minha atividade.

6. R16 - Trata-se de um informativo muito útil e...

Pergunta 2

7. R1 - ... para reforçar a forma correta de abordagem durante a visita.

8. R12 - ... é possível aplicação do conteúdo pelo gerente de contas.

9. R1 - ... e orientações na abordagem durante as visitas.

10. R8 - ... e a segunda parte orienta como se comportar em uma visita.

\section{Pergunta 3}

11. R14 - ... dados do endividamento empresa principalmente na oferta novos créditos. Compra de dividas.

12. R2 - Na visita ao cliente, para tomar conhecimento dos assuntos relacionados ao segmento da empresa, ouvir o cliente com atenção as dicas dadas por ele, sobre o que ele espera do banco como apoio a necessidade de sua empresa.
13. R19 - Utilizei no trabalho as formas de abordagens aos clientes e a importância da preparação da visita.

\section{Pergunta 4}

14. R13 - ... todo conhecimento adquirido melhora nossa abordagem e quando demonstramos conhecimento dos produtos oferecidos gera confiança por parte do cliente.

15. R4 - ... a interação com o cliente, ajudando a melhorar o foco da visita e também na adequação da mesmo para cada cliente.

16. R19 - Principalmente na forma de abordar o cliente e preparar a minha visita ao cliente.

17. R18-O incremento principal que eu tive foi na parte de comunicar-se com o cliente, evitando falar siglas como ...

Pergunta 6

18. R5 - Aplicação imediata.

19. R18 - Da melhor forma possivel, tendo em vista que a visita é fator crucial para os negócios no setor PJ.

20. R1 - ... e trocamos experiências com os outros colegas, o que é mais importante.

21. R5 - Pois, a troca de experiências e informações é fundamental nos dias de hoje.

Pergunta 7

22. R10 - Através da revisão de conceitos do nosso cotidiano

23. R16 - Através da facilidade de acesso e pelo conteúdo. 
Subcategoria Aplicação na Gestão da Tarefa

\section{Unidades de Registro}

Pergunta 2

1. R9 - ... muito útil considerando que o conteúdo tem total aderência ao dia a dia da minha função.

2. $R 2$ - ... realizar vendas e administrar nosso tempo, tem sua utilidade,...

3. R11 - ... permitindo a realização de planejamento,...

4. R8 - A parte de preparação foi mais utilizada como um roteiro...

5. R15 - ... pois como citado na pergunta acima, posso relembrar e aplicar alguns procedimentos que com o passar do tempo vamos nos esquecendo.

6. R4 - ... sempre navegar no infográfico antes de qualquer visita, a fim de tirar o máximo de proveito.

12. R15 - ... nas visitas que faço atualmente procuro seguir o roteiro, estudando a atividade da empresa, sempre ouvindo mais o cliente para entender suas necessidades.

13. R5 - Aprimoramento e habilidade em aplicar os conhecimentos em situações adversas.

14. R16 - Direcionamento para a visita.

Pergunta 5

15. R1-Poderiamos ter uma ferramenta uma espécie de um questionário a ser preenchido e gerar um relatorio para nos auxiliar na analise, posterior a visita.
7. R8 - Muito interessante, pois a visita não se limita somente a ir até o cliente, mas também a se preparar para visitar o cliente e o infográfico nos auxilia neste item.

\section{Pergunta 3}

8. R9 - Melhorou a organização do processo de visita ao cliente - triagem - melhoria na qualidade da visita.

9. R11 - Na realização de planejamento e abordagem para realização de visita.

10. R8 - ... para que já tem visita em sua rotina de trabalho e para os novos gerentes que estão se preparando para visitar novos clientes.

Pergunta 4

11. R9 - Melhorou o tempo de organização das visitas - processo orientado facilita o dia a dia tão cheio de assuntos diversos.

\section{Pergunta 6}

16. R14 - Ganho de tempo na coleta dados para visitas.

17. R14 - Agilidade no atendimento e melhor condução nas visitas com maior propensão negocial.

Pergunta 7

18. R1 - ... durante a oficina debatemos como abordar os clientes durante a visita.

19. R18 - Da melhor forma possível, tendo em vista que a visita é fator crucial para os negócios no setor PJ.

Subcategoria Avaliação/Melhora no Processo da Tarefa/Resultados

Unidades de Registro

\section{Pergunta 3}

1. R13 - Todo conhecimento adquirido nos ajuda na melhor abordagem ao cliente, gerando maior assertividade.

\section{Pertunta 4}

2. R8 - ... pois por mais experiências que temos, a quantidade de informação é muito grande e podemos esquecer de alguns detalhes essenciais para o atingimento de nossos objetivos.

3. R11 - Na realização de melhor qualificação das visitas PJ [pessoa jurídica].
Pergunta 7

4. R14-Agilidade no atendimento e melhor condução nas visitas com maior propensão negocial

5. R9 - Melhorou a qualidade da abordagem feita aos clientes.

6. $R 4$ - Melhorou a qualidade das visitas e consequentemente na oferta de produtos mais adequados, além de permitir melhor análise da real situação dos clientes.

7. R11-Ocorreu um incremento no resultado, através da realização de visitas mais qualificadas. 
Pergunta 2

1. R2 - Devido a correria do dia a dia, muitas vezes não há tempo hábil para acessá-lo ... mas repito, devido a correria do dia a dia, torna seu acesso inviável.

2. R4 - No município onde estou localizado a experiência não foi boa devido à operadora de telefonia, pois o sinal é restrito e a internet móvel é muito lenta.
Pergunta 5

3. R14 - Um pouco lento no carregamento.

4. R13 - .. porém como trabalho no interior do estado (Macaé-RJ) tive alguns problemas com sinal de internet. Seria bom se pudéssemos baixar o conteúdo e acessar sem utilização de dados ou wifi (pelo menos eu não consegui utilizar sem acesso a internet).

5. R8 - A dificuldade encontrada não foi propriamente no infográfico, mas na necessidade de ter acesso à internet pelo celular para consultá-lo.

6. R4 - Dificuldade de internet nos municipios do interior. Somente consigo acessar de casa via wi-fi.

\title{
Categoria Aplicabilidade em Outros Treinamentos
}

\author{
Unidades de Registro
}

Referem-se somente à pergunta 6

1. R10 - ... e acho que sim, pode ser estendido a outros cursos

2. R1 - Acho muito válido para outros cursos.

3. R9 - ... acredito que possa ser adaptado à outros conteúdos na PJ, principalmente direcionados para vendas.

4. R2 - Cursos ou regras sobre produtos de crédito/ seguros/serviços específicos do $B B$, poderiam constar em algum dispositivo, pois o BB possui um portfólio grande de produtos e muitas regras diferentes entres eles, com isso em uma visita, poderíamos consultar na própria visita, as características e a documentação necessária para atender a demanda do cliente.

5. R13 - Com certeza outros cursos seriam bem vindos.

6. R8 - Acho ótimo que outros cursos utilizem esse modelo.

7. R15-Com certeza outros cursos poderiam ser incluidos.
8. R5 - Sugiro que outros cursos, também, deverão usar esse modelo.

9. R19 - Sim, acho que todos os cursos da UniX, poderiam ser neste mesmo dispositivo e conteúdo.

10. R12 - Acredito que outros cursos poderiam utilizar a plataforma mobile, ...

11. R18 - Acho que outros cursos sim poderiam usar esse modelo, como os que utilizamos no dia a dia, a exemplo o de cobrança e recuperação de crédito, informando qual a melhor linha a ser oferecida para parcelar a dívida de determinado cliente.

12. R11 - Acredito que esse modelo poderia ser ampliado para demais cursos.

13. R16 - Acho que outros cursos poderiam usar esse modelo, ...

Fonte: Pesquisa.

A técnica do questionário produz um resultado mais dirigido, porém oa resultados foram tão ricos quanto aqueles obtidos por meio de entrevista e grupo focal. Dessa forma, alguns conjuntos de ideias referem-se diretamente a uma resposta específica, consolidando-se como temas verticalizados no resultado, apresentando resultados mais concentrados.

As perguntas 3, 4, 5, 6 e 7 do questionário possuíam desdobramentos, ou mais de uma pergunta dentro da própria pergunta. A primeira parte da pergunta, nesses casos, ensejou 
respostas do tipo "sim", não" e similares. Essas respostas não constituem conteúdo para a configuração de uma categoria e, por isso, serão registradas por quantidade. Como essas perguntas estão fracionadas, é possível que a mesma resposta contenha uma, duas ou três partes, classificadas em grupos diferentes.

Na pergunta 3, 17 respostas confirmaram diretamente a utilidade do infográfico. Uma delas respondendo "não" e as outras 16 afirmando a utilidade e, em alguns casos, enfatizando o atributo utilidade ("de extrema utilidade, muito útil, com certeza!"). Essas manifestações não estão incluídas em categorias, visto aplicarem-se aos casos de respostas diretas. As outras duas tecem comentários que confirmam o atributo de utilidade.

O mesmo comportamento foi verificado nas pergunta 4 e 7 . A primeira, com 11 respostas diretas afirmando o incremento no resultado do trabalho (excluídas da categorização por não caraterizarem um conjunto próprio de ideias), as outras confirmando a proposição de modo indireto, na segunda parte da pergunta, como por exemplo: "o incremento principal que eu tive foi na parte de comunicar-se com o cliente, evitando falar siglas como...". No que se refere à questão 7, há 12 referências diretas, afirmando que o infográfico incrementou o resultado do trabalho do respondente.

Dessa forma, temos confirmação unânime do item de incremento no resultado do trabalho, considerando-se as respostas diretas e aquelas que afirma de modo indireto, como, por exemplo: "melhorou a qualidade da abordagem feita aos clientes". Ou seja, a resposta seria sim, para a primeira parte, e o texto citado como a segunda parte, porém o respondente expressou-se de modo conjunto.

Com relação à pergunta 5, 17 respostas corroboram o baixo índice de problemas de acesso, à exceção de quatro. Dois registros sobre dificuldades surgiram na pergunta 2. Os resultados não mostram lentidão como um problema significativo, pois apenas um dos registros referiu-se a isso. As manifestações relativas a esse tema, em sua maioria, apontam problemas de rede local (3 em 6). Os usuários atribuíram o acesso ruim por estarem em cidades do interior, como Macaé, no Rio de Janeiro, por exemplo, Um dos participantes apontou dificuldades com o ritmo de trabalho para alegar falta de tempo para acessar o infográfico. Os outros dois relatos não são precisos para se identificar se o problema é do aparelho ou da rede de acesso. 
Quanto ao que pode ser melhorado, não houve desdobramentos. As manifestações a esse respeito, em número de três, informam que não há, ou os usuários não sabem dizer, algo que possa melhorar. Sugere que o Infográfico atende às necessidades dos funcionários.

$\mathrm{Na}$ pergunta seis, a segunda parte refere-se à aplicação em outros cursos, que apresentou 13 menções diretas à concordância da proposição, mostrando que o modelo foi bem aceito. Corrobora também o conceito de utilidade, mas, diferentemente dos modelos estudados, refere-se à utilidada já aplicada e não a uma percepção de que aquilo será útil.

Em resumo, confirmam-se os atributos de utilidade, de modo direto, por meio das respostas à pergunta 3 e indireto, das respostas às questões 4 e 7 , indicando o impacto no resultado do trabalho (afirmando a ocorrência de transferência e implicando em melhor desempenho). Atributos positivos apontados nas manifestações: mobilidade, acessibilidade, disponibilidade, facilidade, ubiquidade, interatividade, praticidade, facilidade de leitura, usabilidade (facilidade de realizar o que se pretende), facilidade de acesso, simplicidade, clareza e objetividade. Motivos identificados: adquirir conhecimento, auxiliar na tarefa, aprimorar a tarefa, relevância e aplicabilidade na tarefa, utilidade.

Com relação às variáveis estudadas, as manifestações dos usuários percorrem praticamente todos os construtos do modelo TAM e derivados, com a diferença de haverem sido exploradas posteriormente ao uso do recurso, em situação prática em ambiente corporativo.

Não houve consistência na indicação de "formas de medir" e, consequentemente, “avaliar” os itens abordados, sugeridos nas perguntas 4 e 7, à exceção de uma manifestação, na pergunta 5, classificada na categoria Aplicabilidade no Trabalho, subcategoria Aplicação na Gestão da Tarefa (UR14), que indica alguma preocupação com a avaliação, ao sugerir um questionário para analisar a visita em momento posterior.

5.6. Resultados do Estudo 6: Atributos e motivos para a adesão ao modelo móvel pelos usuários

A Tabela 22 indica as categorias, subcategorias e as definições constitutivas dos resultados referentes às coletas realizadas por meio de entrevistas individuais presenciais. As incidências por entrevista foram separadas por meio de barra (“//“), com a finalidade de 
explicitar o efeito comparativo. Como as categorias identificadas nas duas entrevistas guardaram similaridade, em termos de classificação, as unidades de registro puderam ser categorizadas pelo mesmo sistema. Antes da barra, estão relacionadas as ocorrências da entrevista 1, em seguida, aqueles da entrevista 2. A Tabela 20, com a organização das unidades de registro. Quando se tratar de categorias que contenham dados das duas entrevistas, os registros estarão identificados dentro das células, com os títulos "entrevista 1" e "entrevista 2".

\section{Tabela 22}

Descrição das categorias, subcategorias, definições constitutivas e volumetria da incidência das expressões dos participantes.

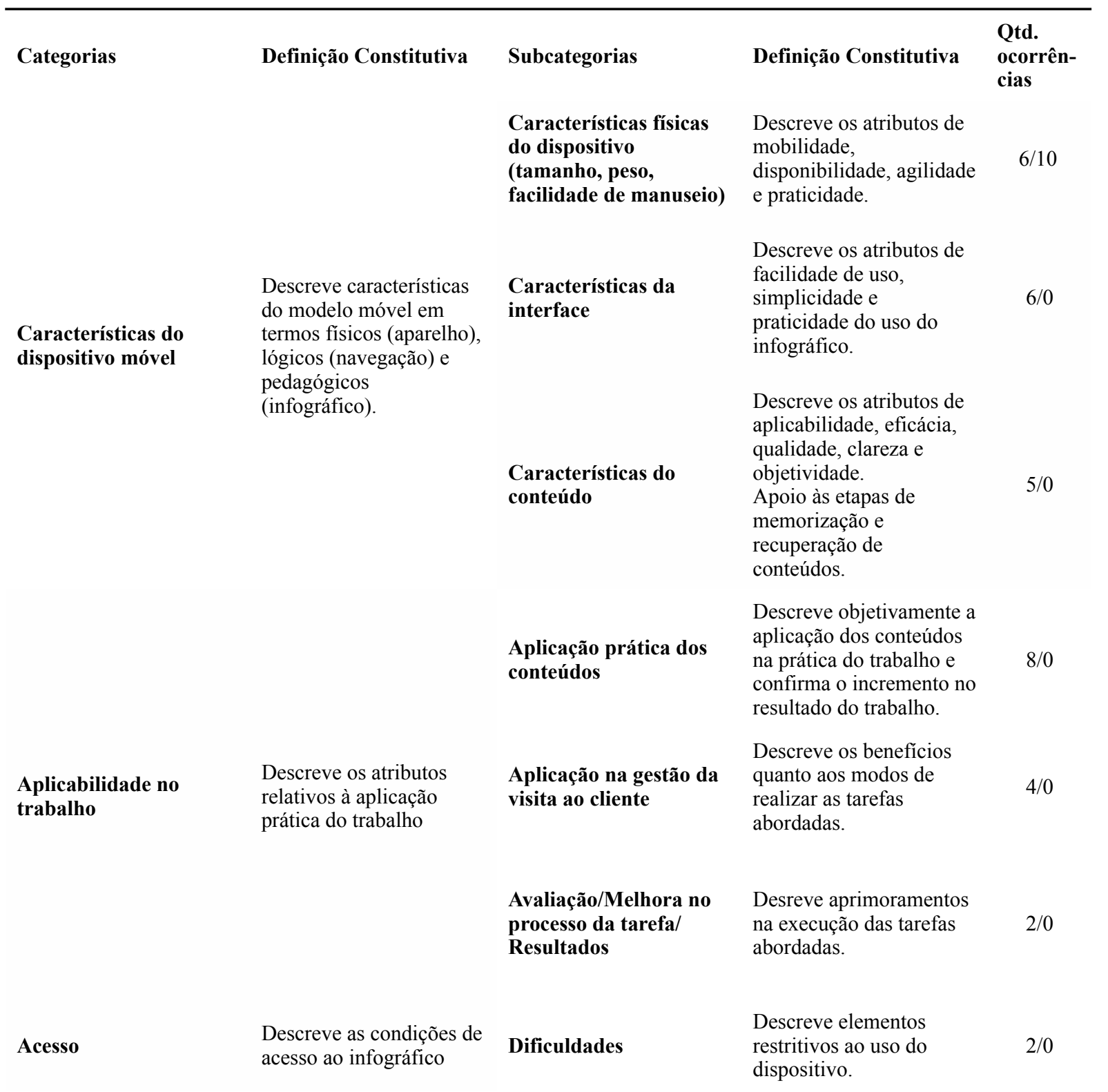




\section{Categorias}

Aplicabilidade em outros treinamentos

\section{Definição Constitutiva Subcategorias}

Qtd.

Definição Constitutiva

A Tabela 23 organiza as unidades de registro dentro das categorias definidas. As categorias que possuem registros das duas entrevistas, estão marcadas após o título com o símbolo "[*]".

\section{Tabela 23}

Consolidação das unidades de registro das duas entrevistas.

\section{Categoria Características do dispositivo móvel [*] \\ Subcategoria Características físicas do dispositivo} Unidades de Registro

Entrevista 1:

1. No trabalho, esperando cliente, às vezes na hora do almoço, no restaurante e final de semana. Às vezes que fico em casa.

2. Tanto que no celular você vai online e olha na hora do almoço.

3. O celular tá ali no bolso, por exemplo, eu vou de táxi para a empresa, então no caminho você já tá, sabe, aproveitando seu tempo ali, já tá consultando. Então já tá ganhando tempo, né?

4. Já. No caminho pro trabalho e de manhã também às vezes. Você tá esperando alguma coisa ali, sabe?

5. Uma revisada e final de semana também, qualquer lugar.

6. Porque ai pode acessar a qualquer hora a qualquer lugar, você tá ali na hora do almoço, ou então você está na fila, ou esperando alguma coisa...
Entrevista 2:

1. Fiz em casa, deitadão lá no sofá, no ar refrigerado, no maior conforto. Eu lembro que era noite, não tenho certeza, mas acho que foi até no fim de semana. Acho que foi num sábado.

2. Eu acho que foi um mix dos dois: eu vou acessar o curso em casa e logicamente no fim de semana, no momento em que eu não estava fazendo nenhuma atividade doméstica, vamos dizer assim, eu estava no momento ocioso do meu fim de semana.

3. Eu fiz em casa. Não prejudica em nada. Estava concentrado. Eu estava relaxado, como eu te falei.

4. Mas eu faço curso em casa direto. No trabalho*, eu tenho muito mais distratores, principalmente na Superintendência em que eu trabalhava atendendo o telefone, é muito dificil você ficar ali fazendo curso sem ser interrompido.

5. ... eu sei que naquela meia hora, ou aquela uma hora, ou hora e meia eu vou estar tranquilo e vou fazer o curso.

6. [Melhora] De aprendizado, com certeza, com certeza. 
7. Eu acho essa liberdade da pessoa fazer o treinamento, eu acho bem legal, porque, assim, hoje em dia, por exemplo, a questão da mobilidade urbana... Se o cara tiver no ônibus lá, bota o fone dele, vai fazendo o treinamento, se ele se sente confortável né?

8. E essa outra questão de eu estar lá em casa, confortável. ... Você com o tabletzinho. Pô, eu fiz no celular né? Mas poderia ter feito também no tablet, na rede, onde você se sentir mais confortável pra fazer. Se você acha que consegue se concentrar naquilo, deitado, sentado numa poltrona, que não seja aquela tradicional de leitura, num puff...

9. Pode...o cara pode tá (sic) no táxi fazendo... Por exemplo, tem agência no centro do Rio, por exemplo de onde eu vim, tem agência no centro que tem cliente em Jacarépaguá, no horário de rush dá duas horas de viagem ...

10. Eu gostei muito de fazer no mobile achei bem interessante.

*Termo original omitido para satisfação do critério de sigilo da organização.

\title{
Subcategoria Características da interface
}

\author{
Unidades de Registro
}

Entrevista 1:

1. Eu acho que sim pelas inovações tecnológicas do infográfico é excelente, um avanço muito bom, principalmente, pra gente no dia a dia, assim, pela acessibilidade: a qualquer hora e qualquer lugar então muito bom.
3. Achei [fácil de usar].

4. O primeiro contato mesmo, que eu acessei, transcorreu bem, fácil pela facilidade, ...

5. Porque é a facilidade, entendeu?

6. Só que com esse aí [infográfico] facilitou muito, assim pelo desenho, layout ...

2. ... assim, também pela facilidade.

\section{Subcategoria Características do conteúdo}

\section{Unidades de Registro}

Entrevista 1:

1. ...o resumo, tudo num lugar eu fui seguindo os passos ali e não tive dificuldade não.

2. Dicas para fazer uma visita e tal.

3. Tem muita coisa para fazer muito questionário pra preencher. Essas coisas do dia a dia. Tem muita ferramenta, mas, assim, quando você vê, o seu ponto cai. Então, facilitou muito...
4. ...quando eu olhei, assim, foi muito bom, o resumo mesmo, as informações ...

5. ... e ajuda muito o resumo, tudo muito bom.

6. ... umas dicas boas eu li. eu não tinha essas dicas antes do infográfico, acho que grava mais sabe. ...

\section{Categoria Aplicabilidade no Trabalho}

\section{Subcategoria Aplicação prática dos conteúdos}

Unidades de Registro 
Entrevista 1:

1. Uma coisa que eu não fazia mesmo era olhar a produção. Por exemplo, onde o pessoal realmente guarda o seu estoque de matéria prima. Às vezes a gente fica só na parte principal, na entrada. Então, se não vai, por exemplo, num cliente que a gente tem, de pão de queijo... Então, entrar, ver onde eles fazem a produção, botar a roupa que eles pedem. Então, é algo que eu não fazia...em frigorifico você vai ver lá onde fica, entra, então uma coisa que me chamou atenção que eu não tinha [ido] ... eu pensava: será que é necessário? Será que tem que ir? Aí, eles convidando, vamos lá conhecer...eu, ano passado, fizemos muitas visitas (risos) então é uma coisa que eu não sabia também e pelo infográfico diz que é bom. Tem que ir.
2. ...era uma coisa que eu estava utilizando no meu dia dia então...

3. Seja gentil, às vezes fico assim um pouquinho tímida, né? Agora já estou mais tranquila, mas nas primeiras vezes eu ficava indecisa: como que eu faço? No cumprimento pega na mão? Os fornecedore, como é que recebem o pagamento, de conhecer o setor de contabilidade, sabe fazendo uns tipos de perguntas especificas me ajudaram...

4. Os passos lá, durante a visita, antes da visita, durante sabe?

5. Por exemplo, no dia que eu fui fazer a visita que eu fui usar na agência porque eu usei o curso de manhã mesmo, eu acessei antes de fazer a visita, porque ai eu lembrei tinha uns detalhes.

6. Eu acho que sim. Ele [o infográfico] já traria informações suficientes para fazer o trabalho.

7. Entrei, passei num concurso tenho que fazer uma visita ele me ajuda? Ajudaria, com certeza.

8. Por esse tipo de iniciativa para o dia a dia, porque todo dia é coisa nova que a gente tem que aprender no banco porque é muita informação que a gente recebe então facilita muito nosso dia dia.

\title{
Subcategoria Aplicação na gestão da visita ao cliente
}

\author{
Unidades de Registro
}

\section{Entrevista 1:}

1. Já é uma coisa que assim: um dia antes mesmo de fazer a visita até utilizei de novo. Na mesma hora olhei, lembrei de alguma coisa que tem que fazer. Porque às vêzes é um detalhe, uma observação, então, vira e mexe... Tem ele e outros cursos também que eu fico fuçando lá [no aplicativo]

2. É, no dia a dia, entendeu? Não é assim que a gente chega na internet e fica olhando que às vezes tem que entrar no site da X (unidade organizacional) o passo a passo, ai se fica, sabe, né? Perdendo tempo. Então, acho assim que esse resumo assim infográfico foi muito útil...
3. Para mim, seria uma ferramenta complementar porque, assim, na prática, você vem praticando. Ai, eu fiz um curso, então pra mim foi complementar mas para primeira vez...

4. Apliquei, sim. Sim a gente observa. Tipo assim, a conversa com os funcionários da empresa [visitadarefere-se ao conteúdo].

\section{Subcategoria Avaliação/Melhora no processo da tarefa/Resultados}

Unidades de Registro

Entrevista 1:

1. Com certeza, gerou [melhor resultado no trabalho].
2. Fica, com certeza, fica feliz quando a gente vai, assim... Realmente o Banco olhou melhor do passado pra cá. A gente não tinha e da gente sair daquele mundinho ele sabe, então foi muito bom, eles se sentem tão importantes ... [refere-se à melhoria no atendimento]

\section{Categoria Acesso}

\section{Subcategoria Dificuldades}

\section{Unidades de Registro}

1. ...porque realmente a gente, na agência, a gente não tem muito tempo mesmo não...
2. A única dificuldade que eu tenho, assim, agora de fazer as coisas é minha internet que é lenta... 
Unidades de Registro

1. Nesses detalhes ai eu gostaria que fosse também para outras. É, eu já vi que tem vários outros cursos ali.

1. Eu acredito que sim... Assim isso ajuda muito que seja no dia a dia da prática, por exemplo algumas coisas no operacional, assim se fosse tudo no infográfico acho que seria bom, pela facilidade.

As entrevistas reforçam diversos atributos relacionados à adoção do modelo, como pode ser visto na Tabela 24 que mostra comparativamente os atributos relacionados pelos planejadores e usuários, relacionando-os às variáveis identificadas nos estudos de m-learning. O objetivo da apresentação da tabela é a tentativa de se abrir perspectivas de identificação de lacunas de pesquisa. A relação tem caráter propositivo (sugestivo), visto que as manifestações dos respondentes não foram tratadas de modo sistematizado.

\section{Tabela 24}

Associação entre as variáveis e atributos identificados nos levantamentos.

\begin{tabular}{|c|c|c|c|}
\hline \multirow{2}{*}{$\begin{array}{l}\text { Variáveis } \\
\text { Relacionadas ao } \\
\text { m-learning }\end{array}$} & \multicolumn{3}{|c|}{ Atributos percebidos } \\
\hline & Grupo Focal & Questionários & Entrevistas \\
\hline $\begin{array}{l}1 \text { - Autoeficácia em m- } \\
\text { learning }\end{array}$ & Facilidade & Interatividade & Autonomia \\
\hline $\begin{array}{l}2 \text { - Percepção de } \\
\text { utilidade }\end{array}$ & $\begin{array}{l}\text { Auxiliar na tarefa, } \\
\text { aprimorar a tarefa, } \\
\text { relevância, aplicabilidade } \\
\text { na tarefa, utilidade }\end{array}$ & $\begin{array}{l}\text { Disponibilidade, } \\
\text { Praticidade, Utilidade, } \\
\text { Relevância, } \\
\text { Aplicabilidade }\end{array}$ & Praticidade, \\
\hline $\begin{array}{l}3 \text { - Autogestão da } \\
\text { aprendizagem }\end{array}$ & - & - & $\begin{array}{l}\text { Adaptabilidade } \\
\text { (adequação à situação } \\
\text { escolhida para acesso), }\end{array}$ \\
\hline $\begin{array}{l}4 \text { - Percepção do valor de } \\
\text { mobilidade }\end{array}$ & Ubiquidade, mobilidade & Mobilidade & Ubiquidade, mobilidade, \\
\hline $\begin{array}{l}5 \text { - Percepção de } \\
\text { facilidade de uso / } \\
\text { Expectativa de esforço }\end{array}$ & $\begin{array}{l}\text { Simplicidade, facilidade } \\
\text { de acesso / usabilidade }\end{array}$ & $\begin{array}{l}\text { Simplicidade, Clareza, } \\
\text { Objetividade }\end{array}$ & Facilidade \\
\hline $\begin{array}{l}6 \text { - Controle do } \\
\text { comportamento percebido }\end{array}$ & Acessibilidade & Acessibilidade & - \\
\hline
\end{tabular}




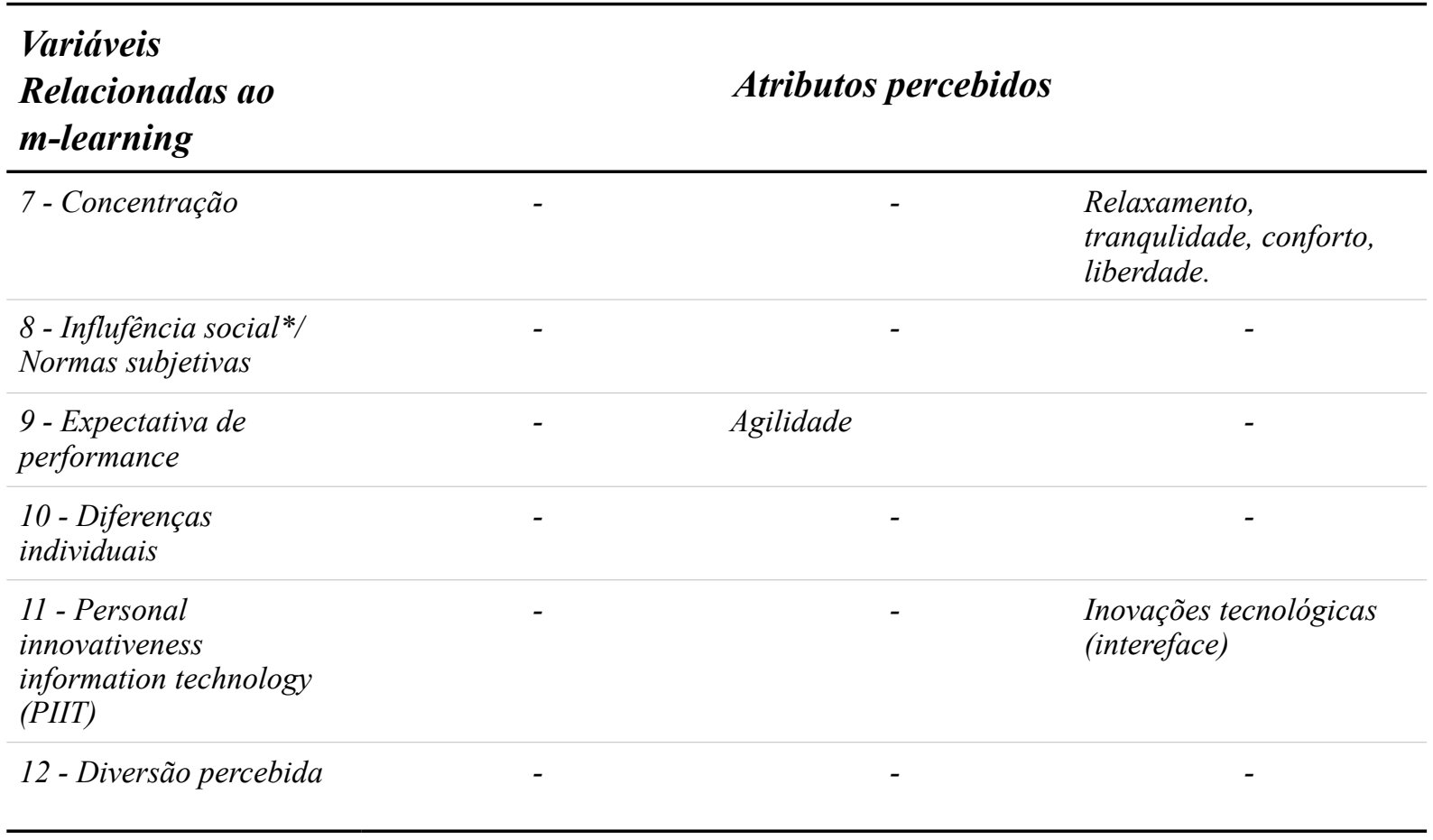

Fonte: pesquisa

*Há disparidade nos resultados dessa variável entre os autores.

Referência dos autores: 1 Fadare, Babatunde, Akomoafe e Lawal (2011), 2 e 5 Davis (1989), 3, 5, 8 e 9 Wang, Wu, Wang (2009), 4, 10 e 12 Huang, Lin, Chuang (2006), 6, 7, 8 e 12 Kurtz, Macedo-Soares, Ferreira e Silva (2015) e 11 Tan et al. (2014).

A primeira percepção na análise conjunta dos resultados é o caráter positivo das manifestações por dois grupos distintos: planejadores instrucionais e usuários. Notam-se poucas evidências de frustrações e limitações sobre o uso do dispositivo móvel, o que corrobora a literatura pesquisada, que apresenta boa receptividade e grandes expectativas sobre os modelos móveis. As três técnicas aplicadas são reforçadoras entre si dos aspectos levantados quanto ao uso do infográfico, como recurso instrucional móvel.

A Tabela 24 mostra também que há dois momentos em estudo: o primeiro que estuda variáveis que predispõem para o uso dos dispositivos/aprendizagem móvel, ou seja, são fatores anteriores ao uso efetivo e o segundo momento, que é da investigação dos fatores atribuídos à prática de estudos no dispositivo. É interessante notar a formação de uma cadeia de construtos, que, ao mesmo tempo que corrobora as variáveis já testadas para a predisposição, associa conceitos de definição dos atributos de uso.

Algumas variáveis com pouca repercussão nos estudos, como: diversão percebida e concentração dão um sinal de que esses atributos não foram percebidos pelos usuários ou 
planejadores. Isso sugere que ou o desenho instrucional não contemplou esses atributos, ou os instrumentos de coleta falharam em capturar essas percepções. São traços importantes na aprendizagem móvel. Diversão percebida permite mais capacidade de engajamento e concentração um melhor aproveitamento do estudo, de modo geral. Influfência social/normas subjetivas, dadas as circunstâncias organizacionais, não parecem ser atributos a serem explorados no desenho instrucional, mas podem ser examinados como fonte de viéses. No objeto estudado, a clientela possui aparelhos iguais, nivelando essa influência. Diferenças individuais é uma variável que poderá estar associada à prática de uso do dispositivo, visto que há liberdade para acesso em qualquer situação.

Autogestão da aprendizagem é uma variável importante por estar associada à autonomia e a opção por estratégias de aprendizagem diversas. Só há referência à ela nos resultados das entrevistas. Surge, ainda, de forma sutil, mas poderá ser trabalhada, orientandose o aprendiz a interferir mais no seu aprendizado.

Alguns atributos deverão ser melhor compreendidos e descritos para poderem ser objetos de análise precisas e avaliações confiáveis. Facilidade, praticidade, simplicidade, por exemplo, são termos vagos para serem estudados. Será necessário um esforço para a compreensão daquilo que o usuário está pensando quanto considera aquela tarefa como fácil, por exemplo. No caso de mobile learning, a facilidade pode ser composta de uma combinação de elementos, como operar com agilidade, usar poucos comandos, entender as instruções rapidamente, ou outros, visto que as atividades e operações no dispositivo são muito integradas. Há que se verificar também se não há superposição de conceitos.

É posseivel se imaginar uma construção de desenho instrucional que possa contemplar as potencialidades dos modelos móveis na aplicação de eventos instrucionais organizacionais, visto que há muito em comum entre a realidade do mercado e as características dos dispositivos móveis e seu respectivo uso. O estudo sugere que os desafios são as amarrações necessárias entre a pesquisa sobre comportamento, aprendizagem, transferência e desenho instrucional. A realidade do nosso tempo aponta para pessoas mais autônomas e objetivas, com anseio de instantaneidade, que buscam diversidade e variedade de coisas, ideias, ambientes etc. A educação corporativa precisa se integrar a esse cenário a fim de se justificar como área organizacional estratégica, que compreende a realidade mercadológica e contribui para o desenvolvimento da instituição na qual se insere. 


\section{DISCUSSÃO}

Um desafio fundamental da análise dos resultados é o aspecto exploratório do estudo. Como ainda temos pouca base de resultados comparativos na literatura, as aproximações ganham muita importância ao mostrarem caminhos e objetos a serem aprofundados e testados quanto ao construto principal deste estudo: a transferência. Vale dizer que a teoria e os modelos disponíveis oferecem pouco material para que se estabeleçam relações seguras entre comportamento, técnica, suporte, tecnologia e avaliação no campo do mobile learning.

Dessa forma, a discussão está proposta em seis frentes, que têm relação direta com a delimitação de objetos e campos de estudo: a) transferência, b) variáveis implicadas (modelo TAM e correlatos), frentes de lacuna e proposição de categorias de variáveis, c) aprendizagem e modelos identificados de desenho instrucional, d) terminologia e definição de variáveis, e) vantagens e limitações dos modelos móveis e f) potencialidades. Em lugar de um modelo que apresenta a identificação/delimitação de uma variável e seu resultado comprobatório, a lógica de análise, neste estudo, estará apoiada em um processo estruturado em: expectativas (predição), ação (modelos) e percepção do usuário (resultado primário).

Em relação ao infográfico estudado, a predisposição e o uso efetivo do recurso estão fundamentados na utilidade prática do dispositivo e em sua facilidade de uso (PU e PEOU) (dentre outras variáveis), visto que a ferramenta pode ser utilizada em situação real de trabalho, como pouco antes de uma visita, por exemplo. O infográfico poderá também ser usado como check list após a visita, confirmando ao profissional que foram executadas todas as etapas necessárias do procedimento.

O check list, por sua vez, pode operar como um feedback para a atuação do usuário, ajudando-o a confirmar que o profissional fez uma visita bem sucedida. Os últimos dois itens ainda não podem ser avaliados por meios objetivos, visto que não há dados suficientes que permitam um cruzamento de informações, porém não é tarefa difícil incluir funções dessa natureza no sistema que suporta o recurso móvel. Por exemplo, não há um registro da data e hora da visita realizada pelo usuário, configurando, assim, a consulta pré ou pós visita. Da 
mesma forma que não há um recurso seguro pelo qual se possa avaliar a qualidade da visita, exceto por instrumentos de autorrelato, que, neste caso, parecem impróprios. Assim, o exame da experiência poderá trazer confirmações sobre os modelos e abrir discussões sobre como melhor utilizá-los.

\section{Transferência}

Em que dimensão o modelo observado pode estar relacionado ao desenvolvimento de CHA - desenvolver conhecimentos, habilidades e atittudes, conforme Pilati e Abbad (2005) e Le Boterf (2003)? Não há sentido no desenvolvimento de ações instrucionais em ambiente corporativo sem que tragam resultados em termos de desempenho, esses indissociáveis do processo de transferência. No estudo, além da observação e aproveitamento dos achados históricos, essa relação surge dos resultados pesquisados em função da ideia de aplicação direta no trabalho, relacionada diretamente à transferência de treinamento, potencializada pelo modelo móvel. O tema se desdobra em duas frentes: análise das implicações dos modelos móveis no esquema da cadeia de eventos de treinamento, conforme representado na Figura 6 e análise aprofundada das variáveis envolvidas no processo de transferência e os atributos referentes a esse processo, levantados no trabalho.

No caso do m-learning, a transferência poderá ocorrer simultaneamente à aprendizagem (aquisição, retenção e generalização), o que fragiliza o modelo utilizado por base para este estudo em sua construção cronologica e lineramente encadeada. Por exemplo, a aprendizagem, a transferência e o impacto poderão se dar na mesma ocasião, na mesma ação, sendo que, a etapa de retenção pode ser reduzida significativamente, em função do desenho instrucional adotado. No infográfico, há mostras desse aspecto, como na subcategoria “aplicação prática dos conteúdos" (estudo 5), que mostra algumas manifestações que exprimem consulta sob aspectos relativos à tarefa (UR 11 e 12), com algumas na própria situação de trabalho, buscando orientações e dados, que em outras circunstâncias necessitariam estar memorizados.

No caso de modelos job aid, o resultado, o feedback e um possível ajuste na instrução podem realizados no mesmo local e ocasião. O estudo de Meer et al. (2015) fala como atributo de satisfação a possibilidade de manipulação do conteúdo (rever, acelerar o 
vídeo, parar etc.), fazendo, ainda, alusão à possibilidade de se fazer anotações. Ora, o fato indica claramente o aumento de poder do usuário sobre o que aprende, além de, por exetensão, indicar que poderá, dependendo do sistema e do desenho instrucional, alterar o conteúdo, adicionando novos itens, atualizando etc. Isso pode ser feito com base no resultado encontrado na situação real de trabalho. O aplicativo (app) Waze (que aponta trajetos e condições de trânsito), por exemplo, possui essa característica. O usuário é estimulado a contribuir com o conhecimento instalado, informando, por meio de edição, dados que complementam o serviço. Essas intervenções represntam parte significativa do que é oferecido aos outros usuários, consistindo em prática colaborativa eficaz e útil.

No objeto estudado, temos algumas evidências nos resultados do grupo focal (estudo 4), que distinguiu uma subcatergoria de resultados definida como "aplicabilidade no trabalho", com relatoss que exprimem uma expecativa de aplicação. Essa expectativa surge corroborada pelos resultados do questionário (estudo 5), na subcategoria "aplicação prática dos conteúdos", com um volume significativo de manifestações (23), que exprimem, de modo robusto, a convergência entre expectativa e resultado.

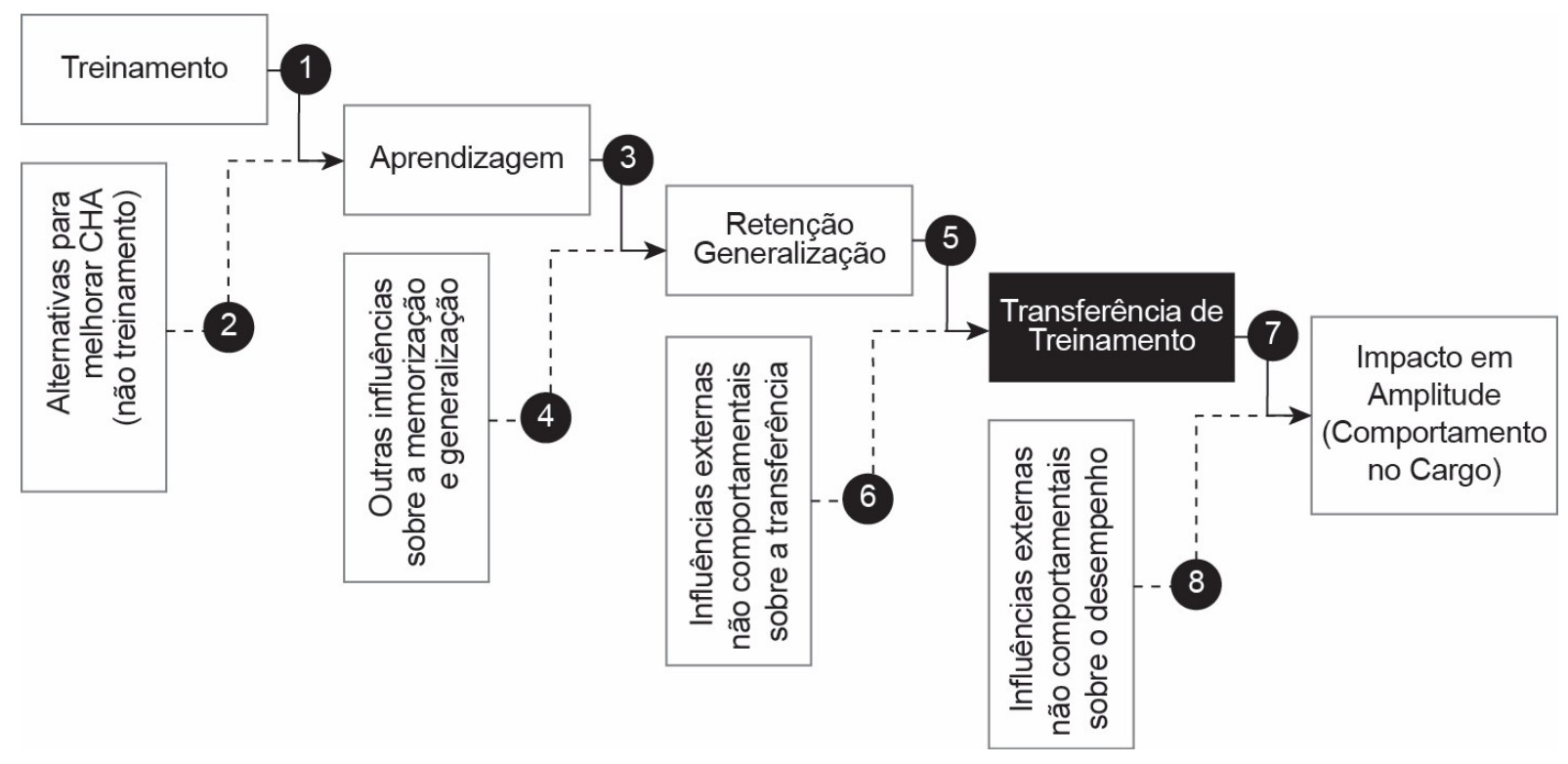

Figura 10. Representação esquemática das relações entre treinamento e resultados, mostrando fatores intervenientes no processo de treinamento.

Fonte: adaptado de Taylor e O'driscoll (1998), conforme citado em Abbad et al. (2012). 
Também com relação aos itens de interferência nos processos definidos no modelo da Figura 10, embora não haja sido feita nenhuma abordagem direta a esses fatores no estudo, é possível prever que esses itens serão potencializados em uma eventual ação móvel, dado que com a mobilidade os usuários estarão naturalmente mais expostos a interferências externas ao treinamento, como definido nas etapas 6 e 8 , que sugerem fatores ambientais e materiais sobre o processo.

Em relação às variáveis estudadas no processo de transferência, o estudo propôs uma relação com os atributos identificados pelos usuários, correlacionando as Tabela 9 e 24, com o propósito de delimitar melhor os conceitos que têm implicações no processo de utilização e aplicação do modelo em estudo (infográfico). Essa relação poderá auxiliar na proposição e definição de construtos e variáveis a serem avaliadas e medidas por instrumentos específicos e adequados. As informações revelam a convergência entre fatores de transferência e aqueles que predispõem à utilização de m-learning (fatores prévios).

A tabela 9 mostra que há grande lacuna no estudo de mobile para as questões de contexto, bem como ausência de variáveis específicas para a clientela nos estudos de transferência mediados por tencologia (sugere um esforço de complementaridade). Algumas variáveis também não encontraram paralelo exato e demandam, por isso, aprimoramento e melhor conceituação. Facilidade de uso, por exemplo, está em m-learning como uma perspectiva, visto que os modelos que testaram essa variável, examinaram predisposição ao uso (tecnologia ou mobile learning) e por isso, está na classe de caraterísticas da clientela. Quando verificada em prática, como indicam os atributos identificados neste estudo, deverá migrar para a uma outra categoria, como desenho/entrega da instrução. Visto o desencontro entre as duas colunas, há um desafio proposto para a testagem de variáveis específicas em $m$ learning para transferência com destaque para aquelas de contexto. Esse estudo também deverá ser posterior à identificação e testagem de variáveis não relacionadas à predisposição, mas sim ao uso efetivo das soluções móveis.

Em Baldwin e Ford (1988), está proposta uma categoria de variáveis chamada ambiente de trabalho, similar àquela definida por Burke e Hutchins (2007), com a diferença que estes últimos aproximaram o conceito da influência de fatores ligados à relação entre o aprendiz e os colegas de trabalho, como suporte de pares, por exemplo. Cheng e Hampson (2008) também propõem uma classificação similar, mas trazem o contexto para a conceito de 
situação. O contexto pode ser entendido, então, como a associação entre ambiente e situação, onde o primeiro seria o local considerado e suas características e o segundo, as circunstâncias que envolvem as condições da experiência em foco. Essa distinção poderá abrir conjuntos diversos de variáveis para a análise do que se expôs como fatores ambientais. Outra reflexão imporante é a interação dos pares, visto que aparentemente, na aplicação direta no trabalho, os modelos móveis tendem a apresentar ações mais individualizadas quanto à operação da tarefa e mais colaborativas quanto à aprendizagem. É uma outra perspectiva a ser compreendida no desenvolvimento dos modelos móveis.

O contexto é apontado como o aspecto mais relevante para a predição de transferência, conforme Abbad (2010) e Pereira (2009). Zerbini (2007) também relata aspectos importantes sobre a variável contexto de estudo, referente a modelos mediados por tecnologia, já considerados também em Reigluth (1999). O trabalho de Driscoll e Carliner (2005) aponta, nessa direção, o risco de atividades de estudo fragmentadas, como um fator de risco para a aprendizagem. No caso do m-learning, dada a flexibilidade proporcionada pelos desenhos, o estudo poderá estar ocorrendo no mesmo momento de sua efetiva aplicação na tarefa, o que irá demandar uma análise e testagem dessa e de outras variáveis especificamente aplicadas ao m-learning. As variáveis de contexto em m-learning deverão ser examinadas com especial atenção, visto que nos modelos móvies, o contexto é fluido e mutável, principalmente se levarmos em conta as variabilidades apontadas nos estudos de Kakihara e Sørensen (2002) (fatoramento do construto mobilidade). Sob esse ponto de vista, há que se propor um modelo de interpretação do modelo de aprendizagem organizacional específico para a realidade móvel, em sua perspetiva variáveis contextuais.

Mobilidade como construto - Aplicação (transferência) e mobilidade estão fortemente imbricadas na aprendizagem móvel, dada sua inclinação para modelos baseados na concepção de aprendizagem situada, ou seja, prevê a aprendizagem em situações diversas. Portanto, pode-se perceber que o construto mais importante dos modelos móveis é a mobilidade, que deverá ser fatorada e testada em seus componentes estruturais e comportamentais para estudo e avaliação dos modelos. Os resultados referentes ao grupo focal aplicado mostram, com relação à transferência, uma expectativa de que a mobilidade implique aplicação efetiva no trabalho, tendo como um dos motivos apontados para a adoção 
do modelo o "apoio à tarefa realizada no trabalho" e um dos atributos "mobilidadel ubiquidade".

O grupo focal apresenta a visão dos planejadores da solução. Com relação à visão dos usuários, temos como um dos motivos apresentados para a utilização do infográfico nos resultados dos questionários "aprimorar a forma de visitar os clientes" e como atributos do modelo, "disponibilidade" e "ubiquidade". Nas entrevistas, a mobilidade surge apenas como atributo, expresso nas conceituações de "ubiquidade", "mobilidade", "liberdade" e “autonomia". Alguns atributos como os dois últimos implicam mobilidade, dado o contexto das respostas. Dessa forma, o estudo confirma a importância e centralidade da mobilidade em aplicação prática.

Contudo, o modelo analisado explora intencionalmente apenas duas dimensões da mobilidade, conforme a proposição de Kukulska-Hulme et al. (2009), conforme mostra a Tabela 25.

\section{Tabela 25}

Aspectos da mobilidade identificados no modelo estudado.

\begin{tabular}{ll}
\hline Tipo de Mobilidade & \multicolumn{1}{c}{ Definição } \\
\hline Física & $\begin{array}{l}\text { Capacidade de deslocamento geográfico. Possibilidade de acesso em lugares } \\
\text { diversos. Há relatos de utilização em diversos locais, como: “... pois mesmo no táxi, } \\
\text { a caminho da visita podemos checar se não esquecemos nada.” }\end{array}$ \\
\hline Tecnológica & $\begin{array}{l}\text { Diversidade de aparatos tecnológicos para consulta. O usuário poderá aprender o } \\
\text { mesmo conteúdo em dispositivos diversos, o que implica em modelagens } \\
\text { específicas. O conteúdo do infográfico encontra-se também no portal de educação } \\
\text { corporativa da organização, facultando o uso de uma ou outra plataforma para } \\
\text { estudo. }\end{array}$ \\
\hline
\end{tabular}

*Termo original substituído para manutenção do critério do sigilo da organização.

\section{Variáveis implicadas (modelo TAM e correlatos), frentes de lacuna e proposição de categorias de variáveis}

A Tabela 24 indica prováveis relações entre as variáveis testadas para a predisposição de uso e os respectivos atributos relacionados, que apontam conceitos aplicados na situação de aprendizagem/trabalho que estão em uma etapa posterior da cadeia de eventos que implicam na transferência. 
Com base no estudo, é possível a proposição de categorias de itens a serem explorados e transformados em variáveis a serem medidas. Segue uma lista sugerida de frentes de conceitos relativos à aprendizagem móvel:

- Influência do ambiente no processo de ensino-aprendizagem. Distinguir entre ambientes: a) fixos - ambientes de caráter estático, como a residência; b) móveis - o sujeito está em locomoção, como parte da prática da aprendizagem, como um vôo de observação; c) informacionais - o ambiente traz informações ao usuário, como uma visita de fiscalização; d) interativos - o ambiente reage ao aprendiza e vice-e-versa, como no caso do RFID, ou e) indiferentes à instrução - a aprendizagem estará no dispositivo por comodidade ou por oferecer algum recurso específico, como o uso no próprio trabalho para consulta ou reflexão.

- Motivação para o uso do dispositivo na situação proposta - O recurso (equipamento e conteúdo) é prático, funcional, fácil de ser usado, disponível quando necessário.

- Motivação para transferência. Poderá em algum momento se confundir com a predisposição para o uso.

- Autoeficácia. O treinamento para a operação do conteúdo (composto sujeito-equipamento) foi eficaz? Desdobrar os itens referentes ao sujeito e aqueles do equipamento: físicos, lógicos e didáticos. Alguns dos itens podem ser detectados por análise de logs, como o tempo médio para a realização de uma tarefa, ou permanência em algum ponto do conteúdo.

- Abertura para novas experiências. Esse construto servirá para avaliar o perfil do público participante.

- Concentração. Esse item deverá ser explorado com precisão, dadas as características da mobilidade, o contexto poderá ser muito integrado à atividade, como poderá também ser uma fonte importante de distração. Tanto o desenho poderá não exigir um nível de concentração muito alto, como poderá recomendar um ambiente propício à imersão mais profunda no conteúdo.

- Avaliação da necessidade de treinamento. É uma etapa de construção do treinamento que sofrerá impacto significativo das potencialidades da realidade móvel. 


\section{Aprendizagem e modelos identificados de desenho instrucional}

Jonassen (1999) afirma que tecnologias não deveriam somente instruir os aprendizes, mas servir de base para a construção de conhecimento. Assim, os aprendizes teriam um papel, também, de desenhista instrucional, ou seja, ao mesmo tempo em que aprende, organiza sua aprendizagem. É nítido o incremento da autonomia do usuário em relação à aprendizagem móvel. Diversos fatores apontam essa direção, como pode ser verificado no estudo dos atributos e variáveis identificadas e sugeridas, bem como nos depoimentos dos intervenientes. Essa afirmação é apenas um indicador de uma das mudanças que a aprendizagem móvel proporcionará no futuro. Outros desdobramentos desse modelo implicarão outras responsabilidades sobre o sistema de TD\&E como um todo. Diante das afirmações de que serão necessárias reinterpretações das ideias e práticas de aprendizagem na realidade móvel, o desenho isntrucional não estará imune a isso, conforme item sobre modelos móveis. Du et al. (2010) apontam estilos de ensino, não alinhados aos novos recursos como uma importante limitação aos modelos móveis. A leitura dessa limitação pode estar associada a diversos fatores, como dimensão dos conteúdos, linguagem aplicada, contextos mal interpretados e uma série de outras ainda por surgir.

Definido também como categoria importante para a transferência, sob a classificação desenho/entrega da instrução, o desenho instrucional assume, em aprendizagem móvel, um papel mais amplo do que as tradicionais abordagens, visto que pode modificar de modo profundo os processos de aprendizagem e transferência. Cheng e Hampson (2008), que realizaram revisão de literatura sobre TD\&E, afirmam que os estudos tradicionais de transferência podem não se adequar à ideia de aprendizagem situada, dado que o conceito de "local de trabalho", presente na maioria das pesquisas sobre transferência, ganha novo significado com o mobile learning. Essa reinterpretação surge com força nesse contexto e tem impacto direto sobre a forma de instrução.

Com relação ao objeto estudado, diante da expectativa organizacional, refletida no documento de avaliação de necessidades, o instrumento móvel age como um intermediário, ou facilitador da ação do profissional. Nas diretrizes descritas, surge a potencialização da experiência da visita ao cliente em direção ao estreitamento do relacionamento e à segurança do negócio. Assim, a realização da visita de modo eficaz é um desejo da organização nessas 
duas direções. Os resultados do trabalho sugerem, de modo global uma boa experiência com aprendizagem, aplicação e satisfação com o resultado percebido, alinhando de forma consistente demanda e execução.

Em um contexto de aprendizagem móvel, será importante verificarmos contextos propositais e acidentais. Se temos um desenho instrucional que aponta para a execução de uma atividade em determinada circunstância, como na execução do trabalho in loco, teremos um nível dado de controle e exame. No modelo estudado por Wang et al. (2009), o local de aplicação foi a própria sala de aula, em que o aluno poderia interagir com o palestrante. Esse é um ambiente com alto nível de controle, que pressupõe aumento do engajamento por imersão no contexto. Se, em contraste, temos uma atividade de consulta livre, essa poderá acontecer em condições sem descrição ou controle. Nesse caso, haverá um provável descontrole de variáveis que pudessem dar pistas ou predizer melhores ou piores resultados da instrução. $\mathrm{O}$ modelo estudado não prevê uma exploração do aspecto ambiental e enquadra-se na segunda situação. Nesse caso, caberá ao aprendiz decidir sobre as influências às quais estará sujeito (ruídos, distratores, ambientes informativos etc.) Será necessário, complementarmente, no desenho instrucional, constarem orientações sobre esse aspecto.

Ambas as situações deverão estar previstas em desenhos que considerem esses fatores. No caso do infográfico estudado, o contexto é desconhecido, podendo exercer influência negativa, como na utilização em deslocamento, por exemplo, que poderá estar sujeito a muitos ruídos, ou positiva, como oferecendo uma situação de maior conforto físico. No caso de contextos intencionais, como no modelo de Wu, Hwang, Tsai, Chen e Huang (2010), o ambiente fornece informações-chave para a aprendizagem por meio de um sistema de RFID - é um modelo similar ao job aid, se aplicado efetivamente no trabalho. Neste caso, além de ser intencional, o contexto é informativo, faz parte do desenho instrucional. O infográfico estudado poderia conter uma extensão de conteúdo que trouxesse informações do cliente que está sendo visitado para reinserção de dados no sistema. Ou ainda, possuir um check-list formal para feedback do usuário. Uma possiblidade relativa ao desenho instrucional é a possibilidade de combinação de conteúdos de aplicações, como em Gikas e Grant (2013), ou ainda a combinação de aplicativos não necessariamente desenvolvidos para o objeto específico, como dicionários, localização geográfica, calculadoras etc. 
Em alguns casos, o objeto mobile poderá ser utilizado apenas como uma mídia, ou um transporte para o conteúdo, em outros, como um recurso instrucional completo, sob a forma de curso. No modelo estudado, o objeto mobile assumiu a configuração de um apoio ao treinamento, como um objeto integrante da estratégia, mas com caráter opcional. Os resultados mostram que há perspectivas de expansão do modelo a outros eventos, o que demadará adaptações a aplicação de novos recursos não explorados no objeto estudado. No estudo de Du et al. (2010) as comparações foram feitas com base na mediação, isolando o papel da ferramenta de mediação, sem explorar outras vantagens do modelo.

A Tabela 26 mostra um comparativo entre as abordagens tradicionais de aprendizagem aplicadas ao treinamento e a abordagem de aprendizagem situada, recomendada para o modelo móvel. Os conceitos associados referem-se à predominância de uma abordagem sobre outras e não processos de modo puro, que não são possíveis. É preciso cautela na observação dos dados alinhados para que não se tenha uma ideia de processos ou etapas estanques, ou ainda uma tendência reducionista. A proposta do esquema é promover a percepção de fatores diversos nas abordagens de aprendizagem.

\section{Tabela 26}

Elementos comparativos entre os modelos.

\begin{tabular}{|c|c|c|c|c|c|c|}
\hline & $\begin{array}{l}\text { Processo de } \\
\text { aprendizagem }\end{array}$ & $\begin{array}{l}\text { Paradigma } \\
\text { predominante }\end{array}$ & $\begin{array}{l}\text { Modo de } \\
\text { aprendizagem } \\
\text { (indivíduo) }\end{array}$ & $\begin{array}{l}\text { Modelo de } \\
\text { aprendizagem } \\
\text { (desenho } \\
\text { instrucional) }\end{array}$ & $\begin{array}{l}\text { Alvo da ação } \\
\text { instrucional - } \\
\text { drive }\end{array}$ & $\begin{array}{l}\text { Processo } \\
\text { Cognitivo }\end{array}$ \\
\hline $\begin{array}{l}\text { Modelo } \\
\text { tradicional }\end{array}$ & Linear & Cognitivista & Indivudualista & $\begin{array}{l}\text { Aprendizagem } \\
\text { tradicional - fora } \\
\text { do contexto do } \\
\text { problema }\end{array}$ & $\begin{array}{l}\text { Objetivos } \\
\text { específicos }\end{array}$ & $\begin{array}{l}\text { Significado } \\
\text { registrado - } \\
\text { memória }\end{array}$ \\
\hline $\begin{array}{l}\text { Modelo } \\
\text { móvel }\end{array}$ & Simultâneo & Contrutivista & Colaborativo & $\begin{array}{l}\text { Aprendizagem } \\
\text { situada }\end{array}$ & $\begin{array}{l}\text { Situação- } \\
\text { problema }\end{array}$ & $\begin{array}{l}\text { Signifcado } \\
\text { construído - } \\
\text { inteligência }\end{array}$ \\
\hline
\end{tabular}

Fonte: pesquisa.

$\mathrm{Na}$ abordagem de aprendizagem situada, a memória cede lugar à percepção. A situação-problema será resolvida pela interação entre agente e contexto (inetligência). Como os indivíduos tendem a reagir de modo diferente, dadas as suas percepções igualmente diferenciadas, a adoção de modelos que permitam a colaboração será de grande valia. Os dispositivos móveis pode prover sistemas que subsituam a memória de determinados 
conteúdos, como o acesso aos sites de busca, ou a uma diversidade de aplicativos, que poderão fornecer informações armazenadas ou inéditas ao usuário. Algumas dessas informações podem estar sendo produzidas no mesmo momento, em qualquer lugar do globo. Essa informação poderá, ainda, estar sendo produzida por colaboração. Com a aplicação dos conceitos descritos como mind tools (Jonassen,1999), a tecnologia poderá, não somente substituir o resgate de informações, como proporcionar algumas operações, expandindo as posssibilidades da aprendizagem situada. No caso da sickroom (Wu et al., 2010), além de trazer informações sobre o paciente, o sistema usado pode, em tese, operar dados de acordo com a situação (horário de ministração de remédios, por exemplo, que depende da hora da visita).

O estudo ainda sugere uma falta de compreensão mais profunda do fenômeno tecnológico. em relação ao quê ele pode produzir e como. Quais suas possibilidades (modelos) e alcance (eficácia) das ferramentas disponíveis? Em que ponto, inserções de voz serão mais eficazes do que texto? Como será o desenho do papel de um eventual tutor/ facilitador/educador em relação ao desenho instrucional? Essas e outras perguntas ainda por serem elaboradas e formuladas determinarão os caminhos do desenho intrucional em uma realidade móvel com todas as suas potencialidades.

\section{Terminologia e definição de variáveis}

É necessário que se faça uma melhor leitura, identificação e descrição das variáveis. Mesmo aquelas já testadas. Esse problema já é apontado por Cheng e Hampson (2008), mostrando que nas pesquisas em TD\&E foram encontradas contradições significativas em resultados, com as mesmas variáveis testadas positivamente e negativamente. Os autores apontam como provável causa a má conceituação das variáveis. No caso dos dispositivos móveis, há que se fazer a apropriação de termos usados de modo vulgar e corriqueiro e posicionar conceitos mais precisos e fatorados com o objetivo de se desenvolver medidas e instrumentos confiáveis. Por exemplo, os respondentes dos questionários referem-se a termos commo "acessibilidade", "facilidade".

No caso do modelo TAM, e seus derivados quando se fala em "percepção de utilidade" e "percepção de facilidade de uso", em 1989, 2006 e 2010, será que isso quer dizer 
a mesma coisa em 2015, principalmente quando se refere à utilidade e à facilidade de uso de um aparato tecnológico? Embora alguns modelos, como Wang et al. (2009) e Huang et al. (2006), hajam adaptado os construtos do modelo para o contexto de aprendizagem móvel, ainda persiste alguma dúvida sobre a percepção do usuário. Como distinguir que a utilidade é do dispositivo ou do modelo de capacitação? No trabalho Saccol et al. (2010) (esse estudo foi realizado entre profissionais de $\mathrm{TI}$ ), as questões do instrumento são feitas em relação ao ambiente desenvolvido (COMTEXT). Desse modo, não há detalhamento, ou fatoramento, dos construtos. Em Wang et al., temos um item no instrumento da seguinte forma: "quando usando m-learning, não percebi que tempo havia passado" (referindo-se à diversão percebida, ou fluxo). $\mathrm{O}$ artigo não nos permite ir a fundo quanto à construção do item, mas percebe-se a indistinção entre modelo de aprendizagem e dispositivo móvel. Não há referências ao ambiente. Ou seja, o usuário poderia associar a perda da noção do tempo ao conforto material da situação em que se encontra. Nos resultados deste trabalho (estudo 6), na subcategoria “características físicas do dispositivo”, essa questão é também tangenciada, mas sob o aspecto do aparelho: “... Estava concentrado. Eu estava relaxado...” e “...fiz em casa, deitadão no sofá, no ar refrigerado, no maior conforto..." Dessa forma, podemos perceber que há a necessidade de melhores definições e fatoramento das variáveis que implicam no uso dos modelos móveis.

Ainda, os resultados deste estudo apontam alguma direção ao mostrar na subcategoria "aplicável em outros cursos", no estudo 5, praticamente unanimidade na concordância na aplicação do modelo em outros cursos, inclusive com sugestões objetivas a determinados cursos, como na UR4: “ ... cursos ou regras sobre produtos de crédito/seguros/ ..." Observemos que essa manifestação pode estar incorporando tecnologia e modelo pedagógico. Uma investigação mais profunda poderá determinar se é possível essa separação e, caso seja, definir e delimitar as variáveis respectivas.

Outro tema que inspira cuidados é a classificação de variáveis pré e pós treinamento. Como está posta em discussão a questão linear dos acontecimentos, será necessária uma avaliação precisa dessa classificação. Percebe-se que o novo passo em direção à descrição de variáveis deverá ser dado àquelas que atuam sobre a utilização dos dispositivos e não mais em direção ao que predispõe o usuário a adotar o modelo. Diferentemente dos modelos de tecnologias testados anteriormente aos dispositivos móveis, esses apresentam um grau de 
aceitabilidade e autoeficácia naturalmente mais desenvolvidos. Dessa forma, o caminho deverá ser trilhado em direção à relação entre modelos de desenho instrucionais e tarefas a serem desempenhadas.

Outra intervenção que poderá surgir dos modelos de job aid é o uso de testes situacionais como avaliação da transferência. Essa modalidade é aderenteà simultaneidade de algumas fases do processo de apredizagem e transferência relativos a esse modelo. $\mathrm{O}$ treinando poderá ser avaliado no decorrer da aplicação do aprendido.

\section{Vantagens e limitações dos modelos móveis}

Kinshuk, Sutinen e Goh (2003) Os autores citam como fatores positivos: a) a pequena dimensão e o peso. Não há apontamentos no presente estudo que corroborem esses atributos como vantagens. É possível que estejam embutidos nos atributo de facilidade, disponibilidade e praticidade, identificados nos resultados do questionário; b) acesso instantâneo. Embora, de modo similar ao atributo anterior, não expresso diretamente, pode estar representado no atributo agilidade, disponibilidade e acessibilidade, também relatados nos resultados do questionário; c) multiplicidade de conteúdos. Não pôde ser comprovado no presente estudo; d) preço acessível. O público do estudo possui aparelhos corporativos e, dessa forma, essa vantagem não faz sentido.

Como limitações, propõem: a) pequenas telas (smartphones ampliaram recentemente os padrões) e dificuldades de input (digitação e operação da inserção de dados ainda são problemas). Essas limitações não surgiram nos resultados deste trabalho. Possivelmente dada a função restrita da interação, que resumia-se a rolagem de telas e pesquisa em links, não havendo entrada de dados. Outras limitações e vantagens são apresentadas em diversos trabalhos, mas convergem de modo geral, com as apresentadas. É possível que, com o pouco desenvolvimento dos modelos, ainda não hajam rerferências mais seguras.

Siau, Lim, e Shen (2001), conforme citado em Wang, Wu e Wang (2009) apontam algumas limitações dado que há uma variável, facilidade de uso, que atua sobre a atitude de usar m-learning. Foram mantidas aquelas que não já fazem mais muito sentido, para efeito de percepção do incremento de potencialidade dos aparelhos: a) telas pequenas - houve significativo incremento nas dimensões das telas; b) menor performance, pouca memória e 
capacidade limitada de memória - Embora o período não estaja muito afastado desta pesquisa, já pode-se imaginar que esses limites já foram bastante expandidos nos últimos anos; c) baterias com baixa duração - outro fator que hoje é facilmente contornado pelos novos modelos com capacidade maior e carregadores portáteis, que permitem carregamento em automóveis e tomadas comuns; d) dificuldades de inserção de dados - como já abordado, diversos mecanismos estão sendo incorporados aos dispositivos móveis que estão gradualmente substituindo a digitação, como recursos de voz, RFID, reconhecimento de imagens etc., mas ainda não é fato superado; e) alto risco de erros no armazenamento $e$ transações - com a incorporação do conceito de nuvem e aumento de performance, esse é também um item em decadência; f) baixa resolução das telas - Esse é um item completamete superado com os novos modelos; g) menor "surfabilidade" - provavelmente, ainda não havia a instalação completa da cultura de aplicativos e o estudo refere-se à navegação web. h) intefaces pouco amigáveis - idem ao item anterior. i) limitações gráficas - problema também já superado. Nenhuma dessas limitações surge neste estudo.

O ritual de estudo fragmentado (os usuários não se dedicam em períodos de tempo muito longos ao conteúdo em dispositivos móveis) e a necessidade do desenvolvimento de metacompetências são apontados por Driscoll e Carliner (2005) e por Glackin, Rodenhiser e Herzog (2014) também como limitações. Os últimos, apenas com relação às metacompetências. Gikas e Grant (2010) também relatam a limitação da fragmentação. No caso estudado, essea característica não pôde ser avaliada, visto que o conteúdo é relativamente pequeno e com pouca relação de continuidade entre os itens, permitindo o acesso independente em pontos distintos. Nos estudos identificados, também não houve confirmação dessas limitações especificamente, configurando-as em um âmbito mais teórico. Tanto a dimensão dos teclados como a experiência fragmentada podem implicar na limitação de respostas mais elaboradas, se forem escritas.

Com relação ao desenvolvimento de metacompetências na utilização dos equipamentos, essa limitação está em contraste com este estudo, que não registrou qualquer indício dessa natureza. $\mathrm{O}$ fato é corroborado pela ausência de manifestações quanto a isso em todos os levantamentos, como também pela profusão de manifestações relatanto a facilidade de uso. Dois fatos podem estar associados: a) os usuários já possuem muita intimidade com o tipo de aparelho usado, pois é de uso profissional e intenso, o que implica um certo grau de 
autoeficácia e b) o desenho instrucional não demanda operações mais complexas, além de acessar o aplicativo e navegar no conteúdo. Glackin et al. (2014) afirmam que estudantes têm facilidade de desenvolver metacompetências na utilização de dispostivos móveis. Este estudo não corrobora essa percepção, visto que o modelo foi aplicado em situação de trabalho e não apresentou nenhum indício dessa distinção, como discutido. Não há interações de outras naturezas, nem comunicação, nem coloboração envolvidas no uso do infográfico. No quesito dificuldades encontradas, as únicas levantadas referiram-se ao acesso a redes. Seria de se esperar outras manifestações, caso houvesse surgido outro tipo de dificuldade nos resultados referentes a dificuldades encontradas, explorada no questionário e nas entrevistas.

O estudo de Tan et al. (2014) aponta três grandes vantagens do m-learning em contraposição ao e-learning: conveniência, colaboração e diversão. Embora fortemente presente na literatura, o construto colaboração não foi previsto no desenho instrucional estudado. O fato pode ter duas origens: a falta de conhecimento das potencialidades do modelo móvel ou a inadequação dessa característica do modelo para os objetivos propostos do treinamento. A primeira situação está claramente exposta nos resultados do grupo focal. No segundo caso, há uma implicação direta no desenho instrucional. Ou seja, o modelo deverá oferecer maiores recursos para o desenhista instrucional e deixar o lugar de coadjuvante na opção por um modelo que inclua iniciativas em mobile. Colaboração é ainda, segundo o estudado, uma condição a ser desenvolvida em termos de desenho instrucional. Contudo, o estudo de Gikas e Grant (2013) aponta como resultado esse construto visto como vantagem pelos aprendizes. Percebe-se que colaboração, no contexto de m-learning, é também um construto carente de melhor definição de seus componentes e formas. A diversão é intuitivamente uma vantagem e pode estar associada a aspecto da Teoria do Fluxo e respectiva capacidade de concentração e melhor aprendizagem.

O estudo de Glackin et al. (2014) aponta com destaque dois benefícios apontados pelos usuários: acessibilidade e a usabilidade. Os resultados deste trabalho atestam que são atributos reconhecidos pelos usuários e manifestados também pelos planejadores instrucionais. Ressalte-se, como dito anteriormente, que há necessidade de melhor interpretação desses conceitos. O termo usabilidade foi interpretado pelo pesquisador, com base no significado da combinação de algumas manifestações, visto que o público aparenta não ter ideia precisa do que significa. 
Um benefício potencial, já apontado, refere-se à aplicação em larga escala de treinamentos. Isso já era um forte indutor do e-learning, mas encontra no m-learning grandes perspectivas de incremento na capacidade de multiplicar acesso, com apontado em Wang, Shen, Novak, Pan (2009), que fala em grande massa de aprendizes. Na instituição estudada, há conteúdos disponíveis para 17 mil alunos. Isso implica elaborar desenho ofertando a ferramenta adequada ao nível de controle do processo de aprendizagem. O estudo também apontou a interatividade como um indutor produziu maior engajamento dos aprendizes.

A transição do uso da memória para a percepção, pode trazer uma dependência da tecnologia, com possíveis problemas de natureza tecnológica ou de desempenho (autoeficácia e metacompetências). O mesmo poderá ocorrer em relação a todos os processos que poderão ser substituídos por aplicações tecnologógicas.

Uma limitação adicional, como ponto de atenção é a possibilidade de treinamento fora do horário de expediente. Com relação aos alunos, isso não é uma limitação, pelo contrário, algumas manifestações indicam que existe o desejo de estudar dessa forma. No entanto, com relação ao ambiente organizacional, esse é um limitador consistente, visto que implica questões jurídicas. Percebe-se um paradoxo entre a possibilidade de se estudar em qualquer lugar a qualquer hora e o conceito de jornada de trabalho.

Apontam-se alguns referenciais de risco, descritos por Phillips (conforme citado em Romiszowski, 2003), em relação ao e-learning, mas que podem ser adaptados e verificados de modo análogo para o m-learning. $\mathrm{O}$ autor aponta três níveis de falhas nos sistemas de $e$ learning: a) nível de produto: desenho inadequado do curso e pouca aderência do conteúdo à realidade do aprendiz, desenho inadequado do ambiente (interface), tecnologia ineficaz, má gestão do ambiente. b) Nível do aprendiz: pouca motivação para a aprendizagem, habilidades inadequadas de auto-estudo, intervenções da vida social, falta de autoeficácia, perda dos prêmios do ensino presencial. c) Nível da organização: promoção equivocada do evento, falta de recompensas, provimento de uma plataforma de qualidade adequada, falha de feedback da organização, falha na organização de uma cultura que valorize a aprendizagem, falhas metodológicas em relação ao objeto oferecido. Se realizada uma investigação específica sobre o mobile learning, essa lista tende a crescer significativamente, dada a sensibilidade a interferências em modelos móveis. Contudo, é uma boa partida para uma adaptação mais estruturada e sistemática dos pontos de atenção no desenho da solução. 


\section{Potencialidades}

No decorrer deste trabalho, diversas potencialidades já puderam ser percebidas, contudo cabe reforçar esse aspecto para que se tome consciência da importância de que os desenhistas instrucionais estejam atentos a recursos que são disponibilizados com muita frequência, trazendo novas e importantes possibilidades para a utilização dos modelos móveis. Os recursos tecnológicos dos dispositivos móveis apresentam diversas potencialidades adicionais, como: touch screen, comunicação gestual, reconhecimento de voz, de figuras (há aplicativos que descobrem fabricantes de vinho pela fotografia dos rótulos), de sons (alguns aplicativos identificam a música que está tocando no ambiente, ou mesmo se o usuário cantarolar algum trecho), geolocalização, identificação por meio da digital do usuário (reconhecimento da impressão digital) e ainda muitos outros. Alguns recursos mais corriqueiros, como gravação de som, voz, imagem e sua respectiva edição ainda não surgiram com força nos modelos estudados, mas estão disponíveis até nos aparelhos mais simples. Braga (2012) testou modelo de utilização de gestos para a construção de figuras. Recurso aproveitado da função touch screen. Foi o único trabalho que se ocupou de potencializar essa funcionalidade. Em termos de recuros didáticos, diversos aparatos baseados em mobile podem estar presentes nos eventos de capacitação como material de apoio: fichas de memorização (similar ao objeto estudado), resumos de normas, enquetes - há uma experiência relatada em Wu et al. (2012) na qual foi disponibilizado um sistema de autoavaliação aos estudantes, que foi útil e a experiência foi considerada positiva -, consultas a outros ambientes, roteiros de estudo, troca de mensagens, que pode servir à tutoria. Enfim, há um vasto potencial de aplicação da tecnologia móvel ao desenho instrucional. Para a organização, o BYOD poderá trazer boas novidades em termos de eficácia, visto que o usuário disporá de um sistema de seu agrado, que será melhor operado também, além de evitar tráfego pelas redes internas das organizações, com riscos à segurança dos sistemas e ônus de performance, devido aos volumes transitados em situações de treinamento. 


\section{LIMITAÇÕES}

Com relação ao contexto geral de aplicação da pesquisa, o ambiente organizacional exerceu alguma influência na manifestação de aspectos positivos do treinamento avaliado e da própria adoção de um modelo com características de avanço tecnológico. Foi percebida, principalmente, nas entrevistas, alguma vibração sobre isso, como se as pessoas entrevistadas houvessem desenvolvido um senso geral positivo por identificar que a organização na qual trabalham oferece elementos modernos para capacitação dos funcionários.

Outro aspecto que pode ter exercido alguma influência foi o fato de o pesquisador pertencer aos quadros da organização. Embora, o contato tenha se restringido ao grupo focal (como apoiador), e às entrevistas (uma, como apoiador e outra como entrevistador), a presença física pode haver interferido nas respostas. Tanto no grupo focal, como na entrevista 1, o pesquisador atuou como mero anotador das falas. A contraposição a essa possibilidade foi a realização de técnicas complementares (triangulação) a fim de minimizar efeitos indesejados. As análises documentais e o questionário, que não sofreram essa influência, têm resultados similares e convergentes.

O grupo focal foi realizado no contexto e nas instalações da organização estudada. Embora os resultados não tenham assumido caráter positivo, negativo, ou qualquer outro de valor - vê-se pelas frequentes afirmações de desconhecimento das potencialidades e caraterísticas -, o fato de que os profissionais que participaram estejam no contexto do próprio trabalho pode haver exercido algum enviesamento nas manifestações.

Confirmando o caráter deliberadamente consensual, pouquíssimos itens foram objeto de discordâncias entre os participantes (desenhistas instrucionais e demandantes do treinamento). Em caso de desenvolvimento de métodos complementares, pode ser necessária a aplicação de um instrumento que controle possíveis viéses, como, por exemplo, o medo de desaprovação pelos pares, conforme Simthson, J. (2000 como citado em Barbour, 2009), que pode haver exercido alguma pressão no balanceamento das respostas.

O desconhecimento sobre o modelo pode haver reduzido especulações e insights em outras direções diferentes daquelas tomadas durante o debate, produzindo, em alguma medida, esterilidade. A terminologia ainda não é técnica e abre espaço para concepções de caráter comum, podendo ser necessário um estudo específico para o desenvolvimento de definições constitutivas próprias e precisas. Mesmo com a explicação dos termos, realizada no 
início do grupo focal, alguns termos podem não haver sido compreendidos com precisão. $\mathrm{O}$ estudo de mobilidade é um exemplo. Esse termo, quando visto pela literatura, ganha um entendimento mais complexo e preciso do que aquele que foi mencionado com significativa frequência nos três estudos que envolveram opiniões.

Quanto ao método, a aplicação de grupos focais, questionários e entrevista (fontes primárias) satisfazem a necessidade de fontes de dados diversificadas, no entanto todos são autorrelatos e, por isso, sujeitos aos viéses específicos. O número de respondentes do questionário é relativamento baixo provavelmente devido à baixa adesão ao modelo móvel. Os formulários foram distribuídos e respondidos nos sitemas da organização, o que pode gerar também um viés de desejabilidade social, visto que os respondentes podem tender a "agradar" a organização em que trabalham. Esse viés já foi detectado na organização em outras ocasiões. No caso das entrevistas, pelo fato de serem face-a-face, acarretaram em uma condução que escapou em alguma medida da condução original, permitindo um discurso muito informal, que, se por um lado, permite maior liberdade à expressão, possibilita a divagação e o excesso de perguntas, como sugere o resultado. Como o roteiro original foi baseado em questões expostas à validação semântica, esse afastamento do roteiro original permite relativa perda do foco dos significados e sentidos a serem explorados.

Como visto na discussão, é necessária uma melhor distinção dos termos a serem verificados: facilidade, mobilidade, acesso, utilidade etc. Parece não ser de domínio dos usuários a distinção entre o dispositivo físico e as funções e características das interfaces. Ao se referir à facilidade de acesso, o usuário pode estar falando em ter o aparelho disponível ou à facilidade de navegação, ou ambos indistintamente. O fatoramento de variáveis poderá, posteriormente, trazer mais luz ao assunto em investigações mais detalhadas e precisas.

Como há poucas iniciativas na organização com treinamento em dispositivos móveis e também pouca cobertura científica para essa tomada de decisão (especialmente com relação a resultados), a opção pela solução em dispositivo móvel se deu possivelmente por uma percepção de vantagens explícitas dos dispositivos móveis e também por intuição, dada a larga experiência do grupo no planejamento instrucional. Ou seja, é uma inciativa de traço experimental, como recurso de treinamento. Fatores como mobilidade (mesmo que no entendimento não técnico) e portabilidade são bastante visíveis tanto para planejadores, como para a clientela deste estudo. Essas considerações foram classificadas como limitação por não 
haver uma exploração mais extensa dos recursos. $\mathrm{O}$ fato pode ter agido como um inibidor de potencialidades do modelo.

Os traballhos examinados, em sua maioria, têm corte transversal e baseiam-se em técnicas de coleta com autorrelato. Grande parte foi aplicada em instituições de ensino (90\%) e os restantes em organizações de trabalho (10\%). Os números mostram carência de experiências em situação real de trabalho, o que inibe comparações. Assim, o campo e este estudo ainda apresentam desafios significativos de modelagem e metodologia de pesquisa, no entanto os resultados acrescentam boas perspectivas e bons dados para tratamento e evolução do estudo dos dispositivos móveis em educação corporativa.

Algumas limitações mostraram-se também importantes para o relato, pois poderão implicar em melhorias para novos estudos. O ambiente corporativo traz grande contribuição à pesquisa quando aplica em realidade modelos ainda não testados suficientemente, mostrando interesse do universo organizacional e trazendo compromisso dos pesquisadores com a perspectiva de resultados organizacionais objetivos e eonomicamente viáveis. No entanto, pelo fato de que as técnicas foram aplicadas com apoio da instituição surge o risco do viés de desejabilidade social, que não foi controlado. Em alguns momentos, pode-se perceber que há algum entusiasmo dos usuários em participar das ações da pesquisa, o que pode ter gerado alguma distorção nos resultados, principalmente nas entrevistas. Em contrapartida, os resultados foram confirmados por mais de uma técnica de exploração e estão, em alguma medida, alinhados com o que prevê a literatura. 


\section{CONSIDERAÇÕES FINAIS E AGENDA DE PESQUISA}

Sob o ponto de vista organizacional (particularmente, para empresas de grande porte), o benefício de massificação de um determinado recurso instrucional pode ser considerado um fator positivo de per si, em se considerando o efeito de escala, mesmo que os resultados de transferência possam estar em níveis ainda insatisfatórios, ou com poucos recursos para a mensuração. Os investimentos vultosos e crescentes em e-learning pelas organizações mostram que o interesse se intensifica também em formatos diversos de oferta, como a intensificação da opção por treinamento com jogos, por exemplo.

Analogamente, a adoção dos dispositivos móveis, potencializa ainda mais a massificação, por suas características intrínsecas (técnicas, físicas e de interface) e extrínsecas (recurso didático), quando permite acesso de modo ubíquo a grandes volumes de conteúdos. Os sistemas de educação mediada por tecnologia seguramente estão amadurecendo como cultura, com pessoas mais acostumadas a sistemas eletrônicos, engenhos de busca, técnicas de pesquisa e estudo, com índices crescentes de autoeficácia. Isso ocorre juntamente com a oferta crescente de novos recursos e avanço nas funcionalidades oferecidas pelos dispositivos.

O aperfeiçoamento dos instrumentos de avaliação é, ainda, um fator que deve ser objeto de estudos intensos para que se proponham formas adequadas para se avaliar os resultados desses tipos de estudo. Muito se deve à multiplicidade de desenhos que os dispositivos móveis permitem, implicando em condições de uso muito diversa, com reflexos diretos no comportamento de uso e, consequentemente, em sua eficácia. Considere-se o tempo e a energia para o desenvolvimento de medidas e instrumentos para caso, caso se opte pelos padrões tradicionais para essas etapas. Uma outra direção é a busca de novas abordagens que priviegiem os modelos que surgem no estudo, como aprendizagem situada e práticas construtivistas.

A expectativa central do trabalho foi buscar elementos para a construção de uma hipótese futura de que os usuários que utilizarem modelos baseados em dispositivos móveis apresentem melhores resultados de transferência do que aqueles que não o fizerem. Essa ideia surge, em caráter mais abrangente, do fato de que o treinando terá à sua disposição mais um recurso didático disponível para consultas ou estudo em qualquer lugar a qualquer tempo (ubiqidade), permitindo que se faça uso dele nas condições decididas pelo usuário, em 
desenhos instrucionais mais customizados, melhor adequados à sua realidade de trabalho e às características de suas tarefas. Pode se intuir que o usuário procederá dessa forma quando as condições forem as mais adequadas para a sua estratégia de aprendizagem.

As contribuições mais significativas deste estudo à pesquisa na área de TD\&E residem nos debates e achados que propõem bases para definições de atributos e categorias de construtos relacionados ao uso, aprendizagem, e transferência de treinamento apoiados por dispositivos móveis. Esses, por sua vez, poderão ser úteis nas identifcações de variáveis definidas que atuam sobre o modelo, possibilitando o estudo de medidas e instrumentos de mensuração. A experiência dos usuários se mostrou rica e sugere que há grandes possibilidades para a aplicação de um modelo móvel em situações análogas ao contexto e à natureza do trabalho executado com o apoio do dispositivo móvel (visitas a clientes). De modo imaginário, há uma infinidade de novas possibilidades com apoio dessa tecnologia, que traz novidades em velocidades nunca experimentadas.

O estudo traz também diversos modelos aplicados e testados, com sucesso, ou não, que mostram o grande potencial dessa modalidade em relação a desenhos instrucionais interessantes e atraentes, bem como traz também informações objetivas para o apoio dessa estratégia, como dimensão de vídeos, modos de utilização, recursos à disposição dos planejadores instrucionais e outros itens que possam ser aproveitados em novos desenhos. A customização de ambientes mobile também surgiu no estudo como diferencial, dadas as condições de uso e os recursos dos dispositivos. Mostra, enfim, que há um novo aprendiz aguardando ser compreendido em seu modo de viver e de aprender e que ele já se mostrou interessado e favorável aos modelos nos quais experimentou a aprendizagem. O método e as técnicas aplicadas também mostraram-se bem úteis aos propósitos do estudo, revelando percepções e confirmando expectativas sobre o assunto. Este estudo buscou apoio de outras ciências, como a psicologia, a pedagogia e a tecnologia informática para compor o corpo de estudo em espectro mais amplo e permittindo um entendimento mais plural da aprendizagem.

Ainda há um baixo índice de adoção do modelo pelos usuários, o que também resultou em quantidades relativamente baixas de respondentes. A adoção do modelo em outros treinamentos (prática fortemente apoiada por planejadores e usuários) poderá trazer novos conjuntos de informações, que, por sua vez, retroalimentarão o sistema e promoverão incrementos no conhecimento sobre essa modalidade. Outra limitação que pode não ter 
afetado a realização da pesquisa, mas poderia ter trazido muitos insumos é a falta de dados extraídos do sistema. A tencologia permite que sejam rastretadas todas as ações realizadas pelos usuários, o que dá ao planejador um retrato detalhado de seus pontos de maior atenção, pontos de dificuldades, horários acessados e outros. Como o objeto estudado não previu esses levantamentos, o sistema não estava programado para disponibilizar essas informações.

Percebe-se que estamos diante de um vasto campo de pesquisa, que deverá ganhar muita substância nos próximos anos, com a emergência de mais resultados. Algumas grandes áreas para a evolução dos trabalhos serão: desenho instrucional móvel, identificação e mapeamento de variáveis que atuem sobre a aprendizagem nesse modelo, desenvolvimento de modelos teóricos para a compreensão do fenômeno em sua integralidade e sistemas de avaliação adequados. Além disso, o investimento em ações que privilegiem a colaboração e construção coletiva de conhecimento serão de grande importância para a amplição do universo conhecido da capacitação e desenvolvimento profissional.

O atual estudo contribui também na direção da redução da distância entre pesquisa e realidade organizacional, avaliando intervenção realizada em situação de trabalho real, com objetivos organizacionais bem definidos e com o compromisso de entrega de resultados. Nos estudos localizados, poucos trabalhos foi realizado em situação similar. Outro problema levantado é a confirmação de variáveis sem o entendimento de como esses fatores podem ser gerenciados. Ou seja, a identificação e definição das variáveis devem apontar direções para o gerenciamento dos fatores implicados no processo. O estudo mostra prováveis variáveis a serem estudadas e a distância entre conceitos e fatos verificáveis para a construção de instrumentos e medidas com os cuidados conceitais necessários.

É possível visualizarmos também repercussões de modo mais geral, em vista do aprofundamento da compreensão do comportamento humano perante uma inovação tecnológica. A utilização de novas tecnologias costumam produzir grandes alterações em nosso modo de vida. Dessa forma, a pesquisa poderá contribuir com achados que vão além do escopo inicial, além de produzir provocações que possam inspirar outros pesquisadores e novas investigações. A afirmação "a tecnologia pode tornar ir ao treinamento uma tarefa obsoleta", de Salas e Cannon-Bowers (2001), foi bastante visionária a respeito da imensa influência da tecnologia na educação corporativa. Efetivamente, isso vem se confirmando com o avanço sistemático e gigantesco da oferta de cursos e eventos em modelos totalmente 
não-presenciais. Com relação aos modelos móveis, podemos ir além: "o treinamento estará permanentemente à disposição do aprendiz, em qualquer tempo e local onde se faça necessário", como previsto e proposto por Sharples em 2000, e compreender um novo modelo de entendimento de como serão as feições do pensamento e do comportamento de novas gerações que estão sendo modificadas por um novo contexto global de vida. Em sistemas mais antigos, o usuário deveria entender a máquina e adaptar-se à sua linguagem, a fim de obter produtos que ela fosse capaz de produzir. Com o tempo, os sistemas informáticos começaram a diminuir o espaço entre a inteligência de funcionamento da máquina e a inteligência de funcionamento do pensamento e comportamento do usuário. Até o ponto de começar a entender as necessidades do usuário e se transformar a fim de atender as necessidades desse sujeito. Isso é visível nos sistemas de busca como o Google e similares. O mesmo deverá se dar com a educação mediada. Dessa forma, as afirmações sobre uma nova pedagogia não parecem, de modo algum, absurdas, ou mesmo pretensiosas.

Cabem, adicionamente de modo mais abrangente, outras reflexões no campo das relações de trabalho, já abordadas de modo ligeiro, mas nas quais cabem maiores e importantes aprofundamentos, como a questão do trabalho e estudo em qualquer hora e lugar. Isso também pode significar uma flexibilização de relações de esforço e remuneração, que podem fragilizar a posição de trabalhadores, bem como proporcionar um déficit de controle por parte do empregador. Como serão controladas as horas de trabalho, de estudo? Como distinguí-las, em alguns casos? O custeio dos aparelhos, dos acessos, das atualizações serão ônus de qual parte? Há, aqui, questões e legais que serão objeto de estudos importantes para uma aplicação segura, ética e produtiva de uma nova maneira de se trabalhar e aprender.

Podemos concluir, na base da reflexão prática mais do que nas pesquisas rigorosas, que os fatores que mais influenciam o sucesso ou fracasso de projetos de e-learning, são pouco relacionados com as tecnologias utilizadas e os detalhes técnicos de desenho dos cursos a serem veiculados por estas tecnologias. São muito mais relacionados com aspectos mais fundamentais e abrangentes que tendem a impactar qualquer projeto inovativo no contexto de sistemas sociais que envolvem seres humanos em interação. Sistemas de educação e treinamento são excelentes exemplos de tal categoria de sistemas, mas os princípios que explicam seu funcionamento e podem prever sucesso ou fracasso são amplamente aplicáveis a qualquer forma de sistema social ou humano (Romiszowski, 2003). 


\section{Agenda de pesquisa}

Fantin (2015) e Meer et al. (2015) propõem mudanças radicias nas concepções de aprendizagem face à aprendizagem situada. Para que isso ocorra, é também necessária a investigação de como serão os resultados da aplicação dos princípios à aprendizagem organizacional. Para isso, o estudo propõe algumas frentes de pesquisa.

A investigação sobre os fatores relacionados ao contexto deve ganhar protagonismo nos estudos sobre aprendizagem móvel, dada sua imporância e suas potencialidades. Como visto, esses contextos podem ser definidos como variáveis do processo de transferência, que serão determinantes de um desenho instrucional específico.

A discussão dos conceitos de modelos de aprendizagem e proposição de novas abordagens, com a inclusão/desenvolvimento de taxonomias específicas de aprendizagem se mostram como possibilidades de tornar modelos móveis eficazes, a fim de que se satisfaça o contexto e os compromissos de ordem organizacional. Nos modelos móveis, o nível de autonomia do aprendiz ganha nova dimensão, permitindo que ele vá mais longe nas decisões de como aprender e aplicar o aprendido no trabalho.

O aspecto motivacional deverá sofrer grande influência sobre a aprendizagem, visto que terá à sua disposição materiais e conteúdos nas mais variadas formas, muitas vezes para realizar a mesma tarefa, como é o caso da cultura dos aplicativos - apps. Engajamento, concentração e outros comportamentos deverão ser vistos por ótica própria, com base nas teorias de comportamento que já se mostraram adequadas ao estudo de mobile learning. Aplicabilidade no trabalho, objetividade e atratididade serão atributos indispensáveis para os modelos móveis e deverão ser contemplados nos desenhos intrucionais e estratégias de ensino.

A identificação e isolamento de variáveis preditoras e moderadoras também deverá ser prioridade, com o objetivo de possibilitar a construção de instrumentos e medidas confiáveis de avaliação dos modelos móveis. O aproveitamento dos recursos informáticos na geração de dados para avaliação do percurso do aprendiz deverá estar pautado para desenvolvimento, visto que esses dados já existem, mas não apareceram na pesquisa de modo significativo, ou seja, com baixa frequência. $\mathrm{O}$ acompanhamento e absorção dos recursos informáticos deverão estar em pauta permanente dos planejadores instrucionais a fím de criar 
maior sintonia entre o que se pode aproveitar para aplicação no desenho instrucional e que será eficaz para a aprendizagem e transferência de treinamento. 


\section{REFERÊNCIAS}

Abbad, G. S., Mourão L., Meneses P. P. M., Zerbini, T., Borges-Andrade J. E., \& Vilas-Boas R. (2012) Medidas de Avaliação em Treinamento, Desenvolvimento e Educação. Porto Alegre.

Abbad, G. S., Pilati, R., Borges-Andrade, J. E., \& Sallorenzo, L. H. (2012) Transferência de treinamento e impacto do treinamento em profundidade. In: Medidas de avaliação em treinamento, desenvolvimento e educação. Porto Alegre: Ed.Artmed. Capítulo 9, p. 145 -160 .

Abbad, G. S., Borges-Andrade, J. E., (2004) Aprendizagem humana em organizações de trabalho. In: Zanelli, J. C.; Borges-Andrade, J. E., Bastos, A. V. B. (Org.). Psicologia, organizações e trabalho no Brasil. Porto Alegre: Artmed, 2004. p. 237-275." (E. 129)

Abbad, G. S., Pilati, R \& Pantoja, M. J., (2003) Avaliação de treinamento: análise da literatura e agenda de pesquisa. R. Adm., São Paulo, v.38, n³, p-205-218, jul./ago./set. 2003.

Abbad, O-C. G. (1999) Um Modelo Integrado de Avaliação de Impacto do Treinamento no Trabalho - IMPACT. Tese de Doutorado. Instituto de Psicologia. Universidade de Brasília (páginas 29-43) 1999.

Aguinis, H. \& Kraiger, K. (2009) Benefits of Training and Development for Individuals and Teams, Organizations and Society. Annual Review of Psychology, 60, p. 451-474.

Anderson, L. W., Krarathwohl, D. R., Airasian, P. W., Cruikshank, K. A, Mayer, R. E., Pintirch, P. R., Raths, J., \& Wittrock, M. C., (2001). A taxonomy for learning, teaching and assessing: a revision of Bloom's taxonomy of educational objectives. Longman.

Baldwin, T.T., \& Ford, J.K. (1988). Transfer of training: a review and directions for future research. Personnel Psychology, 41(1), 63-105.

Bandura, A. (1982) Self-Efficacy Mechanism in Human Agency. American Psychologist (37:2) pp. 122-147.

Barbour, R. (2009). Grupos Focais. Porto Alegre, Artmed.

Bardin, L. (2011). Análise de Conteúdo. São Paulo: Edições 70.

Bidarra, J., Rothschild, M., Squire, K., \& Figueiredo, M. (2013) The Aidlet model: A framework for selecting games, simulations and augmented reality environments in mobile learning. International Journal of Web-Based Learning and Teach Technologies, 8(4), 50-71, October-December 2013.

Blume, B. D., Ford, J. K., Baldwin, T. T. \& Huang, J. L. (2009) Transfer of training: a metaanalytic review. Journal of Management OnlineFirst.

Borges-Andrade, J. E., Abbad, G. S. \& Mourão, L. (2012) Modelos de avaliação e aplicação em TD\&E. In: Medidas de avaliação em treinamento, desenvolvimento e educação. Porto Alegre: Ed. Artmed. Capítulo 1, p. $20-35$.

Borges-Andrade, J. E., Abbad, G. S. \& Mourão, L. (2006) Treinamento, Desenvolvimento e Educação em Organizações e Trabalho. Fundamentos para Gestão de Pessoas. Ed. Artmed. Porto Alegre.

Börner D., Glahn C., Stoyanov S., Kaltz M., \& Specht M. (2010). Expert concept mapping study on mobile learning. Campus-Wide Information Systems, Vol. 27 Iss 4 pp. 240 253 (CELSTEC) - Open Universiteit of the Netherlands, Heerlen, The Netherlands.

Burke, L.A.; Hutchins (2007) H.M. Training Transfer: An Integrative Literature Review. Human Resource Development Review. v. 6; p. 263-297. 
Carbone, P. P., Brandão, H. P., \& Leite, J. B. (2005) Gestão por competências e gestão do conhecimento. Rio de Janeiro: FGV, 2005.

Cheng, E. W. L., \& Hampson, I. (2008) Transfer of training: A review and new insights. International Journal of Management Reviews. Oxford UK.

Ciborra, C. (2002) The Labyrinths of information: challenging the wisdom of systems. New York: Oxford Press.

Csikszentmihalyi, M. (1990) Flow: The psychology of optimal experience. N.Y.: Harper and Row. 1990.

Davis, F. (1989), Perceived Usefulness, Perceived Ease of use, and user acceptance of information technology. Mis Quarterly - September, EEUU.

Driscoll, M. (2002). Blended learning: let's get beyond the hype [electronic version]. eLearning, 54 (http://elearningmag. com/ltimagazine/article/articleDetail.jsp?id=11755).

Driscoll, M., \& Carliner, S. (2005) Advanced Web-Based Training Strategies. San FranciscoCA. Pfeiffer.

Du, H., Hao, J-X., Kwok, R., \& Wagner, C. (2010) Can a Lean Medium Enhance LargeGroup Communication? Examining the Impact of Interactive Mobile Learning. Journal of the American Society for Information Science and Technology, 61(10):2122-2137.

Éboli, M., Fischer, A. L., Moraes, F. C. C., \& Amorim, W. A. C. (2010) Educação corporativa. Ed. Atlas: São Paulo.

Fantin, M. (2015) Novos Paradigmas da Didática e a Proposta Metodológica dos Episódios de Aprendizagem Situada, EAS. Educação \& Realidade, Porto Alegre, v. 40, n. 2, p. 443-464, abr./jun. 2015. http://dx.doi.org/10.1590/2175-623646056.

Fadare, O. G., Babatunde, O. H., Akomoafe, D. T., \& Lawal, O. O. (2011) Behavioral intention for mobile learning on 3G mobile internet technology in south-west part of nigeria. World Journal of Engineering and Pure and Applied Sci. 2011;1(2):19.

Flick, U (2009) Desenho da pesquisa qualitativa. Porto Alegre: Artmed.

Gagné, R. M. (1965). The conditions of learning. New York: Holt, Rinehart \& Winston.

Gagné, R. M. (1977). The conditions of learning. New York: Rinehart \& Winston, $3^{\text {a }}$ edição.

Gagné, R. M.; Briggs, L. J.; \& Wagner, W. (1988) Principles of instrutional design.

Gikas, J., \& Grant, M. M. (2013) Mobile computing devices in higher education: Student perspectives on learning with cellphones, smartphones \& social media. Internet and Higher Education 19 (2013) 18-26.

Glackin, B., Rodenhiser. R. \& Herzog B (2014) A Library and the Disciplines: A Collaborative Project Assessing the Impact of eBooks and Mobile Devices on Student Learning. The Journal of Academic Librarianship 40 (2014) 299-306.

Gonçalves, A. \& Mourão, L. (2011) A expectativa em relação ao treinamento influencia o impacto das ações de capacitação? Revista de Administração Pública. V.45, n.2, p. 483-513, 2011.

Goh, T.; Kinshuk, D. (2004) Getting ready for mobile learning, Proceedings of ED-MEDIA World Conference on Educational Multimedia, Hypermedia \& Telecommunications, Lugano, Switzerland, p. 56-63.

Gondim, S. M. G. (2003) Grupos Focais como Técnica de Investigação Qualitativa: Desafios Metodológicos. Paidéia, 2003, 12(24),149-161.

Graham, C. R. \& Dziuban, C. (2003) Blended Learning Enviroments. Quarterly Review of Distance Education. Fall, Vol. 4 Issue 3, p227-233. 7p. 2 Diagrams, 1 Chart. 
Graham, C. R. (2008) Blended Learning Environments. In Handbook of research on educational communications and techology. Spector, J. M., Merril, M. D., Merriënboer, J. V. Lawrende Erlbaum Associates. Capítulo 23. New York.

Hamblin, A. C. (1978). Avaliação e controle do treinamento. São Paulo: McGraw-Hill do Brasil.

Hyochang, L., Lee, S-G., Kichan, N. (2007) Validating e-learning factors affecting training effectiveness. International Journal of Information Management. Cheonan, Korea p. 22-35.

Huang, J-H, Lin, Y-R, Chuang, S-T (2006) Elucidating user behavior of mobile learning - A perspective of the extended technology acceptance model. The Electronic Library Vol. 25 No. 5, 2007 pp. 585-598. www.emeraldinsight.com/0264-0473.htm.

Hummel, K. A., Hlavacs, H., \& Weissenböck, H. (2002) Web-based online-learning in technically equipped and mobile student societies: A case study. Proceedings of the 5 th International Workshop on Interactive Computer Aided Learning, Villach, Austria.

Hung, J-L., \& Zhang, K. (2012) Examining Mobile Learning Trends 2003-2008: A Categorical Meta-Trend Analysis Using Text Mining Techniques. Journal of Computing in Higher Education (2012) 24:1-17 DOI 10.1007/s12528-011-9044-9.

Hernando, M. M., Arévalo, C. G., Catasús, M. G., \& Mon, C. Z. (2014) Mobile learning: a collaborative experience using QR codes. Revista de Uni-versidad y Sociedad del Conocimiento (RUSC). Vol. 11, No 1. pp. 175-191. doi http://doi.dx.org/10.7238/ rusc.v11i1. 1899Mobile.

Huang, Y.-M., Liao, Y.-W., Huang, S.-H., \& Chen, H.-C. (2014). A Jigsaw-based Cooperative Learning Approach to Improve Learning Outcomes for Mobile Situated Learning. Educational Technology \& Society, 17 (1), 128-140.

Jeng, Y.-L., Wu, T.-T., Huang, Y.-M., Tan, Q., \& Yang, S. J. H. (2010). The Add-on Impact of Mobile Applications in Learning Strategies: A Review Study. Educational Technology \& Society, 13 (3), 3-11.

Jonassen, D. (1999). Computers as Mindtools for Schools, Engaging Critical Thinking. Prentice-Hall, Englewood Cliffs, NJ.

Kukulska-Hulme, A., Sharples, M., Milrad, M., Arnedillo-Sánchez, I. \& Vavoula, G. (2009). Innovation in Mobile Learning: A European Perspective. International Journal of Mobile and Blended Learning, 1(1), pp. 13-35.

Kukulska-Hulme, A. (2011) How should the higher education workforce adapt to advancements in technology for teaching and learning? Internet and Higher Education 15 (2012) 247-254.

Kakihara, M. \& C. Sørensen (2002). Mobility: An Extended Perspective. In Proceedings of the 35th Hawaii International Conference on System Sciences (HICSS-35). IEEE, Big Island, Hawaii. 7th-10th January 2002, 1756- 1766.

Kinshuk, J. S., Sutinen, E. \& Goh, T. (2003) Mobile Technologies in Support of Distance Learning. Asian Journal of Distance Education. New Zealand.

Kurtz, R., Macedo-Soares, T. D., Ferreira, J. B., Freitas, A, S. \& Silva, J. F. (2015) Fatores de Impacto na Atitude e na Intenção de Uso do M-Learning: Um Teste Empírico. Revista Eletrônica de Administração, http://dx.doi.org/10.1590/1413-2311.0542013.46305 ISSN 1413-2311 (versão on line) 
Lasen, A. (2004) Affective technologies - emotions and mobile phones. Acessado em https:// www.academia.edu/472410/Affective Technologies._Emotions_and_Mobile_Phones. Acessado em 08/02/2016.

Le Boterf, G. (1999) Competénce et navigation professionnelle. Paris: Éditions d'Organisation.

McConatha, D., Praul, M. \& Lynch, M. (2008) Mobile Learning in Higher Education: an Empirical Assessment of a New Education Tool. The Turkish Online Journal of Educational Technology - TOJET July 2008 ISSN: 1303-6521 volume 7 Issue 3 Article 2.

Martin, S., Diaz, G., Sancristobal, E., Gil, R., Castro, M., \& Peire, J. (2011) New Technology trends in education: Seven years of forecast and convergence. Elsevier - Computers \& Education 57.

Meer, J., Berg, D., Smith, J., Gunn, A., \& Anakin, M. (2015) Shorter Is Better: Findings of a Bite-Size Mobile Learning' Pilot Project. Creative Education, 2015, 6, 273-282. Dunedin, New Zealand.

Morgan, D. L. (1997). Focus group as qualitative research. Qualitative Research Methods Series. 16. London: Sage Publications.

Mourão, L.; Abbad, G. S. \& Zerbini T. (2014) Avaliação da Efetividade e dos Preditores de um Treinamento à Distância em uma Instituição Bancária de Grande Porte. Revista de Administração. v.49, n. 3, p. 534 - 548.

Muyinda, P., (2007) MLearning: pedagogical, technical and organisational hypes and realities. Campus-Wide Information Systems Vol. 24 No. 2, 2007 pp. 97-104 q Emerald Group Publishing Limited. Kampala, Uganda.

Naismith, L., Lonsdale, P., Vavoula, G., Sharples, M. (2006) Literature review in mobile technologies and learning. Bristol, UK: University of Birmingham. (FutureLab Series. Report, 11). Disponível em: http://archive.futurelab.org.uk/resources/documents/ lit_reviews/Mobile_Review.pdf. Acesso em: 25 out. 2015.

Nonaka, I. \& Takeuchi, H. (1997) Criação do conhecimento na empresa. Rio de Janeiro: Ed. Elsevier.

Ojokoh, B. A., Doyeni, O. A., Adewale, O. S., \& Isinkaye, F. O. (2013) A Mobile-Based ELearning System. International Journal of Web-Based Learning and Teaching Technology, 8(3), 1-17, July-September 20131.

O’Malley, C. (2003) Guidelines for Learning/Teaching/Tutoring in a Mobile Enviroment. Nottinhgham/UK. MOBIlearn/UoN,UoB,OU/D4.1/1.0.

Ortigosa, A., Bravo, J., Carro, R. M., \& Martín, E. (2010) Entornos de Aprendizaje Móviles Adaptativos Y Evaluación: Comole Y Geses. Revista Iberoamericana de Educación a Distancia - RIED v. 13: 2, 2010, pp 167-207.

Parise, D., Parise, M., Maran, V., Battisti, G. (2014) U-Learing - O futuro do EAD? $3^{\circ}$ Seminário Nacional de Inclusão Digital. Abril/2014. http://gepid.upf.br/senid/2014/? page_id $=390$ /.

Peng., H., Su, Y-J, Chou, C. \& Tsaib, C-C (2009) Ubiquitous knowledge construction: mobile learning re-defined and a conceptual framework. Innovations in Education and Teaching International Vol. 46, No. 2, May 2009, 171-183.

Pereira, S. C. M. (2009) Avaliação, com base em modelo lógico, de efeitos de um treinamento estratégico no desempenho de egressos e da organização. Dissertação de Mestrado. Universidade de Brasília. 
Pilati, R. \& Abbad, G. (2005) Análise Fatorial Confirmatória da Escala de Impacto do Treinamento no Trabalho. Psicologia: Teoria e Pesquisa Jan-Abr 2005, Vol. 21 n. 1, pp. 043-051.

Pretti, O., Alonso, K. M., Foerste, E., Toschi, M. S., Neder, M. L. C. \& Bédard, R. (2005) Educação a distância. Liber Livro Editora, 2005. Brasília.

Romiszowski, A. (2003) O futuro de e-learning como inovação educacional: fatores influenciando o sucesso ou fracasso de projetos. Revista Brasileira de Aprendizagem Aberta e a Distância. São Paulo.

Royer, J. (1979). Theories of transfer of learning. Educational Psychologist, 14, 53-69.

Saccol, A. Z., Reinhard, N., Schlemer, E., \& Barbosa, J. L. V. (2010) M-Learning (mobile learning) in Practice: a training experience with IT professionals. JISTEM Revista de Gestão da Tecnologia e Sistemas de Informação, Vol. 7, No. 2, 2010, p.261-280.

Saccol, A. Z., Barbosa, J. L. V., Schlemer, E. \& Reinhard, N., (2011) Mobile Learning in Organizations: Lessons Learned from Two Case Studies. International Journal of Information and Communication Technology Education, 7(3), 11-24, July-September.

Salas, E., \& Cannon-Bowers, J. (2001) The science of training: a decade of progress. Annual Review of Psychology, v. 52, p. 471-499. DOI: 10.1146/annurev.psych.52.1.471.

Santos, A. B. (2012) Avaliação de Impacto de um Treinamento Introdutório sobre o desempenho dos egressos. Dissertação de Mestrado, UnB.

Sharples, M. (2000) The Design of Personal Mobile Technologies for Lifelong Learning. University of Birmingham, Edgbaston, Birmingham B15 2TT, UK.

Sharples, M., Taylor, J., \& Vavoula, G. (2005). Towards a Theory of Mobile Learning. Proceedings of mLearn 2005, Conference, Cape Town. Disponível em http:// www.mlearn.org.za/papers-full.html. Acessado em 27/11/2015.

Silva, A. L. (2011) Avaliação de Treinamentos nos Níveis de Impacto no Trabalho e Resultados Organizacionais. Tese de Doutorado, Universidade de Brasília.

Subhashni, A. (2008) A Review of Benefits and Limitations of Online Learning in the Context of the Student, the Instructor, and the Tenured Faculty. International Journal on ELearning, v7 n1 p5-22. Chesapeake, VA 23327, EEUU.

Tan, W-H, Ooi, K-B, Leong, L-Y \&, Lin, B. (2014) Predicting the drivers of behavioral intention to use mobile learning: A hybrid SEM-Neural Networks approach. Computers in Human Behavior 36 (2014) 198-213.

Tan, W-H, Ooi, K-B, Sim, J-J \& Pushavat, K. (2012) Determinants of mobile learning adoption: an emirical analysis. The Journal of Computer Education Systems; Spring 2012,; 52, 3; ProQuest Science Journals pg. 82.

Todeschini, K. C. L., Silva, A. R. C., Sales, C. T. R., Coelho, A. C. F., Vieira, R. A. \& Brixi, V. P.(2006) Pesquisa em TD\&E no Brasil: um guia de estudo. Em J. E. Borges-Andrade, G. S. Abbad, \& Mourão (Org.) Treinamento, desenvolvimento e educação em organizações e trabalho: fundamentos para a gestão de pessoas. Porto Alegre: Artmed.

Traxler, J. (2007) Defining, Discussing, and Evaluating Mobile Learning. International Review of Research in Open and Distance Learning. v. 8, n. 2.

Velada, R., Caetano, A., Michel, J. W., Lyons, B. D. and Kavanagh, M. J. (2007), 'The effects of training design, individual characteristics and work environment on transfer of training', International Journal of Training and Development, 11, 282-94.

Wang, M., Shen, R., Novak, D., \& Pan, X. (2009) The impact of mobile learning on students' learning behaviours and performance: Report from a large blended classroom. British 
Journal of Educational Technology Vol 40 No 42009 673-695 doi:10.1111/j. 1467-8535.2008.00846.x.

Wang, Y-S, Wand, H-Y, W., \& Shee, D. Y. (2007) Measuring e-learning systems success in an organizational context: Scale development and validation. Elsevier - Computers in Human Behavior 23.

Wang, Y-S, Wu, M-C., \& Wang, H-Y. (2009) Investigating the determinants and age and gender differences in the acceptance of mobile learning. British Journal of Educational Technology Vol 40 No 12009 92-118 doi:10.1111/j.1467-8535.2007.00809.

Wu, P-H, Gwo-Jen Hwang, G-J, Tsai, C-C, Chen Y-C, Yueh-Min Huang, Y-M (2010) A pilot study on conducting mobile learning activities for clinical nursing courses based on the repertory grid approach. Nurse Education Today 31 (2011) e8-e15.

Wu, W-H., Wu, Y-C., Chen, C-Y., Kao, H-Y., Lin, C-H., Huang, S-H. (2012) Review of trends from mobile learning studies: a meta-analysis. Computers \& Education, v.59, $\mathrm{n}^{\mathrm{o}} 2$, Pag. 817-827.

Young, M. F. (1993) Instructional design for situated learning. Educational Technology Research and Development, 1993, Vol.41(1), pp.43-58.

Zerbini, T. (2007) Avaliação de Transferência de treinamento em curso a distância. Tese de doutorado. Universidade de Brasília.

Zerbini, T. \& Abbad, G. S. (2010) Transferência de Treinamento e Impacto do Treinamento no Trabalho: Análise Crítica da Literatura. Revista Psicologia: Organizações e Trabalho, p. 97 - 111, jul-dez.

Zerbini, T., Coelho Júnior, F.A; Abbad, G.S; Mourão, L; Alvim, Silvana \& Loiola, E. (2012) Transferência de treinamento e impacto do treinamento em profundidade. In: medidas de avaliação em treinamento, desenvolvimento e educação. Porto Alegre: Ed.Artmed. Capítulo 8, p. $127-144$. 